\title{
Transformações Geométricas \\ Planas: um Estudo Experimental e Dinâmico
}

\author{
Marco Antonio da Silva Ribeiro
}

Dissertação apresentada ao Instituto de Matemática e

Estatística da Universidade de São Paulo para

obtenção do título de Mestre em Ciências

Programa: Mestrado Profissional em Ensino de Matemática Orientadora: Profa. Dra. Ana Paula Jahn

São Paulo, fevereiro de 2016 


\section{Transformações Geométricas \\ Planas: um Estudo Experimental e Dinâmico}

Esta é a versão original da dissertação elaborada pelo candidato Marco Antonio da Silva Ribeiro, tal como submetida à Comissão Julgadora 

Marco Antonio da Silva Ribeiro

Transformações Geométricas Planas:

um Estudo Experimental e Dinâmico/ Marco Antonio da Silva Ribeiro. - IME-USP-São Paulo, 2016-

233 p. : il. (algumas color.) ; $30 \mathrm{~cm}$.

Orientador: Profa. Dra. Ana Paula Jahn

Dissertação (Mestrado) - Universidade de São Paulo - USP

Instituto de Matemática e Estatística - IME

Programa: Mestrado Profissional em Ensino de Matemática - MPEM, 2016.

1. Palavra-chave: Transformações Geométricas. 2. Palavra-chave: Software Dinâmico. 3. Palavra-chave: Máquinas Matemáticas. I. Orientadora: Profa. Dra. Ana Paula Jahn II. Universidade de São Paulo. III. Instituto de Matemática e Estatística. IV. Transformações Geométricas Planas: um Estudo Experimental e Dinâmico 
Marco Antonio da Silva Ribeiro

\section{Transformações Geométricas Planas: um Estudo Experimental e Dinâmico}

Esta é a versão original da dissertação elaborada pelo candidato Marco Antonio da Silva Ribeiro, tal como submetida à Comissão Julgadora

Trabalho apresentado. IME-USP-São Paulo, 19 de fevereiro de 2016:

Profa. Dra. Ana Paula Jahn

Orientadora

Convidado 1

Convidado 2

IME-USP-São Paulo

2016 

Aos meus pais (in memoriam) Jayme e Carmélia que sempre me incentivaram nos estudos. 



\section{Agradecimentos}

À minha esposa, Márcia e filhos, Adriano e Natasha, pelas incansáveis horas da minha dedicação a este trabalho em detrimento do convívio familiar.

À minha orientadora, Profa. Dra. Ana Paula Jahn, por sua demonstração de profissionalismo, paciência, incentivo, dedicação e pelos comentários e sugestões sempre pertinentes, essenciais no desenvolvimento deste estudo.

Às professoras da banca de qualificação, Profa. Dra. Maria Elisa Esteves Lopes Galvão e Profa. Dra. Rosa Monteiro Paulo, pelas valiosas críticas e sugestões,

Ao Prof. Dr. Nilson José Machado, pelas diversas sugestões esclarecedoras e precisas, que me auxiliaram a concluir esse trabalho, mesmo considerando sua agenda de compromissos intensa, não se furtou em reservar alguns momentos decisivos, que me proporcionaram transformações na maneira de pensar e agir.

À equipe de professores do MPEM do IME-USP, Barbara, Cristina Cerri, Iole, Lisbeth, Marcos Nascimento, Maria Cristina, Martha Salernoo, Oscar Abdounur, Ricardo Bianconi, Francisco Polcino, pelo enriquecimento adquirido nas respectivas disciplinas ministradas.

Aos colegas do curso MPEM com os quais tive contato, tanto os que foram da minha turma quanto os de outras turmas, pelo companheirismo, troca de conhecimentos e experiências profissionais e educacionais, Aline Matheus, Ana Luiza Ozores, Apolo, Caio Moura, Mariana Busatta, Marília Prado, Daniel Cergoli, Fabiana Bomfim, Debora Cona, Herbert Azevedo, Thiago Peleias, Wanessa Trevisan.

À colega Marieta Trancoso pelo apoio essencial nas revisões, formatação, digitalização de diversos documentos, sem o qual não teria sido possível a finalização desse trabalho, além das sugestões enriquecedoras. 

The reason why we are on a higher imaginative level is not because we have a finer imagination, but because we have better instruments...

The gain is more than mere additions; it is a transformation.

By Alfred North Whitehead (WHITEHEAD, 2011, p. 107) 



\section{Resumo}

RIBEIRO, M. A. S. Transformações geométricas planas: um estudo experimental e dinâmico. 2016. 227 f. Dissertação (Mestrado Profissional) - Instituto de Matemática e Estatística, Universidade de São Paulo, São Paulo, 2016.

O presente estudo tem como objetivo fornecer subsídios para uma proposta de ensinoaprendizagem de conteúdos relativos às Transformações Geométricas planas com a utilização de software de Geometria Dinâmica, associado a Máquinas Matemáticas, visando como público-alvo alunos dos anos finais do Ensino Fundamental. Partindo de questões que envolvem tanto o ensino quanto a aprendizagem, ou mais especificamente, a apropriação do conceito de transformação geométrica por parte dos alunos, busca-se investigar em que medida o uso de um ambiente de Geometria Dinâmica associado ao uso de artefatos do tipo sistemas articulados pode contribuir para o desenvolvimento intelectual dos alunos nesse tema. O trabalho compreende um estudo bibliográfico sobre o tema, abordando as transformações geométricas como objetos matemáticos e objetos de ensino, culminando com a elaboração de uma proposta didática para a abordagem desse assunto na Educação Básica, com o uso dos recursos mencionados.

Palavras-chave: Transformações Geométricas, Geometria Dinâmica, Máquinas Matemáticas, Atividades Didáticas. 



\section{Abstract}

RIBEIRO, M. A. S., Plane geometric transformations, a experimental and dynamic study, 2016, 227 p. Dissertation (Professional Master's Degree) - Institute of Mathematics and Statistics (IME), University of São Paulo.

This study aims to provide support for a proposed teaching-learning content related to Plane Geometric Transformations with the use of Dynamic Geometry software, associated with Mathematical Machines, aiming target audience students of the final years of elementary school. Starting from issues involving both teaching and learning, or more specifically, the appropriation of the concept of geometric transformation by the students, we try to investigate to what extent the use of a Dynamic Geometry environment associated with the use of type linkages artifacts can contribute to the intellectual development of students in this subject. The work includes a literature study on the subject, addressing the geometric transformations as mathematical objects and learning objects, culminating in the development of a didactic proposal to address this matter in basic education, using the resources mentioned

Key words: Geometric Transformation, Dynamic Geometry, Mathematical Machines, Teaching activities. 



\section{Lista de ilustrações}

Figura 1 - Tetraedro Epistemológico . . . . . . . . . . . . . . . 45

Figura 2 - Isometria . . . . . . . . . . . . . . . 84

Figura 3 - Exemplo de vetores . . . . . . . . . . . . . . . 87

Figura 4 - Adição de vetores . . . . . . . . . . . . . . . . 88

Figura 5 - Adição de vetor a ponto . . . . . . . . . . . . . . . 88

Figura 6 - Uma translação . . . . . . . . . . . . . . . . . . 89

Figura 7 - Composição de translações . . . . . . . . . . . . . . . . . . . 90

Figura 8 - Translação de figura . . . . . . . . . . . . . . . . . . 91

Figura 9 - Translação de retas e círculos . . . . . . . . . . . . . . . . . 91

Figura 10 - Dados do exemplo $4.4 .1 \ldots \ldots$. . . . . . . . . . . . . . . 9 91

Figura 11 - Solução do exemplo 4.4.1 . . . . . . . . . . . . . . . . . . . . . . . 92

Figura 12 - Dados do exemplo 4.4 .2 . . . . . . . . . . . . . . . . . . . . . . 92

Figura 13 - Solução do exemplo 4.4.2 . . . . . . . . . . . . . . . . . . . 93

Figura 14 - Dados do exemplo 4.4 .3 . . . . . . . . . . . . . . . . . . . . 93

Figura 15 - Solução do exemplo 4.4.3 . . . . . . . . . . . . . . . . . . . . . . . . 94

Figura 16 - Exemplo 4.4 .4 de translação de figura básica . . . . . . . . . . . . . . . 95

Figura 17 - Composição de translações . . . . . . . . . . . . . . . . . . . . 96

Figura 18 - Definição 4.4 .4 Orientação . . . . . . . . . . . . . . . . . . . . . . 98

Figura 19 - Reflexão em torno de um ponto . . . . . . . . . . . . . . . . . . . . . . 99

Figura 20 - Reflexão de uma reta em torno de um ponto . . . . . . . . . . . . . . . 99

Figura 21 - Reflexão de uma círculo em torno de um ponto . . . . . . . . . . . . . 100

Figura 22 - Reflexão em torno de um ponto e paralelogramo . . . . . . . . . . . . . 100

Figura 23 - Combinação duas reflexões em torno de ponto . . . . . . . . . . . . . . 101

Figura 24 - Combinação reflexões em torno de ponto e translação . . . . . . . . . . 102

Figura 25 - Soma de reflexões em torno de ponto e translação . . . . . . . . . . . . 102

Figura 26 - Exercício 4.4 .5 reflexões em torno de ponto . . . . . . . . . . . . . . . . 102

Figura 27 - Exercício 4.4 .6 reflexões em torno de ponto . . . . . . . . . . . . . . . 103

Figura 28 - Definição orientação ângulo . . . . . . . . . . . . . . . . . . . . . . 104

Figura 29 - Rotação centro $O$ e ângulo $\alpha$. . . . . . . . . . . . . . . . . 105

Figura 30 - Teorema $4.4 .3-R_{O, \alpha}$ isometria . . . . . . . . . . . . . 105

Figura 31 - Exemplo de aplicação de rotação . . . . . . . . . . . . . . . . . . 106

Figura 32 - Reflexão em torno de uma reta . . . . . . . . . . . . . . . . 107

Figura 33 - Simetria - Propriedades . . . . . . . . . . . . . . . . 108

Figura 34 - Simetria - Construção . . . . . . . . . . . . . . . . . . . . . . . 109

Figura 35 - Simetria - Construção com régua e compasso . . . . . . . . . . . . . . . 110

Figura 36 - Exemplos de Simetria . . . . . . . . . . . . . . . . . 111 
Figura 37 - Composição de reflexões . . . . . . . . . . . . . . . . . . . . 112

Figura 38 - Reflexão em duas retas paralelas . . . . . . . . . . . . . . . . . . . 112

Figura 39 - Reflexão em duas retas concorrentes . . . . . . . . . . . . . . . . 113

Figura 40 - Ângulo entre retas . . . . . . . . . . . . . . . . . . . . . 114

Figura 41 - Reflexão em três retas . . . . . . . . . . . . . . . . . . . . . 115

Figura 42 - Reflexão com deslizamento . . . . . . . . . . . . . . . . . . 115

Figura 43 - Reflexão com deslizamento . . . . . . . . . . . . . . . . 116

Figura 45 - Composta Reflexões 3 retas . . . . . . . . . . . . . . . . . 120

Figura 46 - Isometrias Próprias e Impróprias . . . . . . . . . . . . . . . . . . . . . 122

Figura 47 - Congruência Direta e Oposta . . . . . . . . . . . . . . . . . . 123

Figura 48 - Homotetia . . . . . . . . . . . . . . . . . . . . . . . 124

Figura 49 - Homotetia-Semelhança . . . . . . . . . . . . . . . . . . . 125

Figura 50 - Homotetia-Círculos . . . . . . . . . . . . . . . . . . 125

Figura 51 - Homotetia em Círculos com $k$ positivo . . . . . . . . . . . . . . 126

Figura 52 - Homotetia-k negativo . . . . . . . . . . . . . . . . . 127

Figura 53 - Homotetia em Círculos com $k$ negativo . . . . . . . . . . . . . . . . 128

Figura 54 - Homotetia-Composição . . . . . . . . . . . . . . . . . . . . 129

Figura 55 - Homotetia-Exemplo de Composição . . . . . . . . . . . . . . . . 130

Figura 56 - Roto-Homotetia . . . . . . . . . . . . . . . . . . . 131

Figura 57 - Composta de Roto-Homotetia . . . . . . . . . . . . . . . 133

Figura 59 - Ferramentas de Construção . . . . . . . . . . . . . . . . . . . . 138

Figura 60 - Tela do GeoGebra e opções para Transformações Geométricas . . . . . 138

Figura 61 - Geometria no GeoGebra . . . . . . . . . . . . . . . . . . . . 139

Figura 62 - Translação . . . . . . . . . . . . . . . . . . . . . . . . . . 141

Figura 63 - Reflexão em Torno de um Ponto . . . . . . . . . . . . . . . . . . . . 143

Figura 64 - Rotação em Torno de um Ponto . . . . . . . . . . . . . . . . . . 145

Figura 65 - Reflexão em Relação a uma Reta . . . . . . . . . . . . . . . . . . . . . 147

Figura 66 - Homotetia . . . . . . . . . . . . . . . . . . . . . . . 152

Figura 67 - Traçador de Elipse . . . . . . . . . . . . . . . . . . . . 153

Figura 68 - Algumas Máquinas Matemáticas . . . . . . . . . . . . . . . . . 154

Figura 69 - Translator de Kempe . . . . . . . . . . . . . . . . . . . . . . 154

Figura 70 -Simetrizadores . . . . . . . . . . . . . . . . . . 155

Figura 71 - Pantógrafo Simetria Central-I . . . . . . . . . . . . . 156

Figura 72 - Pantógrafo Simetria Central-II . . . . . . . . . . . . . . . 157

Figura 73 - Pantógrafo Simetria Central-III . . . . . . . . . . . . . . . 158

Figura 74 - Pantógrafo de Sylvester-Rotação . . . . . . . . . . . . . . . . . 158

Figura 75 - Rotor de Sylvester . . . . . . . . . . . . . . . . . . 160

Figura 76 - Pantógrafo de Scheiner-Homotetia . . . . . . . . . . . . . . . . . 162

Figura 77 - Roto-Homotetia-Sylvester . . . . . . . . . . . . . . 163 
Figura 78 - Roto-Homotetia . . . . . . . . . . . . . . . . . 164

Figura 79 - Reflexão com Deslizamento . . . . . . . . . . . . . . . . . 165

Figura 80 - Duas Reflexões-Translação . . . . . . . . . . . . . . . . . . 165

Figura 81 - Duas Reflexões-Rotação . . . . . . . . . . . . . . . . . . . . 166

Figura 82 - Triangulo Didático . . . . . . . . . . . . . . . . . . . . . 173

Figura 83 - Pantógrafo de Madeira TRIDENT - mod. PME 40 . . . . . . . . . 178

Figura 84 - Pantógrafo para translação . . . . . . . . . . . . . . . . . . 179

Figura 85 - Pantógrafos de Alumínio . . . . . . . . . . . . . . . . . . . 179

Figura 86 - Fixa três pontos não colineares=Identidade . . . . . . . . . . . . . . 225

Figura 87 - Proposição 4.4 .2 Invariância de reta . . . . . . . . . . . . . . . . . 225

Figura 88 - Proposição 4.4 .3 paralelogramo . . . . . . . . . . . . . . . . 226

Figura 89 - Teorema 4.4 .2 ABDC Paralelogramo . . . . . . . . . . . . . . . . . . 227

Figura 90 - Reflexão em torno de uma reta-1 ${ }^{\circ}$ Caso . . . . . . . . . . . . . . . . . . 227

Figura 91 - Reflexão em torno de uma reta-2 ${ }^{\circ}$ Caso . . . . . . . . . . . . . . . . 228

Figura 92 - Ferramentas de Construção . . . . . . . . . . . . . . . . . . . . . . 229

Figura 93 - Ferramentas de Construção Completa . . . . . . . . . . . . . . . . 230 



\section{Lista de tabelas}

Tabela 1 - Quadro Conteúdos e Habilidades $6^{\circ}$ ano . . . . . . . . . . . 56

Tabela 2 - Quadro Conteúdos e Habilidades $7^{\circ}$ ano . . . . . . . . . . . . 56

Tabela 3 - Quadro Conteúdos e Habilidades $9^{\circ}$ ano . . . . . . . . . . . . 57

Tabela 4 - Análise PNLD Ensino Fundamental - Anos Finais . . . . . . . . . . . 61

Tabela 5 - Comentários das coleções do PNLD . . . . . . . . . . . . . . 62

Tabela 6 - Tipos de Transformações Geométricas e operações no GeoGebra . . . . 183 



\section{Lista de abreviaturas e siglas}

$\begin{array}{ll}\text { ABNT } & \text { Associação Brasileira de Normas Técnicas } \\ \text { abnTeX } & \text { Normas ABNT para TeX } \\ \text { A(D)GD's } & \text { Ambientes (Dinâmicos) de Geometria Dinâmica } \\ \text { SDG } & \text { Sistema de Geometria Dinâmica } \\ \text { PCNs } & \text { Parâmetros Curriculares Nacionais } \\ \text { PNLD } & \text { Programa Nacional do Livro Didático } \\ \text { TG } & \text { Transformações Geométricas } \\ \mathbf{E}^{n} & \text { Espaço Euclidiano n-dimensional } \\ \text { GeoGebra } & \text { Software System for Dynamic Geometry and Algebra in the Plan } \\ \text { OA } & \text { Objetos de Aprendizagem } \\ \text { MM } & \text { Máquinas Matemáticas }\end{array}$





\section{Sumário}

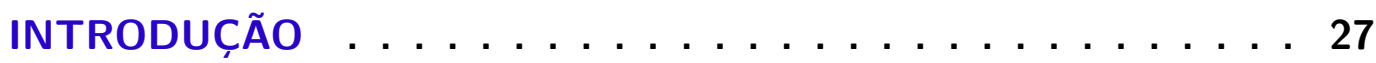

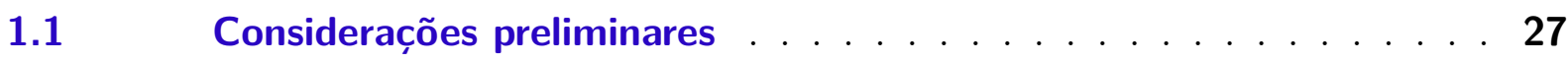

1.2 Objetivos .....................29

1.3 Organização do Trabalho . . . . . . . . . . . . . 29

2 BREVE HISTÓRICO E DESENVOLVIMENTO COGNITIVO DAS TRANSFORMAÇÕES GEOMÉTRICAS . . . . . . . . . 31

$2.1 \quad$ Breve Histórico das Transformações Geométricas . . . . . . . . . 31

2.2 Desenvolvimento Cognitivo e as Transformações Geométricas . . . 35

3 TRANSFORMAÇÕES GEOMÉTRICAS COMO OBJETOS DE ENSINO . . . . . . . . . . . 47

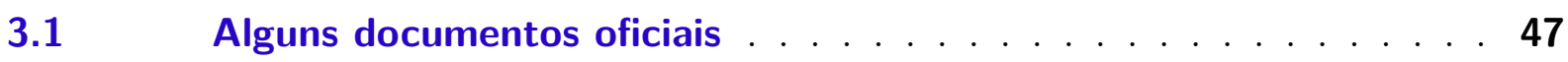

3.2 Proposta Curricular do Estado de São Paulo:

Matemática e suas Tecnologias . . . . . . . . . . . . . 54

3.2.1 Cadernos de Matemática da Secretaria da Educação do Governo do Estado de São Paulo . . . . . . . . . . . . . . . . . . . . . 57

$3.3 \quad$ Análise dos livros didáticos de coleções do PNLD . . . . . . . . . 59

3.4 As transformações geométricas em alguns livros didáticos . . . . 60

3.4.1 A Coleção Matemática - Ideias e Desafios . . . . . . . . . . . . 63

3.4.2 A Coleção Projeto Teláris . . . . . . . . . . . . . . . . 67

3.4.3 A Coleção Vontade de Saber Matemática . . . . . . . . . . . . . 73

4 APRESENTAÇÃO DAS TRANSFORMAÇÕES GEOMÉTRICAS E PROPRIEDADES:

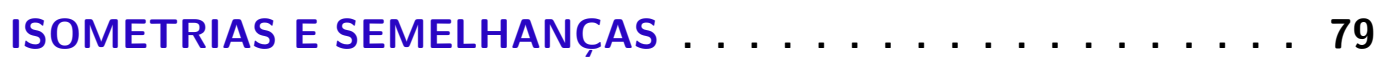

$4.1 \quad$ Introdução . . . . . . . . . . . . . . . 79

4.2 Definições Gerais . . . . . . . . . . . . . . . 80

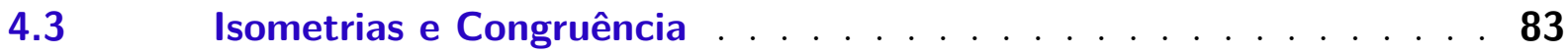

4.4 Tipos de Isometrias $\ldots \ldots \ldots \ldots$

$4.4 .1 \quad$ Translação . . . . . . . . . . . . . . . . 86

4.4.2 Reflexão em torno de um ponto (Half Turn) . . . . . . . . . . . . . 98

$4.4 .3 \quad$ Rotação . . . . . . . . . . . . . . . . . . . . . . . 103

4.4.4 Reflexão em relação a uma reta (Simetria) . . . . . . . . . . . . . 107

4.4.4.1 Composição de reflexões em relação a retas . . . . . . . . . . . . . . . . 111

4.4.4.2 Reflexão transladada - Translação Refletida . . . . . . . . . . . . . . . . 115 
4.4.4.3 Composição de reflexões em relação a retas - continuação . . . . . . . . . . . . . . 117

4.4.5 Isometrias e Congruências: Classificação . . . . . . . . . . . . . . . . . . 120

4.4.5.1 Congruência Direta e Congruência Oposta . . . . . . . . . . . . . . . . . . . . . 121

4.5 Homotetia-Similaridade-Semelhança . . . . . . . . . . . . . . . . . . 122

4.5.0.2 Composição de Homotetias . . . . . . . . . . . . . . . . . . . . . . . . . . . . 127

4.5.0.3 Roto-Homotetia-"Spiral similarity-Dilative rotation" . . . . . . . . . . . . . . . . . 130

4.5.0.3.1 Composição de Roto-Homotetias: . . . . . . . . . . . . . . . . . . . . . . . . . . . 131

4.5.0.3.2 Homotetia Especular (Dilative Reflection) . . . . . . . . . . . . . . . . . . . . . . . . 133

$5 \quad$ USO DE SOFTWARE DINÂMICO PARA $O$

ESTUDO DAS TRANSFORMAÇÕES GEOMÉTRICAS . . . . . . 135

$5.1 \quad$ Introdução . . . . . . . . . . . . . . . . . . 135

5.2 Sobre o GeoGebra . . . . . . . . . . . . . . . . . . . . 136

5.3 Transformações Geométricas

como ferramenta de construção no GeoGebra . . . . . . . . . . . . . 137

5.3.0.4 1. Translação no Geogebra . . . . . . . . . . . . . . . . . . . . . . . . . . . 138

5.3.0.5 Passo-a-passo para a Translação - Quadro 5.3.0.5 . . . . . . . . . . . . . . . . . . 140

5.3.0.6 2. Reflexão em torno de um ponto - (Half Turn) . . . . . . . . . . . . . . . . . . 141

5.3.0.7 Passo-a-passo para a Reflexão em Torno de um Ponto - Quadro 5.3.0.7 . . . . . . . . 142

5.3.0.8 3. Rotação em Torno de um Ponto . . . . . . . . . . . . . . . . . . . . . . . . 143

5.3.0.9 Passo-a-passo para a Rotação em Torno de um Ponto - Quadro 5.3.0.9 . . . . . . . . 144

5.3.0.10 4. Reflexão em Relação a uma Reta-(Simetria) . . . . . . . . . . . . . . . . . . . 145

5.3.0.11 Passo-a-passo para a Reflexão em Relação a uma Reta - Quadro 5.3.0.11 . . . . . . . 146

5.3.0.12 Passo-a-passo para a Reflexão em Relação a uma Reta com figura - Quadro 5.3.0.12 . . 148

5.3.0.13 5. Homotetia de razão $k$. . . . . . . . . . . . . . . . . . . . . . . . . . . 150

5.3.0.14 Passo-a-passo para a Homotetia- Quadro 5.3.0.14 . . . . . . . . . . . . . . . . . . 151

$6 \quad 0$ USO DE MÁQUINAS MATEMÁTICAS PARA TRANSFORMA-

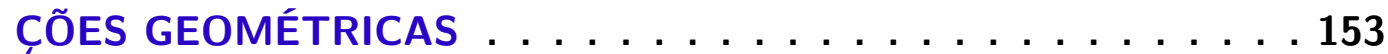

6.1 Máquina de translação: Paralelogramo . . . . . . . . . . . . 154

$6.2 \quad$ Simetrizadores . . . . . . . . . . . . . . . . 155

6.2.0.14.1 Simetrizador Axial: . . . . . . . . . . . . . . . . . . . . . . . . . . . . . . . 155

6.2.0.14.2 Simetrizador Central: . . . . . . . . . . . . . . . . . . . . . . . . . 156

6.2.0.14.3 Outros simetrizadores: . . . . . . . . . . . . . . . . . . . . . . . . 156

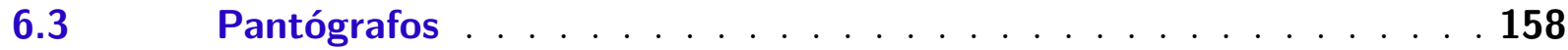

6.3.1 Pantógrafo de Sylvester para rotação . . . . . . . . . . . . . . . . . . . 158

6.3.1.0.4 Rotor de Sylvester: . . . . . . . . . . . . . . . . . . . . . . . . . . . . 160

6.3.2 Pantógrafo de Scheiner para homotetia . . . . . . . . . . . . . . . . . 162

6.3.2.0.5 Roto-homotetia: . . . . . . . . . . . . . . . . . . . . . . . . . . 162

6.3.3 Combinação de pantógrafos . . . . . . . . . . . . . . . . . . . . . . 164 
6.3.3.1 Translação Refletida-Reflexão Transladada-Glide Reflection . . . . . . . . . . . . . . 164

6.3.3.2 Duas Reflexões com eixos paralelos - Translação . . . . . . . . . . . . . . . . . . 164

6.3.3.3 Duas reflexões axiais com eixos incidentes - Rotação . . . . . . . . . . . . . . . 166

7 METODOLOGIA - UMA PROPOSTA DE ENSINO . . . . . . 169

7.1 Metodologia - Introdução . . . . . . . . . . . . . . 169

7.2 Considerações relativas às Atividades propostas . . . . . . . . . 171

$7.3 \quad$ Etapas do trabalho . . . . . . . . . . . . . . . . 177

7.3.1 Formação do grupo de alunos . . . . . . . . . . . . . . . . . 177

7.3.2 Sugestões para a Construção de Máquinas Matemáticas . . . . . . . . . . 178

7.3 .3 Materiais a serem utilizados. . . . . . . . . . . . . . . . . . . . . 180

$7.4 \quad$ Atividades propostas . . . . . . . . . . . . . . 180

7.4.1 Uso do GeoGebra nas transformações geométricas. . . . . . . . . . . . 181

7.4.1.1 Passo-a-passo para a Translação - Quadro 7.4.1.1 . . . . . . . . . . . . . . . . . . 184

7.4.1.2 Passo-a-passo para a Reflexão em Torno de um Ponto - Quadro 7.4.1.2 . . . . . . . . 185

7.4.1.3 Passo-a-passo para a Rotação em Torno de um Ponto - Quadro 7.4.1.3 . . . . . . . . 186

7.4.1.4 Passo-a-passo para a Reflexão em Relação a uma Reta - Quadro 7.4.1.4 … . . . 187

7.4.1.5 Passo-a-passo para a Homotetia- Quadro 7.4.1.5 . . . . . . . . . . . . . . . . 188

7.4.2 Análise e utilização dos artefatos articulados . . . . . . . . . . . . . . . . 189

7.4.3 Fichas do Aluno - Máquinas Matemáticas . . . . . . . . . . . . . . . . . . 189

7.4.3.1 1-Máquina de Kempe para Translação . . . . . . . . . . . . . . . . . . . . . 190

7.4.3.2 2-Máquina para Simetria Central . . . . . . . . . . . . . . . 193

7.4.3.3 3-Máquina para Simetria Axial . . . . . . . . . . . . . . . . . . . 196

7.4.3.4 4-Máquina de Sylvester para Rotação . . . . . . . . . . . . . . . . . . . . . . 199

7.4.3.5 5-Máquina de Schiner para Homotetia . . . . . . . . . . . . . . . . . . . . . . 202

7.4.4 Utilização do GeoGebra na implementação dos artefatos articulados . . . . 205

7.4.4.1 Quadro Simulações das Máquinas Matemáticas . . . . . . . . . . . . . . . . . 206

Conclusões . . . . . . . . . . . . . . . . . . . 207

Referências . . . . . . . . . . . . . . . . . 215

APÊNDICES

APÊNDICE A - DEFINIÇÕES E DEMONSTRAÇÕES COMPLE-

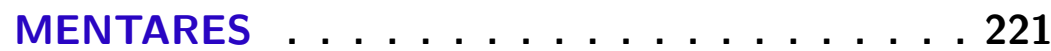

B - QUADROS, TABELAS E FIGURAS COMPLEMENTARES _ . 229

B.1 Menu das ferramentas do GeoGebra . . . . . . . . . . . . . . . . . 229 
B.2

Índice . . . . . . . . . . . . . . . . . . . . . 231

Glossário . . . . . . . . . . . . . . . . . . . . 233 


\section{Introdução}

\subsection{Considerações preliminares}

Um dos aspectos que direcionaram a opção pelo Mestrado Profissional em Ensino de Matemática foi a possibilidade de aliar os conhecimentos e as experiências adquiridos ao longo de doze anos como professor de Matemática na Educação Básica em escolas públicas, àqueles adquiridos no curso de Engenharia Eletrônica e no exercício dessa profissão, marcado pela utilização de recursos tecnológicos de ponta em diferentes áreas da engenharia industrial.

A atuação na rede pública, ainda que em um espectro limitado de abrangência, revelou que o acesso dos alunos a ferramentas tecnológicas é bastante precária - quando não inexistente - no ambiente escolar.

Essa constatação encontra eco nos comentários de Santos (2011, p. 39), que destaca:

Como professor de Matemática da rede pública estadual de ensino, deparei-me com uma das principais dificuldades relatadas pelos professores quanto à utilização de novas tecnologias: a não disponibilidade delas nas escolas. Por muitas vezes, pude perceber o distanciamento entre a teoria e a prática, pois como pesquisador, desenvolvia estudos sobre a utilização da informática na educação matemática, mas a escola não contava com laboratórios de informática (grifos do autor desta dissertação).

Também Nascimento (2012, p. 11) lembra que, embora a informatização das unidades públicas de ensino básico tenha ganhado ímpeto no país, "o processo de incorporação de instrumentos multimidiáticos por parte das escolas ainda é lento e tem encontrado uma série de dificuldades".

No que concerne à inegável relação entre Matemática e tecnologia, D’AMBROSIO (1999) pontua:

Ao longo da evolução da humanidade, Matemática e tecnologia se desenvolveram em íntima associação, numa relação que poderíamos dizer simbiótica. [...] A tecnologia entendida como convergência do saber (ciência) e do fazer (técnica), e a matemática são intrínsecas à busca solidária do sobreviver e de transcender. A geração do conhecimento matemático não pode, portanto ser dissociada da tecnologia disponível.

Assim sendo, a possibilidade de motivar os alunos ao aprendizado com o auxílio de recursos tecnológicos - fornecendo-lhes subsídios mais adequados para enfrentar os desafios que podem vir a encontrar no mercado de trabalho - reveste-se de grande importância. 
Em relação ao uso de software educativo no ensino da Matemática, Santarosa e Gravina (1998, p. 78) enfatizam que a aprendizagem depende de ações que caracterizam o "fazer matemática". Experimentando, interpretando, visualizando, induzindo, conjecturando, abstraindo, generalizando e finalmente demonstrando, o aluno deixa de ser um espectador passivo da apresentação formal do conhecimento e torna-se um ator do processo.

De vez que a importância da relação entre educação escolar e recursos tecnológicos é sobejamente reconhecida nos dias atuais, a discussão ora em curso contempla formas de ensino-aprendizagem e práticas pedagógicas no contexto dessas novas tecnologias (OLIVEIRA, 2015).

Dessa forma, para o presente estudo, buscou-se um tema que permitisse a aplicação de recursos tecnológicos como ferramentas facilitadoras no processo de apreensão e consolidação de determinados conceitos matemáticos.

Já a opção pela Geometria decorreu da possibilidade de despertar o interesse dos alunos pela área, de vez que os objetos geométricos a serem estudadas podem ser relacionados ao cotidiano, aí se incluindo formatos presentes na natureza, em objetos e edificações rotineiramente observados, e em obras de arte, possibilitam ao aluno do Ensino Fundamental o desenvolvimento um tipo especial de pensamento que lhe permite compreender, descrever e representar, de forma organizada, o mundo em que ele vive. A Geometria apresenta-se como um campo profícuo para o desenvolvimento da capacidade de abstrair, generalizar, projetar e transcender o que é imediatamente sensível, como destaca Schneider (2015), que também afirma:

\footnotetext{
Podemos dizer que o conhecimento matemático geométrico faz parte do patrimônio cultural da humanidade, portanto, a sua apropriação é um direito de todos. É inconcebível que a escola e o professor não proporcione $[\mathrm{m}]$ ao aluno a oportunidade de aprender esse conhecimento de forma significativa, estabelecendo relações com o mundo visível. Tirar do aluno o privilégio de aprender geometria é a mesma coisa que lhe negar o direito à educação literária, científica e artística, já que nas formas geométricas presentes no nosso mundo visível esses três patamares se evidenciam a todo o momento.
}

Ocorre que, de um modo geral, as abordagens para o ensino e a aprendizagem de Geometria na Educação Básica são feitas de maneira estática. As figuras planas são apresentadas sem que se dê movimento a elas, o que pode dificultar a compreensão de suas características ou propriedades por parte dos alunos. Sob tais perspectivas, foi eleito como tema de estudo as Transformações Geométricas, que com a utilização de um software de Geometria Dinâmica - no caso, o GeoGebra - pode imprimir um caráter dinâmico ao estudo das figuras, permitindo uma melhor apropriação de suas propriedades geométricas.

Além disso, com inspiração em uma proposta internacional, optou-se por incluir outro tipo de recurso - as Máquinas Matemáticas - como ferramenta adicional a fim 
de complementar a exploração de recursos no processo de ensino e aprendizagem das transformações geométricas.

Considerando a exposição até aqui realizada, formula-se a hipótese de que o uso de recursos adicionais - de informática e/ou de outra natureza - pode despertar o desejado interesse dos alunos na aprendizagem do conceito matemático de Transformação Geométrica, motivando-os e despertando-lhes a atenção e a curiosidade e, consequentemente, levando-os a investigar tais objetos matemáticos e suas propriedades.

\subsection{Objetivos}

A partir das escolhas mencionadas no item anterior, propõe-se um estudo bibliográfico enfatizando aspectos matemáticos, didáticos e cognitivos das transformações geométricas planas, com vista a um aprimoramento do tema e compreensão de seu potencial na formação matemática dos alunos da Educação Básica.

\subsection{Organização do Trabalho}

Nesta Introdução são apresentadas as Considerações Preliminares que justificam a opção do autor pelo tema, com subsídios da literatura especializada; os objetivos do estudo e a organização do trabalho que elenca os capítulos e suas respectivas seções, de forma a identificar os assuntos envolvidos na pesquisa e como foram organizados.

Para a concepção das situações didáticas a serem propostas, entendemos ser importante fazer algumas análises preliminares do objeto de estudo, tanto do ponto de vista do ensino, quanto do ponto de vista matemático. É o que apresentamos no capítulo 3. Assim, analisaremos o que consta em documentos oficiais, especificamente quais são as recomendações para a inserção das transformações geométricas nos currículos oficiais, em particular nos PCNs (Parâmetros Curriculares Nacionais- (BRASIL, 1998), no PNLD (Programa Nacional do Livro Didático) (BRASIL, 2013). Faremos um estudo de como esse objeto é transposto para os livros didáticos e finalizaremos com uma análise desse tópico nos Cadernos de Matemática da Secretaria da Educação do Estado de São Paulo (SÃO PAULO, 2014-2017).

Abordaremos do ponto de vista da História da Matemática como as transformações geométricas foram analisadas e desenvolvidas como objetos matemáticos no capítulo 2, e também como um paralelo histórico e ensino, e como referência utilizaremos o livro Psicogênese e História das Ciências (PIAGET; GARCIA, 2011).

No capitulo 4, por considerar fundamental dar suporte teórico a esse trabalho, serão apresentadas as definições, os conceitos, e propriedades das transformações geométricas, 
que incluem as isometrias, as homotetias, e exemplos de transformações que não conservam distâncias ou colinearidade.

Para realizar esse trabalho, os recursos tecnológicos em referência incluem: um software de Geometria Dinâmica, no caso o GeoGebra que tem a vantagem de ser gratuito e contar com inúmeros recursos didáticos interessantes disponíveis na Internet; e uma outra tecnologia que denominamos Máquinas Matemáticas, ou seja, mecanismos para traçar curvas, realizar transformações e úteis para experimentações. Uma descrição mais detalhada destes dispositivos, suas construções e aplicações faz parte dessa pesquisa e serão apresentadas mais adiante, nos capítulos 5 e 6 .

No capítulo 7, iremos nos concentrar na na indicação de atividades e abordagens para o desenvolvimento de uma sequência didática para alunos dos anos finais do Ensino Fundamental, visando integrar os diferentes recursos acima descritos.

Ao final desse trabalho, faremos uma síntese das propostas deste estudo e teceremos algumas considerações finais. 


\section{Breve Histórico e Desenvolvimento Cogni- tivo das Transformações Geométricas}

\subsection{Breve Histórico das Transformações Geométricas}

"A história da matemática não começa com os gregos". Assim se inicia o capítulo III, intitulado O Desenvolvimento Histórico da Geometria, do livro Psicogênese e História das Ciências, Piaget e Garcia (2011, p. 128). Ainda assim, os autores destacam que tomar a Grécia como ponto de partida não significa alijar injustamente os outros povos da antiguidade do desenvolvimento da matemática, e prosseguem:

seguir o caminho grego permite-nos trabalhar na continuidade histórica: apesar de muitas incertezas iniciais, é possível estabelecer um processo cujas etapas sucessivas podem ser seguidas passo a passo até os nossos dias (PIAGET; GARCIA, 2011, p. 128).

É certo que autores que se debruçaram sobre a História da Matemática mencionam o interesse de babilônios e egípcios pelas medidas de comprimento e de áreas, mas o que se verifica é que esse interesse não incluía a demonstração das fórmulas que utilizavam. Na civilização egípcia, tais fórmulas eram voltadas aos agrimensores e fiscais de obras para a execução de suas tarefas. Tinha-se, então, uma geometria de natureza eminentemente pragmática (MABUCHI, 2000).

Foi somente com os gregos e a noção de discurso lógico que a geometria ganhou o caráter de ciência do espaço. O discurso lógico compreendia "um conjunto hierarquizado de proposições obtidas por raciocínio dedutivo a partir de afirmações iniciais, chamadas axiomas ou postulados" (MABUCHI, 2000, p. 6).

Diferentes historiadores apontam Thales de Mileto (624- 548 a.C.), cujos resultados geométricos, ainda que elementares, representariam o primeiro pensamento dedutivo em Matemática, como o precursor da geometria grega, e mencionam Pitágoras (560 - 480 a.C.) - que enunciou e demonstrou o teorema do triângulo retângulo - como pioneiro na divulgação do conhecimento matemático e geométrico, ainda que no âmbito restrito de sua escola (DAHAN-DALMEDICO; PEIFFER, 2010).

Mas, na quase totalidade dos trabalhos voltados à História da Matemática, os três geômetras gregos considerados os mais importantes da antiguidade são Euclides (aproximadamente. 300 a.C.), Arquimedes (287-212 a.C.), e Apolônio (aproximadamente 225 a.C.). Não é exagero dizer que quase tudo o que se fez de significativo em Geometria, até os dias de hoje e ainda hoje, tem sua semente original em algum dos trabalhos desses três grandes eruditos. 
Os Elementos, de Euclides - que se constitui na contribuição mais importante da antiguidade para a metodologia das ciências, apresenta organizadamente os conhecimentos da Geometria da sua época, ou seja, 300 a.C., sob a forma de uma estrutura axiomática na qual poucas afirmações simples - os axiomas ou postulados - são admitidas como verdadeiras e utilizadas para provar outras mais complexas. Essa foi a primeira axiomatização da história da matemática. "Até o século XVIII, a geometria foi a euclidiana, dita clássica. Somente no século XIX ocorreu uma mudança no significado atribuído à geometria".

Arquimedes aplica pela primeira vez o método, ao qual denomina método da exaustão, à quadratura da parábola. Essa, certamente, é a gênese daquilo que será o cálculo infinitesimal, desenvolvido mais de dezoito séculos adiante.

Apolônio, com os Elementos das Cônicas, introduz não só novos procedimentos mas também uma metodologia e uma renovação conceituais nas quais se identifica o germe remoto da Geometria Analítica do século XVIII. Por essa razão, Apolônio é apontado como o primeiro geômetra a recorrer a um sistema de coordenadas para as suas demonstrações.

Mas, ao longo desses muitos séculos, outros fatos marcaram o desenvolvimento da Geometria.

\begin{abstract}
No período do Renascimento, artistas e arquitetos se interessaram pela representação plana de figuras espaciais a partir do ponto de vista constituído pelo próprio olho. Desenvolveram o estudo da projeção central, ainda chamada projeção cônica, e, em particular, a noção de ponto da fuga. No século XV surgiram alguns elementos de perspectiva. A relação entre a Arte e a Matemática também era forte na obra de Leonardo da Vinci (1452-1519), e a mesma combinação de interesses artísticos e matemáticos se encontra em Albrecht Dürer (1471-1528), na Alemanha. As noções renascentistas sobre perspectiva matemática seriam expandidas mais tarde para um novo ramo da geometria. A preocupação dos pintores e artistas em representar objetos do espaço fez surgir a ideia de projeções centrais e paralelas e, consequentemente, aparecerem as noções de geometria projetiva e de geometria descritiva, importantes na gênese do conceito de transformações (MABUCHI, 2000, p. 9) .
\end{abstract}

Na História da Geometria, o século XVII é marcado pelas concepções de Pierre de Fermat (1601-1655) e René Descartes (1596-1650) que desenvolveram, respectivamente, a Teoria dos Números e a Geometria Analítica (DAHAN-DALMEDICO; PEIFFER, 2010); (PIAGET; GARCIA, 2011). O terceiro apêndice do célebre Discurso do método para bem conduzir a sua razão e procurar a verdade das ciências (1637), de René Descartes, constitui o marco inicial da idade moderna da Matemática (PIAGET; GARCIA, 2011).

Substituindo os pontos de um plano por pares de números, e as curvas por equações, Descartes e Fermat possibilitaram a utilização da álgebra no estudo das propriedades das curvas (PIAGET; GARCIA, 2011). 
Ainda no século XVII, Girard Desargues (1591-1661), arquiteto e engenheiro de Lyon-França, retomou o estudo das cônicas iniciado por Apolônio na antiguidade. Influenciado pelas noções de perspectiva utilizadas pelos artistas do Renascimento, Desargues trabalhou as cônicas com métodos projetivos (MABUCHI, 2000). Com o auxílio das projeções de um círculo sobre um plano, ele obteve a elipse, a hipérbole e a parábola e introduziu a noção de ponto no espaço (BOYER, 1996).

Cinquenta anos depois (1687) do Discurso, Newton (1642-1727) lançou os Principia, no qual apresenta o cálculo diferencial, criado por ele e por Leibniz (1646-1716) em trabalhos independentes. O cálculo diferencial ampliou o alcance da Geometria Analítica e foi complementado posteriormente por Euler e Lagrange Bernouilli (PIAGET; GARCIA, 2011).

Uma vez constituída definitivamente a Geometria Analítica, um corpo de doutrinas que produziu uma profunda revolução no pensamento matemático foi estabelecido. Nesse cenário destacam-se Jean-Victor Poncelet (1788-1867) e Michael Floréal Chasles (17931880), geômetras franceses que incorporaram os sistemas de transformações como método fundamental à geometria (Ibid.).

Poncelet desenvolveu suas primeiras ideias em Geometria Projetiva em uma prisão na Rússia, e posteriormente, reescreveu-as, o que resultou na publicação do Treatise on the Projective Properties of Figures (1822). A ideia da transformação geométrica, até então praticamente ausente dos estudos matemáticos, foi por ele desenvolvida e consta da obra acima mencionada. Nessa obra, uma transformação geométrica aparece como uma correspondência entre as figuras em dois planos, que transforma um ponto do primeiro em um ponto do segundo - projeções e homologia - ou um ponto do primeiro em uma linha do segundo - dualidade: refere-se a provas de casos gerais de figuras a casos particulares. Com efeito, os geômetras já tinham constatado que trocando "ponto" por "linha" e "linha" por "ponto" nos teoremas que tratam de figuras planas, estes permaneciam coerentes e ainda verdadeiros.

Posteriormente, e de acordo com Dahan-Dalmedico e Peiffer (2010), August Ferdinand Möbius (1790-1868) e Chasles, em trabalhos conduzidos independentemente, definiram mais genericamente as transformações projetivas, às quais Chasles denominou homografias - quando se tem a transformação de um plano em outro, que leva pontos a pontos, linhas a linhas, e a crooss-ratio ${ }^{1}$ é preservada.

$\overline{1}$ Considerando quatro pontos distintos em uma reta

$$
r: p 1, p 2, p 3, p 4
$$

define-se cross-ratio desses pontos como:

$$
r=\left(\frac{(p 1-p 2)}{(p 1-p 4)}\right)\left(\frac{(p 3-p 4)}{(p 3-p 2)}\right)
$$


Já a transformação plana na qual pontos correspondem a linhas e linhas correspondem a pontos foi denominada correlação pelo mesmo Chasles (DAHAN-DALMEDICO; PEIFFER, 2010).

A concepção de Möbius para a transformação entre dois planos é muito clara. Com base na ideia de afinidade geométrica (Verwandtschaften) para descrever diferentes tipos de transformações ele estabeleceu que, se a figura transformada é igual à figura inicial, tem-se um deslocamento (displacement); já se a figura transformada é semelhante à figura inicial, tem-se uma semelhança (similitude). Möbius recorreu ao termo de Euler "transformação afim" para designar uma transformação que preserva o paralelismo sem preservar as distâncias. Euler (1701-1783) havia demonstrado que o deslocamento plano é uma rotação, uma translação seguida por uma simetria. Möbius dedicou-se predominantemente à transformação homográfica, à qual denominava collineation (DAHAN-DALMEDICO; PEIFFER, 2010).

Na segunda metade do século XIX, época em que os matemáticos ainda não estavam familiarizados com a geometria não-euclidiana, Felix Klein (1849-1925) publicou duas monografias intituladas Uber die Sogenannte Nicht-Euklidische Geometrie (Da tão falada geometria não-euclidiana). Para tais publicações, datadas de 1871 e 1872, respectivamente, Klein produziu modelos para a geometria de Lobachevskian, e para dois tipos de geometria Riemannian (BURTON, 2007).

Mas, como destaca Burton (2007), a mais importante contribuição de Klein com a geometria foi a criação do Erlanger Programm, uma audaciosa proposta de usar conceitos de grupo para classificar e unificar as principais geometrias então existentes. A premissa de Klein, de que a geometria é "o estudo daquelas propriedades das figuras que permanecem invariantes sob um particular grupo de transformações" não somente possibilitou a codificação de todas as geometrias aparentemente não relacionadas que eram conhecidas no final de 1800, mas também permitia que novas geometrias - decorrentes de diferentes grupos de transformações - fossem definidas. Para tanto, o programa propunha o esquema descrito a seguir.

De acordo com o Programa de Erlanger, a geometria é a investigação das propriedades que se mantêm inalteradas quando uma figura é submetida a um grupo de transformações, e cada geometria tem seu grupo de transformações de controle subjacente. Na geometria métrica euclidiana plana, o grupo de transformações é o conjunto das rotações e translações do plano; na geometria projetiva plana, o grupo de transformações é o conjunto das chamadas transformações projetivas planas; na topologia, o grupo das transformações é o conjunto de todas as transformações topológicas. Nesse contexto, a construção de uma geometria tem início com a escolha do elemento fundamental dessa geometria - ponto, reta, círculo, esfera etc. -, a seguir a totalidade ou espaço desses elementos - plano de pontos, espaço usual de pontos, superfície esférica de pontos, plano 
de retas, feixe de círculos etc. -, e finalmente o grupo de transformações ao qual o espaço de elementos está sujeito (EVES, 1992).

Para Klein, especial interesse deveria ser dedicado às geometrias caracterizadas pelos vários subgrupos do grupo de transformações de uma dada geometria, obtendo-se assim geometrias que abrangem outras (EVES, 1992).

Transformações Geométricas são analiticamente traduzidas como fórmulas para transformações de coordenadas. A conservação de certas propriedades das figuras faz com que sua aparência em expressões algébricas não seja alterada por certas substituições de variáveis. A teoria de invariantes teve sua origem na teoria dos números, mais precisamente no estudo de formas quadráticas empreendido por Gauss em seu Disquisitiones arithmeticae, e foi substancialmente desenvolvida de 1840 em diante por Cayles, Sylvester e Hermite.

A inovação que fez do Erlanger Program um "momento maior na história da geometria e mais geral na história da matemática", segundo Eves (1992, p. 24) reside em ter aliado os conceitos de grupo àqueles da transformação e de Geometria.

\subsection{Desenvolvimento Cognitivo e as Transformações Geométricas}

Piaget e Garcia (2011), no livro intitulado Psicogênese e História das Ciências, publicado originalmente em francês no ano de 1983, realizaram um estudo histórico-crítico examinando os aspectos psicogenéticos e a psicogênese das noções geométricas. Para esses autores, tanto o desenvolvimento histórico da Geometria como a psicogênese das estruturas geométricas caracterizam-se por três etapas de desenvolvimento, trata-se da tríade dialética intra-, inter- e transfigural.

O livro foi prefaciado por Bärbel Inhelder, e segundo ela, "-a obra de Piaget pela criação de uma epistemologia genética apoiada no método psicogenético, tira partido do método histórico-crítico", ou, dito em outras palavras, "a gênese do conhecimento na criança é clarificada e aprofundada pelo estudo histórico do pensamento científico" (PIAGET; GARCIA, 2011, p. 9). Com isso, a teoria psicogenética sustenta que há um paralelo na evolução dos sistemas cognitivos entre os níveis de desenvolvimento intelectual da criança e os níveis de evolução do conhecimento científico, mais ainda, mostra uma surpreendente identidade de evolução do conhecimento científico.

Encontra-se ainda no prefácio de Inhelder (Ibid., p. 13), aquilo que ela parece conceber como novidade na obra:

Mais importante epistemologicamente e mais imprevista é a descoberta de um processo geral que conduz de uma análise intraobjetal, ou análise dos objetos, àquela que podemos chamar de interobjetal, estudando as relações ou transformações entre objetos, para terminar na análise que os autores denominam transobjetal, referentes às construções das estruturas. 
$\mathrm{Na}$ introdução, Piaget e Garcia expõem as ideias de cientistas e historiadores acerca dos processos de desenvolvimento cognitivo, onde a opinião da maioria deles é a de que inexiste qualquer relação entre a formação das noções e das operações nos processos iniciais e sua evolução para patamares superiores. A esse respeito, os autores manifestam-se contrariamente e argumentam sobre os motivos de tal posição.

\begin{abstract}
O interesse reduzido pelo estudo dos estágios elementares está relacionado, sem dúvida, com uma concepção comum de um desenvolvimento dos conhecimentos supostamente linear, cada etapa substituindo-se à precedente, e mantendo, de um modo geral, relações apenas com esta última. Porém, se os estádios sucessivos de construção das diferentes formas do saber são, de fato, sequenciais - ou seja, o resultado das possibilidades oferecidas pelo precedente e condição necessária do subsequente -, eles começam por uma reorganização, num novo nível, das principais aquisições em virtude dos precedentes: daí resulta a integração, nos níveis superiores, de determinadas ligações cuja natureza só pode ser explicada à luz da análise dos estágios elementares (PIAGET; GARCIA, 2011, p. $15)$.
\end{abstract}

Esse processo de construção ao repetir-se "indefinidamente, nível por nível, faz com que o desenvolvimento cognitivo resulte da iteração de um mesmo mecanismo, mas constantemente renovado e alargado por uma alternância de adjunções de novos conteúdos e elaborações de novas formas ou estruturas" (PIAGET; GARCIA, 2011, p. 9).

E prossegue acerca das estruturas cognitivas:

\begin{abstract}
As estruturas cognitivas, por mais que sejam organização de conhecimentos, são essencialmente comparáveis a organismos cujo estado atual é função não somente do ambiente presente, mas também de toda história ontogenética e filogenética. Isto não exclui o caráter normativo que essas estruturas podem ter para o sujeito. Mas é necessário acrescentar que, no caso dos processos cognitivos, há uma outra determinação que é a transmissão cultural. Ou seja, o conhecimento não é nunca um estado, mas um processo influenciado pelas etapas precedentes do desenvolvimento, impondo-se a análise histórico-crítica (PIAGET; GARCIA, 2011, p. 46-47).
\end{abstract}

Na parte final da Introdução, os autores procuram mostrar que os "mecanismos de passagem", constituem o objeto central da obra, e apresentam pelo menos duas características comuns à história das ciências e à psicogênese. O primeiro mecanismo é constituído por um processo geral que caracteriza todo o progresso cognitivo: em caso de superação, o superado é sempre integrado ao superante. O segundo mecanismo é o que conduz do intraobjetal, ou a análise dos objetos, ao interobjetal, ou estudo das relações ou transformações, e daí ao transobjetal, ou construções das estruturas, conforme mencionado anteriormente. A generalidade dessa tríade intra, inter e tans, constitui o melhor dos argumentos em favor de uma epistemologia construtivista, e a sucessão obrigatória do intra 
ao inter e, finalmente ao trans, mostra claramente o caráter construtivista da atividade cognitiva (PIAGET; GARCIA, 2011, p. 50-51).

Em suas conclusões do capítulo sobre o Desenvolvimento Histórico da Geometria, os autores tratam da noção de transformação em geometria, e investigam porque as ideias anunciadas nos porismos de Euclides e nas construções de Pappus, permaneceu durante séculos em estado embrionário (Ibid., p. 151). Na realidade, a própria noção de transformação não foi elaborada durante esse período, as noções foram inicialmente utilizadas em inúmeros casos particulares apenas a título experimental. Essa passagem do uso, ou aplicação implícita, à utilização consciente e à conceitualização constitui o que se convencionou chamar de "tematização".

A razão fundamental da tematização tardia da noção de transformação surge claramente das citações de Poncelet e Chasles, mencionadas pelos autores (PIAGET; GARCIA, 2011, p. 131-133). Foi necessário um longo período de trabalho incessante em álgebra e cálculo infinitesimal, bem como em "tradução geométrica" para se chegar a conceitualizar a própria ideia de transformação geométrica (Ibid., p. 153).

A noção de transformação em Geometria, vista como "instrumento operatório essencial", permite compreender os antecedentes históricos dos processos de construção do conhecimento e "uma base sólida para a teoria epistemológica" (Ibid., p. 155). Essa questão aparece mais bem ilustrada a partir dos movimentos próprios descritos nas relações figurais, ou as relações de base: intrafigural, interfigural e transfigural, conjunto de conceitos desenvolvidos pela Escola de Genebra através das pesquisas em psicologia genética. Passemos a descrever melhor tais conceitos, em particular no contexto das transformações geométricas.

Na etapa intrafigural, os sujeitos não percebem as transformações da figura (ausência de transformações). Não se considera o espaço em si, nem as transformações das figuras no interior de um espaço, centrando-se-se nas propriedades internas das figuras e nas relações internas de duas ou mais figuras, o que resulta numa comparação entre essas figuras. Essa era a abordagem da Geometria no período de Euclides, em que se estudava as propriedades das figuras e dos corpos geométricos enquanto relações internas.

Piaget e Garcia denominam etapa interfigural aquela em que o sujeito utiliza somente referências internas do sistema analisado, ou seja, as figuras estão num plano, e esse conjunto (figuras-plano) apresenta características de totalidade. É a procura de transformações unindo figuras segundo múltiplas formas de correspondência. Associa-se a uma figura-objeto, sua figura-imagem e, o sujeito considera que qualquer mudança de forma de uma figura, deve-se ao deslocamento de suas partes, já que compara posições iniciais e finais com suas respectivas referências. É o período em que a Geometria dominante é a Geometria Projetiva. 
A terceira etapa, transfigural, não trata somente da transformação de uma figura noutra, mas opera sobre todos os pontos do plano, verificando a realização de determinadas condições (manter invariantes alguns elementos ou características). Trata-se, sobretudo, de uma fase que se opera sobre um conjunto de elementos, de relações entre eles, onde as transformações podem ser compostas e decompostas. Essa etapa é caracterizada pela preeminência das estruturas, cuja expressão mais característica é O Programa d'Erlangen, de Félix Klein (PIAGET; GARCIA, 2011, p. 157).

Estas relações ou conexões entre os movimentos ou transformações, consiste numa reinterpretação total dos fundamentos conceituais por meio da análise histórico-crítica e dos processos descritos pela psicologia genética, para a qual:

\begin{abstract}
O desenvolvimento cognitivo nunca é linear, mas exige, no momento de ascensão a qualquer nível, a reconstrução do que foi adquirido nos níveis precedentes. Trata-se de uma reorganização dos conhecimentos à luz de novas informações obtidas de uma reinterpretação dos conceitos básicos (PIAGET; GARCIA, 2011, p. 157).
\end{abstract}

Segundo os autores, o que é notável nesta sucessão intra, inter e transfigural é a coexistência de três propriedades fundamentais. A primeira é que a encontramos em todas as disciplinas, a segunda é que não é específico do pensamento científico e a terceira é que cada etapa repete em suas próprias fases o processo total ([p. 158]piaget2011psicogenese).

Piaget e Garcia (2011) no capítulo IV, A Psicogênese das Estruturas Geométricas (Ibid., p. 159) destaca mais detalhadamente esse processo de construção presente em tal desenvolvimento mediante os movimentos intra/inter/trans e, que intervem desde o inicio, havendo um mesmo funcionamento em todas as etapas, na passagem de uma a outra. Entendem que o modo de construção do espaço apresenta duas características, um espaço dos objetos e uma geometria do sujeito. Os processos de evolução dos conhecimentos de espaço dependem dos instrumentos construídos pelo segundo, o sujeito, existindo aí dois desenvolvimentos distintos. Constata-se que a evolução do espaço provém de uma necessidade geral de explicar as formas através de transformações, tornando-se então possível através da psicogênese.

A primeira etapa da psicogênese do espaço é a das relações intrafigurais que se caracteriza pelas propriedades essenciais e internas entre os elementos de uma figura. Do ponto de vista da representação, verifica-se desde o inicio do desenho, a distinção entre figuras abertas ou fechadas, curvilíneas ou retilíneas, com ângulos retos ou não, com lados em número variável etc.

Piaget e Garcia observam que se esse inicio de estruturação geométrica a partir do intrafigural, contrariamente à história e de acordo com a teoria, as primeiras formas espaciais consideradas pela criança são de natureza topológica e que só mais tarde ela chega às figuras euclidianas e projetivas e, como exemplo cita que só aos quatro anos os sujeitos conseguem copiar quadrados, sabem desenhar bem um pequeno círculo. 
A segunda etapa é a das relações interfigurais que se caracteriza pelas relações das figuras entre si, buscando transformações que relacionem as figuras, considera a posição das figuras reunidas num espaço englobante, cuja estruturação é necessária na medida em que apresenta características de totalidade.

Com alguns experimentos os autores procuram ilustrar as diferenças entre as etapas intrafigural e interfigural: uma criança na primeira etapa consegue desenhar facilmente segmentos perpendiculares enquanto componentes de uma única figura formando uma cruz, ao passo que desenhar retas horizontais ou verticais leva um tempo considerável por exigirem referências exteriores. Verificaram que ao desenharem as chaminés num telhado inclinado, as crianças os desenham, inicialmente, perpendiculares ao telhado, e não verticais.

Outro exemplo de lugar geométrico intrafigural é pensar que dispondo uma série de objetos à distâncias iguais de um personagem se obtém um círculo. Porém, é mais difícil ao sujeito descobrir que os pontos a distâncias iguais de dois jogadores não se reduzem ao único ponto mediano, mas ocupam toda a reta mediana prolongada nas duas direções, essa construção supõe uma organização do plano e vai no sentido do interfigural (PIAGET; GARCIA, 2011, p. 161).

Segundo Piaget e Garcia

A passagem das relações intrafigurais às interfigurais, no decurso da psicogênese, deve-se aos três fatores principais: das exigências de homogeneização dos espaços vazios e cheios, da coordenação das direções ou das distâncias de duas ou mais direções, e de localização dos móveis em caso de deslocamentos (PIAGET; GARCIA, 2011, p. 162).

Esses fatores principais são descritos por Piaget e Garcia através de exemplos, conforme descritos a seguir:

- Exigências de homogeneização dos espaços vazios e cheios: quando entre duas árvores de alguns centímetros de altura, colocadas sobre uma mesa a uma distância de vinte a trinta centímetros uma da outra, for colocada uma parede de dois a três centímetros, e for perguntado a uma criança se essa distância entre as árvores permanece a mesma, só a partir de sete anos é que essa criança responderá afirmativamente. Crianças abaixo dessa idade tendem a responder que a distância diminuiu, indicando para elas que o espaço vazio e o ocupado têm valores distintos. A mesma observação é notada ao se fazer um buraco na parede, e ao ser tampado, algumas crianças respondem que a distância entre árvores diminuiu. Esta heterogeneidade dos espaços vazios e cheios sugere que a criança, antes dos sete anos, não tem concepção de um espaço comum concebido como continente que contém os objetos ou figuras que irão relacionar-se.

- Coordenação das direções ou das distâncias de duas ou três dimensões: Dadas à criança duas folhas de papel idênticas, numa já desenhado um ponto um pouco 
abaixo de uma das extremidades, e pede-se ao sujeito que reproduza na outra folha, um ponto na mesma posição do ponto dado. No início, desenham o ponto numa posição estimada visualmente. Com o uso de régua, e em várias tentativas, traçando reta oblíqua do canto da folha ao ponto, ou reta de medida única, horizontal ou vertical, não obtém o sucesso da posição exata, e é apenas a partir dos sete ou oito anos (estágio das operações concretas) que a criança compreende a necessidade de um par de medidas para fixar a posição do ponto. Em um outro experimento, é apresentado aos sujeitos uma paisagem ou um vilarejo formado por pequenos edifícios colocados com diversas relações de distâncias entre eles em uma determinada mesa, e solicita-se que reproduzam esta paisagem em outra mesa. Os autores concluem que a coordenação de posições leva muito tempo para os sujeitos concluírem pelo estabelecimento de referências.

Ao passar às direções, é evidente que o traçado de uma vertical ou de uma horizontal pelo sujeito exige o estabelecimento de referências interfigurais (PIAGET; GARCIA, 2011, p. 164).

Em relação às direções, o experimento do vaso com água colorida inicialmente na horizontal e depois inclinada que a criança deve reproduzir com desenho de memória, até oito ou nove anos aproximadamente, a criança desenha o nível da água paralelo ao fundo do vaso, mesmo quando este está inclinado, indicando que a criança está ainda no nível intrafigural (o nível da água desenhado é paralelo ao fundo do vaso, água e vaso se fundem num único objeto), só quando desenha paralelo ao nível da mesa é que a criança demonstre que a criança demonstra compreensão interfigural, utilizando referências exteriores. Outros experimentos com fio de prumo mostram resultados parecidos com a noção de vertical.

- Representação dos móveis em caso de deslocamentos: Piaget e Garcia em experiencias utilizando duas réguas A e B, procuram analisar os fatores que levam o sujeito a considerar as relações interfigurais em relação a representação do deslocamento. $\mathrm{A}$ primeira consiste em empurrar perpendicularmente a régua $\mathrm{B}$ pela régua $\mathrm{A}$, primeiro no centro de B, deslocando-a no prolongamento do movimento de A, que é compreendido muito cedo pelas crianças, e depois próximo a uma das extremidades de B, provocando uma leve rotação, e esse movimento a criança só consegue prever a partir dos sete, oito anos, e de forma global, sem considerar as seguintes precisões, que só crianças a partir dos dez, doze anos irão se apropriar: 1) A combinação dos movimentos de translação e rotação ainda não existe; 2) Os deslocamentos de A e B não são colocados ainda em relação a referência fixa externa, mesa, apenas A em relação a B. Em ambos os casos o que falta é a coordenação dos sistemas interno e externo de referências, porque:

Para poder efetuar-se, as relações interfigurais devem ser acompanhadas de transformações interdependentes que se tornam assim transfigurais, o terceiro nível dessa psicogênese (PIAGET; GARCIA, 2011, p. 166).

Na segunda experiência, desliza-se a régua A paralelamente à régua B fixa, ultrapassandoa levemente. De acordo com Piaget e Garcia, crianças até oito anos acham que a 
diferença entre $\mathrm{A}$ e $\mathrm{B}$ no final das réguas é maior que a diferença na parte inicial das réguas, e para os autores isso demonstra que as crianças não diferenciam deslocamentos de alongamentos. Os autores ainda comentam que:

De fato, qualquer mudança de forma de uma figura é causada pelos deslocamentos das partes, e todo deslocamento pode traduzirse em relações interfigurais, uma vez que se trata de comparar posições iniciais e finais com suas respectivas referências. Nesse caso, qualquer figura submetida a mudanças de forma constitui um referencial que comporta as suas formas inicial e final, enquanto as partes deslocadas no seio desse referencial representam, nos seus pontos de partida e chegada, as figuras ou subfiguras destinadas a serem colocadas em relações interfigurais: é por isso que, quando o sujeito centraliza o seu raciocínio nessas relações interfigurais internas em referência a tal referencial limitado, ele está apenas na etapa interfigural, não recorrendo ainda às composições ou transformações de estruturas totais que caracterizam a etapa transfigural (PIAGET; GARCIA, 2011, p. 167).

Piaget e Garcia ainda comentam que a principal característica do deslocamento concebido sob a forma interfigural é o que chamam de "comutabilidade", ou seja, a equivalência entre o que adicionado no fim do deslocamento e o que é subtraído no seu ponto de partida. Assim, nos deslocamentos ocorre uma simples mudança de posição global na figura, não se modificando as relações entre as partes internas da figura, fato cuja compreensão exige a apropriação das etapas intrafigural e interfigural.

Piaget e Garcia constatam que o progresso cognitivo obedece uma mesma lei: o sujeito começa apenas a constatar os resultados sem compreender os seu vínculo com as transformações sistemáticas, ao passo que ele alcança e domina estas a partir do momento em que percebe as suas possíveis compensações (as supressões são compensadas pela adjunções), trata-se inicialmente de ligar o estado final de uma mudança qualquer aos seus estados iniciais.

A partir do momento em que a análise interfigural para relacionar figuras ou objetos físicos, considerados globalmente, torna-se insuficiente para fazer previsões corretas, como quando dois sistemas integram uma estrutura total, como os deslocamentos conforme dois tipos simultâneos de referências ou coordenadas, rotações com translações, vetores de intensidades e direções diferentes, etc., e os autores citam alguns exemplos: movimento de um caracol sobre uma tábua, e esta em movimento em relação a um outro referencial, comparações entre composições de movimentos vistos por observadores fixos e observadores em movimento, composições vetoriais, construções proporcionais (relações entre relações). Piaget e Garcia comentam que esses problemas só podem ser resolvidos por crianças acima de onze, doze anos. O problema consiste em compreender por que essas composições de movimentos, neste caso as translações, ocorrem tardiamente, ao passo que a compreensão dos movimentos componentes é elementar (PIAGET; GARCIA, 2011, p. 175). 
A noção de "transfigural" assume, por essa razão, o seu significado etimológico: aquilo que não pode mais ser verificado diretamente numa única figura, deve se calculado, como exemplos cita o caso da cicloide, fazer avançar uma tábua sobre um cilindro em rotação, o parafuso de Arquimedes, movimento das ondas, como em cordas ou produzidos por gota de líquido vermelho numa bacia com água. Um exemplo importante é descrito nas coordenações entre translações e rotações, como descritos nos casos das réguas A e B acima, e no caso dos dispositivo articulado exigem o recurso dos sistemas interno e externo de referências. É evidente que a maior dificuldade é a de compor num único sistema os dois sistemas de referência, problema geral que só é resolvido no nível das construções transfigurais na medida que comporta contínuas multiplicações de relações (ibid., p.179). Piaget e Garcia (2011) comentam a distinção entre as relações interfigurais e transfigurais da seguinte forma:

\begin{abstract}
as relações transfigurais são muito distintas das interfigurais. Estas consistem simplesmente em introduzir figuras separadas num mesmo sistema espacial: um espaço homogêneo ou isótropo, um sistema de coordenadas ou uma estrutura caracterizada por um único tipo de transformações (deslocamentos, afinidades, etc.), sendo estas provenientes do mecanismo geral de comutabilidade que permite unir os estados sucessivos da figura transformada. Em contrapartida, com as relações transfigurais trata-se sempre de compor uma única totalidade com sistemas distintos e reunir, num conjunto simultâneo, um determinado número de relações fáceis de se estabelecer sucessivamente, mas não dadas na sua associação com as figuras iniciais. Numa palavra, a característica essencial do transfigural é substituir a descrição das figuras pelo cálculo e, mesmo quando o resultado dessas composições pode traduzir em figura, esta é nova e deve ser construída dedutivamente antes de dar origem a uma representação (PIAGET; GARCIA, 2011, p. 181).
\end{abstract}

Piaget e Garcia afirmam que para compreender as formas é preciso considerá-las como resultado de transformações, e estas para serem compreendidas, é preciso superar o geométrico no sentido de um cálculo possível.

Em suas conclusões, os autores procuraram identificar os mecanismos comuns entre a psicogênese e história do conhecimento, o significado da sequência intra, inter e transfigural em suas características gerais, para assim chegarem às suas características espaciais [p. 188]piaget2011psicogenese.

1. Do ponto de vista geral, a sucessão intra, inter e trans é a expressão das condições que as leis de assimilação e de equilibração impõe a toda aquisição cognitiva:

a) Etapa intafigural: ocorre ao abordar um domínio novo, o sujeito deve assimilar inicialmente os dados (objetos, figuras, relações, etc.), aos seus próprios esquemas, e sua análise implica uma equilibração entre a assimilação e a acomodação destes às propriedades objetivamente dadas.

b) Etapa interfigural: os novos esquemas não podem permanecer isolados, logo as exigências de equilibração se imporão a eles, Encontramos formas mais ou menos estáveis de coordenações e transformações. 
c) Etapa transfigural: a multiplicação dos subsistemas ameaça a unidade do todo, sendo necessária uma nova forma de equilíbrio entre as diferenciações e as integrações em sistemas de interações, único meio de harmonizá-las sem perturbações internas ou conflitos entre elas, daí as estruturas formadoras de conjunto que caracterizam o nível trans.

Esses autores elucidam que essa tríade (inter, intra e transfigural) são fases de um processo contínuo, ou seja, "as estruturas atingidas no nível transfigural dão lugar, por sua vez, às análises intra que conduzem a novos inter, depois à produção de super-estruturas trans, e assim indefinidamente" (ibid., p. 189).

2. A interpretação acima leva em conta os aspectos externos de equilibração, Piaget e Garcia (p.190) propõem analisar os aspectos internos, especialmente geométricos, e sustentam que a necessidade lógico-matemática é de origem endógena com valores máximos dentro dos sistemas fechados de transformações construídos pelo sujeito, enquanto os dados de origem exógena permanecem em estado de fato com o mínimo de necessidade intrínseca, dessa forma Piaget e Garcia enfatizam que:

a passagem do intrafigural ao inter e ao transfigural corresponde assim a uma extensão sistemática de necessidade, mas devido a esse processo fundamental de substituição progressiva do exógeno inicial pelas construções endógenas, o quue constitui um outro aspecto do processo de equilibração analisado acima, mas solidário com o primeiro (PIAGET; GARCIA, 2011, p. 190).

Sob a ótica das relações entre o endógeno e o exógeno, as formas ou movimentos intra-inter-trans, são assim descritas por Piaget e Garcia (2011, p.191):

- Forma inicial intrafigural: realismo das figuras, por um lado com existência independente do sujeito, e por outro como dados próprios, emanados da natureza ou do sujeito que pode manipular a figura, com algumas modificações, porém sem construir um sistema de transformaçõesões, mas sim com o objetivo de alcançar as propriedades intrínsecas da figura, permanece no modo de caráter exógeno, limita-se a se submeter aos dados do exterior.

- Forma interfigural: construções endógenas desempenham papel formador, os objetos geométricos tornam-se integrantes de um conjunto de transformações e relações, sujeitos, enquanto em nível operatório e interfigural, consideram os espaços vazios como se estivessem ocupados, é uma forma mais abstrata de envolvimentos, acarretando construções de coordenadas elementares, formas específicas do espaço onde toda a complexidade das relações entre as fontes exógenas e endógenas do saber se encontram.

- Forma transfigural: consiste em subordinar toda aquisição intra e interfigural aos sistemas de conjunto de transformações (é com Lie e Klein que o primado das 
transformações se impõe), primazia do endógeno elaborando estruturas tratadas como dados, que se prestam a novas análises "intra" e a novas construções "inter" e "trans".

A esse respeito a posição de Piaget e Garcia conclui que:

Esta interpretação dos níveis intra, inter e transfigurais em termos de verdades exógenas, exoendógenas (se assim se pode dizer) e cada vez mais endógenas, permite dar um sentido aceitável ao nosso esforço para identificar mecanismos comuns de transição [...] entre um estágio e o seguinte, na psicogênese e na história das ciências (PIAGET; GARCIA, 2011, p. 195).

Para finalizar, destacamos o excerto do trabalho de Jahn (1998), o qual enfatiza que, à parte as polêmicas que tal teoria possa estimular, permanece a conviç̧ão de que há diferentes níveis de aprensão e de significação para as transformações. Abaixo trecho traduzido deste estudo:

Juntamo-nos assim a Laborde e Grenier (1987) para considerar três primeiros níveis:

Nivel 1: a transformação é considerada "como uma relação entre duas configurações geométricas ou uma relação entre duas partes de uma mesma configuração" (o caráter funcional está ausente);

Nível 2: a transformação é considerada como uma aplicação pontual do plano sobre sí mesmo (trata-se do objeto funcional);

Nível 3: a transformação é considerada como uma ferramenta funcional que evidencia as propriedades invariantes ou se destina à resolução de problemas (JAHN, 1998, p....).

Jahn acrescenta outro nível:

Nível 4: a transformação é considerada como elemento de um grupo (as transformações se compõe e se comparam, formando os grupos de transformações) (ibid., p....).

Pelo que foi exposto anteriormente, o nível 1 estaria mais relacionado com o aspecto intrafigural, enquanto os níveis 2 e 3 estariam mais relacionados com as características intrafigurais, e o nível 4 teria uma natureza predominantemente transfigural.

Também Machado (1990) dedicou-se à epistemologia do conhecimento geométrico, caracterizando-o pelo denominado Tetraedro Epistemológico, constituído por quatro faces: a Percepção, a Construção, a Representação e a Concepção.

Não são fases, como as da Lua, que se sucedem linear e periodicamente, mas faces [...], que se articulam mutuamente, configurando uma estrutura a partir da qual, de modo metafórico, pode-se apreender o significado e as funções do ensino da Geometria. Com efeito, não obstante o fato de a iniciação nessa disciplina realizar-se 
por meio da percepção das formas geométricas e de suas propriedades características, através de atividades sensoriais como a observação e a manipulação, desde muito cedo tais atividades relacionam-se diretamente com a construção, a representação ou a concepção de objetos geométricos (MACHADO, 1990, p. 150 e152- grifos do autor desta dissertação)

A Figura 1 ilustra o Tetraedro Epistemológico da Geometria e as relações entre suas faces

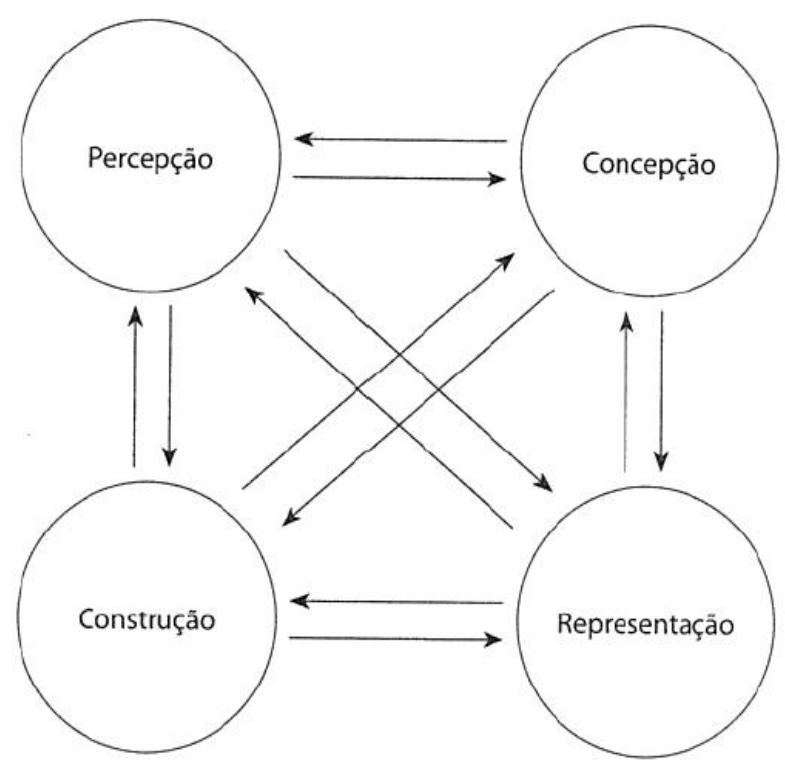

Figura 1: Tetraedro Epistemológico

Fonte: (MACHADO, 1990, p. 151)

Prosseguindo, o autor pontifica:

Percebemos para construir ou quando construímos, para representar ou quando representamos; concebemos o que pretendemos construir, com a mediação das representações, ou construímos uma representação (como uma planta ou uma maquete) para facilitar a percepção; mesmo as concepções mais inovadoras têm como referência percepções ou construções já antes realizadas, contrapondo-se a seus pressupostos ou transcendendo seus limites (MACHADO, 1990, p. 152)

De acordo com Machado (1990), as percepções, as construções, as representações e as concepções alimentam-se mútua e continuamente, como átomos em uma estrutura cujas características moleculares não pode ser subdividida sem prejuízo às propriedades fundamentais da substância correspondente.

Possivelmente, a mais enfática argumentação do autor em defesa do Tetraedro Epistemológico proposto seja a que segue: 
De modo geral e em todos os níveis, o ensino de Geometria carece de atividades integradoras, que propiciem o desenvolvimento harmonioso das quatro faces do conhecimento geométrico que pretendemos caracterizar. É tão importante transitar, como uma criança, da percepção à construção, daí à representação e então à concepção, quanto o é realizar o percurso do arquiteto, que concebe o objeto geométrico antes de representa-lo e construí-lo, e só então torna-lo palpável. O reconhecimento da importância desses e de outros diferentes circuitos, envolvendo as quatro faces do conhecimento geométrico, é um atestado veemente da insuficiência de sua caracterização como uma simples passagem da fase empírica a uma sistematização nos moldes cotidianos (MACHADO, 1990, p. 154) 


\section{Transformações Geométricas como Objetos de Ensino}

Neste capítulo são analisados alguns documentos relacionados às diretrizes curriculares nacionais para o ensino de Matemática, especificamente no que tange aos objetivos do presente estudo, a saber: verificar como são abordadas ou tratadas as transformações geométricas no ensino, e como se dão as menções ao uso de tecnologias no ensino da Geometria.

A abordagem se inicia pelos Parâmetros Curriculares Nacionais (PCN), (BRASIL, 1998), prossegue com as propostas do Currículo do Estado de São Paulo (SÃO PAULO, 2012), e finaliza com a análise dos Cadernos de Matemática da Secretaria da Educação do Estado de São Paulo (SÃO PAULO, 2014-2017) do programa São Paulo faz Escola e de alguns livros didáticos aprovados pelo Programa Nacional do Livro Didático (PNLD) 2014 do Ministério da Educação (BRASIL, 2013).

\subsection{Alguns documentos oficiais}

Para a análise das Diretrizes Curriculares Nacionais da Educação Básica, especificamente em relação à Matemática, utilizou-se os PCN para o ensino de quinta a oitava séries do Ensino Fundamental II - atualmente denominadas de $6^{\circ}$ ao $9^{\circ}$ anos (BRASIL, 1998), que contemplam as transformações geométricas e o uso das tecnologias como ferramentas para o ensino-aprendizagem em Geometria.

$\mathrm{Na}$ introdução deste documento, dirigindo-se aos professores, é enfatizado que:

Os Parâmetros Curriculares Nacionais foram elaborados procurando, de um lado, respeitar as diversidades regionais, culturais, políticas existentes no país e, de outro, considerar a necessidade de construir referências nacionais comuns ao processo educativo em todas as regiões brasileiras (BRASIL, 1998, p. 5).

Já em relação aos objetivos do Ensino Fundamental arrolados nos PCN (BRASIL, 1998, p. 7-8), destacam-se aqueles de maior relevância para o presente estudo, os quais fazem menção para que os alunos sejam capazes de:

- saber utilizar as diferentes linguagens - verbal, musical, matemática, gráfica, plástica e corporal - como meio para produzir, expressar e comunicar suas ideias, interpretar e usufruir das produções culturais, em contextos públicos e privados, atendendo a diferentes intenções e situações de comunicação;

- saber utilizar diferentes fontes de informação e recursos tecnológicos para adquirir e construir conhecimentos; 


\section{$[\ldots]$}

Portanto, vê-se logo no inicio da leitura dos PCN, uma recomendação para que os professores usem recursos tecnológicos, de tal maneira a facilitar o aprendizado por parte dos alunos.

Com relação à estrutura organizacional, os objetivos e conteúdos nos PCN estão organizados em quatro ciclos, cada um correspondendo a duas séries $-1^{\mathrm{o}}$ ciclo $\left(1^{\mathrm{a}}\right.$ e $2^{\mathrm{a}}$ séries $), 2^{\mathrm{o}}$ ciclo $\left(3^{\mathrm{a}}\right.$ e $\left.4^{\mathrm{a}}\right)$, $3^{\mathrm{o}}$ ciclo $\left(5^{\mathrm{a}}\right.$ e $\left.6^{\mathrm{a}}\right)$ e $4^{\mathrm{o}}$ ciclo $\left(7^{\mathrm{a}}\right.$ e $\left.8^{\mathrm{a}}\right)$ - o que evita a excessiva fragmentação de objetivos e conteúdos e torna possível uma abordagem menos parcelada dos conhecimentos, permitindo as aproximações necessárias para que os alunos se apropriem deles, cabendo aos professores ministrar esses conteúdos de forma ampla e flexível.

Quanto aos conteúdos de Matemática, os PCN foram organizados em quatro blocos: Números e Operações; Espaço e Forma; Grandezas e Medidas; e Tratamento da Informação. Iremos nos concentrar no bloco Espaço e Forma, no qual os PCN enfatizam que os conceitos geométricos constituem parte importante do currículo de Matemática no Ensino Fundamental, e que por meio deles, o aluno desenvolve um tipo especial de pensamento que permite compreender, descrever e representar, de forma organizada, o mundo em que vive (BRASIL, 1998, p. 51).

Observamos que o tema transformações geométricas encontra-se no bloco Espaço e Forma a partir do $2^{\circ}$ ciclo (BRASIL, 1997, p. 56), onde na listagem dos objetivos, destaca que, o ensino de Matemática deve levar o aluno a:

- Identificar características das figuras geométricas, percebendo semelhanças e diferenças entre elas, por meio de composição e decomposição, simetrias, ampliações e reduções.

Na parte que trata dos Conteúdos Conceituais e Procedimentais, ainda no bloco Espaço e Forma, (BRASIL, 1997, p. 60), são elencados:

- Identificação de simetria em figuras tridimensionais;

- Identificação de semelhanças e diferenças entre polígonos, usando critérios como número de lados, número de ângulos, eixos de simetria, etc.

- Ampliação e redução de figuras planas pelo uso de malhas.

Em Conteúdos Atitudinais (Ibid., p. 62), os PCN sugerem que os alunos devem procurar ter:

- Sensibilidade para observar simetrias e outras características das formas geométricas, na natureza, nas artes, nas edificações.

Por fim, no tópico intitulado Orientações Didáticas, os PCN pretendem contribuir para a reflexão a respeito de como ensinar, analisando os conceitos e procedimentos e os modos pelos quais se relacionam entre si, e assim comentam: 
Um trabalho constante de observação e construção das formas é que levará o aluno a perceber semelhanças e diferenças entre elas. Para tanto, diferentes atividades podem ser realizadas: compor e decompor figuras, perceber a simetria como característica de algumas figuras e não de outras, etc. (BRASIL, 1998, p. 82)

Vale lembrar como recomendação:

O uso de alguns software disponíveis também é uma forma de levar o aluno a raciocinar geometricamente (Ibid., p. 83).

Assim, na análise dos PCN para o $2^{\circ}$ ciclo ( $3^{\mathrm{a}}$ e $4^{\mathrm{a}}$ séries $)$ do Ensino Fundamental, notamos que é recomendado introduzir os conceitos e propriedades das transformações geométricas de forma que os alunos possam perceber e valorizar aspectos geométricos, utilizando materiais diversos como malhas, espelhos, massas, dobraduras, e também explorando as formas de objetos tridimensionais da natureza como folhas, animais, obras de arte, edificações, etc. O objetivo é trabalhar conceitos de semelhança de figuras e de forma intuitiva perceber simetrias, ampliações, reduções, movimentos, etc.

A partir do $3^{\circ}$ e $4^{\circ}$ ciclo, o tratamento dado pelo PCN (BRASIL, 1998) às transformações geométricas no bloco Espaço e Forma é assim descrito:

Este bloco de conteúdos contempla não apenas o estudo das formas, mas também as noções relativas à posição, localização de figuras e deslocamentos no plano e sistemas de coordenadas.

Deve destacar-se também nesse trabalho a importância das transformações geométricas (isometrias, homotetias), de modo que permita o desenvolvimento de habilidades de percepção espacial e como recurso para induzir de forma experimental a descoberta, por exemplo, das condições para que duas figuras sejam congruentes ou semelhantes.

Além disso, é fundamental que os estudos do espaço e forma sejam explorados a partir de objetos do mundo físico, de obras de arte, pinturas, desenhos, esculturas e artesanato, de modo que permita ao aluno estabelecer conexões entre a Matemática e outras áreas do conhecimento. (BRASIL, 1998, p. 51).

Verifica-se aqui aquilo que foi indicado na seção 1.1 deste trabalho. Em virtude de sua estreita relação com a vida cotidiana, as formas geométricas a serem estudadas estão presentes em imagens rotineiras, aí se incluindo formas presentes na natureza, em objetos e edificações observados no dia a dia, e em obras de arte, daí nossa hipótese que o interesse dos alunos pelo tema surge naturalmente., como que em estado de latência. Assim, quando assentado sobre essa relação, o processo de ensino-aprendizagem da Geometria possibilita que o aluno estabeleça conexões entre a Matemática e as demais áreas do conhecimento humano, e seu dia-a-dia.

Dentre os conteúdos propostos para o ensino de Matemática no terceiro ciclo, podemos ressaltar que os alunos sejam capazes de reorganizar e ampliar os conhecimentos 
abordados no $2^{\circ}$ ciclo, trabalhando com problemas mais complexos de localização no espaço, e as representações das figuras geométricas planas, pela sua decomposição e composição, transformação (reflexão, translação e rotação), ampliação e redução, e que permitam levantar conjecturas sobre algumas propriedades dessas figuras (BRASIL, 1998, p. 68).

Dessa forma, os PCN (BRASIL, 1998, p. 73) destacam no item Conceitos e Procedimentos, orientações no tema Espaço e Forma, que os alunos possam efetuar a transformação de uma figura no plano por meio de reflexões, translações e rotações e a identificação de medidas que permanecem invariantes (medidas dos lados, dos ângulos, da superfície). Ampliação e redução de figuras planas segundo uma razão e identificação dos elementos que não se alteram (medidas de ângulos) e dos que modificam (medidas dos lados proporcionalmente, do perímetro e da área) também são recomendados.

Verificamos, portanto, que a abordagem das transformações geométricas do $2^{\circ}$ ciclo para o $3^{\circ}$ ciclo, passa da observação e da percepção das propriedades das figuras de uma forma intuitiva, utilizando figuras da natureza, objetos do dia-a-dia, para uma abordagem mais complexa, onde devem ser enfatizadas as propriedades das figuras planas que permanecem ou não invariantes, e a utilização do conceito de razão para o estudo das homotetias.

Para o $4^{\mathrm{o}}$ ciclo, (7ª e $8^{\mathrm{a}}$ séries), os PCN (BRASIL, 1998, p. 82) ao tratarem dos Objetivos de Matemática, tem-se que o ensino deve visar o desenvolvimento do pensamento geométrico, por meio da exploração de situações de aprendizagem que levem o aluno a:

- Produzir e analisar transformações e ampliações/reduções de figuras geométricas planas, identificando seus elementos variantes e invariantes, desenvolvendo o conceito de congruência e semelhança.

Observa-se, neste ciclo, que o estudo das transformações geométricas ampliam os conceitos tratados até o $3^{\circ}$ ciclo, ampliando e desenvolvendo os conceitos de congruência e semelhança e, promovendo a identificação de seus elementos variáveis e invariáveis.

Na seção Conteúdos propostos para o ensino de Matemática no quarto ciclo, o PCN (BRASIL, 1998, p. 86) lembra que:

O estudo dos conteúdos do bloco Espaço e Forma tem como ponto de partida a análise das figuras pelas observações, manuseios e construções que permitam fazer conjecturas e identificar propriedades. É importante também na exploração desse bloco desenvolver atividades que permitam ao aluno perceber que pela composição de movimentos é possível transformar uma figura em uma outra.

Na seção Conceitos e Procedimentos (BRASIL, 1998, p. 88-89) o PCN destaca:

- representação e interpretação do deslocamento de um ponto num plano cartesiano por um segmento de reta orientado. 
- desenvolvimento do conceito de congruência de figuras planas a partir de transformações (reflexões em retas, translações, rotações e composições destas), identificando as medidas invariantes (dos lados, dos ângulos, da superfície).

- desenvolvimento da noção de semelhança de figuras planas a partir de ampliações ou reduções, identificando as medidas que não se alteram (ângulos) e as que se modificam (dos lados, da superfície e perímetro).

Assim, nesse ciclo, é previsto um avanço além da conceituação e dedução das propriedades das figuras abordadas nos ciclos anteriores. O conceito de isometria vai permitir a construção de figuras, por reflexão, por translação ou por rotação, fazendo com que o aluno perceba que as medidas dos lados e dos ângulos da figura dada e da figura transformada são as mesmas. As atividades envolvendo isometrias são fundamentais para o desenvolvimento de habilidades de percepção espacial, e podem favorecer a construção da noção de congruência de figuras planas. De forma análoga, o trabalho de ampliação e redução de figuras caracterizado pela homotetia permite a construção da noção de semelhança.

Essa abordagem torna-se ainda mais evidente no bloco que trata dos critérios de avaliação para o $4^{\circ}$ ciclo, (BRASIL, 1998, p. 93), onde o professor deve verificar se o aluno é capaz de estabelecer relações de congruência por meio de diferentes transformações de uma figura no plano (translações, reflexões em retas, rotações); e de obter figuras semelhantes por meio de ampliações e reduções, e também se é capaz de aplicar as propriedades da congruência e as de semelhança em situações-problema.

Nas Orientações Didáticas para Terceiro e Quatro Ciclos - tema Espaço e Forma, o PCN Matemática $3^{\circ}$ e $4^{\circ}$ ciclos $-5^{\mathrm{a}}$ a $8^{\mathrm{a}}$ séries (BRASIL, 1998, p. 95), pretendem contribuir para a reflexão de como ensinar e, em relação às transformações geométricas propõe (Ibid., p. 123-125):

As atividades que envolvem as transformações de uma figura no plano devem ser privilegiadas nesses ciclos, porque permitem o desenvolvimento de conceitos geométricos de uma forma significativa, além de obter um caráter mais "dinâmico" para este estudo. Atualmente, existem software que exploram problemas envolvendo transformações das figuras. Também é interessante propor aos alunos situações para que comparem duas figuras, em que a segunda é resultante da reflexão da primeira (ou da translação ou da rotação) e descubram o que permanece invariante e o que muda. Tais atividades podem partir da observação e identificação dessas transformações em tapeçarias, vasos, cerâmicas, azulejos, pisos etc.

O estudo das transformações isométricas (transformações do plano euclidiano que conservam comprimentos, ângulos e ordem de pontos alinhados) é um excelente ponto de partida para a construção das noções de congruência. As principais isometrias são: reflexão numa reta (ou simetria axial), translação, rotação, reflexão num ponto (ou simetria central), identidade. Desse modo as transformações que conservam propriedades métricas podem servir de apoio não apenas para o desenvolvimento do conceito de congruência de figuras planas, mas também para a compreen- 
são das propriedades destas.

$\grave{A}$ primeira vista as transformações podem parecer um assunto que não tem relação com o dia-a-dia, mas, refletindo e observando um pouco, nota-se, por exemplo, que as simetrias estão muito presentes no cotidiano. Em inúmeros objetos físicos ocorrem aproximações de planos de simetria de reflexão. Em representações planas desses objetos, tais planos de simetria reduzem-se a eixos de simetria. No corpo humano pode-se observar (aproximadamente) um plano de simetria. Assim, também a imagem de um objeto no espelho é simétrica a ele. Há eixos de simetria em diversas criações do homem, como desenhos de aeronaves, edifícios e móveis.

As simetrias centrais e de rotação também surgem em diversas situações: desenhos de flores, logotipos de empresas, desenhos de peças mecânicas que giram, copos, pratos, bordados etc. Os exemplos de translação também são fáceis de encontrar: grades de janelas, cercas de jardins, frisos decorativos em paredes, azulejos decorados etc.

O estudo das transformações que envolvem a ampliação e redução de figuras é um bom ponto de apoio à construção do conceito de semelhança. Além disso, é preciso ficar claro para o aluno como e em que circunstâncias são produzidas figuras semelhantes. Para tanto, é preciso compreender a ideia de razão de semelhança (a razão $k$ que existe entre dois de seus lados homólogos.), por meio de ampliações e reduções que podem ser feitas numa figura pelas transformações conhecidas como homotetias.

O conceito de semelhança está presente no estudo de escalas, plantas, mapas, ampliações de fotos, fotocópias como também quando se verifica, por exemplo, se as medidas das partes do corpo humano se mantêm proporcionais entre um representante jovem e um representante adulto.

Assim, o conceito de semelhança é proveitoso para estabelecer conexões com outros conteúdos matemáticos, como razões e proporções, propriedades das figuras, ângulos, medidas (áreas, volumes) e conteúdos de outras áreas (artes, educação física, ciências, geografia, física).

É importante que os alunos percebam que as transformações foram incorporadas como linguagem básica nos programas de computação gráfica. Assim, ao manipular esses programas, o usuário faz simetrias de todos os tipos, ampliações e reduções.

$[\ldots]$

Nota-se, portanto, que na apresentação do PCN, o assunto transformações geométricas, desde o $2^{\circ}$ ciclo do ensino fundamental, é introduzido inicialmente de forma experimental e intuitiva, explorando os conceitos de simetria (em particular relacionados à simetria axial), é ampliado e aprofundado nos $3^{\circ}$ e $4^{\circ}$ ciclos, com a exploração de temas mais complexos, como a percepção de elementos que permanecem invariantes e os que variam quando são utilizadas as transformações geométricas. As construções com instrumentos convencionais, como régua, compasso, transferidor, são utilizadas para verificação das propriedades das figuras original e da transformada. 
As orientações didáticas para os professores vistas acima, aprofundam os temas apresentados, fornecendo subsídios importantes para o ensino das transformações geométricas, podendo despertar o interesse dos alunos pelo aprendizado da Geometria. Essas orientações contribuem para que haja a possibilidade dos professores tratarem os temas, não de forma estanque, mas sim explorando as conexões entre as transformações e outras áreas do conhecimento, e do cotidiano, além de possibilitar a visão histórica do desenvolvimento e das aplicações das transformações para a solução de problemas. Nota-se também o estímulo ao uso de recursos tecnológicos, como software de geometria dinâmica, lembrando também o uso das transformações em programas de computação gráfica.

No que concerne à importância dos recursos tecnológicos, já na seção Breve Análise da Trajetória das Reformas e do Quadro Atual do Ensino de Matemática (BRASIL, 1998, p. 20) ressalta a

- necessidade de levar os alunos a compreenderem a importância do uso da tecnologia e a acompanharem sua permanente renovação.

Essa relevância dos recursos de informática no contexto do processo de ensino e aprendizagem em matemática evidencia-se na seção O Recurso às Tecnologias da Informação do PCN, (BRASIL, 1998, p. 43-44), que assim se inicia:

As tecnologias, em suas diferentes formas e usos, constituem um dos principais agentes de transformação da sociedade, pelas modificações que exercem nos meios de produção e por suas consequências no cotidiano das pessoas. Estudiosos do tema mostram que escrita, leitura, visão, audição, criação e aprendizagem são influenciados, cada vez mais, pelos recursos da informática. Nesse cenário, insere-se mais um desafio para a escola, ou seja, o de como incorporar ao seu trabalho, tradicionalmente apoiado na oralidade e na escrita, novas formas de comunicar e conhecer. Por outro lado, também é fato que as calculadoras, computadores e outros elementos tecnológicos estão cada vez mais presentes nas diferentes atividades da população.

O uso desses recursos traz significativas contribuições para se repensar sobre o processo de ensino e aprendizagem de Matemática e, possibilita o desenvolvimento, nos alunos, de um crescente interesse pela realização de projetos e atividades de investigação e exploração como parte fundamental de sua aprendizagem.

Nas aulas de Matemática, o uso do computador desempenha diferentes funções (BRASIL, 1998, p. 44):

- fonte de informação, alimentando o processo de ensino e aprendizagem;

- auxiliar no processo de construção de conhecimento;

- meio para desenvolver a autonomia, pelo uso de software que estimulem o raciocínio e a reflexão para a obtenção de soluções; 
- ferramenta para realizar determinadas atividades - uso de planilhas eletrônicas, processadores de texto, banco de dados etc.

Já os software que exploram problemas envolvendo transformações das figuras são bastante elucidativos para a compreensão das transformações geométricas. É interessante propor aos alunos que comparem duas figuras, em que a segunda é resultante da reflexão da primeira - ou da translação ou da rotação - e descubram o que permanece invariante e o que muda.

Resta examinar como os livros didáticos e o material produzido pelas entidades governamentais trabalham esses temas. Também o preparo dos docentes de Matemática e o conhecimento que estes detêm sobre os assuntos relacionados preocupam pois, como destaca o PCN, (BRASIL, 1998, p. 36), é essencial que o professor tenha "clareza de suas próprias concepçôes sobre a Matemática, uma vez que a prática em sala de aula, as escolhas pedagógicas, a definição de objetivos e conteúdos de ensino e as formas de avaliação estão intimamente ligadas a essas concepções".

\title{
3.2 Proposta Curricular do Estado de São Paulo: Matemática e suas Tecnologias
}

Para a análise da proposta curricular de Matemática do Estado de São Paulo, utilizou-se o documento Currículo do Estado de São Paulo: Matemática e suas tecnologias, edição de 2012 (SÃO PAULO, 2012).

Já na Apresentação, o documento "apresenta os princípios orientadores do currículo para uma escola capaz de promover as competências indispensáveis ao enfrentamento dos desafios sociais, culturais e profissionais do mundo contemporâneo." (SÃO PAULO, 2012, p. 7). Assim, o documento explicita o seu direcionamento, de tornar a escola um espaço de cultura e de articulação de competências e de conteúdos disciplinares, de modo a preparar os jovens para lidar com as pressões que marcam a contemporaneidade.

Mais adiante, pondera que

\begin{abstract}
essa sociedade, produto da revolução tecnológica que se acelerou na segunda metade do século $X X$ e dos processos politicos que redesenharam as relações mundiais, já está gerando um novo tipo de desigualdade ou exclusão, ligado ao uso das tecnologias de comunicaşão que hoje medeiam o acesso ao conhecimento e aos bens culturais (ST̃O PAULO, 2012, p. 8),
\end{abstract}

Considerando que a tecnologia imprime um ritmo sem precedentes à aquisição de conhecimentos e gera profunda transformação nas formas de estrutura, organização e distribuição do conhecimento, no que tange à interação entre os conteúdos matemáticos e a informática, o documento (SÃO PAULO, 2012, p. 28) pondera: 
Os computadores atualmente são considerados instrumentos absolutamente imprescindíveis para jornalistas e escritores, mas é no terreno da Matemática que se abrem as mais naturais e promissoras possibilidades de assimilação consciente dos inúmeros recursos que as tecnologias informáticas podem oferecer no terreno da Educação. Ainda que as tais tecnologias estejam presentes e representem papel importante em todas as áreas do conhecimento, a natureza algorítmica dos computadores aproxima-os especialmente dos conteúdos matemáticos.

Em decorrência dos pressupostos apresentados no documento (SÃO PAULO, 2012), e aqui sucintamente mencionados, os conteúdos disciplinares de Matemática para o Ensino Fundamental e para o Ensino Médio foram organizados em três grandes blocos temáticos - NÚMEROS, GEOMETRIA e RELAÇÕES -- que segundo o documento, interagem permanentemente.

No que concerne à Geometria, os construídos elencados são percepção de formas e de relações entre elementos de figuras planas e espaciais; construção e representação de formas geométricas, existentes ou imaginadas, e elaboração de concepções de espaço que sirvam de suporte para a compreensão do mundo físico.

A preocupação inicial do processo de ensino e aprendizagem de Geometria no Ensino Fundamental é o reconhecimento, a representação e a classificação das formas planas e espaciais, preferencialmente trabalhadas em contextos concretos com os alunos de $5^{\mathrm{a}}$ série $/ 6^{\circ}$ ano e $6^{\mathrm{a}}$ série $/ 7^{\circ}$ ano. Já a construção de raciocínios lógicos, de deduções simples de resultados a partir de outros anteriormente conhecidos pode ser a tônica dos trabalhos na $7^{\mathrm{a}}$ série $/ 8^{\circ}$ ano e na $8^{\mathrm{a}}$ série $/ 9^{\circ}$ ano (SÃO PAULO, 2012).

Daí deriva a abordagem espiralada proposta no documento para o tratamento da Geometria, o que significa dizer que os grandes temas podem aparecer tanto nas séries/anos do Ensino Fundamental quanto naquelas do Ensino Médio, sendo a diferença a profundidade do tratamento dada ao tema.

Um aspecto importante a ser destacado na apresentação da Geometria, tanto no Ensino Fundamental quanto no Ensino Médio, é o fato de que o conhecimento geométrico apresenta quatro faces, que se relacionam permanentemente na caracterização do espaço: a percepção, a concepção, a construção e a representação (SÃO PAULO, 2012, p. 42 - grifos nossos).

Em relação ao tema deste trabalho - Transformações geométricas - notam-se algumas menções ao longo do documento, como no trecho:

Um exemplo que ilustra bem essa situação é o estudo da proporcionalidade. Em uma $6^{\mathrm{a}}$ série $/ 7^{\circ}$ ano, o tema pode aparecer sem uma preocupação formal com o uso de representação simbólica, em problemas de ampliação e redução, em problemas de escalas de mapas ou no estudo de frações equivalentes. Havendo um projeto que desperte interesses sobre o estudo mais pormenorizado da proporcionalidade, como a construção de uma maquete do prédio da escola, certamente o professor poderá explorar o tema com uma lente focada até mesmo na representação simbólica (SÃO PAULO, 2012, p. 51 - grifos nossos). 
Tendo em mente as ponderações anteriores, apresentam um Quadro de Conteúdos e Habilidades de Matemática (série/ano por bimestre) para as quatro séries/anos finais do Ensino Fundamental e para as três séries do Ensino Médio. Reiteram que não se pretende que tal lista de conteúdos seja rígida e inflexível, e sim que propicie uma articulação consistente dos diversos temas, tendo em vista os objetivos maiores que fundamentam o presente Currículo (SÃO PAULO, 2012, p. 55).

busca de uma formação voltada para as competências pessoais, uma abordagem dos conteúdos que valorize a cultura e o mundo do trabalho,

\section{$[\ldots]$}

No caso específico da Matemática, proporcionalidade, equivalência, ordem, aproximação, problematização, otimização, entre outras, são exemplos de tais ideias fundamentais, a serem exploradas nos diversos conteúdos estudados.(SÃO PAULO, 2012, p. 55).

Em relação aos aspectos relativos às transformações geométricas, surgem no quadro da maneira que segue:

$\mathrm{Na}$ apresentação dos quadros de conteúdos e habilidades por série/bimestre, vemos que

\begin{tabular}{|c|c|l|}
\hline \multicolumn{3}{|c|}{$5^{\mathrm{a}}$ série $/ 6^{\circ}$ ano do Ensino Fundamental $-3^{\circ}$ Bim. } \\
\hline Conteúdos & Habilidades & Comentários \\
\hline \hline Geometria/ & Compreender a ideia de simetria, & Pretende-se apenas reconhecer \\
Relações & sabendo reconhecê-la em & a simetria em figuras \\
& construções geométricas e & geométricas intuitivamente, \\
Formas & artísticas, bem como utilizá-la & e saber aplicá-la em construções \\
Geométricas & em construções geométricas & elementares, assim como visto \\
Planas & elementares & nas recomendações nos PCN. \\
\hline
\end{tabular}

Tabela 1: Quadro Conteúdos e Habilidades $6^{\circ}$ ano

\begin{tabular}{|c|c|l|}
\hline \multicolumn{2}{|c|}{$6^{\mathrm{a}}$ série $/ 7^{\circ}$ ano do Ensino Fundamental $-2^{\circ}$ Bim. } \\
\hline Conteúdos & Habilidades & Comentários \\
\hline \hline Geometria & Compreender e & Amplia-se nesta série \\
& identificar simetria & além do reconhecimento \\
Simetrias & axial e de rotação & da simetria axial, o \\
& nas figuras geométricas & conceito de rotação, \\
& e nos objetos do & e sugere a associação \\
& dia-a-dia. & aos objetos do cotidiano. \\
\hline
\end{tabular}

Tabela 2: Quadro Conteúdos e Habilidades $7^{\circ}$ ano

pouco conteúdo das transformações geométricas (TG) foram relacionados, não verificamos qualquer referência explícita ao uso das TG para análise de congruência entre figuras geométricas, notadamente quanto às translações, e também não fazem referência à homotetia 


\begin{tabular}{|c|c|l|}
\hline \multicolumn{3}{|c|}{$8^{\mathrm{a}}$ série $/ 9^{\circ}$ ano do Ensino Fundamental - $3^{\circ}$ Bim. } \\
\hline Conteúdos & Habilidades & Comentários \\
\hline \hline Geometria/ & Saber reconhecer a & Na abordagem dos temas \\
Relações & semelhança entre figuras & relacionados às TG, somente \\
Proporcionalidade & planas, a partir da & o tópico da semelhança é \\
O conceito de & igualdade das medidas dos & apresentado, e não fica claro \\
semelhança & ângulos e da proporcionalidade & se serão aplicados os conceitos \\
& entre as medidas lineares & das transformações neste \\
& correspondentes & conceito \\
\hline
\end{tabular}

Tabela 3: Quadro Conteúdos e Habilidades $9^{\circ}$ ano

para abordarem semelhança entre figuras planas. Esses conteúdos serão explicitados nos Cadernos do Professor e do Aluno, que serão objeto de análise a seguir.

\subsubsection{Cadernos de Matemática da Secretaria da Educação do Governo do Estado de São Paulo}

O Caderno do Professor sesp08, criado pelo programa São Paulo Faz Escola, traz orientações didático-pedagógicas fundamentadas nas proposições do Currículo Oficial do Estado de São Paulo (SÃO PAULO, 2012), e pode ser utilizado como complemento à matriz curricular. De acordo com o referido caderno,

As atividades propostas podem ser complementadas por outras que os professores julgarem pertinentes ou necessárias, dependendo do planejamento e da adequação da proposta de ensino deste material à realidade da escola e de seus alunos. O Caderno do Aluno tem a proposição de apoiá-los para que explorem suas competências e habilidades necessárias que comportam a construção do saber e a apropriação dos conteúdos das disciplinas, além de permitir uma avaliação constante, por parte dos docentes, das práticas metodológicas em sala de aula, objetivando a diversificação do ensino e a melhoria da qualidade do fazer pedagógico (SÃO PAULO, op. cit., p. 3).

O documento recomenda que a ideia de simetria seja explorada na $6^{\mathrm{a}}$ série $/ 7^{\circ}$ ano do ensino fundamental por meio de duas interpretações possíveis: simetria axial - ou simetria bilateral, ou simetria de reflexão - e simetria de rotação - ou simetria rotacional. No caderno, o tema é apresentado na "Situação de Aprendizagem 6: refletindo e girando com simetria", e contempla os seguintes itens (SÃO PAULO, 2014-2017, p. 58): 
Conteúdos e temas: simetria axial; simetria rotacional; transformações no plano (reflexão, translação, rotação); ângulo central e inscrição de polígonos.

Competências e habilidades: identificar simetrias por meio da leitura, comparar e interpretar imagens; reconhecer padrões geométricos em diferentes imagens como forma de desenvolver uma melhor apreciação estética das linguagens do desenho, pintura, arquitetura etc.

Sugestão de estratégias: resolução de situações-problema com o uso de imagens que apresentem padrões de simetrias; uso de malhas quadriculadas e de pontos.

O Caderno do Professor traz orientações teóricas, em termos genéricos, da simetria axial e da simetria de rotação e utiliza os termos transformação e "sobreposição" perfeita entre as figuras inicial e final. Os exercícios sugeridos no Caderno do Aluno (SÃO PAULO, 2014-2017, p. 57) solicitam que tracem uma linha nas diversas figuras para indicar o eixo de simetria axial, em outras figuras determinem, sem o uso do transferidor, a medida do ângulo de simetria rotacional.

Em outro exercício, pede-se que o aluno justifique que uma determinada figura não possui eixo de simetria, apesar da placa que a representa possuir. São propostos diversos exercícios, repetindo a mesma solicitação, identificar o eixo de simetria axial e determinar o ângulo de rotação da figura. Um recurso útil é apresentada em desenhos feitos em malhas quadriculadas ou malhas de pontos em que o aluno tenha que desenhar figuras com simetria, completar figuras para que tenham simetria ou, ainda, exercitar movimentos de reflexão, translação e rotação de figuras no plano. A seguir são apresentadas algumas atividades que cumprem esse objetivo (SÃO PAULO, 2014-2017, p. 62).

Além da reflexão e da rotação, outra transformação no plano é apresentada, a translação, e após a parte conceitual (SÃO PAULO, 2014-2017, p. 63), exercícios são propostos com o uso de malhas de pontos e malhas quadriculadas, os conceitos de deslocamento por meio de "setas", com distância, direção e sentido, auxiliam os alunos para a solução dos exercícios.

O Caderno do Professor sugere que seja utilizado o estudo da simetria como porta de entrada para uma apresentação mais detalhada do plano coordenado. Várias atividades são elaboradas para que o aluno comece a se familiarizar com o sistema de representação de pontos por meio de coordenadas.

Nas Considerações sobre a avaliação, o professor deve levar en conta que

Com as atividades apresentadas na Situação de Aprendizagem 6, o aluno deverá familiarizar-se com simetria axial e rotacional, bem como com as principais transformações do plano (reflexão, rotação e translação). Vale lembrar que as transformações do plano serão aprofundadas em outro Caderno e que, portanto, nosso objetivo aqui é apenas estabelecer o primeiro contato do aluno com a percepção visual de simetrias e movimentos no plano (SÃO PAULO, 2014-2017, p. 66). 


\subsection{Análise dos livros didáticos de coleções do PNLD}

O sítio do Ministério da Educação ${ }^{1}$, traz informações sobre o Programa Nacional do Livro Didático (PNLD). A aba "Apresentação" informa que o programa tem como principal objetivo subsidiar o trabalho pedagógico dos professores por meio da distribuição de coleções de livros didáticos aos alunos da educação básica. Após a avaliação das obras, o Ministério da Educação (MEC) publica o Guia de Livros Didáticos com resenhas das coleções consideradas aprovadas. O guia é encaminhado às escolas para que professores e coordenadores escolham, entre os títulos disponíveis, aqueles que melhor atendem ao seu projeto político pedagógico.

Faz parte do programa prover as escolas públicas de Ensino Fundamental e Médio com livros didáticos e acervos de obras literárias, obras complementares e dicionários.

O PNLD é realizado em ciclos trienais alternados. Assim, a cada ano o FNDE (Fundo Nacional de Desenvolvimento da Educação) adquire e distribui livros para todos os alunos de determinada etapa de ensino e repõe e complementa os livros reutilizáveis para outras etapas.

As publicações dos PNLD em vigor são:

- Guia PNLD 2013 Matemática EF Anos Iniciais

- Guia PNLD 2014 Matemática EF Anos Finais

- Guia PNLD 2012 Matemática EM

Para a análise das coleções, iremos nos basear no "Guia de livros didáticos PNLD 2014: Matemática Ensino Fundamental Anos Finais" (BRASIL, 2013), que traz resenhas das coleções aprovadas no processo de avaliação dos livros: dez coleções de livros de Matemática do $6^{\circ}$ ao $9^{\circ}$ anos. Três delas incluem conteúdos multimídia, em DVD, com os chamados Objetos Educacionais Digitais (OED): jogos eletrônicos, simuladores, vídeos ou infográficos.

Para o presente estudo, o interesse é verificar se e como as Transformações Geométricas estão contempladas entre os conteúdos de Geometria dos livros voltados ao sexto, sétimo e oitavo anos do Ensino Fundamental - aprovados no PNLD -, e quais destes propõem o uso de software e de recursos digitais voltados para a Educação Matemática.

A Tabela 4, que precede a análise propriamente dita e traz os livros acima descritos, relacionando título da obra, autor, editora, ano, ilustra a presença ou não de alguns conteúdos de Transformações Geométricas, a saber: simetrias, reflexão, rotação, translação, mosaicos e ladrilhamento e homotetia. A Tabela 5 relaciona os livros e comentários sobre os conteúdos descritos na Tabela 4.

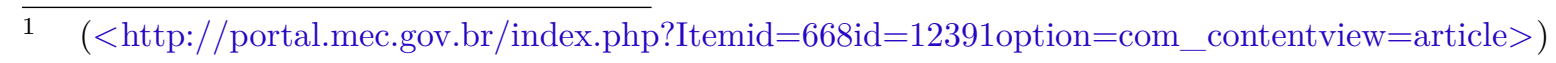


Descrição dos itens da Tabela 4 onde cada marca "X" representa o conteúdo que faz parte do ano da coleção do livro correspondente.

Si Simetrias

Re Reflexão

Ro Rotação

$\operatorname{Tr}$ Translação

Mo Mosaicos e Ladrilhamento

Ho Homotetia (Ampliações e Reduções)

Com isso, pudemos identificar quais coleções abordam as transformações geométricas. A partir daí, selecionamos 3 coleções para uma análise mais detalhada.

\subsection{As transformações geométricas em alguns livros didáticos}

Dentre os livros que constam do Guia de Livros Didáticos PNLD 2014 para o Ensino Fundamental - Anos Finais - da área de Matemática (BRASIL, 2013), selecionamos para análise os seguintes livros, na ordem em que aparecem nas resenhas das coleções, identificadas nas Tabelas 4 e 5 :

3 Matemática - Ideias e Desafios (MORI; ONAGA, 2009)

8 Projeto Teláris - Matemática (DANTE, 2013)

10 Vontade de Saber Matemática (SOUZA; PATARO, 2012)

Para essa seleção, consideramos a quantidade de tópicos relativos às transformações geométricas que aparecem nos livros (cf. Tabela 4 ) levando em conta apenas o Sumário de cada coleção e os respectivos comentários da Tabela 5.

A abordagem feita pelo Guia do PNLD (BRASIL, 2013) inclui, dentre vários itens, um tópico denominado "Análise da obra - Abordagem dos conteúdos matemáticos", onde descrevem a "seleção e distribuição dos conteúdos nas obras", incluindo o tema Geometria. Selecionaremos alguns comentários das resenhas quando, de acordo com nossa interpretação, considerarmos relevante para esta pesquisa, e vamos adotar a mesma numeração acima apenas para facilitar a leitura nas tabelas, e no referido Guia. As Transformações Geométricas inserem-se no Bloco de Conteúdos "Espaço e Forma", que constam nos documentos oficiais vistos no inicio deste Capítulo na seção 3.1. 


\begin{tabular}{|c|c|c|c|c|c|c|c|c|c|c|}
\hline $\mathrm{N}^{\circ}$ & Coleção & Autores & Editora & Ano & $\mathrm{Si}$ & Re & Ro & $\operatorname{Tr}$ & Mo & Ho \\
\hline \multirow[t]{4}{*}{$\overline{11}$} & \multirow{4}{*}{$\begin{array}{l}\text { Descobrindo } \\
\text { e Aplicando } \\
\text { Matemática }\end{array}$} & \multirow{4}{*}{$\begin{array}{l}\text { Mazzieiro, A.S. } \\
\text { Machado, P.A. }\end{array}$} & \multirow[t]{4}{*}{$\overline{\text { Dimensão }}$} & $\overline{6^{\circ}}$ & $\overline{\mathrm{X}}$ & $\bar{X}$ & & & & \\
\hline & & & & $7^{\circ}$ & $\mathrm{X}$ & & & & & \\
\hline & & & & $8^{\circ}$ & & & & & & \\
\hline & & & & $9^{\circ}$ & & & & & & \\
\hline \multirow[t]{4}{*}{2} & \multirow{4}{*}{$\begin{array}{c}\text { Matemática } \\
- \\
\text { Bianchini }\end{array}$} & \multirow{4}{*}{$\begin{array}{l}\text { Bianchini, } \\
\text { E.R. }\end{array}$} & \multirow[t]{4}{*}{ Moderna } & $6^{\circ}$ & & & & & & \\
\hline & & & & $7^{\circ}$ & & & & & & \\
\hline & & & & $8^{\circ}$ & $\mathrm{X}$ & $\mathrm{X}$ & & & & \\
\hline & & & & $9^{\circ}$ & & & & & & \\
\hline \multirow[t]{4}{*}{3} & \multirow{4}{*}{$\begin{array}{c}\text { Matemática } \\
- \\
\text { Idéias e } \\
\text { Desafios }\end{array}$} & \multirow{4}{*}{$\begin{array}{l}\text { Onaga,D.S. } \\
\text { Mori, I. }\end{array}$} & \multirow{4}{*}{$\begin{array}{c}\text { Saraiva } \\
\text { Livreiros } \\
\text { Editores }\end{array}$} & $6^{\circ}$ & $\mathrm{X}$ & & & & $\mathrm{X}$ & \\
\hline & & & & $7^{\circ}$ & $\mathrm{X}$ & $\mathrm{X}$ & & & & $\mathrm{X}$ \\
\hline & & & & $8^{\circ}$ & $\mathrm{X}$ & $\mathrm{X}$ & $\mathrm{X}$ & $\mathrm{X}$ & $\mathrm{X}$ & \\
\hline & & & & $9^{\circ}$ & $\mathrm{X}$ & & & & & $\mathrm{X}$ \\
\hline \multirow[t]{4}{*}{4} & \multirow{4}{*}{$\begin{array}{c}\text { Matemática } \\
- \\
\text { Imenes } \\
\text { Lellis }\end{array}$} & \multirow{4}{*}{$\begin{array}{l}\text { Imenes, L.M.P. } \\
\text { Lellis, M.C.T. }\end{array}$} & \multirow[t]{4}{*}{ Moderna } & $6^{\circ}$ & $\mathrm{X}$ & $\mathrm{X}$ & & & & \\
\hline & & & & $7^{\circ}$ & $\mathrm{X}$ & & $\mathrm{X}$ & & & \\
\hline & & & & $8^{\circ}$ & $\mathrm{X}$ & & & & & \\
\hline & & & & $9^{\circ}$ & & & & & & \\
\hline \multirow[t]{4}{*}{5} & \multirow{4}{*}{$\begin{array}{c}\text { Matemática } \\
- \\
\text { Teoria e } \\
\text { Contexto }\end{array}$} & \multirow{4}{*}{$\begin{array}{l}\text { Centurion, M.R. } \\
\text { Jakubovic,J. }\end{array}$} & \multirow{4}{*}{$\begin{array}{l}\text { Saraiva } \\
\text { Livreiros } \\
\text { Editores }\end{array}$} & $6^{\circ}$ & $\mathrm{X}$ & & & & & \\
\hline & & & & $7^{\circ}$ & $\mathrm{X}$ & & $\mathrm{X}$ & & & \\
\hline & & & & $8^{\circ}$ & & & & & & \\
\hline & & & & $9^{\circ}$ & & & & & & \\
\hline \multirow[t]{4}{*}{6} & \multirow{4}{*}{$\begin{array}{l}\text { Praticando } \\
\text { Matemática }\end{array}$} & \multirow{4}{*}{$\begin{array}{l}\text { Name, M.A. } \\
\text { Zampirolo, M.C. } \\
\text { de V. }\end{array}$} & & $6^{\circ}$ & $\mathrm{X}$ & $\mathrm{X}$ & & & & \\
\hline & & & do & $7^{\circ}$ & & & & & & \\
\hline & & & Brasil & $8^{\circ}$ & & & & & & \\
\hline & & & & $9^{\circ}$ & & & & & & \\
\hline 7 & Projeto & Leonardo,F.M. & Moderna & $6^{\circ}$ & $\mathrm{X}$ & $\mathrm{X}$ & & & & \\
\hline & Araribá & & & $7^{\circ}$ & & & & & & \\
\hline & Matemática & & & $8^{\circ}$ & & & & & & \\
\hline & & & & $9^{\circ}$ & & & & & & \\
\hline 8 & Projeto & Dante, L. R. & Ática & $6^{\circ}$ & $\mathrm{X}$ & $\mathrm{X}$ & & & & \\
\hline & Teláris- & & & $7^{\circ}$ & & & & & & \\
\hline & Matemática & & & $8^{\circ}$ & & & & & & \\
\hline & & & & $9^{\circ}$ & $\mathrm{X}$ & $\mathrm{X}$ & $\mathrm{X}$ & $\mathrm{X}$ & & $\mathrm{X}$ \\
\hline 9 & Projeto & Lopes, A.J. & Scipione & $6^{\circ}$ & & & & & & \\
\hline & Velear - & & & $7^{\circ}$ & & & & & & $\mathrm{X}$ \\
\hline & Matemática & & & $8^{\circ}$ & $\mathrm{X}$ & $\mathrm{X}$ & $\mathrm{X}$ & $\mathrm{X}$ & $\mathrm{X}$ & $\mathrm{X}$ \\
\hline & & & & $9^{\circ}$ & & & & & & \\
\hline 10 & Vontade & Pataro, P.M. & FTD & $6^{\circ}$ & $\mathrm{X}$ & $\mathrm{X}$ & & & & \\
\hline & de Saber & Souza, J. R. & & $7^{\circ}$ & $\mathrm{X}$ & $\mathrm{X}$ & $\mathrm{X}$ & $\mathrm{X}$ & $\mathrm{X}$ & $\mathrm{X}$ \\
\hline & Matemática & & & $8^{\circ}$ & & & & & & \\
\hline & & & & $9^{\circ}$ & $\mathrm{X}$ & $\mathrm{X}$ & $\mathrm{X}$ & $\mathrm{X}$ & $\mathrm{X}$ & $\mathrm{X}$ \\
\hline
\end{tabular}

Tabela 4: Análise PNLD Ensino Fundamental - Anos Finais

Na análise de cada coleção, nos propomos a verificar em cada um dos volumes:

- O comentário da resenha (PNLD) que seja relevante em relação aos tópicos das 


\begin{tabular}{|c|c|c|}
\hline $\mathrm{N}^{\mathrm{O}}$ & Coleção & Comentários \\
\hline 1 & $\begin{array}{l}\text { Descobrindo } \\
\text { e Aplicando } \\
\text { Matemática }\end{array}$ & $\begin{array}{l}\text { Nos conteúdos descritos há pouca menção aos assuntos relativos } \\
\text { às TG (Transformações Geométricas), aparece apenas } \\
\text { no } 6^{\circ} \text { ano como simetria de reflexão, e no } 7^{\circ} \text { como simetria. }\end{array}$ \\
\hline 2 & $\begin{array}{c}\text { Matemática } \\
\text {-Bianchini }\end{array}$ & $\begin{array}{l}\text { Somente em um dos quatro volumes, no } 7^{\circ} \text { ano, há uma } \\
\text { referência à simetria de reflexão }\end{array}$ \\
\hline 3 & $\begin{array}{c}\text { Matemática } \\
- \\
\text { Idéias e } \\
\text { Desafios }\end{array}$ & $\begin{array}{l}\text { Há refência às TG em todos os volumes, e aparentemente } \\
\text { no } 8^{\circ} \text { ano, todos os itens foram contemplados. Na resenha, } \\
\text { as simetrias e as isometrias, mesmo que bem definidas, } \\
\text { não são articuladas entre si, como é desejável. }\end{array}$ \\
\hline 4 & $\begin{array}{l}\text { Matemática } \\
- \\
\text { Imenes } \\
\text { Lellis }\end{array}$ & $\begin{array}{l}\text { Há } 3 \text { volumes, do } 6^{\circ}, 7^{\circ} \text { e } 8^{\circ} \text { anos, com referência a simetrias } \\
\text { de reflexão e de rotação, e segundo a resenha a coleção } \\
\text { aborda homotetias, considerada tema de interesse, mas há pouca } \\
\text { clareza na abordagem das simetrias }\end{array}$ \\
\hline 5 & $\begin{array}{l}\text { Matemática } \\
\text { Teoria e } \\
\text { Contexto }\end{array}$ & $\begin{array}{l}\text { Nos conteúdos descritos, há pouca menção aos assuntos relativos } \\
\text { às TG, aparecendo apenas no } 6^{\circ} \text { ano o tópico sobre simetria axial } \\
\text { e no } 7^{\circ} \text {, sobre simetria axial e de rotação. }\end{array}$ \\
\hline 6 & $\begin{array}{l}\text { Praticando } \\
\text { Matemática }\end{array}$ & $\begin{array}{l}\text { Há pouca menção aos assuntos relativos às TG, aparece apenas } \\
\text { no } 6^{\circ} \text { ano como simetria de reflexão. }\end{array}$ \\
\hline 7 & $\begin{array}{c}\text { Projeto } \\
\text { Arariba } \\
\text { Matemática }\end{array}$ & $\begin{array}{l}\text { Há apenas no } 6^{\circ} \text { ano referência à simetria de reflexão. } \\
\text { Na resenha menciona-se o o uso de mosaicos, geoplano e tangram. }\end{array}$ \\
\hline 8 & $\begin{array}{l}\text { Projeto } \\
\text { Teláris-- } \\
\text { Matemática }\end{array}$ & $\begin{array}{l}\text { No } 7^{\circ} \text { ano há simetria de reflexão, e no } 9^{\circ} \text { ano, todos os temas } \\
\text { das TG são mencionados (translação, reflexão, rotação, e } \\
\text { homotetia). }\end{array}$ \\
\hline 9 & $\begin{array}{c}\text { Projeto } \\
\text { Velear-- } \\
\text { Matemática }\end{array}$ & $\begin{array}{l}\text { No } 7^{\circ} \text { ano há ampliação e redução de figuras geométricas, e no } 8^{\circ} \\
\text { os temas simetrias de translação, reflexão, rotação, mosaicos } \\
\text { e ornamentos. Menciona-se na resenha que é valorizado o estudo } \\
\text { de congruência pelas TG e há uma boa apresentação das simetrias. }\end{array}$ \\
\hline 10 & $\begin{array}{l}\text { Vontade de } \\
\text { Saber } \\
\text { Matemática }\end{array}$ & $\begin{array}{l}\text { No } 6^{\circ} \text { ano, há simetria de reflexão, no } 7^{\circ} \text {, ampliação, simetria } \\
\text { de translação, de reflexão e de rotação, e no } 9^{\circ} \text { ano, homotetia. } \\
\text { Na resenha menciona-se que há valorização do estudo de isometrias } \\
\text { e destaca-se o uso de um software dinâmico como ferramenta auxiliar } \\
\text { de apoio ao ensino. }\end{array}$ \\
\hline
\end{tabular}

Tabela 5: Comentários das coleções do PNLD

transformações geométricas (TG);

- A proposta do(s) autor(es) ao tratar(em) das TG no Manual do Professor;

- Conteúdos abordados em cada volume da coleção sobre TG e sua organização;

- Como os conceitos são introduzidos;

- Atividades propostas pelo(s) autor(es) para apresentar(em) os conceitos das TG que contribuem para a construção do conhecimento; 
- Quais tipos de atividades são propostas para os alunos e como podem resolvê-los;

- Materiais didáticos utilizados e em quais contextos se apoiam;

- Considerações que consideramos relevantes para essa pesquisa.

\subsubsection{A Coleção Matemática - Ideias e Desafios}

Nos comentário da resenha, convém acrescentar que não há articulação e equilíbrio adequados entre atividades experimentais e dedutivas, já que é destinado pouco espaço para investigações, levantamento de hipóteses e verificação de propriedades pelo aluno. As construções geométricas com régua e compasso estão presentes desde o volume 7 , porem sem as necessárias justificativas para os procedimentos empregados. As simetrias e as isometrias, mesmo que bem definidas, não são articuladas entre si, como e desejável.

No Manual do Professor as autoras comentam no bloco de conteúdos "Espaço e Forma", que abordam a geometria das transformações, citando que trata das translações, rotações, reflexões, enfim, dos movimentos, das isometrias e das homotetias. Afirmam que o conceito de transformação geométrica é trabalhado com ênfase na intuição e verificação experimental de algumas conjecturas.

Dentro deste propósito, verificamos que no volume 7, o conceito de Simetria, que é item da unidade "Ângulos e propriedades", é introduzido com atividades que incluem desenho em folha sulfite dobrada com papel-carbono dobrado dentro do sulfite, dobradura e corte com papel (kiriguami), ambas atividades enfatizam a verificação da existência de eixos de simetria e da figura simétrica, e sugerem aos alunos que imaginem a existência de um espelho, colocado no eixo de simetria, para gerar a figura simétrica. Algumas figuras são apresentadas para a verificação de vários eixos de simetria e dentre elas incluem, círculo, floco de neve e retângulo. São propostas atividades para que os alunos contem quantos e quais os eixos de simetria em triângulo equilátero, pentágono, letras e figuras da natureza. Um campo para leitura adicional (Leitura + ) apresenta um mosaico do pintor M. C. Escher, e também algumas figuras obtidas por dobraduras com papel (Origami) e, as autoras afirmam que essas atividades com dobraduras são lúdicas e motivam os alunos, elas envolvem figuras geométricas com simetria.

Portanto, nesse volume 7, o único conceito de TG explorado é identificar eixos de simetria em figuras e, em alguns casos, a existência de uma figura simétrica, não houve abordagem das propriedades envolvidas, ou seja, sobreposição das imagens, inicial e refletida, ortogonalidade, semelhança e congruência. Os exercícios propostos não oferecem dificuldades para os alunos resolverem, pois abordam apenas a identificação e contagem dos eixos de simetria em algumas figuras já relatadas no parágrafo anterior.

No volume 8, dedica-se uma unidade (5) intitulada "Simetria, movimentos e padrões em Geometria", e na apresentação da unidade relacionam a existência de simetria como 
elemento da cultura humana e nas artes, e afirmam que o movimento de figuras geométricas em torno de retas e pontos gera propriedades importantes para o estudo dessas figuras. Sugerem como uma das atividades que os alunos pesquisem, e recortem de jornais e de revistas, figuras que apresentam simetria e repetição de padrões.

A unidade 5 é dividida em quatro capítulos sendo o primeiro, "Simetria", subdividido em dois tópicos, Simetria axial e Simetria Central. Na simetria axial utilizam dobradura e corte (kirigami), assim como apresentado no volume 7, e após dobrarem três vezes um pedaço de papel quadrado, feito o desenho e o corte, perguntam aos leitores para identificarem a existência de figura simétrica e contarem quantos são os eixos de simetria. Em seguida utilizam papel quadriculado para que os alunos copiem uma figura sugerida, tracem um eixo vertical e desenhem a figura simétrica em relação a esse eixo, e apresentam o resultado esperado, sem ao menos permitir que os alunos possam desenhar uma figura qualquer, obter o simétrico, e relacioná-la com o que foi apresentado até esta parte, para que possam discutir propriedades importantes.

O papel quadriculado torna-se útil para explorar a igualdade de medidas de dois pontos correspondentes nas figuras inicial e final em relação ao eixo de simetria, bastando contar quadradinhos, e a ortogonalidade também pode ser verificada com mais facilidade, o que não foi utilizado nesta atividade. Desenvolvem essa propriedade retornando à figura obtida do kiriguami, e por um dos eixos de simetria, identificado por e, traçam uma reta $A B$, marcam $P$ pertencente a $e$, e perguntam a relação entre os objetos, cujas respostam devem ser: $A B$ perpendicular a $e$ e $A P=B P$. Dada a importância dessas conclusões, a atividade carece de precisão tendo em vista que são puramente intuitivas em relação à figura escolhida, o recorte do papel pode não ser perfeito e a identificação da ortogonalidade e medição das distâncias podem ser prejudicadas.

Ainda dentro deste tópico, simetria axial, as autoras apresentam o conceito de "distância de um ponto a uma reta" através da construção de um triângulo $A B C$, um eixo de simetria $r$ e o correspondente triângulo $P S R$, simétrico ao triângulo $A B C$. Traçam segmentos $A^{\prime} P$, e marcam $X$ em $r$ entre $A$ e $P$. Marcam um ponto $Y$ em $r$ e $Z \neq X$. Por meio de personagens afirmam que as retas $A^{\prime} P$ e $r$ são perpendiculares e, afirmam que a medida de $\left(A^{\prime} X\right)$ é a menor medida de qualquer outro segmento com uma extremidade em $A$ e outra em $r$. As autoras dirigem-se aos professores para que certifiquem-se de que seus alunos compreenderam o conceito de distância de um ponto a uma reta, e da importância deste aprendizado.

A seguir, as autoras ensinam em "Desenhando figuras simétricas" por meio de régua e compasso, como desenhar uma figura simétrica à outra, desenhando uma figura, destacando pontos principais, traçando um eixo de simetria e retas perpendiculares por esses pontos ao eixo de simetria. Marcam-se pontos simétricos utilizando o compasso com a ponta seca nos pontos de intersecção do eixo de simetria com as retas perpendiculares e 
marcando os pontos simétricos correspondentes, onde ressaltam as medidas das distâncias de cada ponto e seu simétrico em relação ao eixo de simetria, serem iguais. Concluem esse tópico afirmando que esse tipo de simetria é uma simetria axial ou reflexão sobre uma reta (grifos das autoras). Sugerem aos alunos que façam uma dobra sobre o eixo de simetria, as figuras inicial e final ficaram sobrepostas, ou seja, coincidentes, e que tais figuras tem lados correspondentes com medidas iguais e ângulos correspondentes com medidas iguais, concluindo que são figuras congruentes (grifos das autoras).

Em relação a esse tópico, simetria axial, consideramos o desenvolvimento dos conceitos envolvidos apropriado, ou seja, iniciam com abordagens intuitivas de distâncias e segmentos entre pontos simétricos perpendiculares ao eixo de simetria, (com as devidas ressalvas anteriores), incluem construções de figuras simétricas introduzindo o conceito de distância, uso de régua e compasso para construções e verificações, concluindo e afirmando que figura inicial e final são figuras congruentes. As afirmações nas conclusões desse tópico, apesar da sua importância, poderiam ser introduzidas em atividades onde os alunos pudessem extraí-las, o que poderia contribuir para a apropriação do conhecimento com experimentação e discussão em grupos.

No outro tópico desse capítulo, "Simetria central", as autoras desenvolvem esse conceito solicitando aos alunos que desenhem um triângulo $A B C$ e um ponto $O$, de acordo com a figura sugerida por elas. Desenham retas ligando cada ponto do triângulo ao ponto $O$ e mostram que o ponto $M$, marcado na reta $B O$, com medida igual à medida de $B O$, é o ponto correspondente a $B$, em seguida solicitam que os alunos repitam a operação marcando o ponto $P$ correspondente a $A$, fazendo o mesmo para o ponto $C$ e seu correspondente $N$. O resultado é mostrado pelas autoras em outro desenho obtido das operações acima, e questionam os alunos para concluírem sobre esse novo triângulo. A resposta é apresentada aos professores e afirmam que tem lados e ângulos com medidas respectivamente iguais às do triângulo inicial. Ao final as autoras definem essa simetria de simetria central (grifo das autoras).

Neste tópico consideramos que não foram explorados em mais detalhes os conceitos envolvidos, como a preservação das distâncias correspondentes e nem tampouco uma possibilidade que pudesse ser posta em discussão para a superposição das figuras. A propósito, em nenhum dos tópicos os alunos são convencidos da preservação dos ângulos correspondentes nas figuras iniciais e finais, essa afirmação simplesmente é colocada como verdadeira, sem que haja algum tipo de demonstração.

Algumas atividades são propostas em "Fazer e aprender" e abordam a identificação de pontos simétricos em relação a uma reta a serem confirmados ou não pelo uso de régua, identificação do tipo de simetria, central ou axial apenas visualmente, pois não há medidas nem escalas, identificação de pares de figuras, se são simétricas ou não. Em dois exercícios com a utilização de papel quadriculado, pede-se que os alunos construam figuras 
geométricas simétricas a eixos de simetria e meçam e comparem distâncias entre pontos correspondentes. Outros dois exercícios são similares aos anteriores, porém sem o uso de papel quadriculado, são figuras diversas e pede-se apenas que desenhem figuras simétricas em relação ao eixo de simetria dado, sem escala ou medidas. Outro parecido aos anteriores, porém para obter a figura simétrica em relação ao um ponto dado. A seguir afirmam que os triângulos $A B H$ e $A C H$ são simétricos em relação ao eixo $A H$, e fazem três questões, se os lados e ângulos correspondentes são congruentes, qual lado é congruente ao um dado lado e qual ângulo é congruente a um ângulo dado, porém nenhuma medida é fornecida.

Por fim é apresentada uma questão para ser discutida pelos alunos, uma reta $a$ cortando um segmento $P R$ em um ponto $M$, e um ponto $N$ em $a, M \neq N$, porem, sem mostrar medidas, nem se $a$ é perpendicular ao segmento $P R$. Pelas respostas que aparecem no caderno do professor, ou seja, $a$ é mediatriz de $P R, P$ e $R$ simétricos em relação a $a$, distâncias $N^{\prime} P=N^{\prime} R$, pode não propiciar aos alunos a compreensão e importância destas questões sem enfatizar e convencê-los destas propriedades. A verificação apenas visual não deve ser utilizada para resolver estas questões, e se ao menos a figura fosse construída com régua e compasso, haveria a possibilidade de comprovar as respostas dadas fazendo medições.

Em outro Capítulo, ainda no volume 8, "Movimentos em Geometria" abordam os Padrões geométricos, para introduzirem os conceitos de movimento de translação, mostrando a utilização para o ladrilhamento como deslocamento de um padrão, e utilizam como exemplos, cerâmica, cestas e a obra do artista Escher, Dia e Noite. Os conceitos de direção, sentido e unidade de medida para o deslocamento da figura básica são apresentados através de um diálogo entre dois personagens, e estes concluem a propriedade da igualdade da distância entre pontos correspondentes.

Noutro tópico deste mesmo capítulo as autoras introduzem o movimento de rotação, apresentando os conceitos de centro de rotação, ângulo de rotação e sentido de rotação. Introduzem o conceito da rotação em relação a um ponto mostrando um passo-a-passo em quatro quadros, no primeiro traçam um triângulo $M N P$, e um ponto $A$ externo ao triângulo, e com a utilização de régua, compasso e transferidor, traçam o segmento $A M$ e uma semirreta com extremidade em $A$ fazendo um ângulo de $80^{\circ} \mathrm{com} A M$. Com o compasso marcam o ponto $B$ correspondente a $M$, e repetem a operação para os pontos $N$ e $P$ obtendo os correspondentes $C$ e $D$. Consideramos a introdução à rotação clara e de fácil entendimento por parte dos alunos. Finalizam montando um quadro onde enfatizam a conservação das distâncias dos lados dos triângulos inicial e final, e reafirmam que entre as figuras foi aplicada uma rotação de $80^{\circ}$ no sentido horário e o ponto A é o centro de rotação (grifo das autoras).

Fazem em seguida um resumo dos conceitos de Translação, Rotação e Reflexão, afirmando ao final que com esses movimentos obtêm-se figuras congruentes à figura inicial. 
Como em todos os tópicos, incluem exercícios em Fazer e aprender, para o aprendizado dos conceitos até aqui apresentados. São cinco exercícios para identificar os movimentos de translação, rotação e reflexão, apenas com figuras desenhadas sem medidas. Em um deles, as autoras solicitam aos alunos que identifiquem a combinação de dois movimentos, o que consideramos interessante, porém pouco explorado. Outros sete exercícios são apresentados, e os alunos são solicitados a obter figuras com movimentos, cinco utilizam papel quadriculado, translação (3), reflexão (1) e rotação (1) e outros dois não, um de translação e outro de rotação.

Em outro capítulo, Movimentos e propriedades geométricas, as autoras iniciam com a afirmação: os movimentos conhecidos transformam uma figura em outra mantendo as características da figura inicial, com exceção da posição, e através da construção de triângulo solicitam que os alunos expliquem o que acontece com as figuras movimentadas em relação à figura original, quanto à forma, dimensões dos lados e das medidas dos ângulos, sugerem a utilização de papel transparente, copiando a figura final e sobrepondo-a à figura original, concluindo que as medidas dos lados e ângulos correspondentes iguais, e portanto são figuras congruentes.

Como último item abordam os Padrões e ladrilhamentos, e em seguida uma boa lista de atividades sobre os itens vistos até aqui.

No volume 9 as autoras abordam a homotetia no tópico de Semelhança e proporcionalidade, no item Figuras semelhantes e homotetia, em apenas dois terços da página, e mostram somente a construção de um triângulo de centro $O$ e razão 2 .

Em função da proposta das autoras apresentada no Manual do Professor, que o conceito de transformação geométrica é trabalhado com ênfase na intuição e verificação experimental de algumas conjecturas, consideramos que os itens apresentados e as atividades propostas, são suficientes para que os alunos possam compreender as transformações como figuras em movimento. No entanto, as autoras não oferecem atividades que os alunos possam explorar e se aprofundar em questões consideradas relevantes, como questões envolvendo semelhança e congruência das figuras nas transformações geométricas, e esses movimentos em nenhum dos textos faz referência ao termo transformação geométrica no plano.

\subsubsection{A Coleção Projeto Teláris}

Nos comentário da resenha, não há menção a algum tópico das TG para esta coleção, e vale ressaltar que aparecem no volume 7 e 9, como iremos analisar a seguir.

No Manual do professor, a parte específica para o volume 7 (p.47), o autor destaca que o trabalho informal com simetria, será realizado por meio de dobraduras e recortes, e 
a simetria de uma figura em relação a outra será explorada intuitivamente, a um ou mais eixos de simetria.

O tópico Simetria no volume 7 (p.73-76) faz parte do Capítulo 2 (p.49) Geometria: sólidos geométricos, regiões planas e contornos, iniciando-se com a apresentação do conceito eixo de simetria através de dobradura com papel, exemplificado com três figuras. $\mathrm{O}$ autor solicita que os alunos procurem e recortem de jornais e revistas figuras simétricas, e também uma que não apresente simetria, com isso introduz o conceito de figura assimétrica.

Nos exercícios propostos, exige-se apenas a identificação da existência ou não de simetria em várias figuras, e em dois com o uso de papel quadriculado, o autor fornece desenhos apenas da metade das figuras, e fornece traçado o eixo de simetria em cada um deles, e solicita que os alunos completem as figuras de modo que a figura obtida apresente simetria em relação ao eixo traçado.

A seguir são mostradas figuras que apresentam simetria em relação a mais de um eixo, e exercícios são propostos para que os alunos tracem os vários eixos de simetria das figuras. Pede-se também que desenhem uma figura diferente das apresentadas com apenas dois eixos de simetria.

Até este ponto, a simetria explorada correspondia às da própria figura, o item seguinte, Simétrica de uma figura, o autor apresenta figura refletida em espelho, o reflexo de uma figura na superfície de um lago, e conclui que figura e seu reflexo são simétricas, uma em relação à outra, e com alguns exercícios, com o uso de papel quadriculado, pede-se que desenhem a figura simétrica à figura dada, análogos aos exercícios do item anterior, acrescentando apenas um exercício para repetição de padrão para a construção de painéis.

No volume 9, o tema Transformações geométricas (p.157-170) é retomado como um tópico inserido no capítulo Semelhança (p. 132), e o autor, na parte específica do Manual do Professor, em Espaço e Forma (p. 47), afirma: "o conceito de semelhança é um conceito fundamental em Matemática, tratamos as transformações geométricas que preservam a congruência (translação, reflexão e rotação) e da homotetia, transformação que não preserva congruência, mas preserva ângulos e proporcionalidade entre medidas dos lados (no caso de um polígono)".

Ressalte-se que o tópico relativo à semelhança abordado pelo autor, prepara o aluno para as transformações geométricas que virão a seguir, diversas figuras, desenhadas em papel quadriculado ou não, exploram a ampliação e redução das mesmas. Em um dos itens, Leitura, o autor fornece informações históricas da evolução dos recursos tecnológicos para ampliar, reduzir, reproduzir, rotacionar, inverter e deformar imagens.

Para exemplificar, o autor mostra uma tela de computador com imagens inicial e final numa redução, e também um pantógrafo, descrito como utilizado, desde a antiguidade, em diversas áreas, como Geografia, na confecção de mapas (uma figura exemplifica essa 
utilização); utilizada na Engenharia, facilitando a confecção de plantas de construções, na serralheria, servindo para cortar chapas metálicas; na ourivesaria, empregada para fazer gravações em alianças e anéis, etc. Trata em seguida de figuras semelhantes e figuras congruentes, e a nosso ver, se bem empregadas em sala de aula tornarão a aprendizagem das transformações geométricas pelos alunos mais interessantes.

Na introdução do tópico Transformações geométricas, o autor afirma que é possível efetuar certos movimentos ou transformações com figuras no plano de tal modo que sua forma e seu tamanho sejam preservados. A seguir faz uma sugestão ao professor para que comente com os alunos o movimento de translação da Terra em relação ao Sol.

Pela nossa análise, acreditamos não ter sido essa uma boa sugestão para introduzir o conceito da translação geométrica, o que poderia confundir os alunos, pois além da translação, a Terra efetua o movimento de rotação, e por outro lado estamos trabalhando com as TG no plano e não no espaço. O movimento de translação da Terra, além de descrever uma trajetória aproximadamente elíptica, não poderia ser associado a um vetor para a translação na sugestão acima.

A introdução propriamente dita é feita corretamente no primeiro item do tópico, Translação, utilizando o conceito de vetor orientado para levar o ponto $A$ a um ponto $A^{\prime}$, e da igualdade de segmentos $A A^{\prime}=B B^{\prime}$ quando para dois pontos $A \neq B$ é efetuada a translação. Através de uma personagem em uma fala, apresenta o conceito da unicidade, utilizando o segmento orientado $\overrightarrow{B B^{\prime}}$ para fazer a translação de um ponto $A$, obtendo-se um único ponto $A^{\prime}$, tal que $A A^{\prime}=B B^{\prime}$ e onde $A^{\prime}$ é o quarto vértice do paralelogramo $A A^{\prime} B^{\prime} B$ que tem $B B^{\prime}$ e $A A^{\prime}$ como lados.

O autor aborda e conceitua as propriedades importantes da translação, utiliza a notação usual para os pontos obtidos através desta transformação geométrica, e da característica da formação de um paralelogramo com a translação de dois pontos distintos.

Nos exercícios propostos neste item, e com a utilização de papel quadriculado, os alunos são questionados para identificarem os paralelogramos formados pela translação de um polígono de seis arestas onde são marcados cinco dos seis vértices nas figuras inicial e final, examinar as figuras e marcar opções verdadeiras para alguns segmentos selecionados e, também, para identificarem entre cinco vetores desenhados, qual é o representante da translação. Avaliamos que o exercício proposto enfatiza todas as propriedades importantes da translação, e acreditamos que não ofereça dificuldade para que os alunos respondam corretamente tais questões.

O autor faz uma advertência para que os professores esclareçam os alunos que a notação para representar um segmento orientado (vetor) é a mesma para representar uma semirreta, mas os conceitos são diferentes.

Em outro item, Figuras transladadas, o autor mostra a obtenção da figura trans- 
ladada, e define-a como imagem da figura inicial, onde cada ponto da figura inicial está ligado à imagem por meio de um segmento orientado, e utiliza a notação usual, figura $P Q R S$ e sua imagem $P^{\prime} Q^{\prime} R^{\prime} S^{\prime}$. Em outro quadro, utilizando papel quadriculado, solicita que os alunos examinem o exemplo onde são dados um polígono (trapézio) identificando os quatro pontos $A B C D$, e um segmento orientado com dimensão, direção e sentido. No mesmo quadro são desenhadas as figuras inicial e final, bem como os quatro segmentos orientados levando cada ponto à sua imagem.

Os exercícios propostos neste item são idênticos ao quadro de apresentação do conceito acima, ou seja, desenhar a imagem que será obtida de uma figura dada (polígonos) por meio de uma translação dado o segmento orientado. Noutro exercício, o autor questiona os alunos a responderem que figuras geométricas são formadas analisando a figura dada como exemplo para introduzir o conceito deste item, e o que espera é a formação de paralelogramos.

Um item interessante, Translações sucessivas, o autor, utilizando papel quadriculado, apresenta várias figuras e duas translações, com segmentos orientados de cores distintas, obtendo-se figuras de cores distintas para ilustrar a translação. Utiliza a notação usual para os pontos $\left(A, A^{\prime}, A^{\prime \prime}\right)$ Os dois exercícios propostos é uma reprodução do exemplo, apenas mudando figuras e segmentos orientados, e solicita-se obter as figuras transladadas. Não identificamos que os alunos tenham alguma dificuldade para executarem esta atividade.

O próximo item, Reflexão em relação a uma reta, o autor orienta o professor quanto ao paralelismo dos segmentos orientados que levam cada ponto da figura exemplo à sua imagem, bem como à igualdade das distâncias de um ponto $P$ e de sua imagem $P^{\prime}$ à reta mediatriz do segmento $\left(P P^{\prime}\right)$, lembrando que é perpendicular aos segmentos orientados. Essas orientações dirigidas ao professor representam as propriedades da reflexão em relação a reta que devem ser enfatizadas aos alunos pelo professor.

Utilizando a mesma personagem que traz mensagens (por balões) para os leitores, diz que a figura imagem é congruente à original.

Através de dois círculos o autor explora outra propriedade da reflexão em relação a uma reta, onde ressalta os sentidos opostos do deslocamento dos pontos das figuras inicial e sua imagem. Em outro exemplo convida os leitores a desenharem a imagem de uma figura após a reflexão em relação a uma reta dada, e ressalta as propriedades vistas na introdução ao item, ou seja, a reta mediatriz dos segmentos que ligam cada ponto à sua imagem, o de serem perpendiculares, e dos sentidos opostos na leitura dos pontos da figura inicial e da final.

Os exercícios propostos, de fácil resolução, pedem apenas que os alunos desenhem as figuras imagens, em papel quadriculado, por reflexão a uma reta dada, bem como as retas orientadas que levam cada ponto à sua imagem, e nas respostas aos exercícios 
ressalta-se o fato dessas retas serem perpendiculares à mediatriz. Os exercícios propostos contemplam figuras que podem ser exploradas pelo professor para exercitarem outras características dessa transformação, como a reflexão de uma reta em relação a outra reta, a reflexão de um círculo, de um triângulo, onde nestes últimos a reta base para a reflexão passa pelo interior da figura.

O autor faz uma observação onde define a reta usada para fazer a reflexão como eixo de reflexão ser um eixo de simetria quando a figura obtida corresponder à figura original. Outros exercícios são propostos utilizando as figuras de um retângulo, um triângulo isósceles, um quadrado e um paralelogramo para os alunos traçarem os eixos de simetria, onde todas as figuras são desenhadas com todas as suas medidas.

O item abordado a seguir, Rotação, é bem definido na introdução como um giro de uma figura em relação a um ponto, denominado centro de rotação, segundo um determinado ângulo em um determinado sentido, obtendo-se uma figura congruente à figura inicial. O autor lembra que o sentido do deslocamento dos pontos nas figuras inicial e final é o mesmo. Assim como nos itens anteriores, o conceito de rotação foi bem definido.

Em seguida o autor faz um passo-a-passo para construir uma figura imagem pela rotação em relação a um ponto, por um ângulo dado, e um sentido de rotação, utilizando transferidor, que em nossa avaliação permite que os alunos não tenham dificuldades para se apropriarem desses conceitos. Os exercícios propostos, todos com o uso de papel quadriculado, os alunos solicitados a desenharem a figura imagem pela rotação em relação a um ponto dado.

O autor faz uma observação ao final dos itens vistos até agora onde ressalta que a translação, reflexão e rotação são movimentos ou transformações geométricas que preservam congruência (itálico do autor), isto é, a figura transformada é sempre congruente à figura original, e esses movimentos são fundamentais em Geometria, por não deformar a figura original, também são chamados de movimentos rígidos ou de isometrias (iso=mesma; metria=medida).

No próximo item, Outro tipo de transformação: a homotetia, o autor inicia afirmando tratar-se de uma transformação geométrica que, em geral, não preserva a congruência, e com exemplos de proporcionalidade numa semirreta, utilizando a razão entre segmentos da reta, e as atividades são do mesmo tipo que a dos exemplos, desenha-se um segmento na semirreta, dá-se a razão e pede-se para marcar o ponto imagem, e acreditamos que os alunos não terão dificuldades para solucioná-los, utilizando apenas régua milimetrada.

Em seguida, em destaque, dá a definição de homotetia, com centro $\mathrm{O}$ e razão $k>0$, na semirreta, usando a notação $H(O, k)$. A seguir, nas atividades, são fornecidas as razões, e os alunos deverão marcar um ponto $P$, distinto de $O$, e determinar o ponto $P^{\prime}$ para cada exercício, que, em nossa opinião, não oferecem nenhuma dificuldade para solucioná-los. 
Noutro item, Propriedades importantes de uma homotetia, o autor define que as figuras que se correspondem por uma homotetia são chamadas de figuras homotéticas, e nelas os ângulos correspondentes são congruentes, os segmentos correspondentes são paralelos e a razão entre suas medidas é sempre a mesma e igual à razão da homotetia, e ainda, lembra que figuras relacionadas por homotetia são sempre semelhantes, porém a recíproca não é verdadeira, e continua, se duas figuras são semelhantes, é sempre possível que uma chegue à outra fazendo um ou mais movimentos rígidos ( rotação, translação ou reflexão), seguidos de uma homotetia, propriedades essas que são mostradas por meio de exemplos, de forma clara e didática.

Nas atividades propostas, são dadas as figuras homotéticas, e os alunos devem dizer qual a razão, e qual deveria ser a faixa da razão para haver redução, pra haver ampliação e para reproduzir a mesma figura, e em outro exercício são dadas as medidas de um retângulo e o valor da razão, e pede-se para construir um retângulo semelhante ao primeiro, e calcular o perímetro do segundo. Em nossa avaliação, os exercícios propostos não apresentam dificuldades para os alunos, considerando que tenham assimilado a parte teórica e a didática empregada pelo autor de forma clara e objetiva para a série na qual se aplica, ou seja, no $9^{\circ}$ ano do ensino fundamental.

O item seguinte, Transformações geométricas, correspondência biunívoca, congruência e semelhança, o autor faz uma revisão das TG vistas até o presente item, com as seguintes observações: a correspondência biunívoca, cada ponto da figura inicial tem um correspondente na figura final, e vice-versa, e se $P$ e $Q$ são pontos distintos da figura inicial, então seus correspondentes $P^{\prime}$ e $Q^{\prime}$ da figura final são pontos distintos; translação, rotação e reflexão são chamadas de isometrias, e a figura obtida é congruente à figura inicial; na homotetia as figuras inicial e final são semelhantes.

Os exercícios apresentados para esse item contemplam a teoria vista, e com figuras desenhadas em papel quadriculado, e outras não, as questões envolvem semelhança, congruência, cálculo da razão em figuras homotéticas, e indicação de quais combinações de TG resultam na obtenção da figura final. Consideramos que os exercícios apresentados oferecem um pouco mais de atenção por parte dos alunos, porém as dificuldades poderão ser sanadas pelo professor, considerando que envolvem vários conceitos vistos nas TG apresentadas pelo autor.

Para finalizar esse capítulo, no item Outras situações que envolvem semelhança, são propostas atividades para a construção de figuras semelhantes, por redução ou ampliação, e outras questionando sobre ser ou não semelhantes, justificando as respostas. A última questão é colocada como Projeto em equipe, propondo que os alunos escolham figuras em jornais ou revistas e façam um quadriculado sobre elas, como no exemplo do autor, em seguida deverão estabelecer razões de semelhança para ampliações e reduções da figura.

Considerando a proposta do autor ao tratar das TG no Manual do Professor; tanto 
para o volume 7, quanto para o volume 9 , os conteúdos em cada volume da coleção são bem organizados, com destaque para os conceitos e propriedades que devam ser enfatizadas, onde são reproduzidas em balões de fala de uma personagem ou em retângulos com letras e cores distintas do texto. Esses conceitos são mostrados em exemplos que podem ser bem assimilados pelos alunos.

Emprega notações adequadas, e somente a prática no ensino para alunos desta faixa etária poderá responder se são de fácil compreensão ou não. As atividades propostas pelo autor apresentam os conceitos abordados, e acreditamos que possam contribuir para a construção do conhecimento por parte dos alunos. Alguns exercícios irão exigir um pouco mais de atenção, e consideramos desejado para instigar a curiosidade, o gosto e o aprendizado das transformações geométricas.

Na maioria dos exemplos, e das atividades empregadas, o autor se utiliza de papel quadriculado, régua milimetrada, transferidor, e em quase todos fornece as medidas dos segmentos e dos ângulos, onde necessários. Registra-se, como visto na introdução da análise desta coleção, nas leituras complementares, o uso de recursos tecnológicos como computador e artefato do tipo máquina matemática (pantógrafo). A abordagem dos tópicos de TG ressaltam os conceitos de semelhança e congruência como desejado, e são bem apresentados, seguindo uma ordem onde cada assunto posterior está ligado ao assunto visto em tópicos anteriores.

Em função desta análise, consideramos essa coleção adequada para o estudo e aprendizagem das transformações geométricas, e fornece ao professor subsídios para exercem suas atividades no ensino.

\title{
3.4.3 A Coleção Vontade de Saber Matemática
}

Sobre esta coleção, e em complemento ao mencionado no Quadro 5, a resenha faz o seguinte comentário:

\begin{abstract}
Um destaque da obra é a exploração de conceitos e de propriedades das figuras geométricas com apoio em instrumentos de desenho, em um software de geometria dinâmica e em materiais concretos. Além disso, é bem conduzida a discussão das isometrias de rotação e de translação no plano. No entanto, tais transformações são mal articuladas com o conceito de simetria (BRASIL, 2013, p. 92).
\end{abstract}

Os tópicos relativos às transformações geométricas nesta coleção estão distribuídos pelos volumes 6, 7 e 9. Nas Orientações para o professor do volume 6, os autores destacam:

O estudo de simetria tem como objetivo auxiliar em conceituações de semelhança e congruência, buscando que os alunos desenvolvam a capacidade de perceber se duas figuras possuam ou não a mesma forma e mesmo tamanho, independentemente da posição que elas ocupam no plano. No capítulo será trabalhada a simetria de reflexão, sendo que as 
simetrias de rotação e translação serão estudadas em outros volumes desta coleção (op. cit. p.53).

Em seguida os autores sugerem que o professor peça aos alunos que realizem uma atividade de dobradura, conforme indicado nas imagens do exemplo, utilizando uma folha de papel de forma quadrada, que após três dobraduras e recorte com tesoura sem ponta, obtenham uma figura com quatro eixos de simetria.

O tópico, Figuras simétricas (p.193) esta inserido no capítulo 8, Polígonos, formas circulares e simetria (p.178), onde são introduzidos os conceitos de figuras simétricas e eixo de simetria por meio de duas figuras onde foram traçados segmentos de reta dividindo-as em duas partes iguais, e afirmam: ao dobrarmos as figuras ao longo do segmento de reta, elas vão se sobrepor.

Consideramos um bom inicio para se discutir com os alunos semelhança e congruência de uma forma intuitiva. Os autores refazem essas definições em destaque, incluindo ainda o caso de figura assimétrica, e um passo-a-passo passo para os alunos poderem obter uma figura simétrica.

Os exercícios propostos neste tópico se referem à identificação da existência e quantidade de eixos de simetria, e na classificação se simétrico ou assimétrico. Em outros exercícios, os autores utilizam os conceitos vistos acima com dobraduras para se utilizarem do termo reflexão, ou mais precisamente, figuras simétricas em relação ao eixo por reflexão. Incluem exercícios com a utilização de papel quadriculado e com espelho.

Os exercícios propostos, e de maneira diversificada, podem despertar nos alunos a curiosidade sobre o tema simetria, abordado, a nosso ver de uma forma completa, clara e de fácil assimilação.

O livro 7 dessa coleção dedica o capítulo 11 (p.270) para o tema, Transformações de figuras e simetria, e os objetivos propostos pelos autores são elencados na parte Orientações para o professor (p.62), ou seja:

- Identificar figuras semelhantes.

- Compreender o conceito de escala.

- Realizar ampliação e redução de figuras.

- Determinar a escala de ampliação e redução de figuras.

- Compreender o conceito de simetria.

- Verificar se uma figura é simétrica em relação ao eixo de simetria. 
- Identificar o eixo de simetria.

- Reconhecer simetria de rotação.

- Desenhar figuras simétricas em relação a um eixo de simetria.

- Desenhar figuras com simetria de rotação.

$\mathrm{Na}$ introdução ao referido capítulo, os autores colocam obras dos artistas Max Ferguson e Ron Muek e sugerem ao professor que explore discussões sobre as obras de arte no que tange à ampliação e redução de figuras, em seguida iniciam com o tópico, Ampliação, redução e reprodução de figuras. São colocadas fotos ampliadas e reduzidas, desenhos em malha quadriculada com figuras ampliadas e reduzidas para no final, e em destaque, os autores definem que figuras que apresentam a mesma forma, preservando os mesmos ângulos e proporcionalidade entre os lados correspondentes, são chamadas figuras semelhantes.

Nota-se que os autores apresentam uma série de exercícios sobre o tema ampliação e redução de figuras para no final introduzirem o conceito de figuras semelhantes, e a nosso ver, favorece o entendimento por parte dos alunos desse conceito, pois verificam essa propriedade intuitivamente, e ao final confirmam o que já podiam ter obtido nas atividades. Nas atividades seguintes são utilizadas folhas quadriculadas, em diversas escalas, e o objetivo é determinar relações de proporcionalidade entre medidas de lados correspondentes das figuras.

Essas observações estão de acordo com a proposta dos autores que, entre diversas sugestões, solicitam ao professor que verifique se os alunos perceberam que ao ampliar ou reduzir uma imagem, as formas são mantidas, ocorrendo alteração apenas em suas dimensões, implicando em imagens semelhantes.

O próximo tópico, Figuras simétricas, praticamente retoma o que havia sido abordado no volume 6 , e as atividades são praticamente com os mesmos objetivos, identificar e contar os eixos de simetria, identificar figuras simétricas e assimétricas, dobrar folhas sobre o segmentos desenhados verticalmente que separam duas figuras para concluírem se são figuras simétricas ou não.

No tópico seguinte, Simetria de Rotação, o procedimento de abordagem do tema é análogo à forma que os autores utilizam ao longo da coleção, mostram através de uma sequência de passos, rodando a figura em relação a um ponto, em um sentido, para ao final conceituarem a rotação, em destaque, negritando os conceitos envolvidos, ou seja, rotação em torno do ponto $O$, simetria de rotação, e ângulo de rotação no sentido horário ou anti-horário.

Os exercícios propostos uns solicitam que os alunos identifiquem onde houve rotação de figuras, em outros meçam, utilizando transferidor, qual a medida do ângulo de rotação 
da figura, e também, reproduzam a figura fornecida com o uso de papel quadriculado, e desenhem a figura simétrica com rotação de $180^{\circ}$ em relação a um ponto dado.

Uma das propostas dos autores que merece destaque é a sugestão de utilização de software de geometria dinâmica no tópico, Acessando tecnologia, construção de figuras simétricas (p. 282), e neste caso sugerem o uso do GeoGebra. Utilizam o software em duas aplicações, reflexão em relação a uma reta, e rotação em torno de um ponto, por um determinado ângulo e sentido de rotação, com uma sequência de quadros e as instruções para o uso das ferramentas, de forma clara e de fácil entendimento.

Nas atividades seguintes, todos os tópicos vistos neste capítulo são incluídos, ampliação e redução de figuras, cálculos de razão de ampliação/redução, identificação de figura simétrica, contagem do número de eixos de simetria, e dois exercícios com o uso do software GeoGebra, um para reflexão e outro para rotação.

Considerando a proposta dos autores nas orientações ao professor, os conceitos abordados nos tópicos e temas vistos neste volume, se bem explorados pelo professor em sala de aula, podem contribuir para que os alunos tenham um entendimento adequado sobre a identificação de figuras semelhantes, e incentivados ao uso dos diversos materiais e ferramentas, incluindo o uso de software de geometria dinâmica, e com isso possam ser despertados a "gostar" de geometria.

O livro 9 dessa coleção dedica o capítulo 4 (p.70) para o tema, Simetria, e os objetivos propostos pelos autores são elencados na parte Orientações para o professor (p.35), ou seja:

- Reconhecer as simetrias de rotação e translação.

- Construir figuras simétricas utilizando simetria de rotação ou de translação.

- Determinar o ângulo de rotação de figuras simétricas por rotação.

- Identificar a direção, o sentido e a distância em uma simetria de translação.

$\mathrm{Na}$ abertura desse capítulo os autores exploram a figura de uma bailarina em frente a um espelho e sugerem que o professor utilize a imagem para permitir aos alunos perceberem elementos relacionados à simetria de maneira contextualizada, incluindo informações acerca da fabricação de espelhos, uma vez que os alunos tem contato no seu dia a dia com superfícies reflexivas.

O primeiro tópico deste capítulo, Simetria de rotação, retoma o mesmo assunto visto no volume 7 , agora vistos com mais detalhes. O primeiro detalhe é a ampliação do conceito de rotação, particularizando o giro por um ângulo de $180^{\circ}$ com a denominação de 
Em seguida, como no volume 7, faz um passo-a-passo para a construção de uma figura simétrica por rotação utilizando régua, compasso e transferidor, de fácil compreensão e execução por parte dos alunos.

As atividades propostas seguem a mesma abordagem vista em atividades relacionadas com outros tópicos dessa coleção, identificação da figura simétrica por rotação em relação a um ponto, identificação e medição do ângulo de rotação levando em conta o sentido horário e o anti-horário, e com uma novidade, a utilização de uma figura (triângulo) desenhada em papel quadriculado em plano cartesiano, onde os alunos deverão identificar as coordenadas dos vértices da figura inicial e final por rotação em relação à origem dos eixos ortogonais.

A nosso ver, as atividades propostas não apresentam dificuldades para que os alunos possam resolvê-las, e contribuem para o aprendizado dos conceitos e propriedades até aqui apresentados, de forma clara e objetiva.

O próximo tópico, Simetria de translação (pg.75), é apresentado com a utilização de exemplos desenhados em papel quadriculado, com translações cujas medidas podem ser verificadas pela contagem de quadradinhos, e o conceito apresentado em destaque enfatiza que a transformação de uma figura que sofre um deslocamento de acordo com uma distância, uma direção e um sentido, mantendo seu tamanho e sua forma, é chamada

\section{simetria de translação.}

As atividades propostas exigem apenas a identificação e verificação das figuras simétricas por translação, em outros os alunos devem indicar a direção, a distância e o sentido das translações das figuras apresentadas, e por último é dada a direção, o tamanho da seta e a figura, desenhada em papel quadriculado, pede-se que os alunos desenhem a figura simétrica por translação.

Para finalizar este capítulo os autores apresentam o tópico, Explorando o tema, sugerindo que os alunos leiam o texto, A fundamental beleza da natureza, e cujo objetivo é discutir a associação entre beleza e simetria. Figuras como uma borboleta, uma face humana, com seus respectivos eixos de simetria, são colocadas como exemplos de simetria bilateral. Outra imagem colocada é o famoso desenho de Leonardo da Vinci (1945-159), O Homem Vitruviano (1492) para que os alunos observem as simetrias e as proporções do corpo humano.

Atividades de revisão dos tópicos vistos neste capítulo são apresentadas a seguir, e com poucas diferenças em relação aos tipos de questões que foram formuladas anteriormente. Não foi explorado, por exemplo, o uso do software de geometria dinâmica, como utilizado no volume 7 (p.282), que poderia enriquecer o aprendizado e estimular os alunos a praticarem as transformações geométricas, notadamente as translações. A combinação de várias transformações também não foi explorada pelos autores nesta coleção, que a nosso ver, 
podem oferecer oportunidades para os alunos fazerem a conexão entre as os vários tipos e propriedades das transformações vistas até o presente capítulo.

O último tópico abordado pelos autores neste volume 9, Homotetia (p.137), está inserido no capítulo 6, Semelhança (p. 122). No início do tópico os autores definem a homotetia como a transformação utilizada para ampliar ou reduzir uma figura, e citam algumas maneiras para executarem essas operações, como por exemplo, usando um pantógrafo, um programa de computador.

Como exemplo, usam a figura de um triângulo $A B C$, marcam um ponto $O$, externo ao triângulo, e com a utilização de um compasso marcam os pontos $A^{\prime} B^{\prime} C^{\prime}$ tais que a ampliação seja 1 para 2. Em outro exemplo desenham em um quadrilátero $A B C D$, um ponto $O$, interno ao quadrilátero e na intersecção das diagonais do quadrilátero, e com o uso do compasso marcam os pontos $A^{\prime} B^{\prime} C^{\prime} D^{\prime}$, nas diagonais correspondentes, tais que a redução seja de 2 para 1.

Nas atividades propostas, todas com polígonos, são fornecidas as medidas dos lados e dos ângulos internos, os alunos deverão construir figuras homotéticas sendo dadas as razões de ampliação, ou redução, conforme o caso, ou calcular a razão quando são fornecidas as medidas dos segmentos que ligam o ponto externo a vértices correspondentes das figuras inicial e final.

Consideramos pouco explorado esse tópico, onde o conceito de homotetia fora apresentado por meio de exemplos simples, e não apresentaram, que poderia ser útil para o entendimento dos alunos, uma relação de homotetia geral, como por exemplo, $O A^{\prime}=k O A$ e permitir a discussão dos valores atribuídos a $k$ e o resultado esperado para a homotetia.

Um ponto a ser ressaltado neste presente capítulo é apresentado no tópico Acessando tecnologias, onde utilizam o software GeoGebra para exemplificar as aplicações de ampliação de figuras, e empregam as mesmas figuras utilizadas no início do tópico da homotetia. Por sinal, os autores utilizam o software GeoGebra em vários capítulos dessa coleção em temas diversos, não só para geometria, mas também para funções. Empregam também exemplos com a utilização do programa Microsoft Mathematics para outras aplicações em geometria, álgebra, etc., que é um fator de elogio para os autores, sugerindo aos professores que se utilizem de tecnologias na prática do ensino. 


\section{Apresentação das transformações geométri- cas e propriedades: isometrias e semelhanças}

\subsection{Introdução}

Em Geometria, a abordagem do método das transformações geométricas envolve, basicamente, a aplicação dos conceitos e propriedades das funções. Essa abordagem foi introduzida e explorada por Klein, como vimos na obra de Piaget e Garcia (PIAGET; GARCIA, 2011), ou seja, "Klein descrevia a Geometria como o estudo das propriedades das figuras que permanecem invariantes sob um particular grupo de transformações". I. M. Yaglom em yaglom1 "Geometric Transformations I" com propriedade procura uma maneira de precisar, na Introdução, uma resposta para a questão: "O que é Geometria", e conclui: "Geometria é a ciência que estuda aquelas propriedades de figuras geométricas que não se alteram pelos movimentos das figuras, apesar de ainda não se considerar satisfeito, continua, "Um movimento é uma transformação geométrica do plano (ou do espaço) que leva cada ponto $A$ em um novo ponto $A^{\prime}$ de tal maneira que a distância ${ }^{1}$ entre dois pontos $A$ e $B$ é igual à distância entre os pontos $A^{\prime}$ e $B^{\prime}$, e conclui que devemos, por enquanto, aceitar de uma maneira intuitiva e então estudar cuidadosamente todas as suas propriedades.

No volume 2, vide (YAGLOM, 1962b), Yaglom procura aperfeiçoar a resposta à questão proposta no volume 1, "O que é Geometria", tratando o conceito de "distância" entre dois pontos, e conclui que, apesar da importância desse conceito, outras propriedades das figuras geométricas também devem ser analisadas, e cita como exemplos, ângulos, diagonais, perpendicularismo, entre outros, e no desenvolvimento desse assunto afirma que em certas ocasiões não é o comprimento de alguns segmentos que define a regra, mas somente "a razão dos comprimentos" de dois ou de vários segmentos. O conceito de comprimento de um segmento leva em conta a unidade de medida desse segmento, enquanto a razão entre segmentos independe da unidade de medida, unidade esta que deve ser a mesma para todos os segmentos considerados, não importando qual a unidade adotada. Segue que os conteúdos dos teoremas em geometria não devem depender de uma particular unidade de medida.

1 distância entendida como em geometria analítica, ou seja:

Sejam $x_{a} ; y_{a} ; z_{a}$ e $x_{b} ; y_{b} ; z_{b}$ as coordenadas dos pontos $A$ e $B$ no espaço euclidiano então a distância no plano $x y$ é $\sqrt{\left(x_{b}-x_{a}\right)^{2}+\left(y_{b}-y_{a}\right)^{2}}$ e a distância no espaço $x y z$ é $\sqrt{\left(x_{b}-x_{a}\right)^{2}+\left(y_{b}-y_{a}\right)^{2}+\left(z_{b}-z_{a}\right)^{2}}$ 
Portanto o conceito de distancia entre pontos, que de acordo com essa definição em geometria deve representar um papel básico, na realidade não deve aparecer diretamente nos teoremas geométricos. Yaglom cita que a definição de geometria apresentada por F. Klein, de alguma maneira diferente da apresentada por ele no vol.1, diz: "geometria é a ciência que estuda aquelas propriedades de figuras geométricas que não se alteram por transformações por semelhança (similarity transformations). Transformações por semelhança pode ser definida como aquelas "transformações que não alteram as razões das distâncias entre pares de pontos. A definição de Klein, em um sentido definido, diz que a geometria não deve somente não fazer distinção entre figuras congruentes, mas não deve também fazer distinção entre figuras semelhantes.

\subsection{Definições Gerais}

Nesta e nas demais seções, vamos nos restringir à apresentação das definições, teoremas e proposições, sem efetuarmos as devidas demonstrações que se fazem necessárias, e sem prejuízo do entendimento do material a ser exposto. Estas demonstrações estarão disponíveis no apêndice A na página 221, e portanto poderão ser consultadas quando for conveniente para complementação do estudo.

Definição 4.2.1. Aplicação

Uma aplicação $\alpha$ de um conjunto $\mathcal{B}$ em um conjunto $\mathcal{B}^{\prime}$ é uma correspondência na qual cada elemento $\boldsymbol{M}$ de $\mathcal{B}$ é associado a um elemento bem definido $\boldsymbol{M}$ ' de $\mathcal{B}^{\prime}$.

O elemento $\boldsymbol{M}$ ' é chamado $\boldsymbol{i m a g e m}$ de $\boldsymbol{M}$, enquanto $\boldsymbol{M}$ é chamado de $\boldsymbol{i m a g e \boldsymbol { m }}$ inversa de $\boldsymbol{M}^{\prime}$ por $\alpha$. Se $\boldsymbol{M}$ ' é a imagem de $\boldsymbol{M}$ pela aplicação $\alpha$, podemos escrever:

$$
M^{\prime}=\alpha(M)
$$

\section{Definição 4.2.2. Transformação}

Consideremos uma aplicação $\alpha$ do conjunto dos pontos do plano em si mesmo, isto é, uma correspondência que a cada ponto $P$ do plano associa um único ponto desse plano, e será indicado por $\alpha(P)$. Diremos que $\alpha$ é sobrejetora se para todo ponto $Q$ do plano existir um ponto $P$ de tal forma que $\alpha(P)=Q$, e a aplicação é injetora se $\alpha(R)=\alpha(S)$ implica $R=S$.

Uma aplicação que é simultaneamente injetora e sobrejetora é dita bijetora, com isso podemos garantir que para todo ponto $Q$ do plano existe um único ponto $P$ tal que $\alpha(P)=Q$.

Uma tal aplicação de um conjunto $\mathcal{B}$ no conjunto $\mathcal{B}^{\prime}$ é também chamada "um-a-um" se nenhum elemento de $\mathcal{B}^{\prime}$ tenha mais que um membro de $\mathcal{B}$ para o qual corresponda. 
Portanto, sob uma aplicação de $\mathcal{B}$ em $\mathcal{B}^{\prime}$ :

1. cada elemento de $\mathcal{B}$ corresponde a algum elemento definido de $\mathcal{B}^{\prime}$;

2. elementos distintos de $\mathcal{B}$ correspondem a elementos distintos de $\mathcal{B}^{\prime}$ (ou, em outras palavras, dois elementos distintos de $\mathcal{B}$ não tem a mesma imagem);

3. cada elemento de $\mathcal{B}^{\prime}$ tem um elemento correspondente de $\mathcal{B}$.

Uma aplicação um-a-um de um conjunto sobre si mesmo, isto é, uma aplicação de um conjunto $\mathcal{B}$ sobre precisamente o conjunto $\mathcal{B}$, é chamada uma transformação de $\mathcal{B}$.

Definição 4.2.3. Uma transformação do plano é uma aplicação bijetora do conjunto dos pontos do plano sobre si mesmo.

Portanto, dito de outra forma, uma transformação geométrica é uma correspondência biunívoca do conjunto de "todos os pontos" do plano, (ou de todos os pontos do espaço) sobre si mesmo. Este é um aspecto muito importante, quando dizemos, por exemplo, que "movimentamos um triângulo $A B C$ " por alguma das isometrias ${ }^{2}$, não movimentamos apenas o triângulo $A B C$ mas todos os pontos do plano (ou do espaço) onde o triângulo esta contido pela mesma isometria, embora muitas vezes estamos interessados em analisar as relações entre uma dada figura (o triângulo $A B C$ ) e sua transformada por essa isometria. Essa definição, de transformação geométrica como uma aplicação bijetora, é essencial para o que se segue.

Sendo $f$ uma transformação do plano, temos não somente que para todo ponto $P$ do plano existe um único ponto $Q$ tal que $f(P)=Q$, mas também da mesma forma vale a recíproca: para todo ponto $Q$ do plano existe um ponto $P$ tal que $f(P)=Q$.

Portanto segue destas considerações a existência da aplicação $f^{-1}$, chamada de inversa da transformação $f$, definida por $f^{-1}(Q)=P$ se e somente se $f(P)=Q$. Verificamos também que $f^{-1}$ é uma transformação e que $\left(f^{-1}\right)^{-1}=f$.

Indicamos por $g \circ f$ uma aplicação composta de duas transformações $f$ e $g$ do plano, definida por:

$$
(g \circ f)(P)=g(f(P))
$$

que é também uma transformação do plano. Também podemos verificar que se $f, g$ e $h$ são transformações do plano, então vale $(h \circ g) \circ f=h \circ(g \circ f)$.

Isto é, dadas duas transformações geométricas do plano (ou do espaço), o resultado da composição das duas é a que se obtém se aplicarmos uma a seguir à outra. Isto é, se $f$ transforma o ponto $P$ no ponto $P^{\prime}$ e $g$ transforma o ponto $P^{\prime}$ em $P^{\prime \prime}$, a composta $g \circ f$ transforma o ponto $P$ no ponto $P^{\prime \prime}$. É fácil demonstrar que esta aplicação é também uma

2 a definição de isometria será dada mais adiante, por ora vamos admitir que isometria "movimenta" os pontos do plano. 
transformação geométrica do plano (ou do espaço) e que a operação composição tem a propriedade associativa, mas não a propriedade comutativa.

Definimos também a transformação identidade por:

$$
I d(P)=P
$$

para todo $P$ do plano, e que podemos verificar a validade de:

$$
f \circ I d=f=I d \circ f, \quad f \circ f^{-1}=I d=f^{-1} \circ f
$$

onde $f$ é uma transformação qualquer do plano.

\section{Definição 4.2.4. Grupo de Transformações do Plano}

As definições vistas acima podem ser elencadas abaixo como as propriedades mais importantes na composição de transformações no plano, ou seja, vamos denotar por $F$ o conjunto de todas as transformações do plano onde valem:

1. se $f, g \in F$ então $g \circ f \in F$;

2. se $f, g, h \in F$ então $(h \circ g) \circ f=h \circ(g \circ f)$;

3. existe em $F$ um elemento $I d$ tal que $f \circ I d=I d \circ f=f \quad \forall f \in F$;

4. $\forall f \in F \quad \exists \quad f^{-1} \in F$ tal que $f \circ f^{-1}=I d=f^{-1} \circ f$.

O conjunto $F$ munido da operação de composição e satisfazendo simultaneamente as propriedades descritas acima (composta, associativa, identidade e inversa), possuem uma estrutura algébrica de grupo. Definimos então que $F$ é o grupo das transformações do plano.

Se duas transformações $f$ e $g$ quaisquer de um grupo $G$ satisfazem também a propriedade comutativa, isto é, $g \circ f=f \circ g$, dizemos que $G$ é um grupo comutativo ou abeliano.

Definição 4.2.5. Um subconjunto não vazio $G$ de transformações do plano é um subgrupo de $F$ se estão satisfeitas as seguintes condições:

i se $f, g \in G$ então $g \circ f \in G$;

ii se $f \in G$ então $f^{-1} \in G$.

Observamos que se $G$ é um subgrupo de $F$, então $G$, munido da operação de composição, é também um grupo (de fato, basta verificar que as propriedades de 1-4 da definição 4.2.4 acima são satisfeitas). 
Observação 4.2.1. Alguns autores abreviam a operação de composição de transformações $f \circ g$ escrevendo simplesmente $f g$ e dizem "produto de $g$ multiplicado por $f$ à esquerda", ou "produto de $f$ multiplicado por $g$ à direita", ou simplesmente "o produto "efe-ge". Assim, retirando o símbolo da transformação composta "o" da composição de transformações não causaria confusão. Desde que a propriedade associativa é assegurada na composição de transformações, então " $(f \circ(g \circ h)) \circ(j \circ k)$ " seria escrito " $f g h j k$ ".

Em " $f=g_{n} g_{n-1} \ldots g_{2} g_{1}$ " para um inteiro positivo $n$ a transformação $f$ é expressa como um produto de $n$ transformações. Ainda, se $g_{i}=g$, podemos escrever $f=g^{n}$. Além disso, se $g=h^{-1}$, então escrevemos " $f=h^{-n}$ ".

Definição 4.2.6. Involução; uma particular transformação $f$ de ordem 2 é uma involução se $f^{2}=I d$ onde $f \neq I d$. Outra caracterização dizemos que uma transformação não identidade $f$ é uma involução se $f=f^{-1}$. Essa observação segue do fato que $f^{2}=I d$ e $f=f^{-1}$ serem equivalentes, basta multiplicar os dois lados da primeira por $f^{-} 1$ e os dois lados da segunda por $f$. Note que a transformação identidade não é uma involução por definição.

Definição 4.2.7. Consideremos a notação $A B$ para representar a distância do ponto $A$ ao ponto $B$, ou seja, admitida fixada uma unidade de comprimento, podemos também indicar por $d(A B)$, ou $\overline{A B}$, o comprimento do segmento de reta $A B$. A reta que passa por $A$ e $B$ representaremos por $\overleftrightarrow{A B}$.

Dizemos que o ponto $B$ está entre os pontos $A$ e $C$ e escrevemos $A-B-C$ se:

1. $A, B, C$ são três pontos distintos;

2. $A, B, C$ são colineares;

3. $A B+B C=A C$

\subsection{Isometrias e Congruência}

Definição 4.3.1. Dizemos que o Espaço Euclidiano é o espaço que contem os objetos comuns que conhecemos da geometria: retas, circulos, esferas, e assim por diante, e representamos por $\mathbf{E}^{n}$ um espaço Euclidiano n-dimensional. O espaço Euclidiano é absolutamente uniforme (o termo técnico é "homogêneo"). Essa uniformidade do espaço Euclidiano é a característica chave da geometria Euclidiana, ela é que nos permite mover objetos dentro do espaço Euclidiano sem distorcê-los. Objetos distantes podem ser movimentados e colocados sobre outros objetos para que se possa compará-los, sem alterar suas formas e suas características.

Objetos são movidos de um lugar a outro no espaço pela ação de "funções".

$$
f: \mathbf{E}^{n} \rightarrow \mathbf{E}^{n}
$$


toma cada ponto $P \in \mathbf{E}^{n}$ e move-o para uma nova posição $f(P) \in \mathbf{E}^{n}$.

As funções mais importantes no $\mathbf{E}^{n}$ são aquelas que preservam distâncias.

Definição 4.3.2. Isometria. Uma função $f: \mathbf{E}^{n} \rightarrow \mathbf{E}^{n}$ é uma isometria se, para todos os pontos $P$ e $Q$ em $\mathbf{E}^{n}$, (fig.2).

$$
f(P) f(Q)=P Q
$$

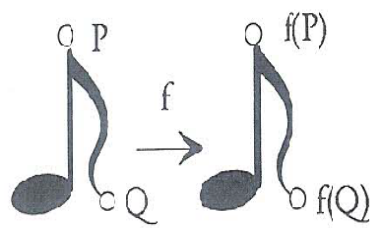

UMA ISOMETRIA

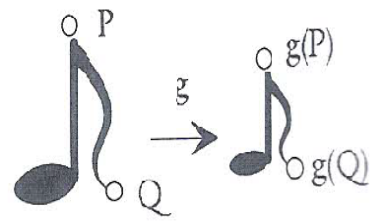

UMA NĀO ISOMETRIA

Figura 2: Isometria

(JENNINGS, 1966, p. 2)

Notação. Vamos usar $P^{\prime}$ para denotar $f(P)$, a imagem de $P$ pela isometria $f$.

Isso significa que, uma isometria entre os planos Euclidianos $\Pi$ e $\Pi^{\prime}$ pertencentes ao $\mathbf{E}^{n}$, é uma função $f: \Pi \rightarrow \Pi^{\prime}$ que preserva distâncias, isto é, dados quaisquer dois pontos $P, Q \in \Pi, P^{\prime}=f(P)$ e $Q^{\prime}=f(Q)$, tem-se que $d(P Q)=d\left(P^{\prime} Q^{\prime}\right)$, onde $P^{\prime}, Q^{\prime} \in \Pi^{\prime}$.

Definição 4.3.3. Congruência. Subconjuntos $A, B \subseteq \mathbf{E}^{n}$ são congruentes (representado por $A \cong B$ ) se houver uma isometria $f$ tal que $f(A)=B$.

Teorema 4.3.1. O conjunto de todas as isometrias do plano é um subgrupo do conjunto de todas as transformações do plano (vide demonstração na página 221 do Apêndice A).

Teorema 4.3.2. A composição de duas isometrias é uma isometria. A inversa de uma isometria é uma isometria (vide demonstração na página 222 do Apêndice A).

Observação 4.3.1. Uma isometria é definida para ser uma transformação que preserva distâncias entre pontos. Vamos mostrar que uma isometria preserva outras relações geométricas. Pode parecer estranho exigir que uma transformação que preserve apenas distâncias seja suficiente para garantir que isso também preserve comprimentos, ângulos, áreas, volumes, e muitas outras propriedades geométricas, isto é, isometrias preservam o tamanho e forma de cada figura. Mas devemos recordar que na geometria Euclidiana estamos assumindo como válido o Postulado Lado-Ângulo-Lado (LAL). O Postulado LAL assegura que as medidas de distâncias e ângulos não são independentes, mas estão interligadas. Quando trabalharmos nas demonstrações dos próximos teoremas deveremos pensar dos modos como LAL estão sendo usados, direta ou indiretamente. 
Terminologia. Tendo em vista que isometrias movem objetos ao redor enquanto preservam relações geométricas, uma isometria é também chamada de um "movimento rígido".

Teorema 4.3.3. Propriedades das Isometrias. Seja $f: \Pi \rightarrow \Pi$ uma isometria.

1. f preserva colinearidade; isto é, se $P, Q$ e $R$ são três pontos colineares, então $f(P)$, $f(Q)$ e $f(R)$ são colineares.

2. $f$ preserva estar-entre de pontos; isto é, se $P, Q$ e $R$ são três pontos tais que $P-Q-R$ então $f(P)-f(Q)-f(R)$.

3. $f$ preserva segmentos; isto é, se $A$ e $B$ são pontos e $A^{\prime}$ e $B^{\prime}$ são suas imagens por $f$, ent $\tilde{a} o f(\overline{A B})=\overline{A^{\prime} B^{\prime}}$ e $\overline{A B} \cong \overline{A^{\prime} B^{\prime}}$.

4. f preserva ponto médio; isto é, se $P-Q-R$ e $P Q=Q R$, ou seja, $Q$ é o ponto médio do segmento $\overline{P R}$, então $P^{\prime} Q^{\prime}=Q^{\prime} R^{\prime}$, e $Q^{\prime}$ é o ponto médio do segmento $\overline{P^{\prime} R^{\prime}}$.

5. $f$ preserva retas; isto é, se $r$ é uma reta, então $f(r)$ é uma reta.

6. f preserva semi-retas; isto é, se $\overrightarrow{O P}$ é uma semi-reta, então $\overrightarrow{O^{\prime} P^{\prime}}$ é uma semi-reta.

7. f preserva estar-entre de semi-retas; isto é, se $\overrightarrow{O P}, \overrightarrow{O Q}$ e $\overrightarrow{O R}$ são três semi-retas tais que $\overrightarrow{O Q}$ está-entre $\overrightarrow{O P}$ e $\overrightarrow{O R}$, então $\overrightarrow{O^{\prime} Q^{\prime}}$ está-entre $\overrightarrow{O^{\prime} P^{\prime}}$ e $\overrightarrow{O^{\prime} R^{\prime}}$.

8. f preserva triângulos; isto é, se $\triangle B A C$ é um triângulo, então $f(\triangle B A C)$ é um triângulo e $f(\triangle B A C) \cong \triangle B A C$.

9. $f$ preserva ângulos; isto é, se $\angle B A C$ é um ângulo, então $f(\angle B A C)$ é um ângulo e $f(\angle B A C) \cong \angle B A C$.

10. f preserva perpendicularismo; isto é. se $\overleftrightarrow{O P}$ é perpendicular a $\overleftrightarrow{O Q}$ em O, então $\overleftrightarrow{O^{\prime} P^{\prime}}$ é perpendicular a $\overleftrightarrow{O^{\prime} Q^{\prime}}$ em $O^{\prime}$

11. f preserva paralelismo; isto é, se $\overleftrightarrow{A B}$ é paralela a $\overleftrightarrow{C D}$, então $\overleftrightarrow{A^{\prime} B^{\prime}}$ é paralela a $\overleftrightarrow{C^{\prime} D^{\prime}}$.

12. f preserva círculos; isto é, se $\mathscr{C}$ é um círculo com centro $O$ e raio r, então $f(\mathscr{C})$ é um círculo de centro $f(O)$ e raio $r$.

13. $f$ preserva áreas; isto é, se $R$ é uma região poligonal, então $f(R)$ é uma região poligonal, e chamando de $\alpha(R)$ a área da região $R$, então $\alpha(f(R))=\alpha(R)$.

Demonstração do teorema 4.3.3 estão disponíveis no Apêndice A na página 222 , onde vamos provar alguns dos itens das propriedades das isometrias listadas acima. 
Definição 4.3.4. Colineação. A transformação $f$ do plano que tem a propriedade de transformar pontos colineares em pontos colineares é dita uma colineação. Se $r$ é uma reta do plano, então $f(r)$ também é uma reta desse plano. Lembrando que uma reta $r$ é um conjunto de pontos, segue que $f(r)$ também é um conjunto de pontos, e $f(P) \in f(r)$ para todo $P \in r$.

Definição 4.3.5. Diremos que uma transformação $f$ do plano fixa um ponto $P$ se $f(P)=P$. Neste caso, $\boldsymbol{P}$ é chamado um ponto fixo da transformação $f$. Dado $\mathscr{A} \subset E^{2}$, diremos que $f$ fixa $\mathscr{A}$, ponto a ponto, se $f(P)=P \quad \forall P \in \mathscr{A}$, isto é, $f$ fixa "todos os pontos" de $\mathscr{A}$.

Proposição 4.3.1. Se uma isometria do plano fixa dois pontos distintos de uma reta então ela fixa, ponto a ponto, esta reta (vide demonstração na página 224).

Teorema 4.3.4. Uma isometria que fixa três pontos não colineares é a transformação identidade; isto é, se $A, B$ e $C$ são três pontos não colineares e $f$ é uma isometria tal que $f(A)=A, f(B)=B$ e $f(C)=C$ então $f=I d$ (vide demonstração na página 224).

Teorema 4.3.5. Sejam $f, g: \Pi \rightarrow \Pi$ isometrias, e $A, B$ e $C$ três pontos não colineares em $\Pi$ tais que $f(A)=g(A), f(B)=g(B)$ e $f(C)=g(C)$, então $f(P)=g(P) \quad \forall P \in \Pi$ (vide demonstração na página 224).

\subsection{Tipos de Isometrias}

Nesta seção abordaremos em detalhes os diferentes tipos de isometrias no plano, que serão definidas e caracterizadas, e indicados para cada uma delas os elementos teóricos necessários para a devida compreensão. Iremos mostrar que existem apenas quatro tipos de isometrias $f: \Pi \rightarrow \Pi$ do plano Euclidiano $\Pi \in E^{n}$, além da função identidade, a saber: translação, rotação, reflexão e reflexão transladada.

Iremos ainda verificar que cada isometria Euclidiana é uma combinação de reflexão, translação e rotação.

\subsubsection{Translação}

Iniciaremos a apresentação pela translação que é muitas vezes considerada a transformação geométrica mais simples, e é normalmente a primeira isometria a ser apresentada aos alunos. No estudo da translação precisamos nos lembrar do conceito de vetor como uma classe de equipolência de segmentos orientados.

Existem grandezas chamadas escalares, que são caracterizadas por um número (e a unidade correspondente): $50 \mathrm{~m}^{2}$ de área, $4 \mathrm{~m}$ de comprimento, $7 \mathrm{~kg}$ de massa. Outras, no entanto, requerem mais que isso. Por exemplo, para caracterizarmos uma força ou uma 
velocidade, precisamos dar a direção, a intensidade (módulo) e o sentido.

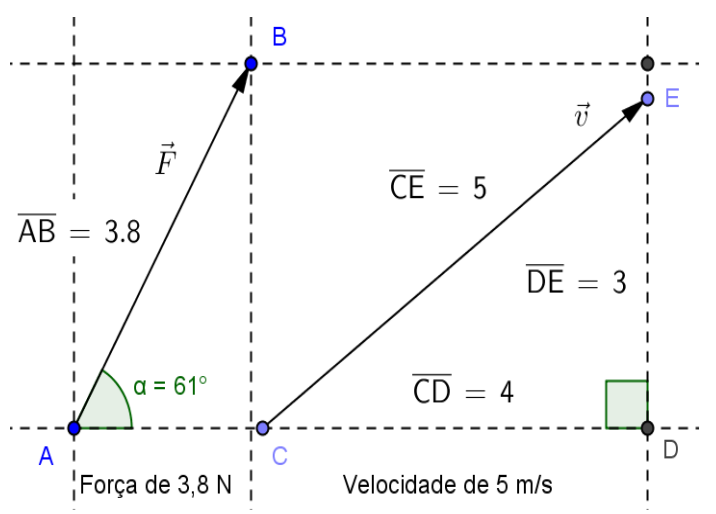

Figura 3: Exemplo de vetores

Tais grandezas são chamadas vetoriais e dizemos que duas flechas de mesmo comprimento, mesma direção (isto é, paralelas) e mesmo sentido definem a mesma grandeza vetorial e tais flechas são ditas equipolentes.

Definição 4.4.1. Vetor. Um segmento orientado é um par ordenado $(A, B)$ de pontos do espaço. $A$ é dito origem, $B$ extremidade do segmento. Os segmentos orientados $(A, A)$ são ditos nulos.

Observe que se $A \neq B,(A, B) \neq(B, A)$.

Se $(A, B)$ e $(C, D)$ são equipolentes, e indica-se $(A, B) \sim(C, D)$ se ou ambos são nulos ou se tem o mesmo módulo, mesma direção e mesmo sentido.

Portanto, um vetor (do Latim "vehere"= transportar) é uma classe de segmentos orientados do $E^{n}$. Se $(A, B)$ é o segmento orientado, o vetor correspondente, ou seja, o vetor cujo representante é $(A, B)$, será indicado por $\overrightarrow{A B}$. Usamos também letras $(\vec{u}, \vec{v}, \vec{a})$ para representá-los.

Vetores são adicionados ou subtraídos uns dos outros da maneira usual, ou seja, a cada par de vetores $\vec{u}$ e $\vec{v}$, o vetor soma $\vec{u}+\vec{v}$ será obtido procedendo-se do seguinte modo: seja $(\mathrm{A}, \mathrm{B})$ um representante qualquer do vetor $\vec{u}$, posicionamos a origem do vetor $\vec{v}$ na extremidade $B$ do vetor $\vec{u}$. Seja $C$ a extremidade do vetor $\vec{v}$. Fica assim determinado o segmento orientado $(A, C)$. Por definição, o vetor $\overrightarrow{A C}$, cujo representante é o segmento orientado $(A, C)$, é o vetor soma de $\vec{u} \operatorname{com} \vec{v}$. Para a subtração $\vec{u}-\vec{v}$ basta invertermos o 
sentido de $\vec{v}$ (oposto de $\vec{v}$ ) efetuando à adição de $\vec{u}+(-\vec{v})$ como descrito acima.

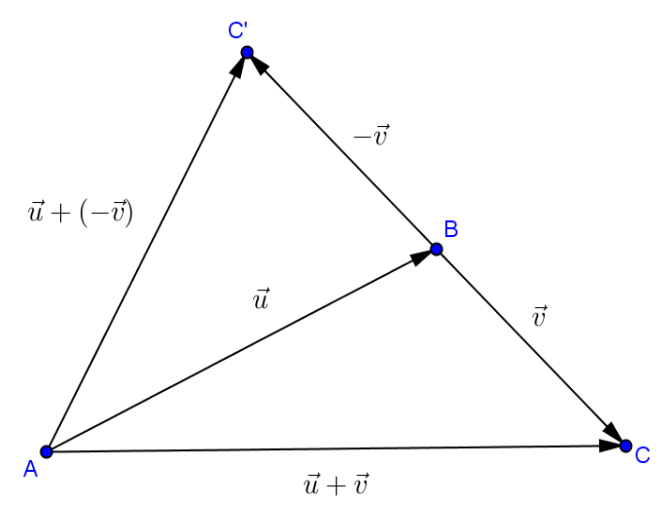

Figura 4: Adição de vetores

Vetores também podem ser adicionados a pontos. Se $P$ e $Q$ são pontos do $E^{n}$ e $\vec{v}$ que leva $P$ a $Q$, como mostrado na figura 5 abaixo, onde:

$$
Q=P+\vec{v}, \quad P=Q-\vec{v}, \quad \vec{v}=Q-P
$$

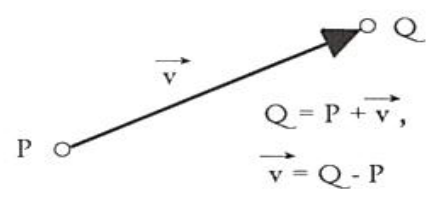

Figura 5: Adição de vetor a ponto

(JENNINGS, 1966, p. 6)

Esta operação tem as seguintes propriedades:

1. $P+\overrightarrow{0}=P$;

2. $(P+\vec{v})+\vec{w}=P+(\vec{v}+\vec{w})$;

3. se $P+\vec{v}=P+\vec{w}$ então $\vec{v}=\vec{w}$;

4. se $P+\vec{v}=Q+\vec{v}$ então $P=Q$.

Definição 4.4.2. Translação é a transformação geométrica que move objetos ao longo de uma linha reta no espaço em uma determinada direção e sentido sem rotaciona-los 
ou alterar sua orientação ou dimensões. Há uma correspondência um-a-um entre vetores do $E^{n}$ e translações: a translação $T$ associada ao vetor $\vec{v} \in E^{n}$ atua pela adição de $\vec{v}$ a cada ponto da figura. A soma de ponto com vetor define a aplicação chamada translação na direção do vetor $\vec{v}$, ou translação de vetor $\vec{v}$, ou simplesmente, translação no plano por:

$$
T_{\vec{v}}(P)=P+\vec{v}
$$

$\vec{v}$ é o vetor deslocamento da translação $T$ (fig.6).

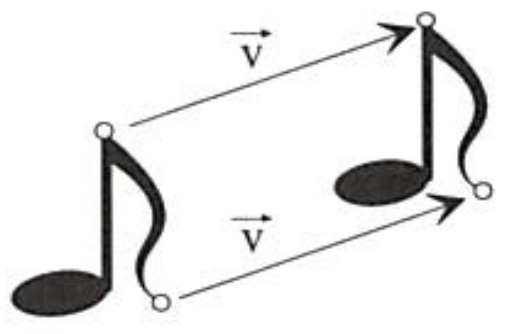

Figura 6: Uma translação

(JENNINGS, 1966, p. 7)

Observação 4.4.1. Toda translação é uma isometria do plano pois, para $P$ e $Q$ pontos distintos do plano, se $P^{\prime}=T_{\vec{v}}(P)$ e $Q^{\prime}=T_{\vec{v}}(Q)$, então:

$$
P^{\prime} Q^{\prime}=\left|Q^{\prime}-P^{\prime}\right|=|[(Q+\vec{v})-(P+\vec{v})]|=|Q-P|=P Q .
$$

isto é, preserva distâncias, e ainda;

- Se $\vec{v}=0$, temos que $T_{\overrightarrow{0}}(P)=P+\overrightarrow{0}=P=I d(P), \quad \forall P$;

- a composta de duas translações é uma translação, pois

$$
\left(T_{\vec{v}} \circ T_{\vec{w}}\right)(P)=T_{\vec{v}}\left(T_{\vec{w}}(P)\right)=T_{\vec{v}}(P+\vec{w})=(P+\vec{w})+\vec{v}=P+(\vec{w}+\vec{v})=T_{\vec{w}+\vec{v}}(P), \forall P
$$

Ou seja, a composição de translações é equivalente ao vetor adição (fig.7):

$$
T_{\vec{v}} \circ T_{\vec{w}}=T_{\vec{v}+\vec{w}}
$$

- a operação de composição é comutativa, isto é:

$$
T_{\vec{v}} \circ T_{\vec{w}}=T_{\vec{w}} \circ T_{\vec{v}}
$$




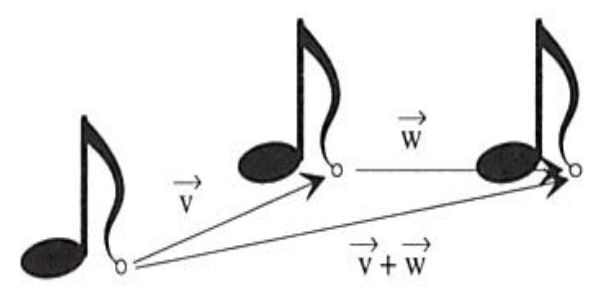

Figura 7: Composição de translações (JENNINGS, 1966, p. 8)

- Sendo transformações, as translações são inversíveis; podemos verificar facilmente que

$$
\left(T_{\vec{v}}\right)^{-1}=T_{-\vec{v}}
$$

- Fazendo $\vec{v}=\vec{w}$ na expressão $T_{\vec{v}} \circ T_{\vec{w}}=T_{\vec{w}+\vec{v}}$, temos

$$
T_{\vec{v}} \circ T_{\vec{v}}=T_{2 \vec{v}}
$$

Podemos verificar que para todo natural $n$,

$$
\left(T_{\vec{v}}\right)^{n}=T_{\vec{v}} \circ T_{\vec{v}} \circ \cdots \circ T_{\vec{v}}=T_{n \vec{v}}
$$

como as translações são inversíveis e $\left(T_{\vec{v}}\right)^{-1}=T_{-\vec{v}}$, teremos também

$$
\left(T_{\vec{v}}\right)^{-n}=\left[\left(T_{\vec{v}}^{-1}\right)\right]^{n}=T_{-n \vec{v}}
$$

Em resumo, para todo inteiro $n$ vale

$$
\left(T_{\vec{v}}\right)^{n}=T_{n \vec{v}}
$$

Os pontos de uma figura $F$ são movidos por uma translação para um conjunto de pontos formando uma nova figura $F^{\prime}$. Dizemos que a nova figura $F^{\prime}$ é obtida de $F$ por uma translação. Às vezes dizemos que a figura $F^{\prime}$ é obtida deslocando a figura $F$ "por inteira" numa direção " $N N^{\prime \prime}$ a uma distância $a$. Aqui a expressão "por inteira" significa que "todos" os pontos da figura $F$ são movidos na mesma direção e sentido, e à mesma distância. Isso significa que todos os segmentos que interligam os pontos correspondentes da $F$ e $F^{\prime}$ são paralelos, tem a mesma direção e a mesma distância (fig.8). Se a figura $F^{\prime}$ é obtida de $F$ por uma translação na direção $N N^{\prime}$, então a figura $F$ é obtida de $F^{\prime}$ por uma translação na direção oposta a $N N^{\prime}$ (na direção $N^{\prime} N$ ); isso nos permite falar em par de figuras relacionadas por uma translação.

Seja $T_{\vec{v}}$ a translação na direção $N N^{\prime}$ onde $|\vec{v}|=a$, então podemos escrever;

$$
T_{\vec{v}}(F)=F^{\prime} \quad \text { e } \quad T_{-v}\left(F^{\prime}\right)=F
$$




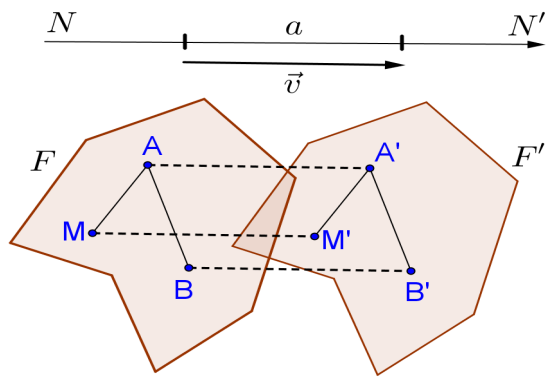

Figura 8: Translação de figura

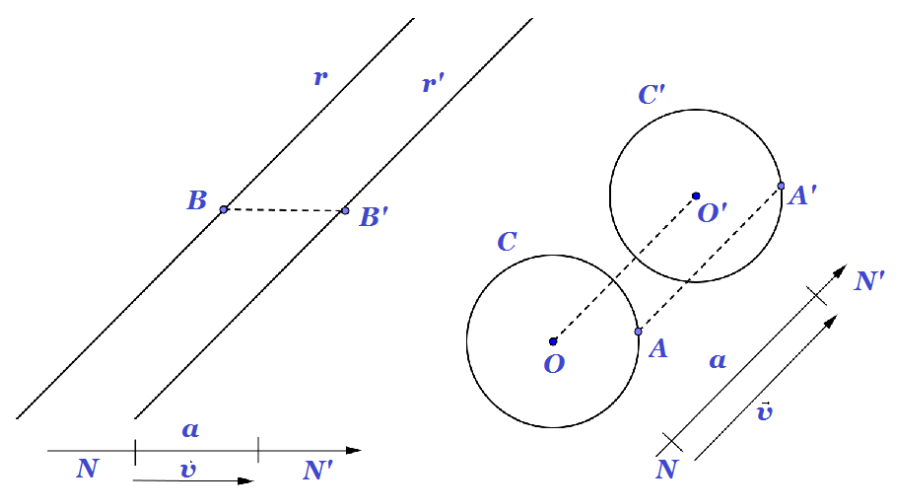

Figura 9: Translação de retas e círculos

Translação move uma reta $r$ em uma reta paralela $r^{\prime}$, e um círculo $C$ em uma circulo igual $C^{\prime}$ (fig.9).

Alguns casos típicos da utilização da translação para resolver problemas de construção estão nos exemplos seguintes.

Exemplo 4.4.1. Dados os pontos $M$ e $N$ e os círculos $C_{1}$ e $C_{2}$, construir um paralelogramo $M N P Q$ onde $P$ pertençe a $C_{2}$ e $Q$ pertence a $C_{1}$ (figura 10)

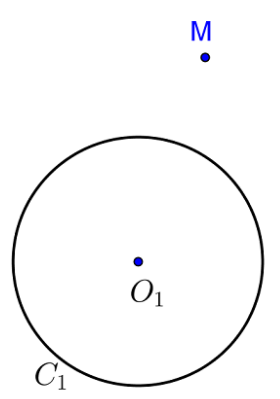

.$^{N}$

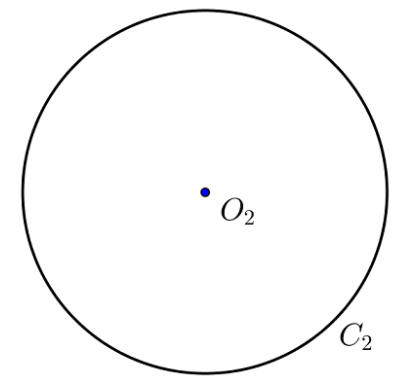

Figura 10: Dados do exemplo 4.4.1 
Solução: Seja $\vec{u}=\overrightarrow{M N}$. Como $M N P Q$ é um paralelogramo, a translação $T_{\vec{u}}$ leva $Q$ em $P$. Aplicando essa transformação ao círculo $C_{1}$ temos que $C_{1}^{\prime}=T_{\vec{u}}\left(C_{1}\right)$ contem o ponto $P$. Logo o vértice $P$ do paralelogramo $M N P Q$ é um ponto de intersecção dos círculos $C_{2}$ e $C_{1}^{\prime}$ (fig. 11). Para obter $C_{1}^{\prime}$ basta aplicar a translação ao centro $O_{1}$ de $C_{1}$ obtendo $O_{1}^{\prime}=T_{\vec{u}}\left(O_{1}\right)$ e em seguida traçar o círculo de centro $O_{1}^{\prime}$ com mesmo raio de $C_{1}$. Neste exemplo, os dados apresentados permitiriam a obtenção de duas soluções: $M N P Q$ e $M N P^{\prime} Q^{\prime}$.

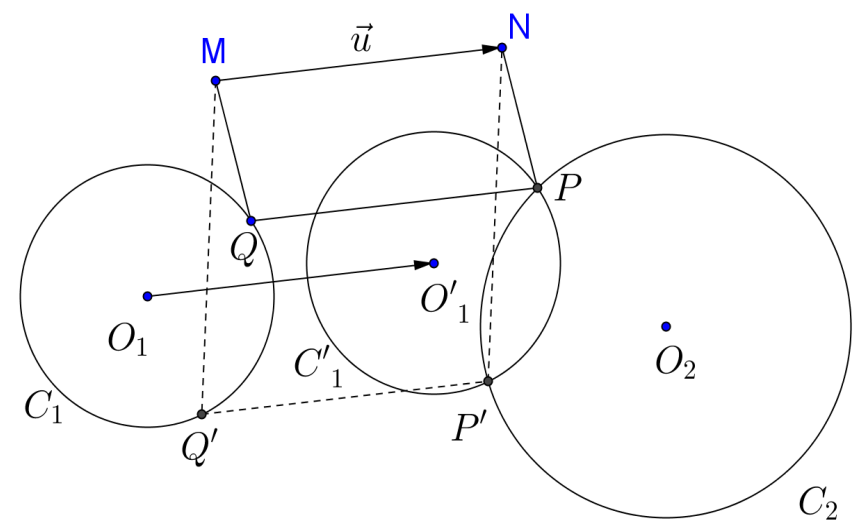

Figura 11: Solução do exemplo 4.4.1

Exemplo 4.4.2. Em que ponto deve-se construir uma ponte $M N$ através de um rio que separa duas cidades $A$ e $B$ de tal maneira que o caminho $A M N B$ da cidade $A$ à cidade $B$ seja o menor possível. Assuma que as margens do rio são linhas retas e paralelas e que a ponte $M N$ seja perpendicular às margens do rio (fig.12). Solução:Sendo as margens do

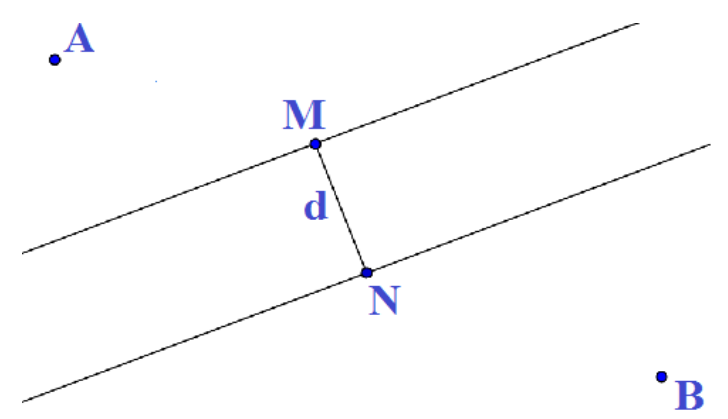

Figura 12: Dados do exemplo 4.4.2

rio retas paralelas e a extensão da ponte $M N$ com dimensão $d$ (distância entre as margens do rio) é sempre a mesma não dependendo da sua localização, assim vamos assumir o exercício resolvido fazendo a translação do segmento $M N$ para uma nova posição $A N^{\prime}$, de tal maneira que o ponto $M$ coincida com o ponto $A$ (fig.13). 
Então $A M=N^{\prime} N$, e dessa forma temos;

$$
A M+N B=N^{\prime} N+N B
$$

Portanto o caminho $A M N B$ será o menor caminho se e somente se os pontos $N^{\prime}$, $N$ e $B$ forem colineares.

Temos então a seguinte construção: Do ponto $A$ trace uma perpendicular à margem do rio e marque o ponto $N^{\prime}$ de tal forma que o segmento $A N^{\prime}$ tenha a mesma dimensão da largura $d$ do rio, traçe um segmento ligando $N^{\prime}$ a $B$, e seja $N$ o ponto de intersecção desse segmento com a margem do rio próxima à cidade $B$, construa a ponte através do rio partindo de $N$ encontrando a margem oposta em $M$.

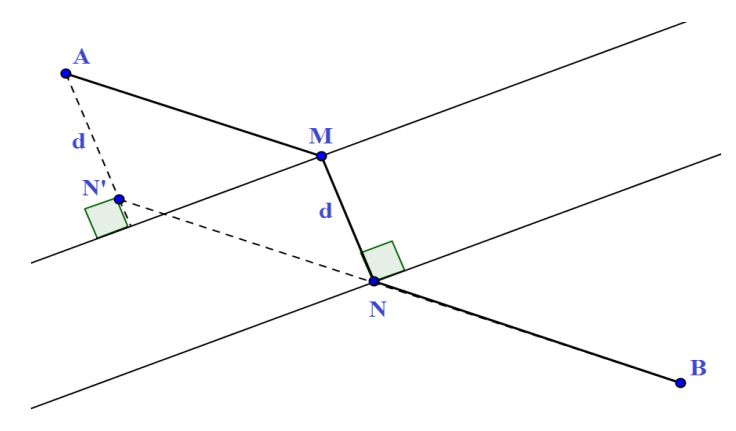

Figura 13: Solução do exemplo 4.4.2

Exemplo 4.4.3. Dadas as cordas $A B$ e $C D$ de um círculo, determine no círculo um ponto $X$ tal que as cordas $A X$ e $B X$ "cortem" em $C D$ um segmento $E F$ que tenha o comprimento a dado (fig.14).

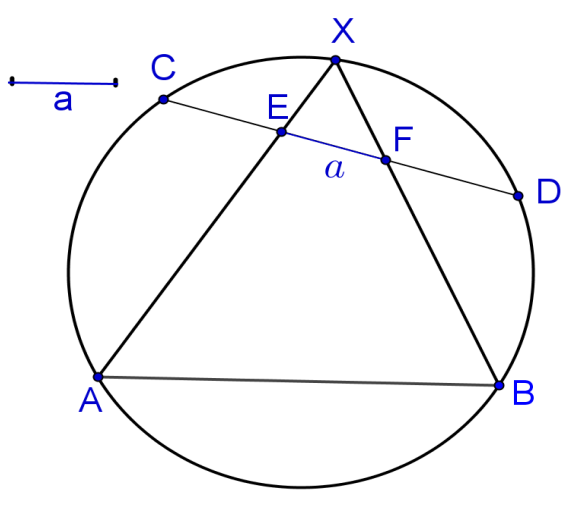

Figura 14: Dados do exemplo 4.4.3

Solução: Assuma que o problema foi resolvido. Faça a translação do segmento $A X$ à distância $a=E F$ na direção da reta $C D$, e marque a nova posição de $A^{\prime} X^{\prime}$ (fig.15). 
É fácil ver que $A^{\prime} X^{\prime}$ passa pelo ponto $F$, e ainda

$$
\angle A^{\prime} F B=\angle A X B=\frac{1}{2} A m B ;^{3}
$$

portanto devemos considerar o ângulo $A^{\prime} F B$ como conhecido.

Então temos a seguinte construção: Translade o ponto $A$ à distância $a$ na direção da corda $C D$, e marque essa nova posição como $A^{\prime}$. Usando o segmento $A^{\prime} B$ como corda, construa um arco circular que subtende um ângulo igual ao $\angle A X B$ (isto é, se $Y$ é qualquer ponto do arco circular, então $\left.\angle A^{\prime} Y B=\angle A X B=\frac{1}{2} A m B\right)$.

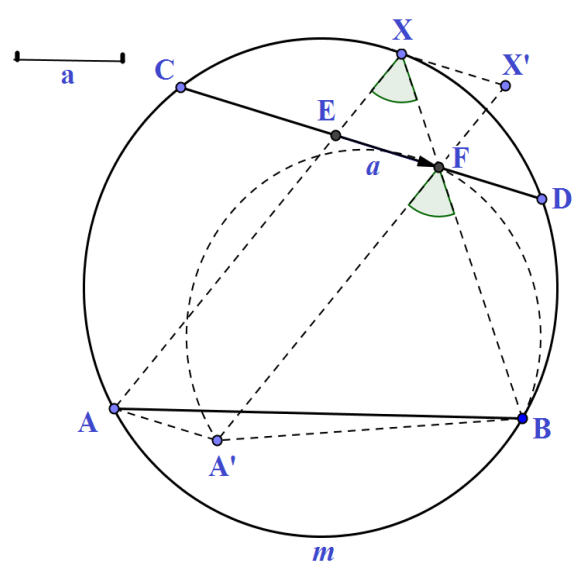

Figura 15: Solução do exemplo 4.4.3

- Se esse arco circular interceptar a corda $C D$ em dois pontos, ambos devem ser tomados como o ponto $F$, e o ponto $X$ é obtido como o ponto de intersecção do círculo original com a reta $B F$. Neste caso o problema tem duas soluções;

- Se o arco circular é tangente a $C D$, o ponto de tangência deve ser tomado como o ponto $F$, e o problema tem uma única solução;

- Se o arco não interceptar $C D$ em nenhum ponto, o problema não tem solução;

- Se for assumido que $C D$ é interceptado pela extensão da corda $A X$ e $B X$ (e que os pontos $E$ e $F$ são externos ao círculo - na extensão da corda $C D$ ), então o problema pode ter quatro soluções. (Isto é devido ao fato que $A$ deve ser transladado em ambas as direções opostas).

Exemplo 4.4.4. Na ilustração abaixo, fig. 16, temos um exemplo de um conjunto gerado pela translação de uma figura básica. 


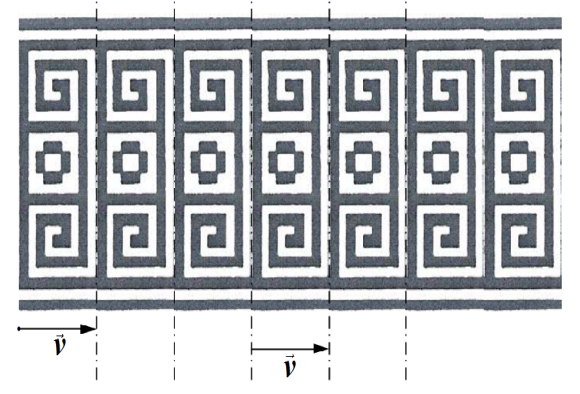

Figura 16: Exemplo 4.4.4 de translação de figura básica

Observação 4.4.2. Como vimos, uma translação é um exemplo de uma transformação do plano que leva cada ponto $A$ em algum outro ponto $A^{\prime}{ }^{4}$. Claramente nenhum ponto permanece em seu lugar por esta transformação; em outras palavras, uma translação não tem pontos fixos, não leva nenhum ponto em si mesmo.

No entanto existem retas que permanecem no mesmo lugar por uma translação; todas as retas paralelas à direção da translação são levadas em si mesmas (as retas deslizam sobre sí mesmas), e portanto essas retas, e somente essas, são retas fixas pela translação.

Vamos considerar uma outra propriedade das translações: Sejam $F$ e $F^{\prime}$ duas figuras relacionadas por uma translação, sejam $A$ e $B$ quaisquer dois pontos da figura $F$ (veja fig.8). Desde que $A A^{\prime} \| B B^{\prime}$ e $A A^{\prime}=B B^{\prime}$, o quadrilátero $A A^{\prime} B^{\prime} B$ é um paralelogramo; consequente, $A B \| A^{\prime} B^{\prime}$ e $A B=A^{\prime} B^{\prime}$. Portanto, se as figuras $F$ e $F^{\prime}$ estão relacionadas por uma translação, então segmentos correspondentes dessas figuras são iguais, paralelos $e$ tem a mesma direção.

Reciprocamente, se para cada ponto da figura $F$ corresponde um ponto de outra figura $F^{\prime}$ tal que o segmento interligando um par de pontos em $F$ é igual a, paralelo a, e tem a mesma direção ao segmento interligando o correspondente par de pontos em $F^{\prime}$, então $F$ e $F^{\prime}$ são relacionados por uma translação.

De fato, escolha qualquer par de pontos correspondentes $M$ e $M^{\prime}$ das figuras $F$ e $F^{\prime}$, e sejam $A$ e $A^{\prime}$ um outro par qualquer de pontos correspondentes dessas figuras (veja fig.8). É dado que $M A \| M^{\prime} A^{\prime}$ e $M A=M^{\prime} A^{\prime}$, consequentemente o quadrilátero $M M^{\prime} A^{\prime} A$ é um paralelogramo, e portanto, $A A^{\prime} \| M M^{\prime}$ e $A A^{\prime}=M M^{\prime}$, isto é, o ponto $A^{\prime}$ é obtido de $A$ por uma translação na direção da reta $\overrightarrow{M M^{\prime}}$ à distância igual a $M M^{\prime}$. Mas desde que $A$ e $A^{\prime}$ é um par arbitrário de pontos correspondentes, isso significa que a figura $F^{\prime}$ inteira é obtida de $F$ por uma translação na direção $M M^{\prime}$ a uma distância igual a $M M^{\prime}$.

Como vimos nas observações sobre translação em 4.4.1, analisaremos em detalhes o resultado da aplicação de duas transformações uma após outra (translação composta).

4 Essa transformação é uma isometria conforme definição 4.3.2, desde que leva cada segmento $A B$ em um segmento $A^{\prime} B^{\prime}$ de mesmo comprimento. 
Suponha que a primeira translação leva a figura $F$ na figura $F^{\prime}$ e a segunda leva a figura $F^{\prime}$ na figura $F^{\prime \prime}$ (fig.17). Vamos mostrar que existe uma única translação levando a figura $F$ na figura $F^{\prime \prime}$.

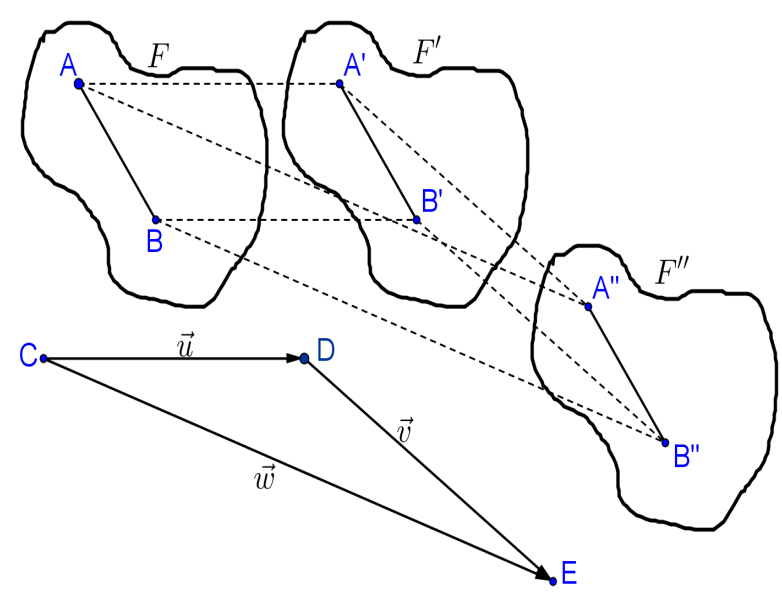

Figura 17: Composição de translações

De fato, a primeira translação leva o segmento $A B$ da figura $F$ no segmento $A^{\prime} B^{\prime}$ da figura $F^{\prime}$, então $A^{\prime} B^{\prime} \| A B$ e $A^{\prime} B^{\prime}=A B$ e os segmentos $A^{\prime} B^{\prime}$ e $A B$ tem a mesma direção; da mesma forma a segunda translação leva $A^{\prime} B^{\prime}$ no segmento $A^{\prime \prime} B^{\prime \prime}$ tal que $A^{\prime \prime} B^{\prime \prime} \| A^{\prime} B^{\prime}$ e $A^{\prime \prime} B^{\prime \prime}=A^{\prime} B^{\prime}$ e os segmentos $A^{\prime \prime} B^{\prime \prime}$ e $A^{\prime} B^{\prime}$ tem a mesma direção. Disso fica claro que segmentos correspondentes $A B$ e $A^{\prime \prime} B^{\prime \prime}$ das figuras $F$ e $F^{\prime \prime}$ são iguais, paralelos e tem a mesma direção. Mas isso significa que existe uma translação levando $F$ a $F^{\prime \prime}$. Portanto, qualquer sequência de duas translações pode ser substituída por uma única translação. $\mathrm{O}$ que significa que a soma de duas translações é uma translação.

Chamando a primeira translação de $T_{\vec{u}}$, a segunda de $T_{\vec{v}}$, e $\vec{w}=\vec{u}+\vec{v}$ temos;

$$
F^{\prime \prime}=T_{\vec{w}}(F)=\left(T_{\vec{v}} \circ T_{\vec{u}}\right)(F)=T_{\vec{v}}\left(T_{\vec{u}}(F)\right)=T_{\vec{v}}\left(F^{\prime}\right)=F^{\prime \prime}
$$

Vamos apresentar a seguir as propriedades acima formalizadas em teoremas, proposições e corolários, observando que as demonstrações estão disponíveis no Apêndice A.

Proposição 4.4.1. Uma translação na direção de um vetor não nulo não tem pontos fixos, isto é, se $\vec{v} \neq 0$, não existe $P$ tal que $T_{\vec{v}}(P)=P$

(Dem: vide página 225).

Teorema 4.4.1. Dados dois pontos $P$ e $Q$ do plano, existe uma única translação $T_{\vec{v}} q u e$ leva $P$ a $Q$, ou seja $T_{\vec{v}}(P)=Q$.

(Dem: vide página 225). 
Definição 4.4.3. Dizemos que um subconjunto $\mathscr{A}$ do plano é invariante por uma transformação $f$ se $f(\mathscr{A})=\mathscr{A}$

Proposição 4.4.2. Uma translação na direção de um vetor não nulo $\vec{v}$ deixa invariantes as retas paralelas à direção de $\vec{v}$ e somente essas retas.

(Dem: vide página 225).

Observação 4.4.3. Uma transformação $f$ fixa, ponto a ponto um subconjunto $\mathscr{A}$ do plano (veja definição 4.3.5) então necessariamente, $\mathscr{A}$ é invariante por $f$. A proposição 87 acima mostra que a recíproca deste fato não é verdadeira: se $r$ é uma reta paralela à direção de um vetor não nulo $\vec{v}$, então $r$ é invariante por $T_{\vec{v}}$ e, no entanto, $T_{\vec{v}}$ não fixa $r$ ponto a ponto.

Proposição 4.4.3. Se $A^{\prime}=T_{\vec{v}}(A), B^{\prime}=T_{\vec{v}}(B)$ com $A$ e $B$ pontos distintos do plano $e$ $\vec{v} \neq 0$, então o quadrilátero $A B B^{\prime} A^{\prime}$ é um paralelogramo (eventualmente degenerado) (vide fig.88 na página 226).

(Dem: vide página 226).

Corolário 4.4.1. Dois segmentos $A B$ e $A^{\prime} B^{\prime}$ cujos extremos estão relacionados por uma translação são lados de um paralelogramo $A B B^{\prime} A^{\prime}$ (eventualmente degenerado), ou seja, os segmentos orientados $A B$ e $A^{\prime} B^{\prime}$ são paralelos, congruentes e com mesma direção e sentido.

Demonstração. Imediata a partir da Proposição 4.4.3.

Corolário 4.4.2. Dada uma reta $r$ do plano, $T_{\vec{v}}(r) \| r$.

Demonstração. Como $T_{\vec{v}}$ é uma isometria, $T_{\vec{v}}(r)$ é uma reta que, pelo corolário anterior, contem um segmento $A^{\prime} B^{\prime}$ paralelo (ou colinear) a um segmento $A B$ contido em $r$, sendo, portanto, paralela à $r$.

Observação 4.4.4. Retas coincidentes serão consideradas como particulares retas paralelas.

Proposição 4.4.4. Dados dois segmentos orientados tais que $A B \| A^{\prime} B^{\prime}, A B=A^{\prime} B^{\prime}$ e com mesmo sentido, ou seja, o quadrilátero $A B B^{\prime} A^{\prime}$ é um paralelogramo, eventualmente degenerado, então existe uma única translação $T_{\vec{v}}$ tal que $T_{\vec{v}}(A)=A^{\prime}, T_{\vec{v}}(B)=B^{\prime}$.

(Dem: vide página 226).

Teorema 4.4.2. Sejam $A, B, C$ pontos não colineares, então $T_{\overrightarrow{A B}}=T_{\overrightarrow{C D}}$ se e somente se $A B D C$ é um paralelogramo.

(Dem: vide página 226).

A proposição a seguir é uma recíproca da Proposição 4.4 .3 e nos dá uma caracterização para as translações. 
Proposição 4.4.5. Seja $f$ uma transformação do plano tal que para todo par de pontos distintos $P$ e $Q$ o $P Q Q^{\prime} P^{\prime}$ é um paralelogramo (eventualmente degenerado), onde $P^{\prime}=f(P)$ e $Q^{\prime}=f(Q)$; então $f$ é uma translação.

(Dem: vide página 226).

\subsubsection{Reflexão em torno de um ponto (Half Turn)}

Definição 4.4.4. Orientação. A fig. 18 abaixo ilustra este conceito importante da geometria comparando duas figuras cujas fronteiras são percorridas em um sentido definido. Um triângulo orientado é uma tripla ordenada de pontos não colineares. Aqui os pontos são vértices do triângulo, e a orientação é dada pela ordem em que os vértices aparecem. Dizemos que os triângulos $A B C$ e $A^{\prime} B^{\prime} C^{\prime}$ tem a mesma orientação desde que em ambos, os vértices são percorridos no mesmo sentido (sentido horário), e se dirão figuras equiversas. Por outro lado, os triângulos $A B C$ e $A^{\prime \prime} B^{\prime \prime} C^{\prime \prime}$ tem orientações opostas, e dizemos, figuras contraversas.
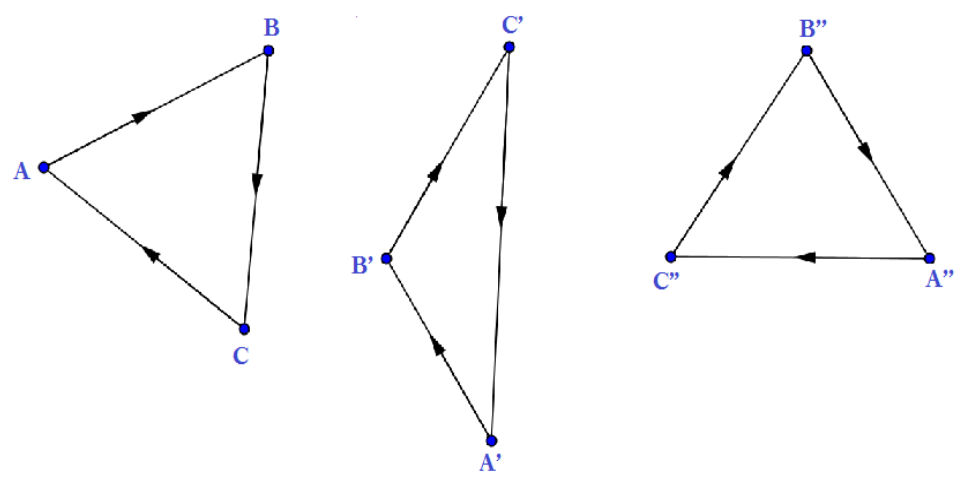

Figura 18: Definição 4.4.4 Orientação

Nas transformações, se as figuras $F$ e $F^{\prime}=f(F)$ forem equiversas, diremos que $f$ sera concorde, caso contrário, se as figuras forem contraversas, $f$ será discorde.

Definição 4.4.5. O ponto $A^{\prime}$ é dito ser obtido do ponto $A$ através de uma reflexão em torno de $M$ (chamado de centro de simetria) se $M$ é o ponto médio do segmento $A A^{\prime}$ (fig.19).

A reflexão em torno de um ponto é também chamada de meia-volta, meio-giro (half turn), ou rotação de $180^{\circ}$.

Da mesma forma $A$ é obtido de $A^{\prime}$ pela reflexão em torno de $M$; o que nos permite falar em par de pontos relacionados pela reflexão em torno de um ponto dado, ou seja, $A^{\prime}$ é simétrico a $A$ em relação a $M$. 
Usaremos a notação $R_{M}(P)$ para representar a reflexão de um ponto qualquer do plano $P$ em relação a $M$, ou seja; $P^{\prime}=R_{M}(P)$ se e somente se $M$ é o ponto médio do segmento $P P^{\prime}$. Assim é fácil notar que;

$$
\begin{gathered}
R_{M}(M)=M, \quad R_{M} \circ R_{M}(P)=R_{M}\left(R_{M}(P)\right)=R_{M}\left(P^{\prime}\right)=P, \quad \forall P \in E^{n}, \mathrm{ou} ; \\
R_{M}{ }^{2}=I d \quad \text { que é o mesmo que escrever } R_{M}=\left(R_{M}\right)^{-1} \quad{ }^{5}
\end{gathered}
$$

O conjunto de todos os pontos obtidos de uma dada figura $F$ por uma reflexão em torno de um ponto $M$ dado, forma a figura $F^{\prime}$ (fig.19), da mesma forma a figura $F$ é obtida de $F^{\prime}$ pela rflexão em torno do mesmo ponto $M$.

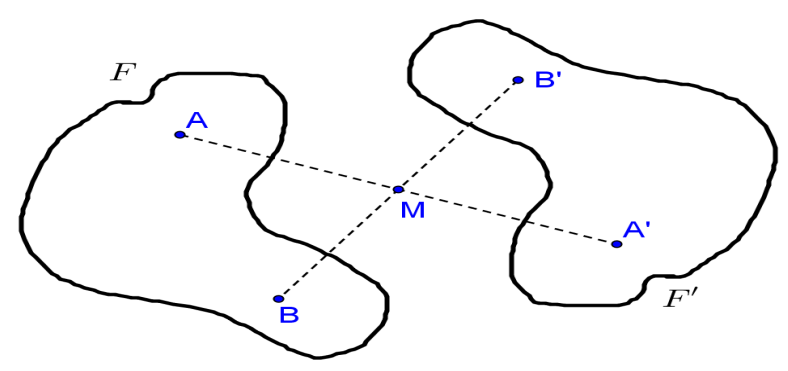

Figura 19: Reflexão em torno de um ponto

Por uma reflexão em torno de um ponto $M$, uma reta $r$ leva a uma reta $r^{\prime}$ paralela a $r$ (vide fig.20). Considerando que se $M \in r, \forall P \in r$ então $R_{M}(P)=P^{\prime} \in r$, isto é, a reflexão neste caso fixa a reta, mas não fixa ponto a ponto a reta, exceto o ponto $M$, centro da reflexão.

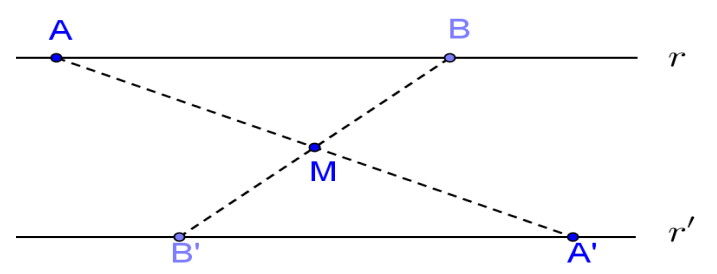

Figura 20: Reflexão de uma reta em torno de um ponto

Para provar, por exemplo, que um círculo $C$ de raio $r$ é levado, por uma reflexão em torno de um ponto $M$, a um círculo congruente $C^{\prime}$ de raio $r$, é suficiente observar que $\triangle A M O \cong \triangle A^{\prime} M O^{\prime}$, na fig.21; consequentemente, a posição do ponto $A$ cuja distância a $O$ é $r$, será levado a $A^{\prime}$ cuja distância a $O^{\prime}$ é igual a $r$.

$5 \quad R_{M}$ é uma involução, conforme definição 4.2.6. 


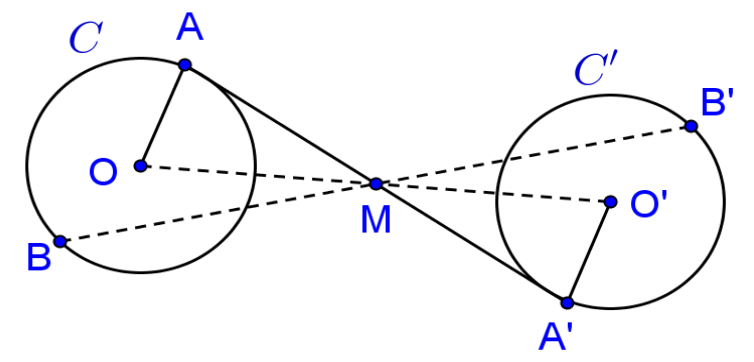

Figura 21: Reflexão de uma círculo em torno de um ponto

Se $F$ e $F^{\prime}$ são suas figuras relacionadas por uma reflexão em torno de um ponto $M$, e se $A B$ e $A^{\prime} B^{\prime}$ são segmentos correspondentes dessas duas figuras (fig.22), então $A B A^{\prime} B^{\prime}$ é um paralelogramo (desde que suas diagonais sejam dividas ao meio no ponto de intersecção $M)$.

Disso podemos afirmar que; segmentos correspondentes de duas figuras relacionadas por uma reflexão em torno de um ponto $M$ dado, são iguais, paralelos e com direções opostas. Vamos mostrar que, reciprocamente, se para cada ponto da figura F pode-se associar um ponto da figura $F^{\prime}$ tal que os segmentos que ligam pontos correspondentes dessas figuras são iguais, paralelos, e com direções opostas, então $F$ e $F^{\prime}$ são relacionadas por uma reflexão em torno de algum ponto.

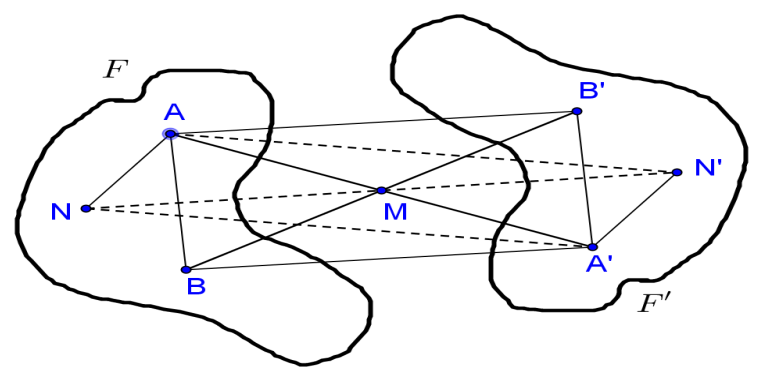

Figura 22: Reflexão em torno de um ponto e paralelogramo

De fato, escolhendo um par de pontos correspondentes $N$ e $N^{\prime}$ das figuras $F$ e $F^{\prime}$ e seja $M$ o ponto médio do segmento $N N^{\prime}$. Sejam $A$ e $A^{\prime}$ um par de pontos correspondentes qualquer, dessas figuras (veja fig.22). Por hipótese $A N \| A^{\prime} N^{\prime}$ e $A N=A N^{\prime}$; consequentemente $A N A^{\prime} N^{\prime}$ é um paralelogramo, e portanto o ponto médio da diagonal $A A^{\prime}$ coincide com o ponto médio $M$ da diagonal $N N^{\prime}$. Isso é; o ponto $A^{\prime}$ foi obtido de $A$ por uma reflexão em torno do ponto $M$, e desde que $A$ e $A^{\prime}$ é uma par de pontos arbitrários, segue que $F^{\prime}$ foi obtido de $F$ por uma reflexão em torno de $M$.

Vamos considerar três figuras $F, F_{1}$ e $F_{2}$ tais que a figura $F_{1}$ é obtida de $F$ por uma 
reflexão em torno do ponto $M_{1}$ e a figura $F_{2}$ é obtida de $F_{1}$ por uma reflexão em torno do ponto $M_{2}$ (fig.23). Seja $A^{\prime} B^{\prime}$ um segmento arbitrário da figura $F_{1}$, e sejam $A B$ e $A^{\prime \prime} B^{\prime \prime}$ os correspondentes segmentos das figuras $F$ e $F_{2}$. Então os segmentos $A^{\prime} B^{\prime}$ e $A B$ são iguais, paralelos e com direções opostas; os segmentos $A^{\prime} B^{\prime}$ e $A^{\prime \prime} B^{\prime \prime}$ são também iguais, paralelos, e de direções opostas. Consequentemente os segmentos $A B$ e $A^{\prime \prime} B^{\prime \prime}$ são iguais, paralelos e de mesma direção. Mas uma vez que os segmentos correspondentes das figuras $F$ e $F_{2}$ são iguais, paralelos e de mesma direção, então $F_{2}$ deve ser obtido de $F$ por meio de uma translação. Então a soma de duas reflexões é uma translação.

Desde que $M_{1} M_{2}$ é o segmento que liga os pontos médios dos lados $A A^{\prime}$ e $A^{\prime} A^{\prime \prime}$ do triângulo $A A^{\prime} A^{\prime \prime}$, segue que $A A^{\prime \prime} \| M_{1} M_{2}$ e $A A^{\prime \prime}=2 M_{1} M_{2}$; isto é, cada ponto $A^{\prime \prime} d a$ figura $F_{2}$ é obtido do correspondente ponto $A$ da figura $F$ por uma translação na direção $M_{1} M_{2}$ por uma distância igual ao dobro do segmento $M_{1} M_{2}$. Se $T_{\vec{u}}$ é a translação que leva $M_{1}$ a $M_{2}$ e $T_{\vec{v}}$ é a translação que leva $A$ a $A^{\prime \prime}$; então $T_{\vec{v}}=T_{2 \vec{u}}$.

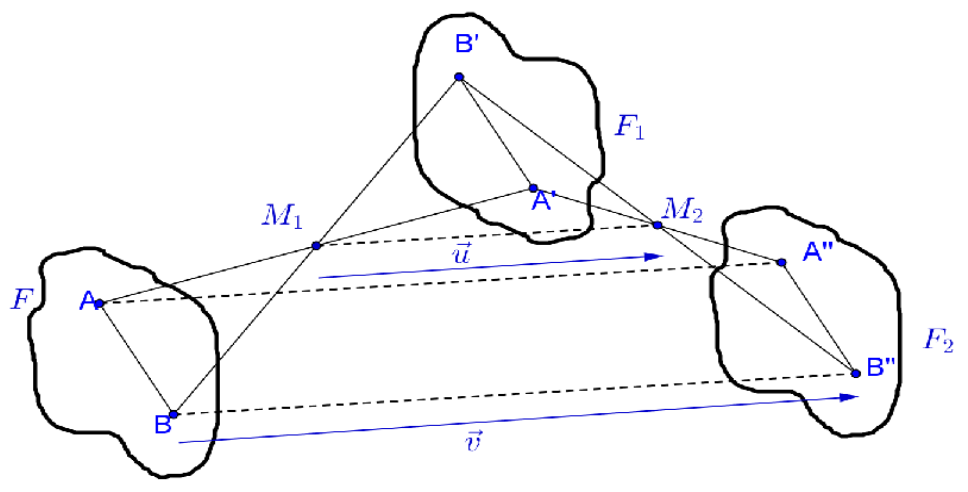

Figura 23: Combinação duas reflexões em torno de ponto

Do mesmo modo pode ser mostrado que a soma de uma translação e uma reflexão em torno de um ponto $M$, ou de uma reflexão em torno de um ponto e uma translação, é uma reflexão em torno de um novo ponto $M_{1}$ (fig.24).

Vamos descrever a seguir uma observação importante. A sequência de reflexões em torno dos pontos $M_{1}$ e $M_{2}$ (fig.25: $A \rightarrow A_{1} \rightarrow A^{\prime}$ ) é equivalente a uma translação de distância $2 M_{1} M_{2}$ na direção de $M_{1}$ para $M_{2}$, enquanto a sequência dessas mesmas reflexões, tomadas na ordem contrária (fig.25: $A \rightarrow A_{1}^{\prime} \rightarrow A^{\prime \prime}$ ) é equivalente a uma translação da mesma distância na direção de $M_{2}$ para $M_{1}$. Então, a soma de duas reflexões em torno de pontos depende essencialmente da ordem em que essas reflexões estão sendo executadas. Esta circunstância é, em geral, característica da adição de transformações:

A soma de duas transformações depende, em geral, da ordem dos termos.

A seguir alguns exemplos de aplicação da rotação em torno de um ponto. 


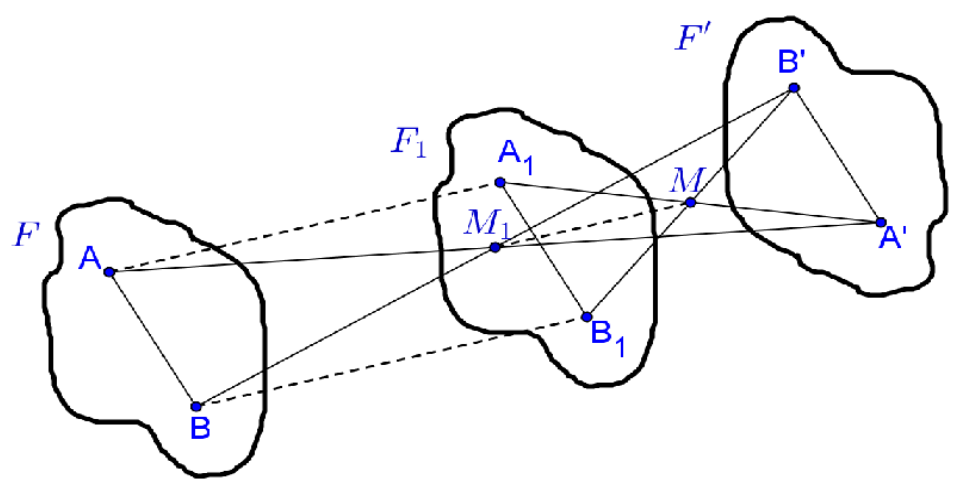

Figura 24: Combinação reflexões em torno de ponto e translação

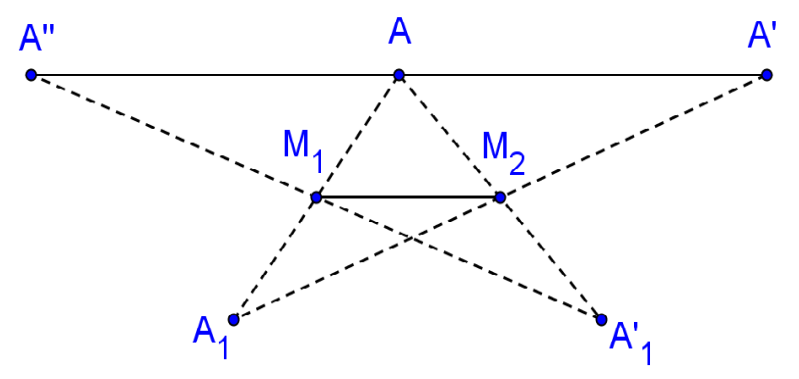

Figura 25: Soma de reflexões em torno de ponto e translação

Exemplo 4.4.5. Prove que os pontos médios dos lados de um quadrilátero arbitrário $A B C D$ formam um paralelogramo (fig.26). Solução exercício 4.4.5; se $M, N, P$ e $Q$ são

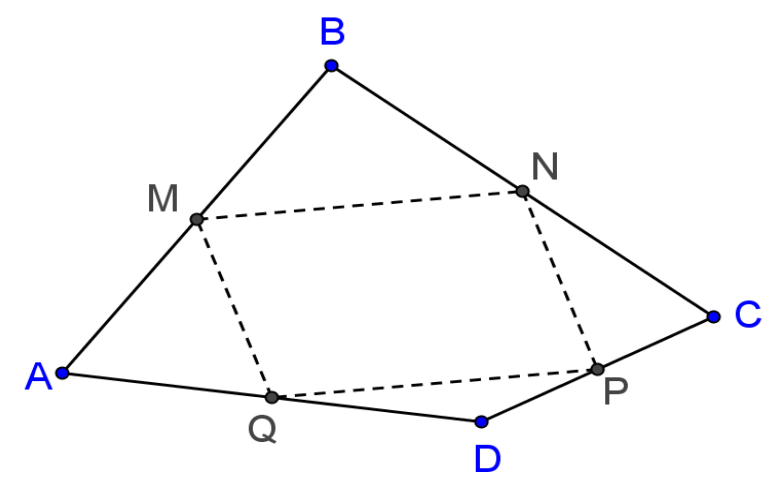

Figura 26: Exercício 4.4.5 reflexões em torno de ponto

pontos médios dos lados do $A B C D$, então quatro reflexões sucessivas em torno dos pontos $M, N, P$ e $Q$ levará o ponto $A$ em si mesmo, isto é $R_{Q}\left(R_{P}\left(R_{N}\left(R_{M}(A)\right)\right)\right)=A=I d(A)$. Isso é possível somente no caso da soma das quatro reflexões em torno de $M, N, P$ e $Q$, a qual é igual à soma de duas translações nas direções de $M N$ e $P Q$ pelas distâncias $2 M N$ e $2 P Q$ respectivamente, é a transformação identidade. Mas isso significa que os segmentos 
$M N$ e $P Q$ são paralelos, iguais em comprimento e com direções opostas, isto é, o $M N P Q$ é um paralelogramo.

Exemplo 4.4.6. Sejam $M_{1}, M_{2}, M_{3}, M_{4}, M_{5}, M_{6}$ os pontos médios dos lados de um hexagono arbitrário. Prove que existe um $\triangle T_{1}$ cujos lados são iguais e paralelos aos segmentos $M_{1} M_{2}, M_{3} M_{4}, M_{5} M_{6}$, e um $\triangle T_{2}$ cujos lados são iguais e paralelos aos segmentos $M_{2} M_{3}, M_{4} M_{5}, M_{6} M_{1}$ (fig.27). Solução exercício 4.4.6; como no exercício 4.4.5, con-

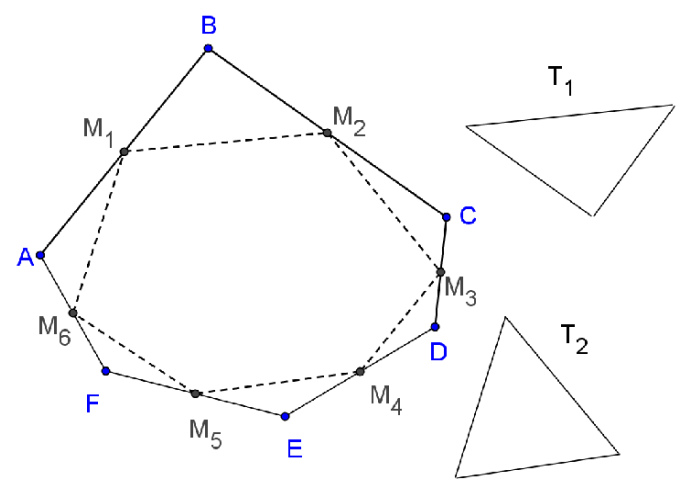

Figura 27: Exercício 4.4.6 reflexões em torno de ponto

cluímos que a soma de translações nas direções $M_{1} M_{2}, M_{3} M_{4}$, e $M_{5} M_{6}$ pelas distâncias $2 M_{1} M_{2}, 2 M_{3} M_{4}$, e $2 M_{5} M_{6}$ é a transformação identidade. Logo, há triângulos cujos lados são paralelos a $M_{1} M_{2}, M_{3} M_{4}$, e $M_{5} M_{6}$ e iguais a $2 M_{1} M_{2}, 2 M_{3} M_{4}$, e $2 M_{5} M_{6}$; mas isso significa que há também triângulos cujos lados são paralelos e tem o mesma dimensão dos segmentos $M_{1} M_{2}, M_{3} M_{4}$, e $M_{5} M_{6}$.

Da mesma forma prova-se que existem triângulos cujos lados são paralelos a, e tem a mesma dimensão dos segmentos $M_{2} M_{3}, M_{4} M_{5}, M_{6} M_{1}$.

Observação 4.4.5. Usando o mesmo método usado no exercício 4.4.6; pode-se mostrar que qualquer conjunto de $2 n$ pontos $M_{1}, M_{2}, \ldots M_{2 n}$ serão os pontos médios dos lados de algum $2 n$-ágono se e somente se exista um $n$-ágono cujos lados sejam paralelos e tenham o mesmo comprimento dos segmentos $M_{1} M_{2}, M_{3} M_{4}, \ldots M_{2 n-1} M_{2 n}$; e também exista um $n$-ágono cujos lados sejam paralelos e tenham o mesmo comprimento dos segmentos $M_{2} M_{3}, M_{4} M_{5}, \ldots M_{2 n} M_{1}$.

\subsubsection{Rotação}

Para o estudo das rotações vamos inicialmente definir a orientação, a medida e a representação de um ângulo $\alpha$ dado;

Definição 4.4.6. A medida direta de um ângulo $\alpha=\angle P O P^{\prime}$ será denotado por $d\left(\angle P O P^{\prime}\right)$ e será assim definido;

$$
d\left(\angle P O P^{\prime}\right)=m\left(\angle P O P^{\prime}\right), \quad \alpha>0
$$


quando $\angle P O P^{\prime}$ é medido no sentido anti-horário, e

$$
d\left(\angle P O P^{\prime}\right)=-m\left(\angle P O P^{\prime}\right), \quad \alpha<0
$$

quando $\angle P O P^{\prime}$ é medido no sentido horário.

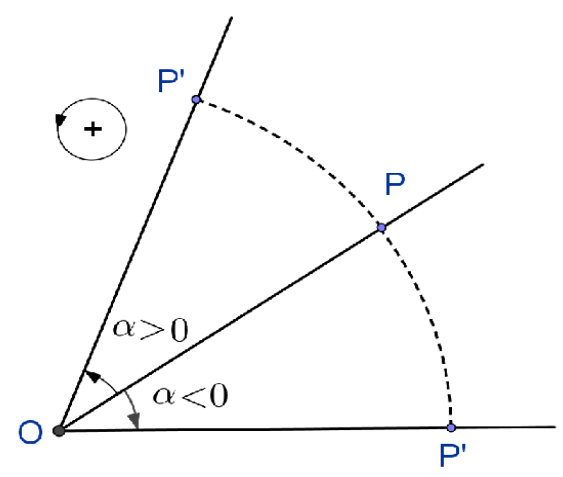

Figura 28: Definição orientação ângulo

Definição 4.4.7. Seja $O$ um ponto fixado no plano e seja $\alpha$ um ângulo dado. Uma rotação de centro $O$ e ângulo $\alpha$ é uma transformação que leva cada ponto $P$, distinto de $O$, a um ponto $P^{\prime}$ tal que $O P=O P^{\prime}$ e $\angle P O P^{\prime}=\alpha$, medido na direção escolhida, ou seja, $O P$ é o raio de um semi-círculo de centro $O$ que deve ser girado através de um ângulo $\alpha$ na direção que escolhemos para coincidir com $O P^{\prime}$. Vamos denotar a rotação de centro $O$ e ângulo $\alpha$ por $R_{O, \alpha}$.

Utilizando a medida do ângulo em radianos, podemos escrever; dados $O$ fixo no plano e um número real $\alpha$,

$$
\left.\left.R_{O, \alpha+2 k \pi}=R_{O, \alpha}, \quad \alpha \in\right]-\pi, \pi\right], \quad k \in Z
$$

Decorre imediatamente da definição que se $\alpha=0$ então $R_{O, 0}=I d$, e portanto $R_{O, \alpha}$ fixa todos os pontos do plano; e se $\alpha=\pi$ então $R_{O, \pi}=R_{O}$, isto é, a rotação coincide com a reflexão em torno do ponto $O$.

O conjunto de todos os pontos obtidos de uma figura $F$ por uma rotação $R_{O, \alpha}$ forma uma nova figura $F^{\prime}$ (fig.29), reciprocamente $F$ é obtido de $F^{\prime}$ por uma rotação de mesmo centro $O$ e com o mesmo ângulo $\alpha$, porem em direção contrária ( $-\alpha$, ou um ângulo na mesma direção de $\alpha$ mas de valor $360^{\circ}-\alpha$ ), isso nos permite falar em par de figuras obtidas uma da outra por rotação.

Verificamos que pela definição, $R_{O, \alpha}(P)=P^{\prime}$ se e somente se $R_{O,-\alpha}\left(P^{\prime}\right)=P$, o que nos permite escrever: $\left(R_{O, \alpha}\right)^{-1}=R_{O,-\alpha}$

Teorema 4.4.3. Toda rotação do plano é uma isometria desse plano. 


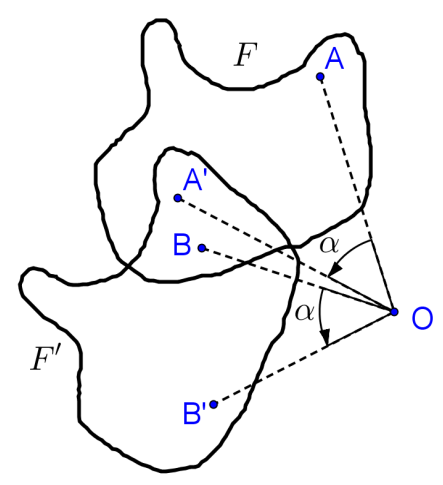

Figura 29: Rotação centro $O$ e ângulo $\alpha$

Demonstração. Suponha que $R_{O, \alpha}$ leva pontos distintos do plano $P$ e $Q$ aos pontos $P^{\prime}$ e $Q^{\prime}$, respectivamente. Se $O, P, Q$ são colineares, então $P Q=P^{\prime} Q^{\prime}$ por definição. Se $O, P, Q$ não são colineares, então $\triangle P O Q \cong \triangle P^{\prime} O Q^{\prime}$ por $L A L$ e $P Q=P^{\prime} Q^{\prime}$ (veja fig.30). Portanto $R_{O, \alpha}$ é uma transformação que preserva distâncias.

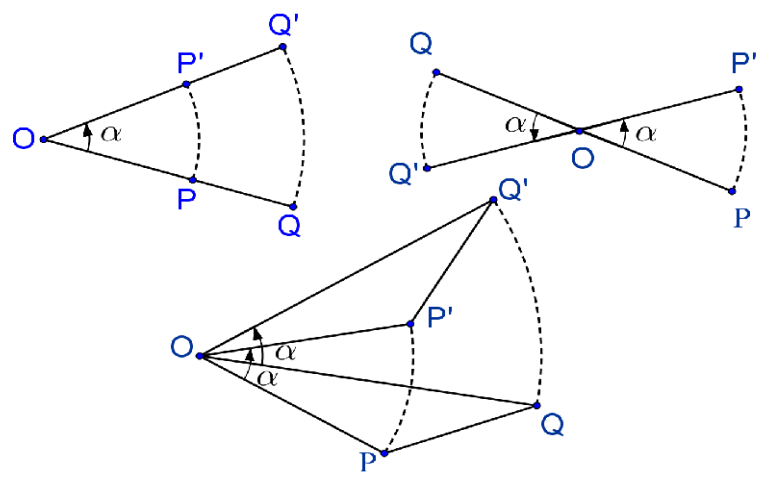

Figura 30: Teorema 4.4.3- $R_{O, \alpha}$ isometria

Exemplo 4.4.7. Como um exemplo do uso de rotação, vamos considerar o seguinte enunciado;

Se triângulos equiláteros $A B R, B C P, C A Q$, construídos externamente aos lados do $\triangle A B C$, os segmentos de reta $A P, B Q, C R$ são iguais, concorrentes e inclinados de $60^{\circ}$ um com o outro (fig.31).

Após traçar as linhas $B Q$ e $C R$, as quais se cruzam em $G$, observamos que uma rotação de $60^{\circ} \mathrm{em}$ torno de $A$ leva o $\triangle A R C$ em $\triangle A B Q$. Desta forma $\angle R G B=60^{\circ} \mathrm{e}$ $R C=B Q$. De forma análoga mostra-se que $P A=C R$. Então; $A P=B Q=C R$. Além disso, desde que

$$
\angle R G B=60^{\circ}=\angle R A B \text { e } \angle C G Q=60^{\circ}=\angle C A Q
$$


os quadrângulos $A R F G$ e $C Q A G$ são cíclicos, e desde que $\angle B G C=120^{\circ}$ enquanto $\angle C P B=60^{\circ}, B P C G$ é o terceiro quadrângulo cíclico. Por outro lado os circuncirculos dos três triângulos $B P C, C A Q, A B R$ passam todos pelo ponto $G$. Esse ponto é chamado de ponto de Fermat do $\triangle A B C$. Tendo definido que este é o ponto de intersecção de $B Q$ e $C R$, vemos também que $G$ também está em $A P$.

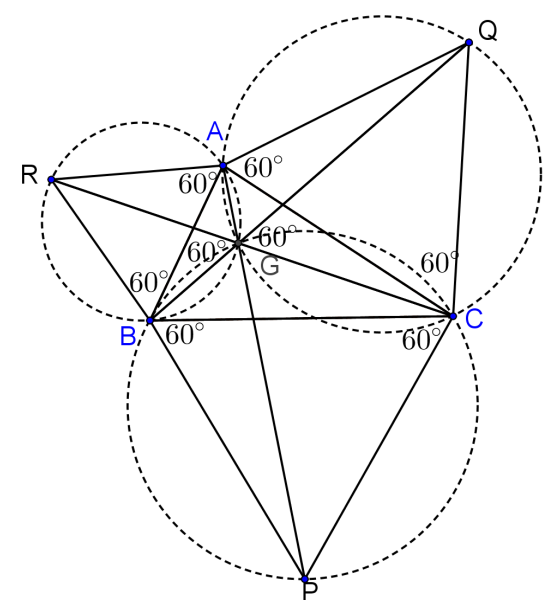

Figura 31: Exemplo de aplicação de rotação 


\subsubsection{Reflexão em relação a uma reta (Simetria)}

Já vimos na definição 4.4 .5 a Reflexão em torno de um ponto, também chamada de half-turn, meia-volta, ou meio-giro, agora veremos neste item aquela que é considerada, sob um certo aspecto, a mais importante classe de isometrias no plano, a Reflexão em torno de uma reta, muitas vezes chamada simplesmente de "Reflexão". ou mais comumente ainda de Simetria. A razão dessa importância, como veremos mais adiante, é a de se poder obter qualquer isometria do plano usando somente reflexões em relação a retas (na verdade, toda isometria Euclidiana é uma combinação dos três tipos fundamentais: reflexão, translação, e rotação).

Definição 4.4.8. Reflexão em relação a uma reta. Seja $r$ uma reta no plano $\Pi$. A reflexão em relação a reta $r$ é a função $R_{r}: \Pi \rightarrow \Pi$ assim definida: $R_{r}(X)=X \quad \forall X \in r$, e para $X \notin r, R_{r}(X)=X^{\prime}$ é tal que a mediatriz do segmento $X X^{\prime}$ é a reta $r$. Noutras palavras, seja $Y$ o pé da perpendicular baixada de $X$ sobre $r$. Então $Y$ é o ponto médio do segmento $X X^{\prime}$ (figura 32 ). $X^{\prime}$ é dito ser a imagem do ponto $X$, e $r$ é chamado de eixo de simetria.

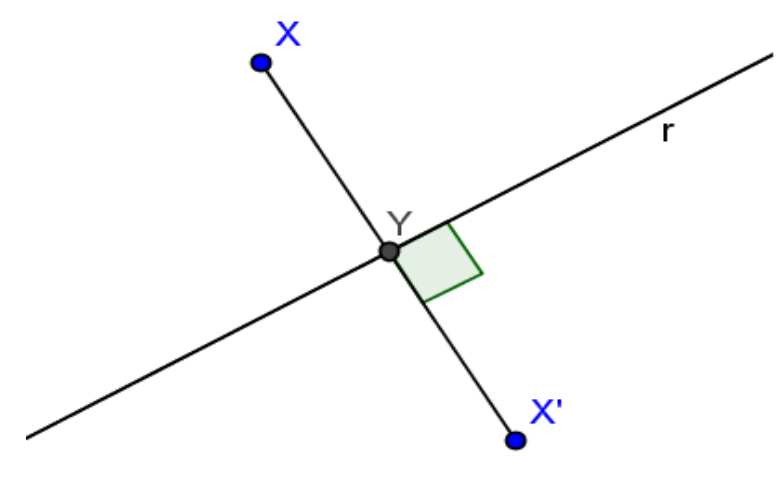

Figura 32: Reflexão em torno de uma reta

Listamos abaixo algumas propriedades da reflexão em relação a uma reta:

1. Os pontos fixos da reflexão $R_{r}: \Pi \rightarrow \Pi$ são os pontos da reta $r$. Para todo $X \in \Pi$ tem-se que $R_{r}(X)=X$, logo $R_{r} o R_{r}=I d$, ou seja $\left(R_{r}\right)^{-1}=R_{r}$, como vimos na definição 4.2 .6 de involução, isto é, tanto a reflexão em relação a um ponto quanto à reflexão em relação a uma reta são exemplos de involuções do plano;

2. Se um ponto $A^{\prime}$ é a imagem de $A$ em relação a $r$, então, reciprocamente, $A$ é a imagem de $A^{\prime}$ em relação a $r$, (veja Figura(33-a)), o que nos permite falar de par de pontos que são imagens um do outro para uma dada reta, e dizemos que $A^{\prime}$ é simétrico a $A$ em relação a reta $r$, e escrevemos:

$$
R_{r}(A)=A^{\prime}, \quad R_{r}\left(A^{\prime}\right)=A ;
$$


3. A reflexão $R_{r}$ preserva retas, isto é, uma reta $s$ tem como imagem uma outra reta, $s^{\prime}($ veja Figura $(33-\mathrm{a}))$;

4. A reflexão $R_{r}$ torna distâncias e ângulos invariantes. Um polígono fechado e sua imagem, entretanto, tem orientação invertida. (veja Figura(33-b)), conforme definição de orientação dada em 4.4.4;

Uma consequência do item 4 é que os ângulos $\theta$ e $\theta^{\prime}$ mostrados na Figura (33-a) são iguais $\left(\theta=\theta^{\prime}=\frac{\pi}{2}\right)$, isso implica que $A A^{\prime}$ e $r$ são retas perpendiculares.

Juntamente com a relação $A F=A^{\prime} F$, esse fato nos dá uma forma simples de construção para a obtenção de imagens em relação a uma reflexão $R_{r}$ : o segmento de reta que liga pontos correspondentes $A$ e $A^{\prime}$ é perpendicular a $r$, que divide o segmento de reta $A A^{\prime}$ em duas partes iguais (fig.33).

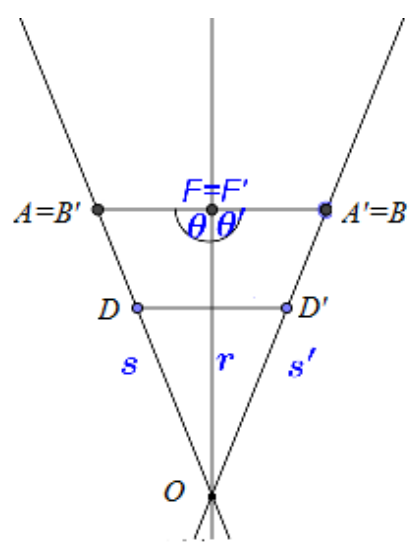

(a)

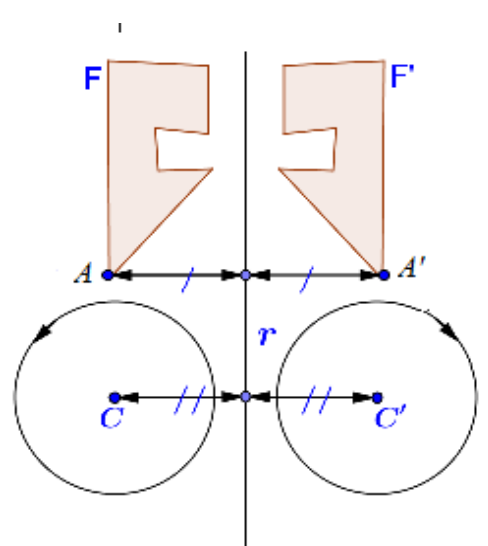

(b)

Figura 33: Simetria - Propriedades

adaptada de (JEGER, 1969, p. 21)

5. Se dois diferentes pontos $A$ e $A^{\prime}$ são dados arbitrariamente, então existe uma única reflexão $R_{r}$ tal que $R_{r}(A)=A^{\prime}$ e $R_{r}\left(A^{\prime}\right)=A$. O eixo $r$ é a mediatriz do segmento $A A^{\prime}$;

6. Dadas as retas $O D$ e $O D^{\prime}$, então existe uma única reflexão $R_{r}$ interceptando as duas retas em $O$. O eixo $r$ é a bissetriz do ângulo $D O D^{\prime}$ (veja Figura(33-a))

7. O conjunto de todas as imagens em relação à $r$ da figura $F$ forma uma figura $F^{\prime}$, chamada a imagem da figura $F$ por reflexão em $r$ (veja Figura(33-b)), reciprocamente $F$ é a imagem de $F^{\prime}$ em relação a $r$.

Observação 4.4.6. . Uma maneira de obter a imagem de uma figura qualquer em relação a uma reta $r$ consiste em girar o plano que contêm a figura de $180^{\circ}$ ao redor 
da reta $r$ no espaço tridimensional. Dobre a folha ao longo do eixo de simetria $r$, então trace a figura do outro lado. (Veja Figura (34). Essa construção explica porque reflexões são isometrias (demonstrado no Apêndice A na página 227), pois é óbvio que girando meramente um plano não altera as dimensões ou forma de qualquer figura do plano.

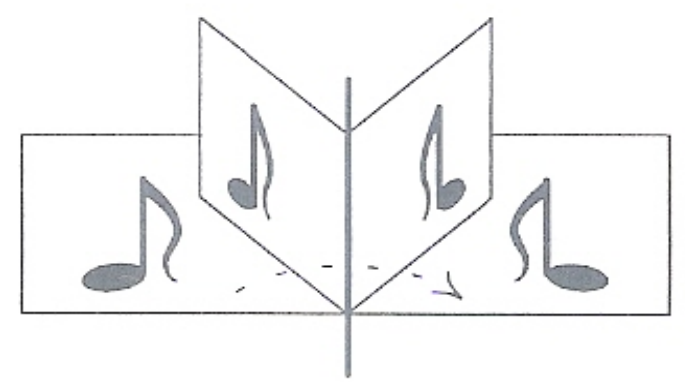

Figura 34: Simetria - Construção

(JENNINGS, 1966, p. 4) 
Outra forma de construção de um ponto $P^{\prime}$, simétrico a $P$ em relação a uma dada reta $L$, utilizando "régua e compasso". Se $P \notin L$, desenhe dois círculos com os respectivos centros em $L$, passando por $P$ (qualquer tais dois círculos, com centros conforme a figura 35 irão efetuar a construção). Os dois círculos irão se interceptar em um outro ponto no lado oposto a $L$, esse ponto é a reflexão de $P\left(R_{L}(P)=P^{\prime}\right)$.

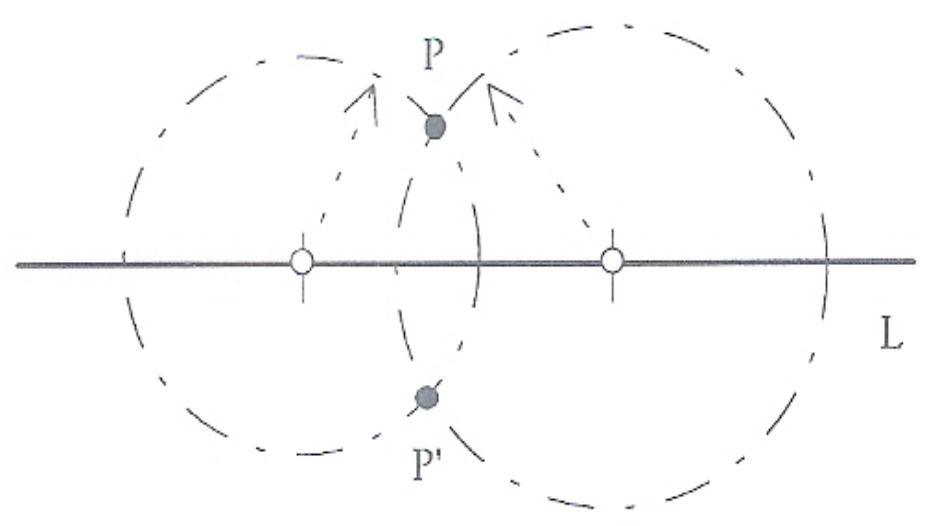

Figura 35: Simetria - Construção com régua e compasso (JENNINGS, 1966, p. 4) 
Abaixo algumas imagens para ilustrar a simetria:
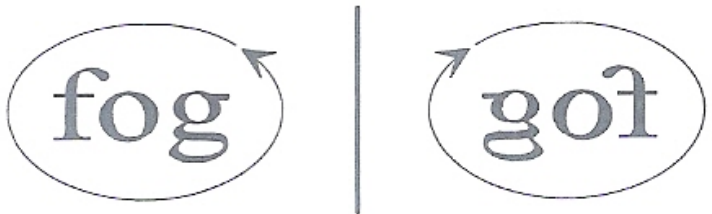

(a) Inversão - Orientação

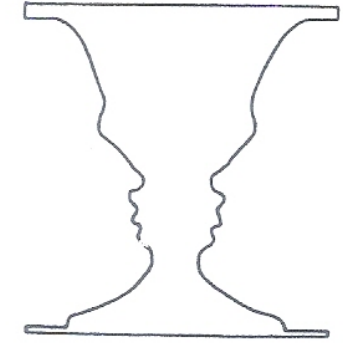

VASO OU PERFIL DE UM ROSTO?

(RUBIN)

(b) Vaso ou Perfil?

Figura 36: Exemplos de Simetria

(a)-de (JENNINGS, 1966, p. 6)

(b)-de (ALVES; GALVÃO, 1996, p. 98)

Observação 4.4.7. Essa característica da reflexão em relação a uma reta, que inverte a orientação de uma figura no plano, é também chamada de uma isometria imprópria, (adiante definiremos isometrias próprias e impróprias).

\subsubsection{Composição de reflexões em relação a retas}

Esse é um dos pontos fundamentais do estudo das isometrias, a composição de reflexões em relação a retas permite obter as outras isometrias, a saber, translações e rotações (como observado no início desta seção), e dividiremos nosso estudo conforme os eixos de simetria sejam paralelos ou concorrentes.

Nesta seção iremos enunciar os teoremas e proposições sem demonstrações, apenas em alguns casos o faremos conforme considerarmos necessário.

Observação 4.4.8. A nomenclatura utilizada para tratar as composições de isometrias pode variar conforme o autor, uns utilizam a expressão produto de isometrias, (LEDERGERBER-RUOFF, 1982) e (PINHEIRO, 1986), outros utilizam o termo soma de isometrias ((YAGLOM, 1962a) por exemplo. Por outro lado, (ALVES; GALVÃO, 1996) e (LIMA, 1996) utilizam expressões matemáticas de composta de isometrias, como $f \circ g$. Neste trabalho poderemos utilizar ou uma ou outra das nomenclaturas, sem prejuízo do entendimento, conforme utilizarmos uma linguagem com mais ou menos formalismo.

É comum em salões de cabeleireiro, a existência de paredes espelhadas, o resultado é uma série de sucessivas reflexões. Abaixo figuras ilustram essa combinação, com vários e com dois espelhos paralelos: 


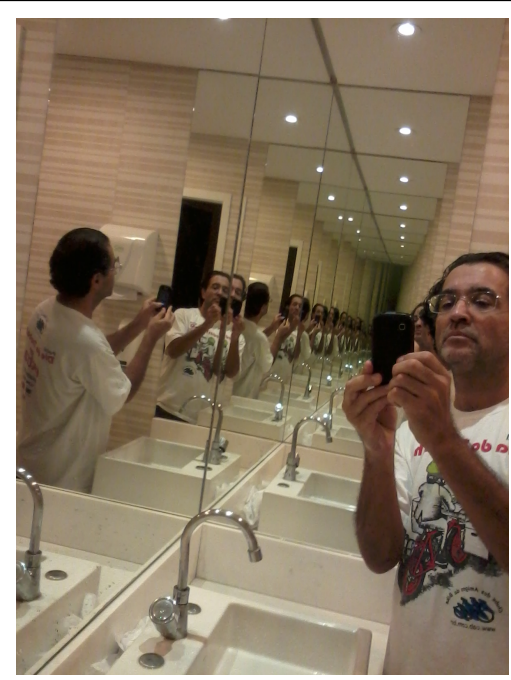

(a) Composições sucessivas

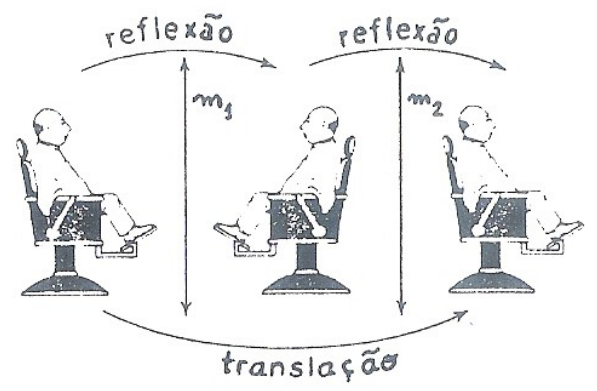

(b) Duas reflexões

Figura 37: Composição de reflexões

(b)-de (ALVES; GALVÃO, 1996, p. 101)

Proposição 4.4.6. A composta de duas reflexões na mesma reta é a transformação identidade.

De fato, conforme o item 2 da definição 4.4 .8 de reflexão em relação a $r$, vimos que a imagem de $A$ por $r$ é $A^{\prime}$, e a segunda reflexão em $r$, leva $A^{\prime}$ de volta a $A$, ou seja, o resultado de duas reflexões na mesma reta deixa a posição de um ponto inalterada:

$$
R_{r}\left(R_{r}(A)\right)=\left(R_{r} \circ R_{r}\right)(A)=\operatorname{Id}(A)=A
$$

Proposição 4.4.7. A composta de duas reflexões em retas paralelas distintas é uma translação na direção perpendicular às duas retas, com dobro da distância entre elas.

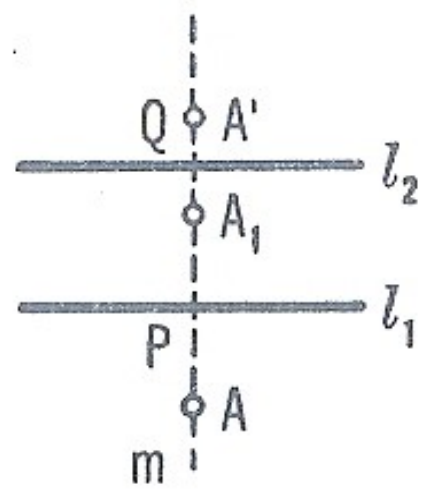

Figura 38: Reflexão em duas retas paralelas

(YAGLOM, 1962a, p. 49) 
É fácil verificar que a imagem de $A$ por $l_{1}$ é $A_{1}$ e a imagem de $A_{1}$ por $l_{2}$ é $A^{\prime}$ e $A, A_{1}$ e $A^{\prime}$ estão alinhados em $m$. Se $P$ e $Q$ são os pontos de intersecção de $m$ com $l_{1}$ e $l_{2}$ respectivamente, então $A P=P A_{1}, A_{1} Q=Q A^{\prime}$, e daí (veja Figura (38):

$$
A A^{\prime}=A P+P A_{1}+A_{1} Q+Q A^{\prime}=2 P A_{1}+2 A_{1} Q=2 P Q
$$

Podemos escrever, conforme as notações vistas para translação que:

$$
R_{l_{2}} \circ R_{l_{1}}=T_{2} \overrightarrow{P Q}
$$

Observação 4.4.9. A igualdade $R_{l_{2}} \circ R_{l_{1}}=T_{2 \overrightarrow{P Q}}$ também pode ser lida da direita para a esquerda, ela nos diz que toda translação $T_{\vec{v}}$ (na Fig. $38, \vec{v}=\overrightarrow{P Q}$ ) pode exprimir-se como a composta de duas reflexões em torno de retas paralelas situadas uma da outra a uma distância igual à metade do comprimento do vetor $v$. Essas retas podem ser tomadas em qualquer parte do plano, desde que mantenham essa distância, que sejam perpendiculares à direção de $\vec{v}$ e que o sentido do vetor $v$ seja da reta $l_{1}$ para $l_{2}$.

Proposição 4.4.8. A composta de duas reflexões em relação a retas concorrentes é uma rotação com centro no ponto de intersecção dessas retas, e com o dobro do ângulo entre elas.

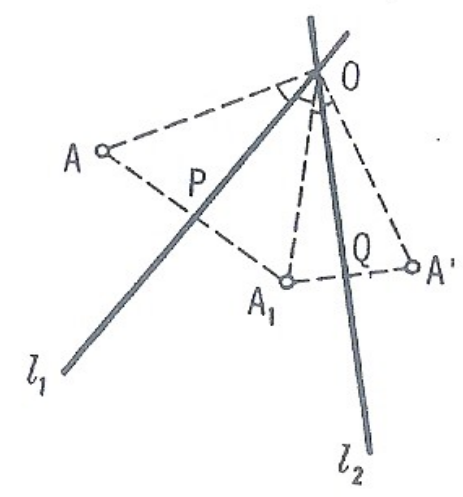

Figura 39: Reflexão em duas retas concorrentes

(YAGLOM, 1962a, p. 50)

Seja $A_{1}$ a imagem de $A$ por $l_{1}$, e $A^{\prime}$ a imagem de $A_{1}$ por $l_{2}$, onde $O$ é o ponto de intersecção de $l_{1}$ e $l_{2}$ (Figura 39). Se $P$ e $Q$ são os pontos de intersecção de $A A_{1} \operatorname{com} l_{1}$ e de $A_{1} A^{\prime}$ com $l_{2}$ respectivamente, segue que:

$$
\triangle A O P \cong \triangle A_{1} O P, \quad \triangle A_{1} O Q \cong \triangle A^{\prime} O Q
$$

Disso temos que:

$$
O A=O A_{1}, \quad O A_{1}=O A^{\prime}
$$




$$
A O P=P O A_{1} \quad A_{1} O Q=Q O A^{\prime}
$$

E para o exemplo, no caso da figura 39 temos

$$
\begin{aligned}
A O A^{\prime} & =A O P+P O A_{1}+A_{1} O Q+Q O A^{\prime} \\
& =2 P O A_{1}+2 A_{1} O Q \\
& =2 P O Q .
\end{aligned}
$$

Podemos escrever:

$$
R_{l_{2}} \circ R_{l_{1}}=R_{O, 2 \alpha}
$$

com $\alpha$ sendo o ângulo entre as retas $l_{1}$ e $l_{2}$ concorrentes em $O$.

Observação 4.4.10. Lembremos uma definição: o ângulo da reta $r$ para a reta $s$ (Figura 40) é o ângulo orientado não-obtuso $\alpha=A \hat{O} B$, onde $A \in r$ e $B \in s$. Neste caso, o ângulo de $s$ para $r$ é $B \hat{O} A=-\alpha$. Analogamente à observação 4.4.9, e em relação à figura 39 podemos escrever $R_{O \alpha}=R_{l_{2}} \circ R_{l_{1}}$ e dizer que toda rotação no plano pode ser expressa como a composta de duas reflexões em torno de retas concorrentes no centro de rotação e formam entre si um ângulo igual à metade do ângulo de rotação. A composição $R_{l_{2}} \circ R_{l_{1}}$ deve ser tomada na ordem certa, de modo que $\alpha$ seja o dobro do ângulo da reta $l_{1}$ para a reta $l_{2}$ (e não de $l_{2}$ para $l_{1}$ ).

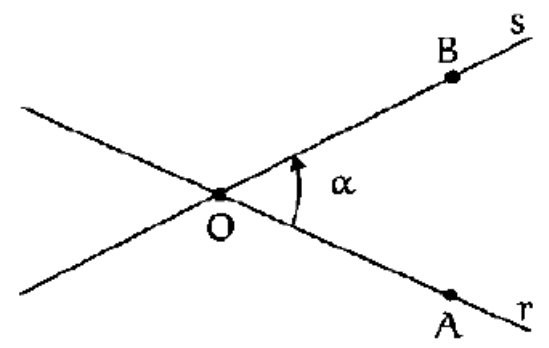

Figura 40: Ângulo entre retas

Uma consequência interessante é dada pelo corolário abaixo, onde a combinação das reflexões em torno de duas perpendiculares resulta numa reflexão em torno do ponto de intersecção.

Corolário 4.4.3. Sejam $l_{1}$ e $l_{2}$ retas perpendiculares se interceptando em um ponto $O$, então $R_{l_{2}} \circ R_{l_{1}}=R_{l_{1}} \circ R_{l_{2}}=R_{O}$.

Proposição 4.4.9. A composta de três reflexões em três retas distintas e paralelas ou em três retas distintas e concorrentes se interceptando em um único ponto é uma reflexão em relação a uma reta. 

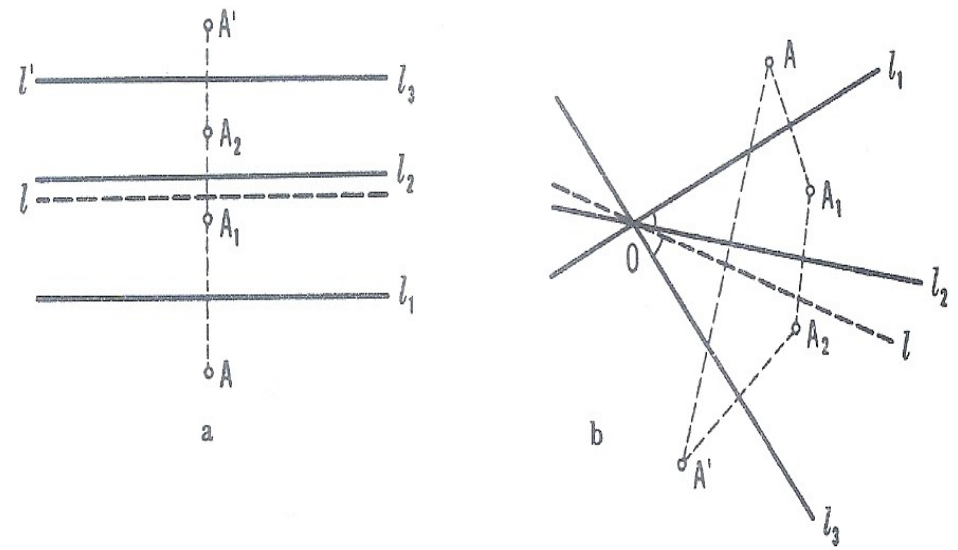

Figura 41: Reflexão em três retas

(YAGLOM, 1962a, p. 53)

O procedimento para efetuar as reflexões consiste em utilizar as proposições (4.4.7) e (4.4.8), conforme o caso, compondo, pela ordem, a composta das duas primeiras, com a terceira.

\subsubsection{Reflexão transladada - Translação Refletida}

Definição 4.4.9. Reflexão com deslizamento (Glide Reflexion) ou Reflexão transladada ou translação refletida num determinado eixo, é a isometria resultado da soma de uma reflexão em relação a uma reta e uma translação na direção desta reta.

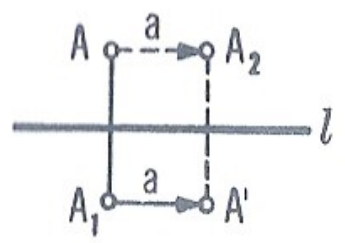

a

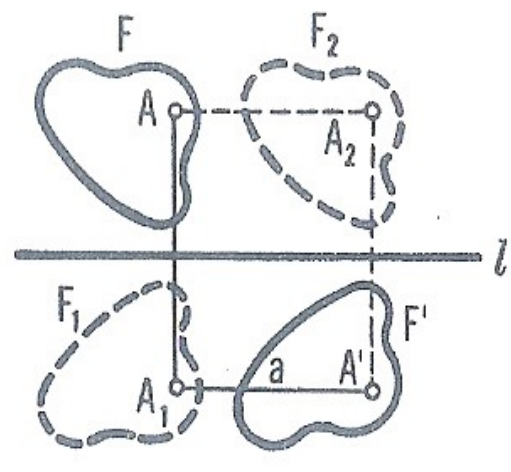

b

Figura 42: Reflexão com deslizamento (YAGLOM, 1962a, p. 48)

Seja o ponto $A_{1}$ a imagem de um ponto $A$ em relação a reta $l$, e seja o ponto $A^{\prime}$ obtido de $A_{1}$ por uma translação pela distância a na direção da mesma reta (Figura 
42a). Neste caso dizemos que o ponto $A^{\prime}$ foi obtido do ponto $A$ por uma reflexão com deslizamento no eixo $l$ através de $a$ (reflexão transladada). A soma pode ser obtida em outra ordem, é fácil ver na Figura 42a; $A_{2}$ é obtido de $A$ por uma translação através da distância a na direção de $l$ e $A^{\prime}$ é obtido de $A_{2}$ por uma reflexão em relação a $l$ (translação refletida).

O conjunto de todos os pontos que são obtidos por uma reflexão com deslizamento de uma figura $F$ forma a figura $F^{\prime}$ (Figura 42b). Reciprocamente podemos dizer que a figura $F$ pode ser obtida da figura $F^{\prime}$ por uma reflexão com deslizamento no mesmo eixo $l$ (com direção oposta de translação); o que nos permite falar de figuras relacionadas por uma reflexão com deslizamento.

Um exemplo da reflexão com deslizamento é dada pela figura 43.

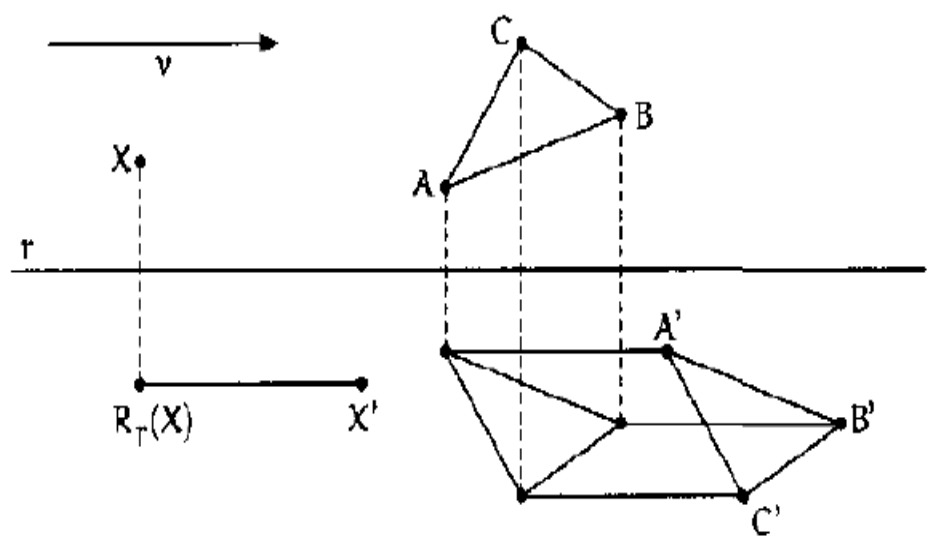

Figura 43: Reflexão com deslizamento

(LIMA, 1996, p. 23)

Uma definição mais formal podemos encontrar em *[p. 111]alves1996estudo:

Sejam $r$ e s retas distintas do plano, ambas perpendiculares a uma reta $t$. A isometria $R_{t} \circ R_{s} \circ R_{r}$ é chamada uma reflexão transladada de eixo $t$, ou ainda, uma translação refletida de eixo $t$. Desde que $r$ e $s$ são retas distintas segue, da proposição 4.4.7, que $R_{s} \circ R_{r}=T_{\vec{v}}$ paralela à direção do vetor não nulo $\vec{v}$. : Reflexão transladada\} (ALVES; GALVÃO, 1996, p. 111)

Além disso, o corolário 4.4.3 nos garante que $R_{t} \circ R_{s}=R_{s} \circ R_{t}, \quad R_{t} \circ R_{r}=R_{r} \circ R_{t}$, e, portanto, $R_{t} \circ\left(R_{s} \circ R_{r}\right)=\left(R_{t} \circ R_{s}\right) \circ R_{r}=\left(R_{s} \circ R_{t}\right) \circ R_{r}=R_{s} \circ\left(R_{t} \circ R_{r}\right)=R_{s} \circ\left(R_{r} R_{t}\right)=$ $\left(R_{s} \circ R_{r}\right) \circ R_{t}$.

Concluímos que $R_{t} \circ T_{\vec{v}}=R_{t} \circ R_{s} \circ R_{r}=R_{s} \circ R_{r} \circ R_{t}=T_{\vec{v}}$, ou seja, toda reflexão transladada de eixo t pode ser escrita como a composta de uma translação $T_{\vec{v}}$ e de uma reflexão $R_{t}$, com a reta $t$ 
Além disso, o corolário 4.4.3 nos garante que $R_{t} \circ R_{s}=R_{s} \circ R_{t}, \quad R_{t} \circ R_{r}=R_{r} \circ R_{t}$, e, portanto, $R_{t} \circ\left(R_{s} \circ R_{r}\right)=\left(R_{t} \circ R_{s}\right) \circ R_{r}=\left(R_{s} \circ R_{t}\right) \circ R_{r}=R_{s} \circ\left(R_{t} \circ R_{r}\right)=R_{s} \circ\left(R_{r} R_{t}\right)=$ $\left(R_{s} \circ R_{r}\right) \circ R_{t}$.

Concluímos que $R_{t} \circ T_{\vec{v}}=R_{t} \circ R_{s} \circ R_{r}=R_{s} \circ R_{r} \circ R_{t}=T_{\vec{v}}$, ou seja, toda reflexão transladada de eixo t pode ser escrita como a composta de uma translação $T_{\vec{v}}$ e de uma reflexão $R_{t}$, com a reta $t$ paralela à direção do vetor não nulo $\vec{v}$, sendo que a composição pode ser efetuada em qualquer ordem.

A igualdade $T_{\vec{v}} \circ R_{t}=R_{t} \circ T_{\vec{v}}$ pode ser vista como justificativa para as expressões reflexão transladada e translação refletida.

Sendo $\{A\}=r \cap t$ e $\{B\}=s \cap t$ temos que o ponto $A$ não pertence à reta $s$ bem como o ponto $B$ não pertence à reta $r$. Usando novamente o corolário 4.4.3 segue que $R_{t} \circ R_{s} \circ R_{r}=\left(R_{t} \circ R_{s}\right) \circ R_{r}=R_{B} \circ R_{r}$ e $R_{t} \circ R_{s} \circ R_{r}=R_{s} \circ\left(R_{r} \circ R_{t}\right)=R_{s} \circ R_{A}$.

Assim toda reflexão transladada é a composta de uma reflexão em relação a uma reta $r$ seguida de uma reflexão em relação a um ponto $B$ não pertencente a $r$ e também é a composta de uma reflexão em relação a um ponto $A$ seguida de uma reflexão em relação a uma reta $s$ que não passa por $A$. Podemos também enunciar a recíproca:

Proposição 4.4.10. Dados uma reta $n$ do plano e um ponto $A$ não pertencente a $n$ então $R_{A} \circ R_{n}$ e $R_{n} \circ R_{A}$ são reflexões transladadas de eixo $t$, onde $t$ é a reta perpendicular a $n$ por $A$.

A seguir, podemos destacar outras propriedades da reflexão transladada:

1. Uma reflexão transladada não tem pontos fixos. A única reta do plano que é invariante por uma reflexão transladada é o seu eixo.

2. Conforme Figura 4.4.4.2, a reflexão transladada de eixo $t, T=R_{t} \circ R_{s} \circ R_{r}=R_{t} \circ T_{\vec{v}}$, a igualdade $F(P)=R_{M}(P)$ prova não somente que $F$ não tem pontos fixos, mas também que o ponto médio do segmento $\overline{P Q}$, onde $Q=F(P)$, pertence ao eixo $t$ da reflexão transladada.

3. Sendo $F=R_{t} \circ T_{\vec{v}}=T_{\vec{v}} \circ R_{t}$ uma reflexão transladada de eixo $t$, temos $F^{2}=T_{2 \vec{v}}$ de modo que $\left[F^{2}\right]$ é um grupo cíclico com infinitos elementos. Como $\left[F^{2}\right] \subset[F]$, segue que o grupo cíclico gerado por uma reflexão transladada tem infinitos elementos.

\subsubsection{Composição de reflexões em relação a retas - continuação}

Voltando ao estudo da composição de reflexões em relação a retas temos:

Proposição 4.4.11. A composta de reflexões em três retas, interceptando em pares em três pontos, ou tal que duas delas são paralelas e a terceira interceptando-as, é uma reflexão 
com deslizamento. Em outras palavras, se $l_{1}, l_{2}$ e $l_{3}$ são três retas distintas do plano, então $R_{l_{3}} \circ R_{l_{2}} \circ R_{l_{1}}$ é uma reflexão transladada se e somente se $l_{1}, l_{2}$ e $l_{3}$ não são nem paralelas nem concorrentes (fig.42).

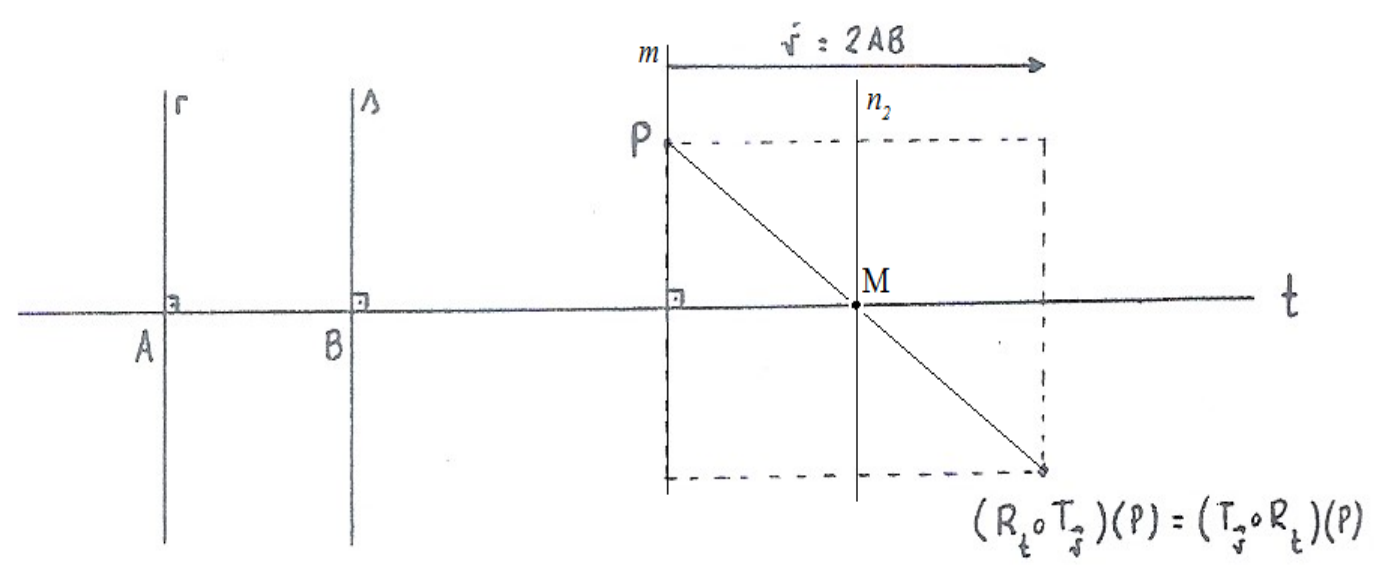

Além disso, o corolário 4.4.3 nos garante que $R_{t} \circ R_{s}=R_{s} \circ R_{t}, \quad R_{t} \circ R_{r}=R_{r} \circ R_{t}$, e, portanto, $R_{t} \circ\left(R_{s} \circ R_{r}\right)=\left(R_{t} \circ R_{s}\right) \circ R_{r}=\left(R_{s} \circ R_{t}\right) \circ R_{r}=R_{s} \circ\left(R_{t} \circ R_{r}\right)=R_{s} \circ\left(R_{r} R_{t}\right)=\left(R_{s} \circ R_{r}\right) \circ R_{t}$.

Concluímos que $R_{t} \circ T_{\vec{v}}=R_{t} \circ R_{s} \circ R_{r}=R_{s} \circ R_{r} \circ R_{t}=T_{\vec{v}}$, ou seja, toda reflexão transladada de eixo t pode ser escrita como a composta de uma translação $T_{\vec{v}}$ e de uma reflexão $R_{t}$, com a reta $t$

Além disso, o corolário 4.4.3 nos garante que $R_{t} \circ R_{s}=R_{s} \circ R_{t}, \quad R_{t} \circ R_{r}=R_{r} \circ R_{t}$, e, portanto, $R_{t} \circ\left(R_{s} \circ R_{r}\right)=\left(R_{t} \circ R_{s}\right) \circ R_{r}=\left(R_{s} \circ R_{t}\right) \circ R_{r}=R_{s} \circ\left(R_{t} \circ R_{r}\right)=R_{s} \circ\left(R_{r} R_{t}\right)=\left(R_{s} \circ R_{r}\right) \circ R_{t}$.

Concluímos que $R_{t} \circ T_{\vec{v}}=R_{t} \circ R_{s} \circ R_{r}=R_{s} \circ R_{r} \circ R_{t}=T_{\vec{v}}$, ou seja, toda reflexão transladada de eixo t pode ser escrita como a composta de uma translação $T_{\vec{v}}$ e de uma reflexão $R_{t}$, com a reta $t$

Além disso, o corolário 4.4.3 nos garante que $R_{t} \circ R_{s}=R_{s} \circ R_{t}, \quad R_{t} \circ R_{r}=R_{r} \circ R_{t}$, e, portanto, $R_{t} \circ\left(R_{s} \circ R_{r}\right)=\left(R_{t} \circ R_{s}\right) \circ R_{r}=\left(R_{s} \circ R_{t}\right) \circ R_{r}=R_{s} \circ\left(R_{t} \circ R_{r}\right)=R_{s} \circ\left(R_{r} R_{t}\right)=$ $\left(R_{s} \circ R_{r}\right) \circ R_{t}$.

Concluímos que $R_{t} \circ T_{\vec{v}}=R_{t} \circ R_{s} \circ R_{r}=R_{s} \circ R_{r} \circ R_{t}=T_{\vec{v}}$, ou seja, toda reflexão transladada de eixo t pode ser escrita como a composta de uma translação $T_{\vec{v}}$ e de uma reflexão $R_{t}$, com a reta $t$

Sejam as retas $l_{1}$ e $l_{2}$ concorrentes em $O$ (Figura 45a). A composta das reflexões em $l_{1}$ e $l_{2}$ é uma rotação com centro em $O$ e ângulo $2 l_{2} l_{1}$ (veja proposição 4.4.8); portanto a composta dessaa reflexões podem ser substituídas pela composta de reflexões em qualquer duas retas $l_{1}^{\prime}$ e $l_{2}^{\prime}$, concorrentes no mesmo ponto $O$ e formando o mesmo ângulo de $l_{1}$ e $l_{2}$. Escolhendo as retas $l_{1}^{\prime}$ e $l_{2}^{\prime}$ tal que $l_{2}^{\prime} \perp l_{3}$, e substituindo a composta das reflexões $l_{1}, l_{2}$ e $l_{3}$ pela composta das reflexões nas retas $l_{1}^{\prime}, l_{2}^{\prime}$ e $l_{3}$ (isto é, pela composta de uma reflexão em $l_{1}^{\prime}$ e um meio-giro relação ao ponto $O_{1}$ de intersecção de $l_{2}^{\prime}$ e $l_{3}$ - ou, o que é a mesma 
coisa, pela composta de uma reflexão em relação a $l_{1}^{\prime}$ e uma reflexão em relação ao ponto $O_{1}$ - devido ao Corolário 4.4 .3 a composta de reflexões em duas retas perpendiculares é um meio-giro em relação ao ponto de intersecção).

Agora vamos substituir a composta das reflexões nas retas perpendiculares $l_{2}^{\prime}$ e $l_{3}$ pela composta de reflexões em duas novas retas perpendiculares $l_{2}^{\prime \prime}$ e $l_{3}^{\prime}$, interceptando no mesmo ponto $O_{1}$, e tal que $l_{2}^{\prime \prime} \| l_{1}^{\prime}$ (Figura 45b; essa mudança é permitida porque a composta das reflexões em $l_{2}^{\prime \prime}$ e $l_{3}^{\prime}$ é também uma reflexão em torno do ponto $O_{1}$ ) Da mesma forma a composta das reflexões em $l_{1}^{\prime}, l_{2}^{\prime}$ e $l_{3}$ é substituída pela composta das reflexões em $l_{1}^{\prime}$, $l_{2}^{\prime \prime}$ e $l_{3}^{\prime}$. Mas pela Proposição 4.4 .7 a composta nas retas paralelas $l_{1}^{\prime}$ e $l_{2}^{\prime \prime}$ é uma translação na direção da reta $l_{3}^{\prime}$ perpendicular à $l_{1}^{\prime}$ e $l_{2}^{\prime \prime}$. Portando a composta das reflexões em $l_{1}^{\prime}$, $l_{2}^{\prime \prime}$ é igual à composta de uma translação na direção $l_{3}^{\prime}$ e uma reflexão em relação a $l_{3}^{\prime}$, isto é, uma reflexão transladada (glide reflection) de eixo $l_{3}^{\prime}$.

No caso de $l_{1}$ e $l_{2}$ serem paralelas, e $l_{2}$ e $l_{3}$ se interceptarem num ponto $O$, o procedimento é exatamente do mesmo modo. Neste caso é necessário primeiramente substituir a composta das reflexões em $l_{2}$ e $l_{3}$ pela composta de reflexões em retas $l_{2}^{\prime}$ e $l_{3}^{\prime}$ que se interceptem no mesmo ponto $O$, e tal que $l_{2}^{\prime} \perp l_{1}$ e então substituir a composta das reflexões nas retas perpendiculares $l_{1}$ e $l_{2}^{\prime}$ pela composta das reflexões nas retas perpendiculares $l_{1}^{\prime}$ e $l_{2}^{\prime \prime}$, interceptando no mesmo ponto $O_{1}$ e tal que $l_{2}^{\prime \prime}=l_{3}^{\prime}$.)

Das Proposições 4.4.7, 4.4.8, 4.4.9 e 4.4.11, podemos enunciar um teorema que generalize as proposições em referência:

Teorema 4.4.4. A composta de um número par de reflexões em relação a retas é uma translação ou uma rotação; a composta de um número impar de reflexões em relação a retas é uma reflexão em relação a reta, ou uma reflexão transladada (reflexão com deslizamento, glide refletion).

Com isso podemos enunciar os seguintes teoremas:

Teorema 4.4.5. Toda isometria do plano é a composta de, no máximo, três reflexões em relação a retas.

Teorema 4.4.6. Toda isometria $f: E^{n} \rightarrow E^{n}$ é uma composição de rotações, translações, e reflexões.

Corolário 4.4.4. Toda isometria é uma composição de reflexões.

Corolário 4.4.5. Uma fórmula para a isometria geral no $R^{2}$. Toda isometria $f$ : $E^{2} \rightarrow E^{2}$ tem a forma:

$$
f(x, y)=\left(a_{0}+x \cos \theta \mp y \sin \theta, \quad b_{0}+\sin \theta \pm y \cos \theta\right)
$$


Onde, $a_{0}, b_{0}$, e $\theta$ são constantes, $f(0,0)=\left(a_{0}, b_{0}\right)$ são coordenadas padrão no $R_{2}$, e os sinais de adição ou subtração é positivo se $f$ preserva orientação e negativo se $f$ altera a orientação.

\subsubsection{Isometrias e Congruências: Classificação}

Neste item abordaremos a congruência entre figuras no plano, já vista na definição de congruência em 4.3.3 da seção 4.3, agora as abordaremos relacionado-a com os tipos de isometrias e suas combinações, vistas nos itens anteriores. Veremos também algumas classificações das isometrias, citadas anteriormente. Inicialmente faremos um estudo mais detalhado das isometrias próprias e impróprias, resultado de combinações de reflexões. Um movimento no plano é uma coleção de isometrias (figura 46). Uma translação e uma reflexão transformam o mesmo triângulo $A B C$ nos triângulos $A^{\prime} B^{\prime} C^{\prime}$ e $A_{1} B_{1} C_{1}$. É intuitivamente plausível que se pode passar continuamente de $A B C$ para $A^{\prime} B^{\prime} C^{\prime}$ mas, sem sair do plano, não é possível deslocar $A B C$ até $A_{1} B_{1} C_{1}$. Essa observação estabelece a distinção entre uma isometria própria e uma imprópria.

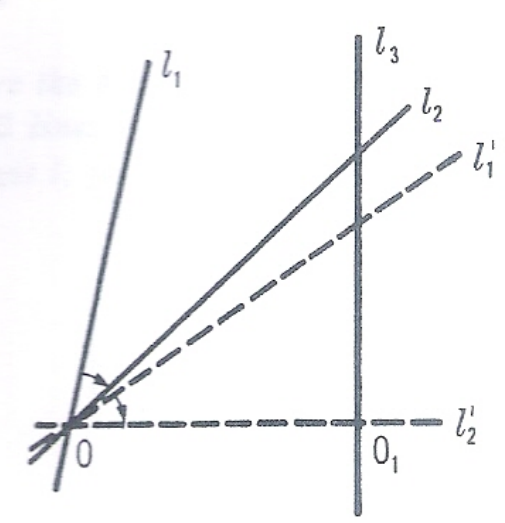

a

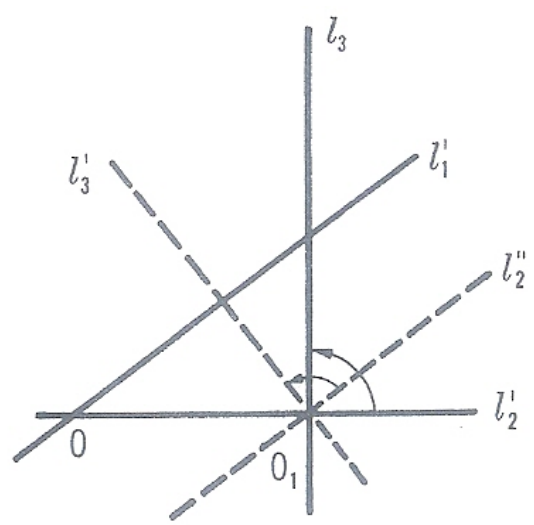

b

Figura 45: Composta Reflexões 3 retas

(YAGLOM, 1962a, p. 54)

Definição 4.4.10. Isometrias Próprias e Impróprias: uma isometria chama-se própria, ou ainda par ou direta, quando é a etapa final de um movimento, sem sair do plano, por outro lado chama-se imprópria, impar, ou oposta, quando nenhum movimento no plano termina com a isometria. Outra forma de definir isometria é dada por (LEDERGERBER-RUOFF, 1982, p. 86):

1. Uma isometria que é igual a um produto de um número par de reflexões em retas chama-se isometria própria. 
2. Uma isometria que é igual a um produto de um número impar de reflexões em retas chama-se isometria imprópria.

3. O produto de duas isometrias próprias ou de duas isometrias impróprias é uma isometria própria.

4. O produto de uma isometria própria e de uma isometria imprópria é uma isometria imprópria.

Acrescentamos outras propriedades descritas por outros autores (como em (??, p. 31) e (ALVES; GALVÃO, 1996, p. 135), p.135):

5. Translações e Rotações são isometrias próprias, enquanto Reflexões (em relação a um ponto e em relaçao a uma reta) e Reflexões com deslizamento são isometrias impróprias.

6. De forma análoga ao item (3) Elon diz: se $S$ e $T$ são isometrias próprias então a composta $S \circ T$ e as inversas $S^{-1}, T^{-1}$ são próprias, além disso, se $S$ e $T$ são isometrias impróprias, a composta $S \circ T$ é uma isometria própria.

7. Se $S$ é uma isometria imprópria então, para toda reflexão $R_{r}$, as isometrias compostas $S \circ R_{r}$ e $R_{r} \circ S$ são próprias.

8. Nenhuma isometria do plano é, simultaneamente, própria e imprópria.

9. Toda isometria do plano ou é própria ou é imprópria.

\subsubsection{Congruência Direta e Congruência Oposta}

Recordemos a definição dada em 4.3.3: Duas figuras geométricas $\mathcal{A}$ e $\mathcal{A}^{\prime}$ do plano são congruentes se existe uma isometria $F$ do plano tal que $F(\mathcal{A})=\mathcal{A}^{\prime}$.

Assim como descrito para isometrias próprias e impróprias, pares de figuras congruentes no plano podem ser de dois tipos. É possível que duas figuras congruentes possam coincidir movendo uma das figuras, mas sem remove-la do plano em que está originalmente situada, tal como no exemplo da Figura $47 \mathrm{a}, F$ e $F^{\prime}$ (onde pode-se faze-las coincidir por meio de uma rotação em relação ao ponto $O$ ). Mas é também possível para duas figuras do plano, porém, para fazê-las coincidir, é necessário remover uma delas do plano e gira-la "para o outro lado". Tal como as figuras $F_{1}^{\prime}$ e $F^{\prime}$ na Figura 47b, é impossível mover a figura $F_{1}^{\prime}$ no plano tal que ela coincida com a figura $F^{\prime}$. No exemplo da Figura $47 \mathrm{~b}, F_{2}^{\prime}$ é obtida por meio de uma reflexão em relação a reta $l$ da figura $F_{1}^{\prime}$, e $F^{\prime}$ por meio de uma rotação em relação a $O$ fa figura $F_{2}^{\prime}$ (fig.47).

Definição 4.4.11. Duas figuras serão congruentes diretas, se uma delas pode ser movida inteiramente no plano para que coincida com a segunda figura, e opostas quando for impossivel fazê-las coincidir por movimentos dentro do plano. 


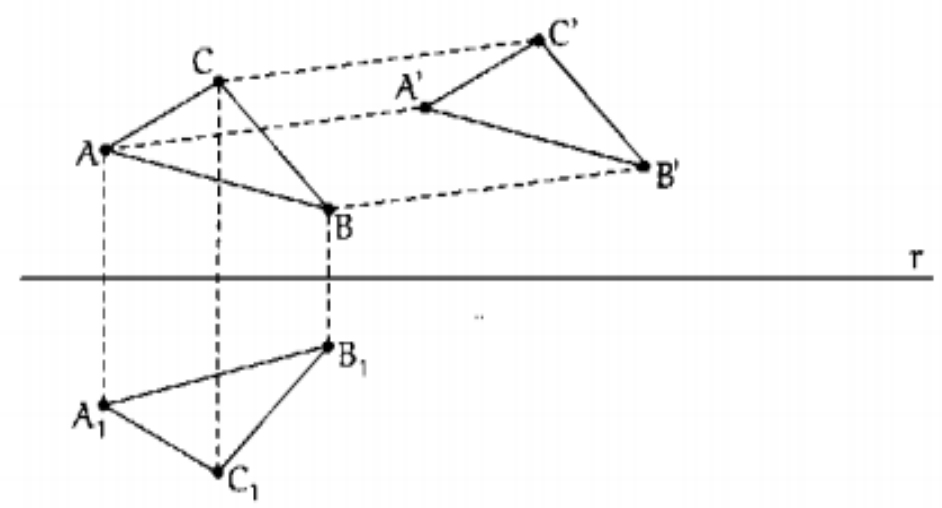

Figura 46: Isometrias Próprias e Impróprias

(LIMA, 1996, p. 30)

Para analisarmos a congruência entre duas figuras do plano se é direta ou oposta, basta escolhermos qualquer três pontos $A, B$ e $C$ não colineares da figura $F$ e os pontos correspondentes $A^{\prime}, B^{\prime}$ e $C^{\prime}$ da figura $F^{\prime}$ (fig.47), e checar as orientações dos triângulos $\triangle A B C$ e $A^{\prime} B^{\prime} C^{\prime}$ se é direta ou reversa, como definido em 4.4.4. Diremos que duas figuras são "congruentes", somente quando não faça diferença se são oposta ou diretamente congruentes. Podemos resumir as considerações vistas até agora, com a utilização das isometrias conhecidas:

Teorema 4.4.7. Qualquer duas figuras diretamente congruentes no plano podem ser feitas coincidir por meio de uma rotação ou uma translação.

Teorema 4.4.8. Qualquer duas figuras opostamente congruentes no plano podem ser feitas coincidir por meio de uma reflexão (em relação a um ponto ou em relação a uma reta) ou uma reflexão transladada (translação refletida, "glide refletion").

Podemos agrupar os teoremas 4.4.7 e 4.4.8:

Teorema 4.4.9. Qualquer duas figuras geométricas do plano são congruentes se e somente se estão relacionadas por uma translação, uma rotação, uma reflexão em relação a uma reta ou uma reflexão transladada.

\subsection{Homotetia-Similaridade-Semelhança}

As transformações geométricas apresentadas até agora tem uma característica comum: elas transformam cada figura do plano em uma figura congruente. Todas as transformações com essa propriedade de preservar distâncias são chamadas transformações 
congruentes ou isometrias.

É possível, no entanto, fazer um bom uso de uma transformação que leva uma figura do plano para uma figura semelhante. Uma tal semelhança preserva ângulos, mas deve alterar distâncias. Entretanto, todas as distâncias devem ser aumentadas (ou diminuídas) na mesma razão, chamada de razão de magnificação (ampliação/redução). Podemos então definir essa transformação como:

Definição 4.5.1. Uma homotetia $H(O, k)$ (ou também: similaridade central), onde $O$ é um ponto no plano e $k$ é um número real não nulo, é uma transformação que fixa o ponto $O$ e associa qualquer outro ponto $P \neq O$ um ponto $P^{\prime}$, tal que $O, P, P^{\prime}$ são colineares e $O P^{\prime}=k \cdot O P$. O ponto $O$ é chamado o centro e $k$ a razão da homotetia (coeficiente de similaridade).

Teorema 4.5.1. A homotetia $H(O, k)$ leva um segmento de reta $A B$ em um segmento paralelo $A^{\prime} B^{\prime}$ com $A^{\prime} B^{\prime}=k \cdot A B$.

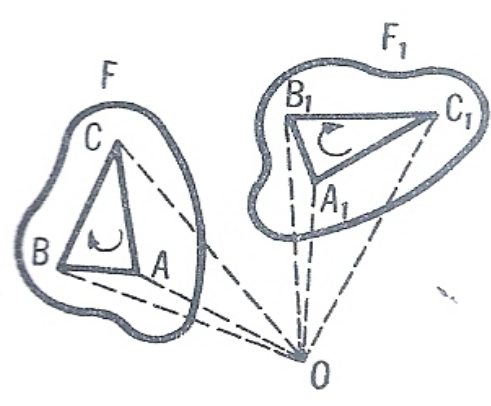

a

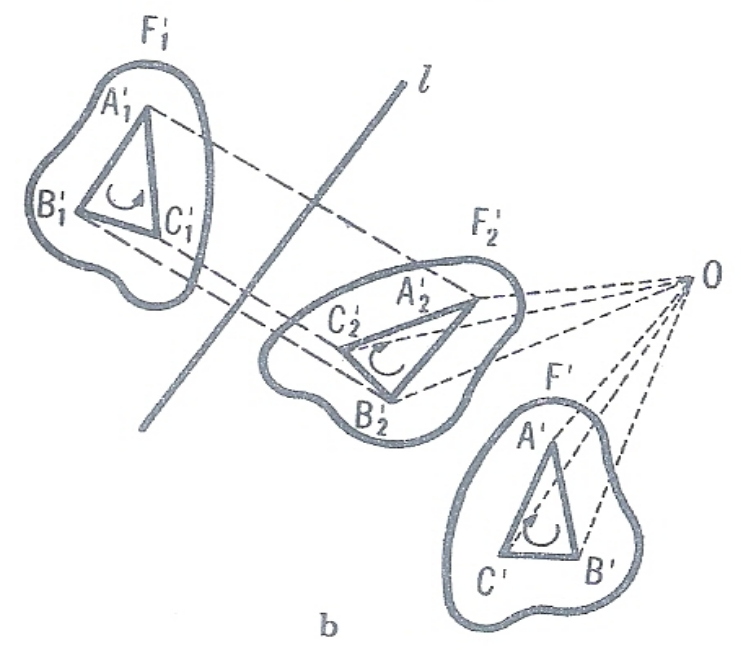

b

Figura 47: Congruência Direta e Oposta

(YAGLOM, 1962a, p. 60)

Observação 4.5.1. Conforme o valor de $k$ ser positivo ou negativo, podemos classificar as homotetias:

- Se $k>0$ dizemos: homotetia com razão positiva ou homotetia direta (Figura 48a);

- Se $k<0$ dizemos: homotetia com razão negativa ou homotetia inversa (Figura 48b);

- Para $k=1$, teremos a transformação identidade, uma isometria, um caso especial de homotetia; 
- Para $k=-1$, também teremos uma isometria, a reflexão em torno do ponto $O$, isto é $H(O,-1)=R_{O}$, também um caso especial de homotetia;

- Podemos definir homotetias recíprocas, isto é, se $H(O, k)(A, B, C)=\left(A^{\prime}, B^{\prime}, C^{\prime}\right)$, sua recíproca será: $H(O, 1 / k)\left(A^{\prime}, B^{\prime}, C^{\prime}\right)=(A, B, C)$ (vide exemplo na Figura 48), assim podemos falar em pares de figuras homotéticas.

Corolário 4.5.1. O centro de homotetia pertence a todas as retas que ligam pontos a seus transformados (retas concorrentes). Em outras palavras, O pertence a toda reta do tipo $O P^{\prime}=H(O, k)(O P)$. Uma propriedade que decorre diretamente da definição 4.5.1 (na verdade, é a mesma da colinearidade!), mas que aparece quando descobrimos alguma homotetia.

Corolário 4.5.2. Uma homotetia mapeia qualquer triângulo dado em um triaângulo semelhante. Em geral. mapeia cada polígono em um polígono semelhante.

Corolário 4.5.3. Uma hometetia preserva ângulos entre retas.

Teorema 4.5.2. Uma homotetia é determinada por dois pontos distintos e suas imagens.

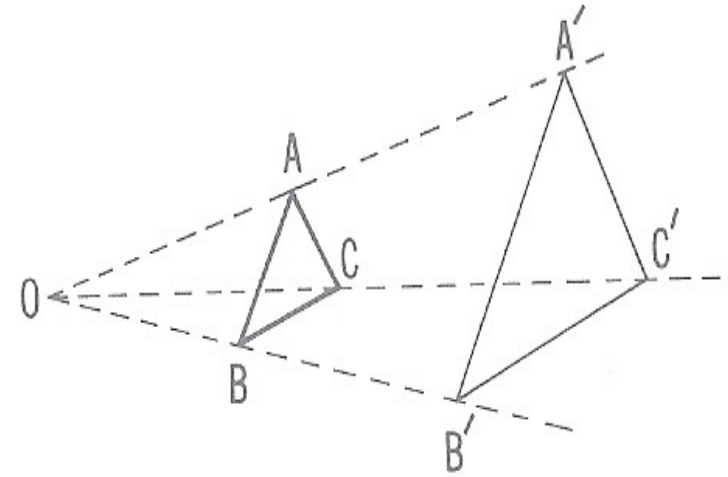

a

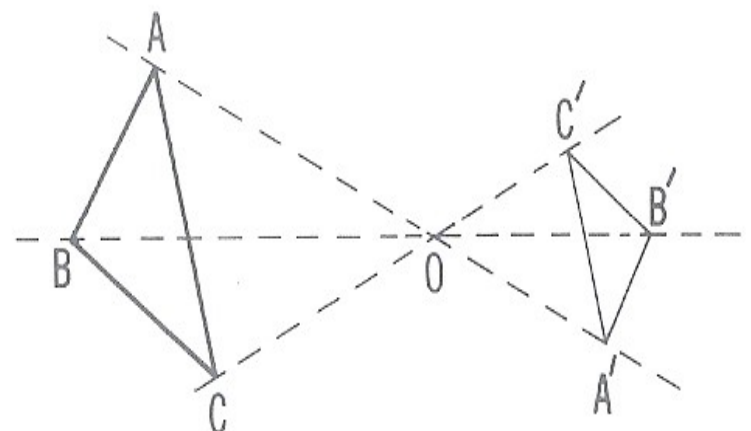

b

Figura 48: Homotetia

(COXETER; GREITZER, 1967, p. 94-95)

Uma homotetia, associa uma reta $l$ a uma reta $l^{\prime}$ paralela a $l$, para encontrar $l^{\prime}$ é suficiente encontrar a imagem $A^{\prime}$ homtética a algum ponto $A \in l$, e traçar por $A^{\prime}$ uma reta $l^{\prime} \| l$ (Figura 49a). Se duas retas $l$ e $m$ se interceptam com um ângulo $\alpha$, então suas imagens $l^{\prime}$ e $m^{\prime}$ se interceptam com o mesmo ângulo $\alpha$. Então o $\triangle A^{\prime} B^{\prime} C^{\prime}$, homotético ao $\triangle A B C$ tem os mesmos ângulos correspondentes congruentes, portanto os dois triângulos são semelhantes $\left(\triangle A^{\prime} B^{\prime} C^{\prime} \simeq \triangle A B C\right)$ (Figura 49b).

Teorema 4.5.3. Uma homotetia $H(O, k)$ associa um círculo de raio $r$ em um outro círculo cujo raio $r^{\prime}$ é $|k| \cdot r$ e cujo centro $C^{\prime}$ é a imagem homotética do centro $C$ do círculo dado. 
Dois círculos são sempre homotéticos. Na maioria dos casos, eles admitem duas homotetias, uma direta e uma inversa. No caso de círculos disjuntos, os centros de homotetias são fáceis de encontrar: são as interseções das tangentes comuns internas (inversa- $O_{-}$) e das tangentes comuns externas (direta- $O_{+}$) (vide Figura 50).
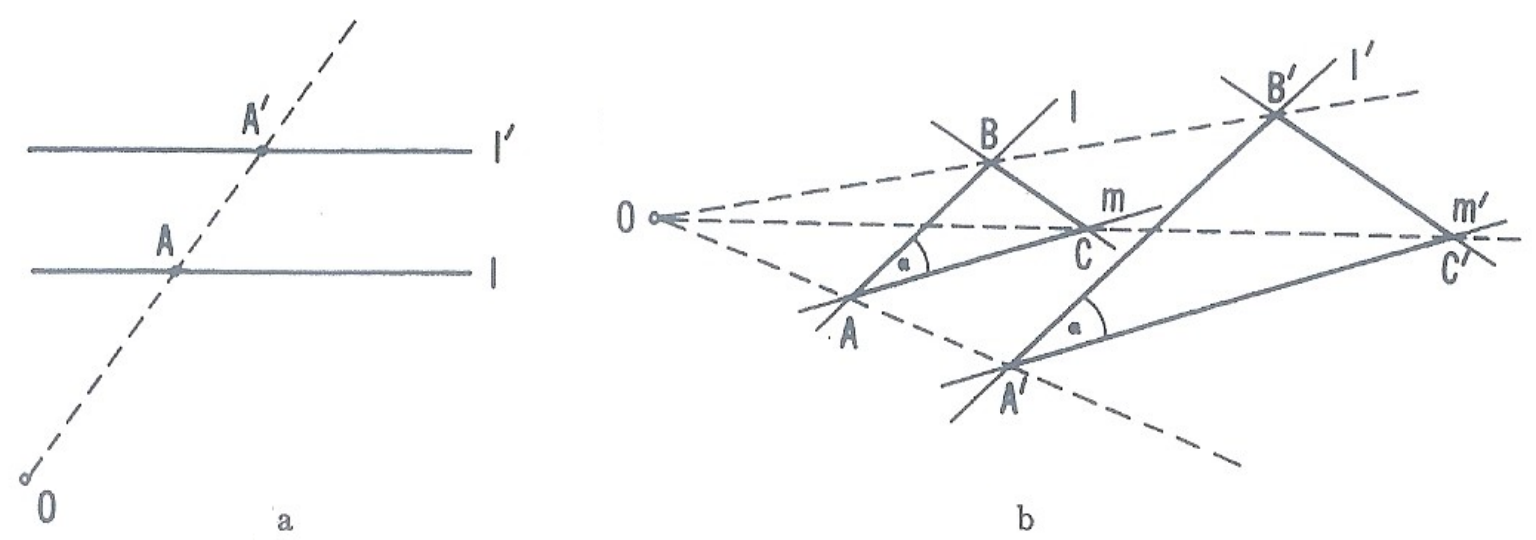

Figura 49: Homotetia-Semelhança

(YAGLOM, 1962b, p. 10)

É suficiente tomar o centro de similaridade dos círculos o ponto $O$ que pertença à reta $A A^{\prime}$, fora do segmento $\overline{A A^{\prime}}$, e tal que $O A^{\prime} / O A=r^{\prime} / r$, fazendo a razão $r^{\prime} / r$ o coeficiente de similaridade $k>0$ ( vide Figura 51).

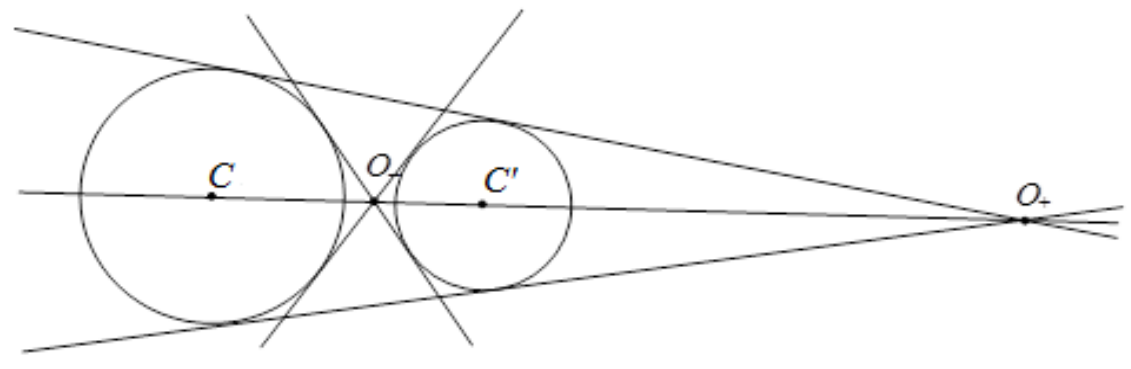

Figura 50: Homotetia-Círculos

(SHINE, 2009, p. 3)

O ponto $O$ é chamado centro exterior de homotetia dos círculos $S$ e $S^{\prime}$. Para construir o ponto $O$ de dois círculos $S$ e $S^{\prime}$ é suficiente desenhar qualquer duas paralelas e homotéticos raios $A M$ e $A^{\prime} M^{\prime}$ nesses círculos e então ligar $M$ a $M^{\prime} ; O$ é o ponto de intersecção de $A A^{\prime}$ e $M M^{\prime}$. Se o círculo menor não estiver localizado no interior do círculo maior, como vimos na Figura 50, o ponto $O$ é também a intersecção das tangentes externas e comuns aos dois círculos (Figura 51a); se $S$ e $S^{\prime}$ são tangentes internamente, então o centro de homotetia coincide com o ponto de tangência (Figura 51b). 
Uma homotetia de centro $O$ e com coeficiente de similaridade negativo, isto é, $k<0$, é a composição de uma homotetia com o mesmo valor de $k$, porém positivo, isto é $|k|$, com o mesmo centro $O$ e uma reflexão em torno desse ponto $O$ (half turn), tomado em qualquer ordem. No exemplo da Figura 52a, dado $k<0$ pode-se efetuar inicialmente uma homotetia com centro $O$ e tomando $|k|$ como a razão da homotetia (levando a figura $F$ em $F_{1}$ ), seguida de um meio-giro (half turn) de centro $O$ (levando $F_{1}$ a $F^{\prime}$ ); ou inicia-se com um meio-giro em relação a $O$ (levando $F$ a $F_{2}$ ) seguida da homotetia de centro $O$ e razão $|k|\left(F_{2}\right.$ para $\left.F^{\prime}\right)$.

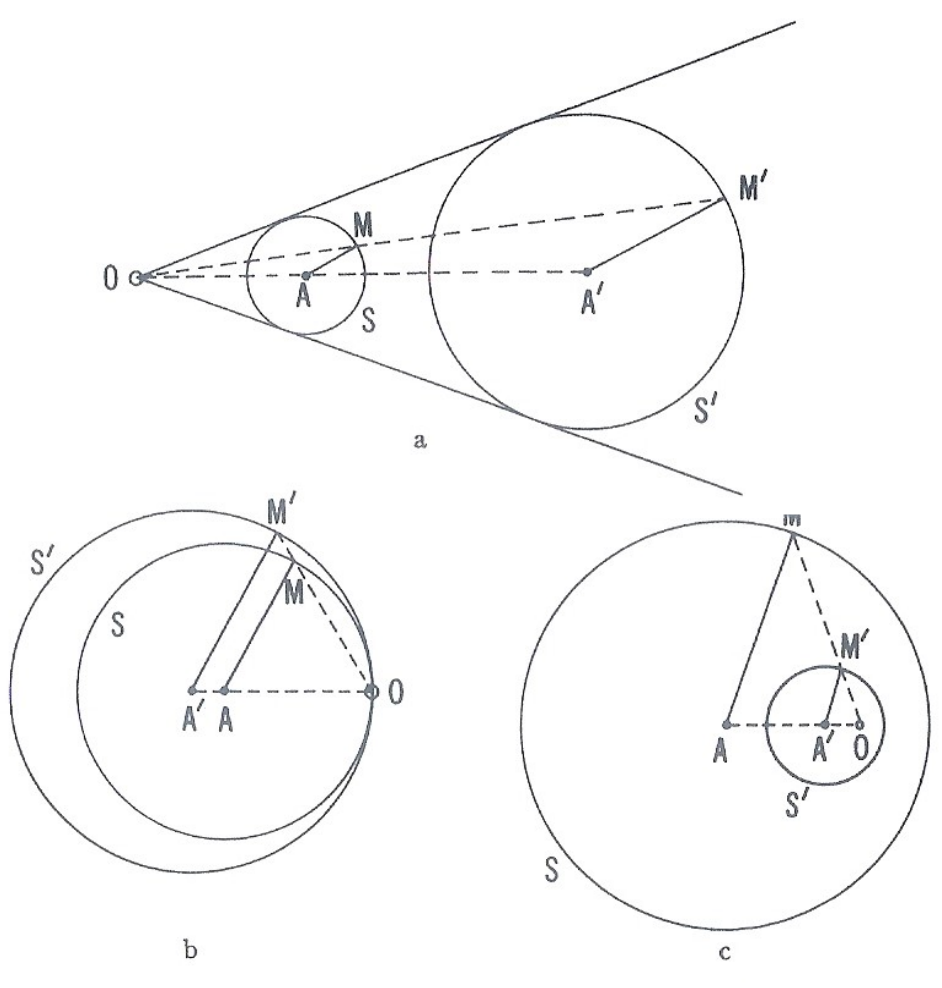

Figura 51: Homotetia em Círculos com $k$ positivo (YAGLOM, 1962b, p. 11)

Uma homotetia com o coeficiente de similaridade negativo $(k<0)$ também leva uma reta $l$ a uma reta paralela $l^{\prime}$, mas agora o centro da homotetia situa-se entre as retas $l$ e $l^{\prime}$ (veja Figura 52b).

Uma homotetia de centro $O$ e razão negativa $k<0$ leva um círculo $S$ de raio $r$ em outro círculo $S^{\prime}$ de raio $r^{\prime}$, com $O A^{\prime} / O A=-r^{\prime} / r$, cujo centro da homotetia $O$ situa-se entre $A$ e $A^{\prime}\left(A-O-A^{\prime}\right)$, chamado de centro de similaridade interior dos círculos $S$ e $S^{\prime}$ (veja Figura 53).

Para determinar o centro de similaridade interior dos dois círculos $S$ e $S^{\prime}$ é suficiente desenhar qualquer dois raios paralelos e com direções opostas $A M$ e $A^{\prime} M^{\prime}$ nos círculos, $O$ é o ponto de intersecção de $A A^{\prime}$ e $M M^{\prime}$ (Figura 53). Se $S$ e $S^{\prime}$ não se interceptam, então 


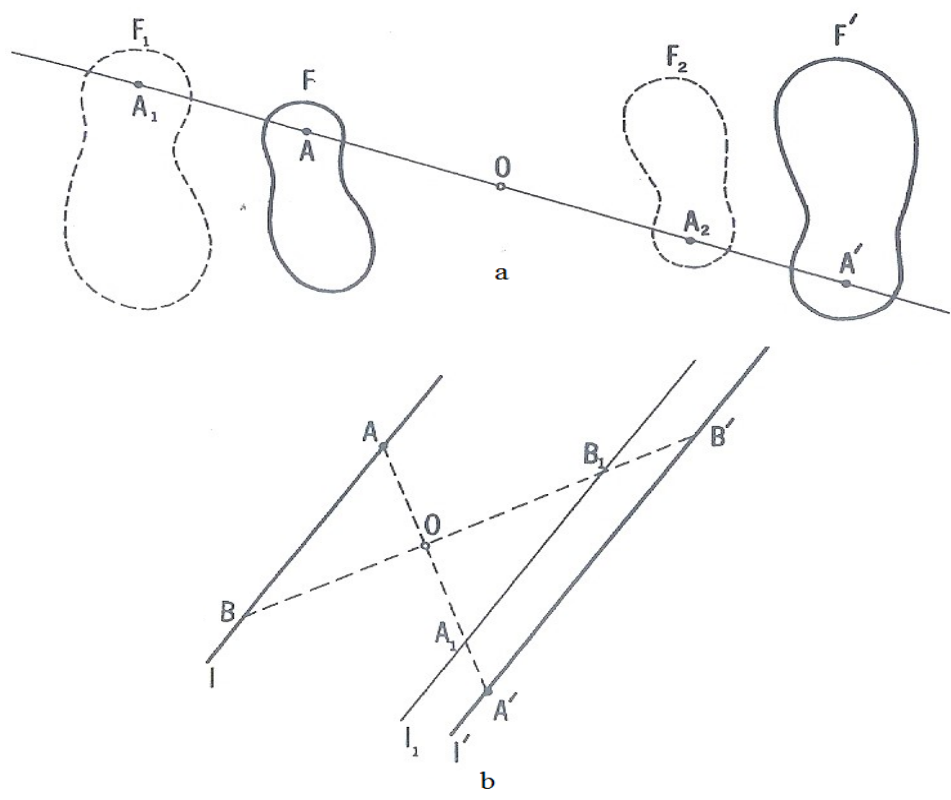

Figura 52: Homotetia-k negativo

(YAGLOM, 1962b, p. 13)

seu centro de similaridade interior também pode ser determinado pelo ponto de intersecção das suas tangentes internas (Figura 53a); se $S$ e $S^{\prime}$ são tangentes externamente, então $O$ é o ponto de tangência (Figura 53b).

\subsubsection{Composição de Homotetias}

Teorema 4.5.4. A composição de duas homotetias com centros $\mathrm{O}_{1}, \mathrm{O}_{2}$ e coeficientes de homotetias $k_{1}$ e $k_{2}$ é uma homotetia com centro $O$ e coeficiente $k_{1} k_{2}$ se $k_{1} k_{2} \neq 1$, com $O$, $\mathrm{O}_{1}$ e $\mathrm{O}_{2}$ alinhados, e uma translação se $k_{1} k_{2}=1$.

$$
H\left(O_{1}, k_{1}\right) \circ H\left(O_{2}, k_{2}\right)=H\left(O, k_{1} k_{2}\right), \quad k_{1} k_{2} \neq 1
$$

Seja a figura $F_{1}$ homotética a $F$ com centro $O_{1}$ e coeficiente $k_{1}$; seja $F^{\prime}$ homotética à figura $F_{1}$ com centro $O_{2}$ e coeficiente $k_{2}$ (veja Figura 54, onde por simplicidade mostraremos o caso de coeficientes $k_{1}$ e $k_{2}$ positivos). Neste caso, segmentos correspondentes em $F$ e $F_{1}$ são paralelos e com razão constante $k_{1}$; segmentos correspondentes em $F_{1}$ e $F^{\prime}$ são paralelos e com razão $k_{2}$, segue que segmentos correspondentes em $F$ e $F^{\prime}$ são paralelos e com razão $k_{1} k_{2}$.

Multiplicando os membros da esquerda e da direita das equações

$$
A_{1} B_{1} / A B=k_{1} \quad \text { e } \quad A^{\prime} B^{\prime} / A_{1} B_{1}=k_{2}, \quad \text { obtemos } \quad A^{\prime} B^{\prime} / A B=k_{1} k_{2}
$$

Dados os centros $O_{1}$ e $O_{2}$ e os coeficientes $k_{1}$ e $k_{2}$, vamos mostrar como determinar o centro $O$ resultado da composta com coeficiente $k_{1} k_{2}$ (ou, no caso $k_{1} k_{2}=1$, como 


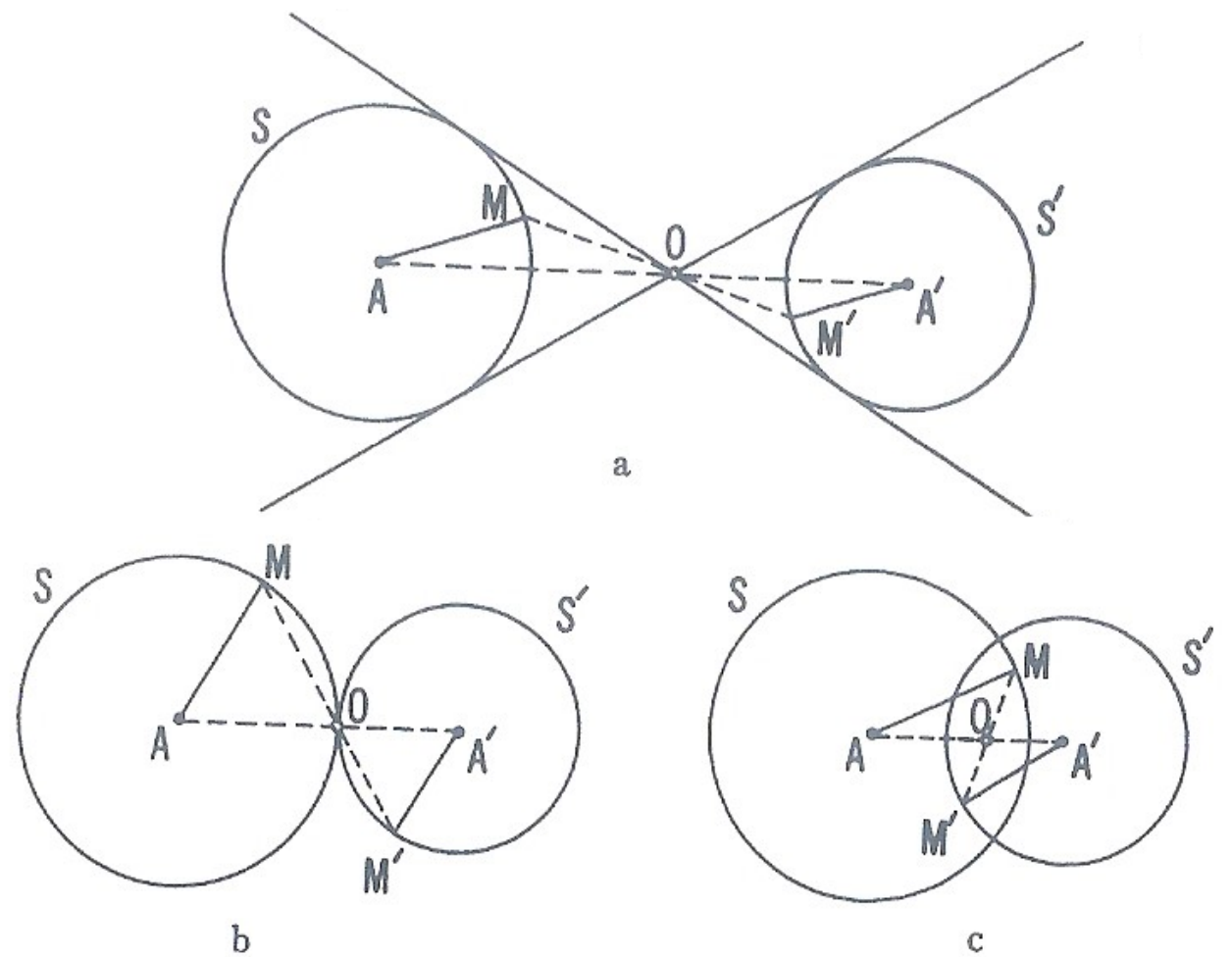

Figura 53: Homotetia em Círculos com $k$ negativo

(YAGLOM, 1962b, p. 14)

determinar o módulo, direção e sentido da translação resultado da composta). Se $O_{1}$ coincide com $\mathrm{O}_{2}$ então coincide com $O$ também (Figura 54c); vamos assumir então que $O_{1}$ e $O_{2}$ não coincidem. A primeira homotetia mantem o centro $O_{1}$ no lugar, enquanto a segunda leva $O_{1}$ ao ponto $O_{1}^{\prime}$ na reta $O_{2} O_{1}$ tal que $O_{2} O_{1}^{\prime} / O_{2} O_{1}=k_{2}$ (Figura 54a,b). Então a composta de duas transformações leva $O_{1}$ em $O_{1}^{\prime}$. Disso segue que, se $k_{1} k_{2}=1$ (Figura 54b), então a composta de duas transformações é uma translação na direção da reta $O_{1} O_{1}^{\prime}$ (isto é, na direção da reta $O_{2} O_{1}$, já que $O_{1}^{\prime}$ esta na reta $O_{1} O_{2}$ ) com distância $a=O_{1} O_{1}^{\prime}$; desde que $O_{2} O_{1}^{\prime} / O_{2} O_{1}=k_{2}$, a também pode ser representado na forma:

$$
a=O_{2} O_{1}^{\prime}-O_{2} O_{1}=\frac{O_{2} O_{1}^{\prime}-O_{2} O_{1}}{O_{2} O_{1}} O_{2} O_{1}=\left(k_{2}-1\right) O_{2} O_{1} .
$$

Se $k_{1} k_{2} \neq 1$ (Figura 54a), então o centro $O$ desejado localiza-se na reta $O_{1} O_{1}^{\prime}$, isto é, na reta $O_{1} O_{2}$, e $O O_{1}^{\prime} / O O_{1}=k_{1} k_{2}$.

Uma expressão mais conveniente para determinar a posição de $O$ pode ser dada pela expressões:

$$
\begin{gathered}
O_{2} O_{1}^{\prime} / O_{2} O_{1}=k_{2} \quad \text { e } O O_{1}^{\prime} / O O_{1}=k_{1} k_{2} \quad \text { segue que } \\
\frac{O_{1} O_{1}^{\prime}}{O_{2} O_{1}}=\frac{O_{2} O_{1}^{\prime}-O_{2} O_{1}}{O_{2} O_{1}}=k_{2}-1 \quad \text { e } \quad \frac{O_{1} O_{1}^{\prime}}{O O_{1}}=\frac{O O_{1}^{\prime}-O O_{1}}{O O_{1}}=k_{1} k_{2}-1
\end{gathered}
$$

Pode-se resumir o que foi exposto e enunciar um importante teorema: 
Teorema 4.5.5. Dos três centros de homotetia: Seja a figura $F_{1}$ a homotetia da figura $F$ com centro $O_{1}$, e também a homotetia da figura $F^{\prime}$ com centro $O_{2}$. Se $O_{1}$ não coincide com $O_{2}$, então a reta $O_{1} O_{2}$ (eixo de homotetia das três figuras $F, F_{1}$ e $F^{\prime}$ ) passa pelo centro de homotetia $O$ das figuras $F$ e $F^{\prime}$ (Figura 54a), ou é paralela à direção da translação que leva $F$ a $F^{\prime}$ (Figura 54b). Se $O_{1}$ coincide com $O_{2}$, então $O_{1}$ é o centro de homotetia para $F$ e também para $F^{\prime}$ (Figura 54c).

No exemplo abaixo, para $j k \neq 1, H(O, k)$ leva o $\triangle A B C$ ao $\triangle A^{\prime} B^{\prime} C^{\prime}$ e $H(Q, j)$ leva o $\triangle A^{\prime} B^{\prime} C^{\prime}$ ao $\triangle A^{\prime \prime} B^{\prime \prime} C^{\prime \prime}$, então $H(P, j k)$ leva o $\triangle A B C$ ao $\triangle A^{\prime \prime} B^{\prime \prime} C^{\prime \prime} ; O, P$ e $Q$ são colineares, a reta $O Q$ é o eixo de homotetia (Figura 55).
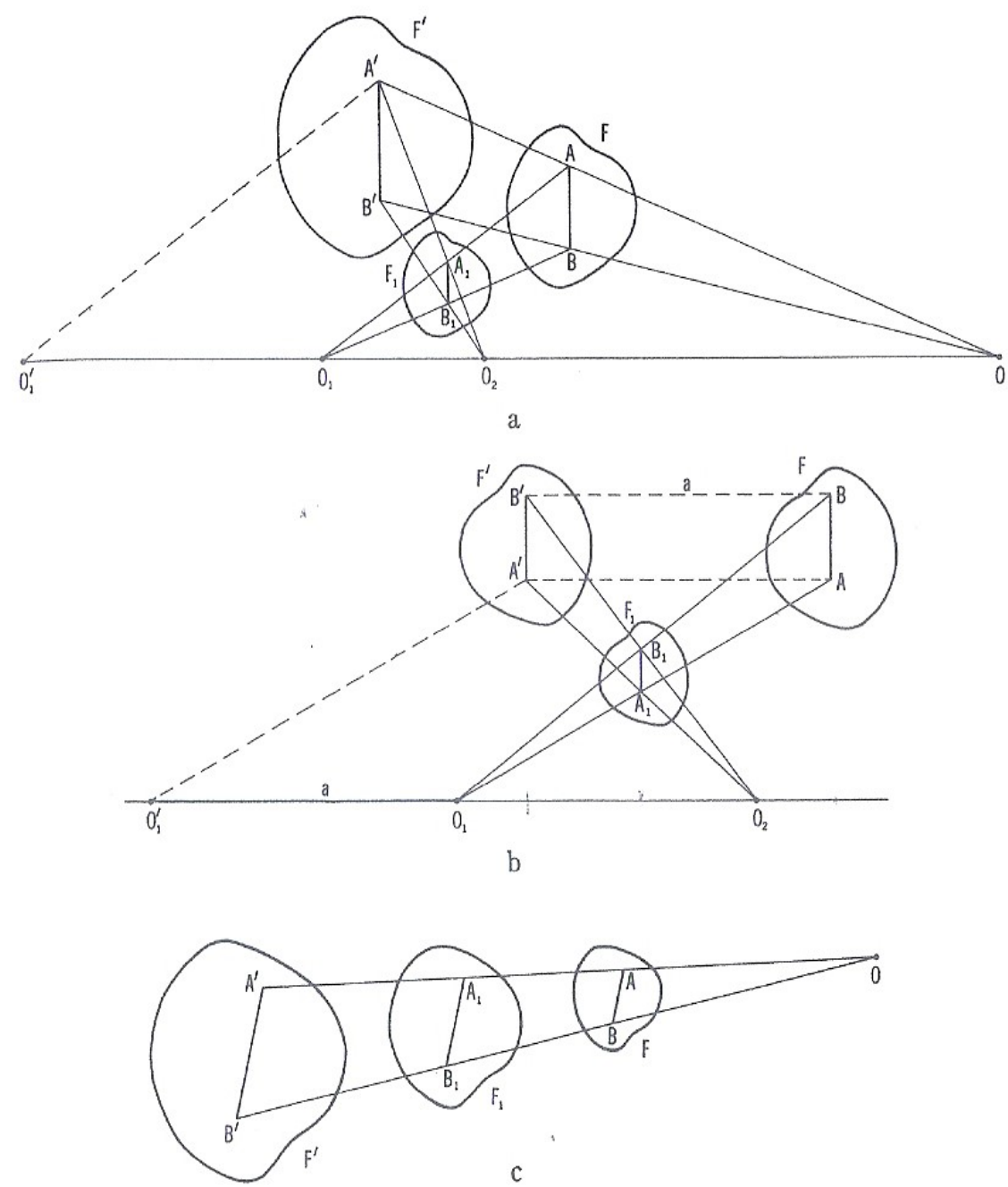

Figura 54: Homotetia-Composição

(YAGLOM, 1962b, p. 27) 


\subsubsection{Roto-Homotetia-"Spiral similarity-Dilative rotation"}

Abordaremos neste item uma combinação de uma homotetia de centro $O$ e uma rotação de mesmo centro $O$ e ângulo $\alpha$ tomado em determinado sentido.

Definição 4.5.2. Uma Roto-Homotetia com centro $O$, ângulo de rotação $\alpha$ e coeficiente de homotetia $k$ é a transformação composta de uma homotetia com centro $O$ e coeficiente de homotetia $k$ e uma rotação em relação ao ponto $O$ através de um ângulo $\alpha$, tomado em quaquer ordem, ou seja: $H(O, k) \circ R_{O, \alpha}=R_{O, \alpha} \circ H(O, k)$.

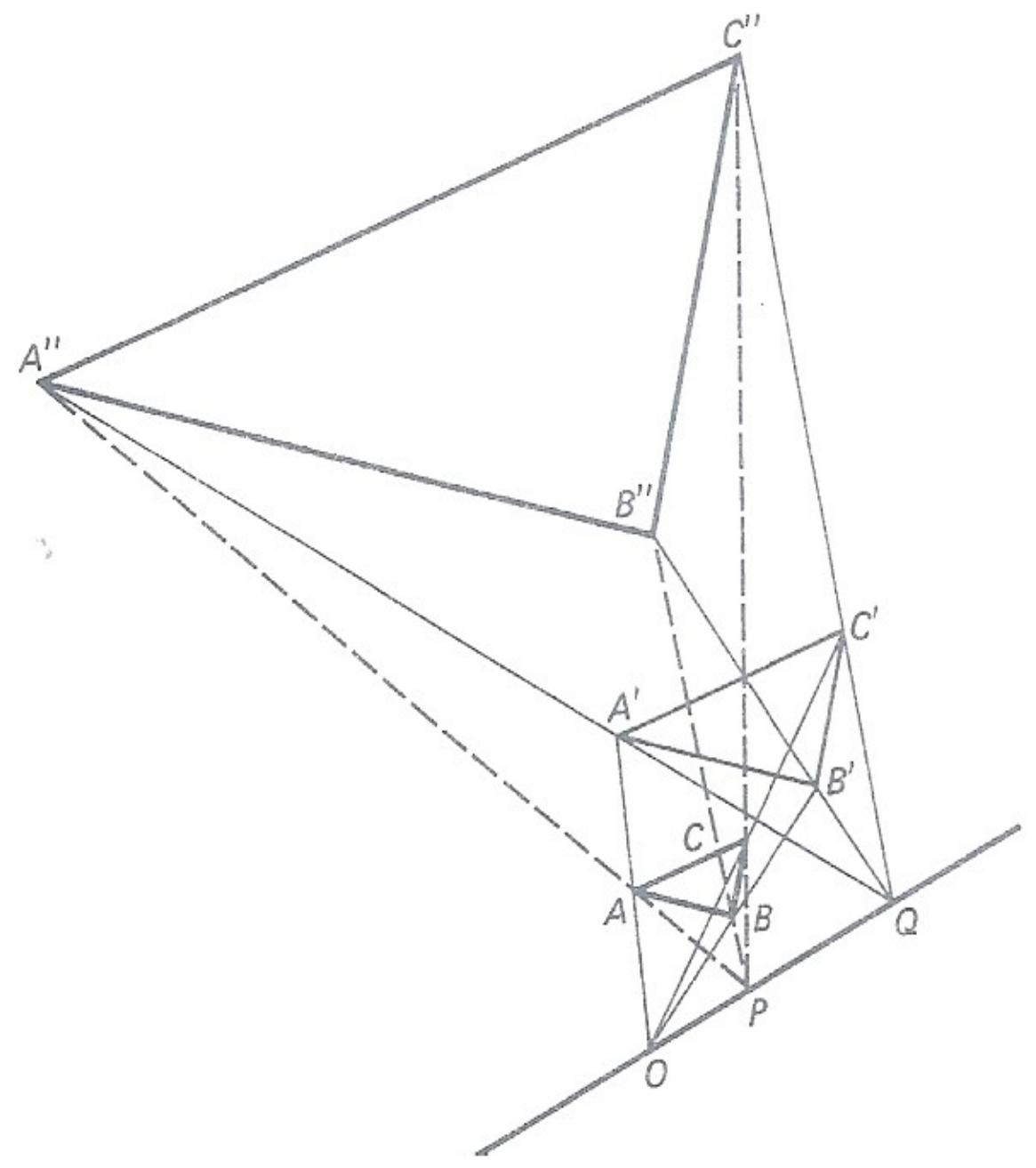

Figura 55: Homotetia-Exemplo de Composição (DODGE, 1972, p. 25)

Seja a figura $F_{1}$ centralmente semelhante à figura $F$ com centro $O$ e coeficiente de homotetia $k>0$. Fazendo uma rotação em $F_{1}$ através de um ângulo $\alpha$ em relação ao ponto $O$ no sentido $\alpha>0$ obtemos a figura $F^{\prime}$ (Figura 56. Também podemos obter $F^{\prime}$ fazendo uma rotação em relação a $O$ de $\alpha$ em $F$ obtendo $F_{2}$ e em seguida uma homotetia 
de centro $O$ e razão $k$ em $F_{2}$, reciprocamente $F$ pode ser obtido de $F^{\prime}$ com o mesmo centro $O$, ângulo de rotação $-\alpha$ e coeficiente de homotetia $1 / k$, então podemos falar em pares de figuras obtidas por roto-homotetia.

Observação 4.5.2. Algumas observações em relação a roto-homotetia:

1. Uma rotação em relação a um ponto é um caso especial de roto-homotetia com coeficiente $k=1$;

2. Uma homotetia também é um caso especial de roto-homotetia com ângulo $\alpha=0^{0}$ se $k>0$, e com $\alpha=180^{0}{ }^{6}$ se $k<0$;

3. Segmentos correspondentes nas figuras $F^{\prime}$ e $F$ tem a mesma razão $k$ e formam entre si o mesmo ângulo $\alpha$.

\subsection{Composição de Roto-Homotetias:}

A composta de duas roto-homotetias com coeficientes de homotetia $k_{1}$ e $k_{2}$ e ângulos de rotação $\alpha_{1}$ e $\alpha_{2}$ é uma nova roto-homotetia com coeficiente de homotetia $k_{1} k_{2}$ e ângulo de rotação $\alpha_{1}+\alpha_{2}$, excluindo dois casos, quando $k_{1} k_{2}=1$ e $\alpha_{1}+\alpha_{2}=360^{0}$ (múltiplo de $\left.360^{\circ}\right)$, neste caso a composta resulta em uma translação.

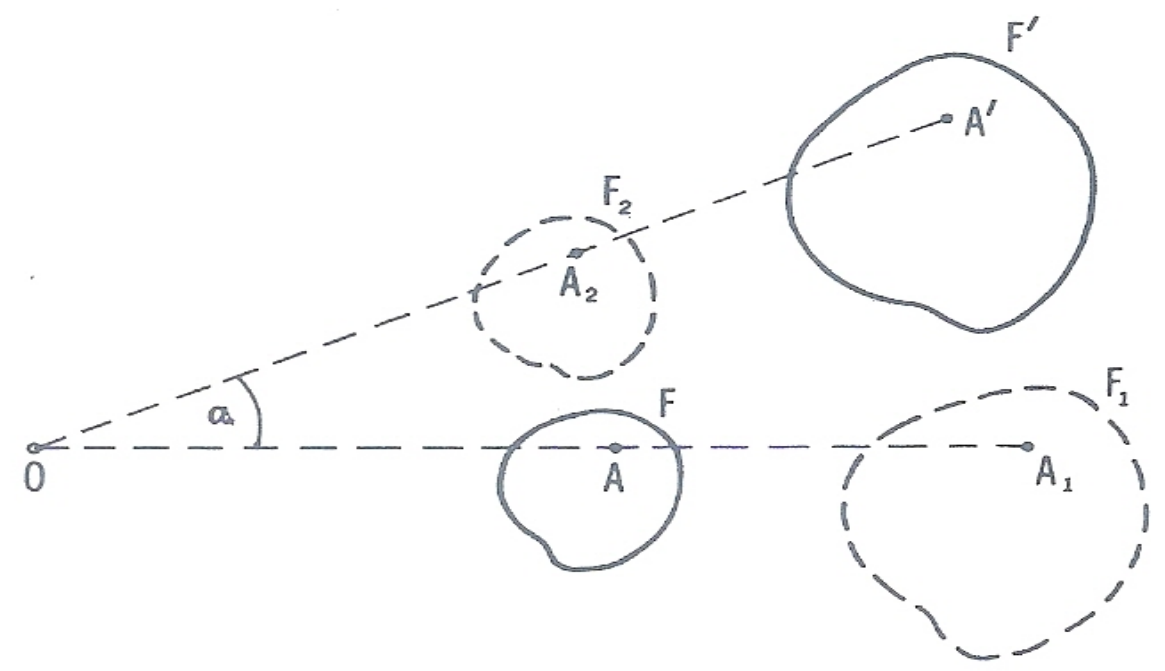

Figura 56: Roto-Homotetia

(YAGLOM, 1962b, p. 36)

Seja a figura $F_{1}$ obtida de $F$ por uma roto-homotetia de centro $O_{1}$ e coeficiente $k_{1}$ e com ângulo de rotação $\alpha_{1}$, e seja $F^{\prime}$ obtida de $F_{1}$ por uma roto-homotetia de centro $O_{2}$ $\overline{6}$ na verdade, múltiplos de $\alpha=0^{0}$, e de $\alpha=180^{\circ}$ respectivamente. 
e coeficiente $k_{2}$ e com ângulo de rotação $\alpha_{2} \cdot{ }^{7}$ Sejam $A B, A_{1} B_{1}$ e $A^{\prime} B^{\prime}$ os correspondentes segmentos correspondentes nas figuras $F, F_{1}$ e $F^{\prime}$ respectivamente (Figura 57. Então $A_{1} B_{1} / A B=k_{1}$, e $A B$ e $A_{1} B_{1}$ formam um ângulo de $\alpha_{1}, A^{\prime} B^{\prime} / A_{1} B_{1}=k_{2}$, e $A_{1} B_{1}$ e $A^{\prime} B^{\prime}$ formam um ângulo de $\alpha_{2}$.

Dessa forma,

$$
\frac{A^{\prime} B^{\prime}}{A B}=\frac{A_{1} B_{1}}{A B} \cdot \frac{A^{\prime} B^{\prime}}{A_{1} B_{1}}=k_{1} k_{2}
$$

e os segmentos $A B$ e $A^{\prime} B^{\prime}$ formam um ângulo de $\alpha_{1}+\alpha_{2}$. Portando, segmentos correspondentes em $F$ e $F^{\prime}$ tem constante de homotetia $k_{1} k_{2}$ e formam um ângulo constante de $\alpha_{1}+\alpha_{2}$, o que significa que a figura $F^{\prime}$ foi obtida de $F$ por meio de uma roto-homotetia de coeficiente $k_{1} k_{2}$ e ângulo de rotação $\alpha_{1}+\alpha_{2}$.

Observação 4.5.3. Definido a roto-homotetia como uma composição de uma homotetia e uma rotação em relação a um mesmo centro, nós naturalmente gostaríamos de saber qual é a composição de uma homotetia e uma rotação cujos centros são distintos, a simples e resposta surpreendente-uma roto-homotetia (spiral similarity)-uma consequência do fato que nenhum tipo de homotetia complicada existe, enunciamos(COXETER; GREITZER, 1967, p. 97):

Teorema 4.5.6. Quaisquer duas figuras semelhantes são relacionadas ou por uma translação ou por uma roto-homotetia.

\footnotetext{
7 lembrando a convenção do sentido de rotação é sempre medido no anti-horário, para $\alpha>0$.
} 


\subsection{Homotetia Especular (Dilative Reflection)}

Chamamos de Homotetia Especular uma composta de uma homotetia de centro $O$ e uma reflexão em relação a uma reta que passa por $O$.

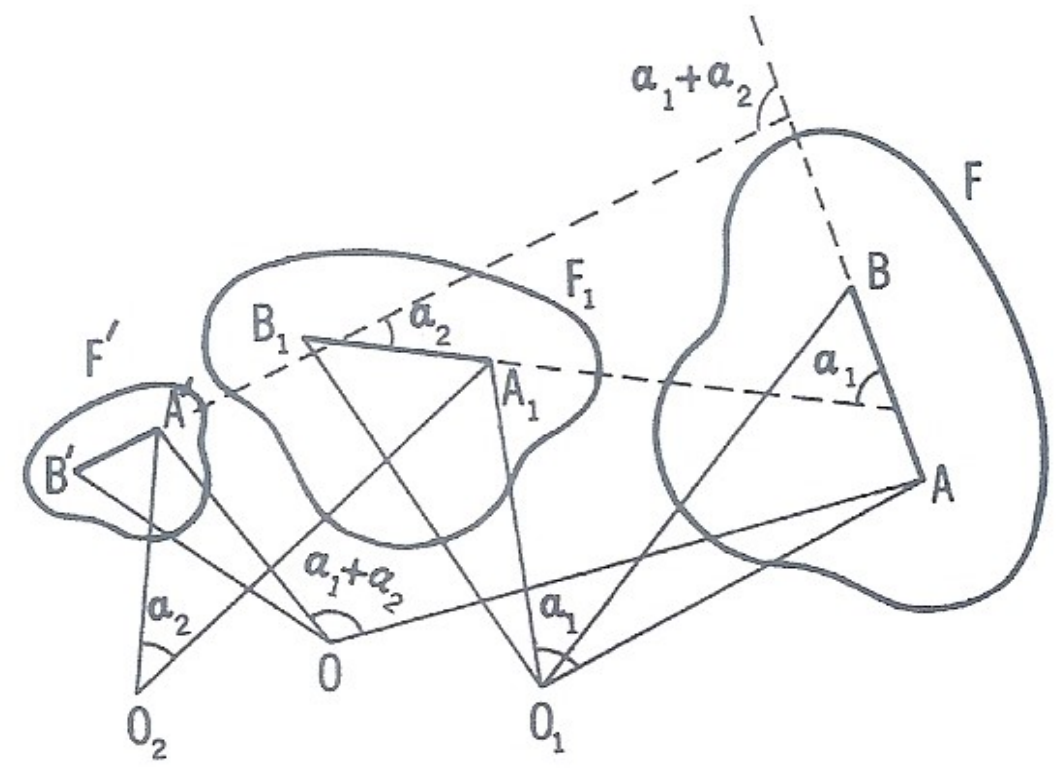

Figura 57: Composta de Roto-Homotetia

(YAGLOM, 1962b, p. 41)

Seja a figura $F_{1}$ homotética à figura $F$ com centro de homotetia em $O$ e coeficiente de homotetia $k$, seja $F^{\prime}$ obtida de $F_{1}$ por reflexão em relação à reta $l$ que passa por $O$ (Figura ??). Neste caso dizemos que $F^{\prime}$ é obtida de $F$ por meio de uma homotetia especular com coeficiente de homotetia $k$; o ponto $O$ e a reta $l$ são chamados centro e eixo da homotetia especular. Da mesma forma podemos obter $F^{\prime}$ fazendo primeiro uma reflexão em relação a $l$ de $F$ obtendo $F_{2}$, e em seguida uma homotetia de centro $O$ e coeficiente $k$ de $F_{2}$.

Da mesma forma que fizemos distinção entre congruência direta e congruência oposta, vistos em 4.4.11, também podemos utilizar os termos semelhança direta, (concorde, equiversa) e semelhança oposta, (discorde, controversa) para a família das homotetias enunciando os seguintes teoremas:

Teorema 4.5.7. Quaisquer duas figuras diretamente semelhantes no plano podem ser feitas coincidir por meio de uma roto-homotetia ou por uma translação.

Teorema 4.5.8. Quaisquer duas figuras opostamente semelhantes no plano podem ser feitas coincidir por meio de uma homotetia especular ou por meio de uma reflexão com deslizamento (reflexão transladada, translação refletida). 



\section{Uso de software dinâmico para o estudo das transformações geométricas}

\subsection{Introdução}

A expressão "Sistema de Geometria Dinâmica (SDG)" é usado neste trabalho como um termo genérico para descrever um certo tipo de software o qual é usado predominantemente para construção, e exploração de propriedades e resolução de problemas em Geometria. Um dos primeiros software desse tipo - o Cabri-géomètre - foi apresentado no "ICME-6, em Budapest, no ano de 1988". Desde então, uma grande variedade de software análogos foram lançados, como GEOLOG, Geometry Inventor, Geometer's Sketchpad, Thales, Cinderella, Régua e Compasso, e mais recentemente o GeoGebra, apenas para dar alguns exemplos. Esses software, em geral, são disponibilizados em diferentes idiomas, e suas versões disponibilizam ferramentas similares, que podem ser usadas por manipulação direta, isto é, não necessitam de comandos específicos em linguagem de programação (STRÄSSER, 2002).

Não há dúvidas que o uso da tecnologia computacional tem mudado fundamentalmente a produção matemática nos últimos 50 anos.De fato, com os avanços tecnológicos, foram abertos novos campos de pesquisa como fractais e teoria do caos, e muitos outros foram ampliados ou "rejuvenescidos".

Em seu artigo intitulado; "Some pitfall of dynamic geometry software", Michael de Villiers (VILLIERS, 2006) afirma que em termos de ensino da Matemática, a disponibilidade de diferentes tipos de software alterou significativamente muitos aspectos do que tem sido visto como "Matemática-tradicional", e questiona se seria ainda relevante passar horas forçando e exercitando os alunos em, por exemplo, fatorar expressões polinomiais, particularmente as complexas, quando há software disponíveis que podem executar essas operações mais rapidamente e de forma mais eficiente? De fato, essa questão é pertinente e deve ser pensada e discutida pelos professores de Matemática dos diferentes níveis de ensino.

Por outro lado, o autor adverte que não basta a introdução de novas tecnologias no ensino, se não forem desenvolvidas novas maneiras de ensinar e, que o uso, por exemplo, de um software de geometria dinâmica, devido a suas especificidades e dinamismo, alterando o estilo de ensinar no ambiente convencional de lousa, papel e lápis, não devendo apenas ser usado como um quadro negro moderno com régua e compasso virtuais.

Assim, para usar novas tecnologias para ensinar Matemática, deve-se aprender a 

estudo das transformações geométricas

usá-la de tal maneira a transformar as atividades matemáticas, capacitando os alunos a fazerem coisas que anteriormente não seria possível de serem implementadas. Isso não quer dizer que as atividades anteriores tornaram-se obsoletas, ou redundantes - talvez algumas sim - mas o importante é criar possibilidades para explorar as potencialidades dessas tecnologias de forma a apoiarem as aprendizagens. Como analisado por vários educadores matemáticos, significa que necessitamos desenvolver novas sequências de ensino, modificando as metodologias de tal maneira que a incorporação de um software no ensino, em particular de geometria dinâmica, possa realmente ser benéfico para os estudantes e acrescentar sobretudo qualidade para as atividades matemáticas da sala de aula (MAN; LEUNG, 2005).

Voltando para os SGD, uma das maiores vantagens do uso da geometria dinâmica é sua precisão, efeito visual e imediata atualização dos dados das figuras produzidas quando manipuladas (em tempo real), o que proporciona observar ou checar muitos casos em pouco espaço de tempo. Entretanto, as provas e demonstrações, o rigor das verificações e os significados permanecem e, não devem ser substituídos pela apresentação visual e colorida das imagens construídas. Com isso, software de geometria dinâmica torna-se uma ferramenta muito útil como procuraremos discutir nos tópicos que seguem.

\subsection{Sobre o GeoGebra}

O software GeoGebra (Software System for Dynamic Geometry and Algebra in the Plan) foi originado no projeto da dissertação de mestrado (master' thesis) de Markus Hohenwarter na Universidade de Salzburg em 2002. Foi projetado para combinar características de software de geometria dinâmica (como o Cabri-géomètre, Geometer's Sketchpad, por exemplo) e um sistema de álgebra por computador ${ }^{1}$ (por exemplo, Derive, Maple) em um sistema simples, integrado e fácil de usar para ensino e aprendizagem da Matemática. Durante os últimos anos, o GeoGebra foi desenvolvido em código aberto, por um grupo de 15 desenvolvedores e mais de 100 tradutores por todo o mundo. Ele está disponível em mais de 52 idiomas. O desenvolvimento da comunidade internacional foi catalizada por um website para o GeoGebra (<http://geogebra.org >). Neste site, além de poder baixar as versões do Geogebra, pode-se também encontrar diversos materiais e recursos digitais, além de ajudas e acesso ao fórum e informações sobre eventos ligados ao Geogebra.

Com o GeoGebra, é possível criar páginas interativas na web com applets agregados - também chamadas páginas dinâmicas de trabalho - as quais podem ser acessadas com qualquer navegador de Internet que suporta o Java. Essas páginas de trabalho são

1 possui um sistema "CAS" (Computer Algebra System) simples, o qual tem a propriedade de lidar com variáveis para números, vetores e pontos, e oferece alguns comandos poderosos, desde inclinação de retas a diferenciação e integração de funções, além de determinar as raízes, máximos e mínimos de funções. 
totalmente independentes do próprio programa, isto é, o software GeoGebra não precisa estar instalado para o uso da página. Portanto, GeoGebra é também uma ferramenta útil para se criar conteúdos para auto aprendizagem (e-learning), e os chamados Objetos de Aprendizagem (OA). Esses objetos de aprendizagem e ambientes de demonstração são distribuídos livremente e compartilhados por educadores matemáticos e professores em plataformas colaborativas online, como o "GeoGebraWiki" (<www.geogebra.org/wiki >) ou ainda o "GeoGebraTube!" (<https://www.geogebratube.org/>), onde já se conta com mais de 100.000 materiais, número que está sempre sendo atualizado.

A característica mais importante do GeoGebra é a conexão que faz entre Geometria, Álgebra, Cálculo e Estatística. No GeoGebra construções dinâmicas podem ser feitas com o uso do mouse como em outros sistemas de geometria dinâmica, essas construções podem ser alteradas dinamicamente arrastando pontos livres ou elementos de base (dragging). Além disso, é possível entrar com as coordenadas dos pontos ou vetores, equações das retas, seções cônicas ou funções, números e ângulos diretamente.

\subsection{Transformações Geométricas como ferramenta de construção no GeoGebra}

As ferramentas disponíveis no GeoGebra na figura 60, cuja versão utilizada é a 4.4.43.0, apresenta as opções de utilização das transformações geométricas. ${ }^{2}$.

Há a opção de se trabalhar com a tela toda para a Geometria, e nesta, com um sistema de eixos cartesianos e malha quadriculada, ou com ambos. Pode-se também optar em ter a janela de Álgebra aberta ou não, bem como a janela da planilha. A escolha dessas opções vai depender das atividades que serão criadas. A janela apenas para a Geometria proporciona uma área maior de trabalho, por outro lado, com a janela de Álgebra aberta é possível a visualização de todos os valores atribuídos aos objetos matemáticos, bem como as respectivas equações, quando for o caso, e tem-se a opção de alterar diretamente os valores, bem como outras propriedades do objeto, como nome, cor, tamanho, entre outras.

As opções elencadas acima são efetuadas na barra lateral à direita da tela de trabalho, bem como em "Exibir", na barra horizontal superior. Observamos que não é objeto desse trabalho apresentar em detalhes cada uma das ferramentas do GeoGebra, apenas as necessárias para o desenvolvimento do noso estudo.

Vamos utilizar o menu das "Ferramentas de Construção"; vide figura 59, como referência para a construção e manipulação dos objetos no GeoGebra (Vide no Apêndice B da página 229 na seção B.2 uma tabela com o menu completo das ferramentas do

2 Observação: Todas as figuras apresentadas nesse trabalho foram feitas no GeoGebra, algumas foram digitalizadas de livros, com as respectivas referências à fonte 


\section{GeoGebra).}

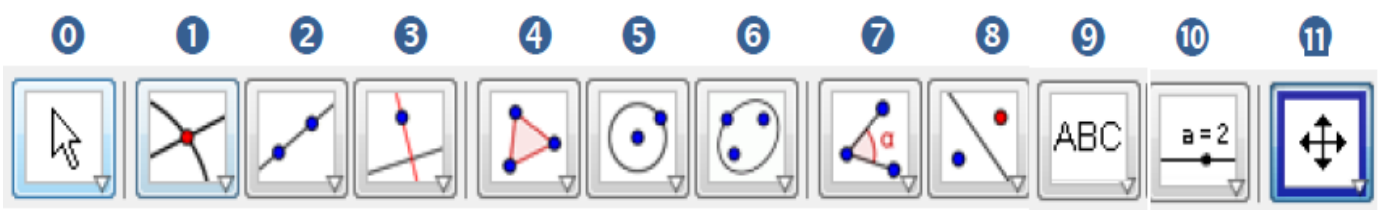

Figura 59: Ferramentas de Construção

Dentre as ferramentas disponibilizadas em cada menu, nota-se que aparecem as de transformações geométricas, em particular: Reflexão em Relação a uma Reta, Reflexão em Relação a um Ponto, Inversão, Rotação em Torno de um ponto, Translação por um vetor e Homotetia (conforme figura 60. Vamos ilustrar como cada ferramenta de transformação pode ser utilizada, indicando como são caracterizadas no GeoGebra e destacando algumas possibilidades para a elaboração das atividades da sequência didática que será proposta.

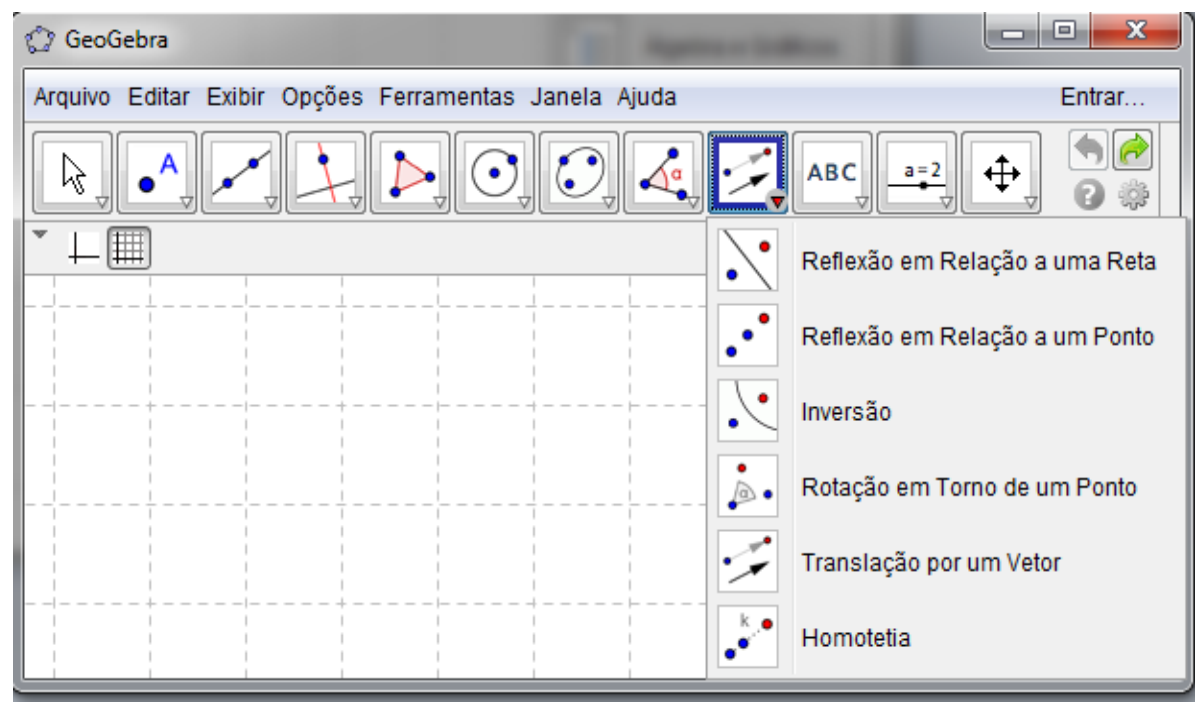

Figura 60: Tela do GeoGebra e opções para Transformações Geométricas

\subsubsection{1. Translação no Geogebra}

A ferramenta "Translação por um vetor" do Geogebra permite obter a imagem de qualquer figura por translação. Como o próprio nome indica, para ser usada, necessita como argumento (objeto de entrada) de um vetor, para indicar a direção, sentido e módulo da translação.

Qualquer figura geométrica pode ser o objeto para a exemplificação, vamos optar por uma figura simples, por exemplo um polígono . 
1. Ao abrirmos o GeoGebra selecionamos "Geometria", na barra lateral direita, conforme figura 61 abaixo.

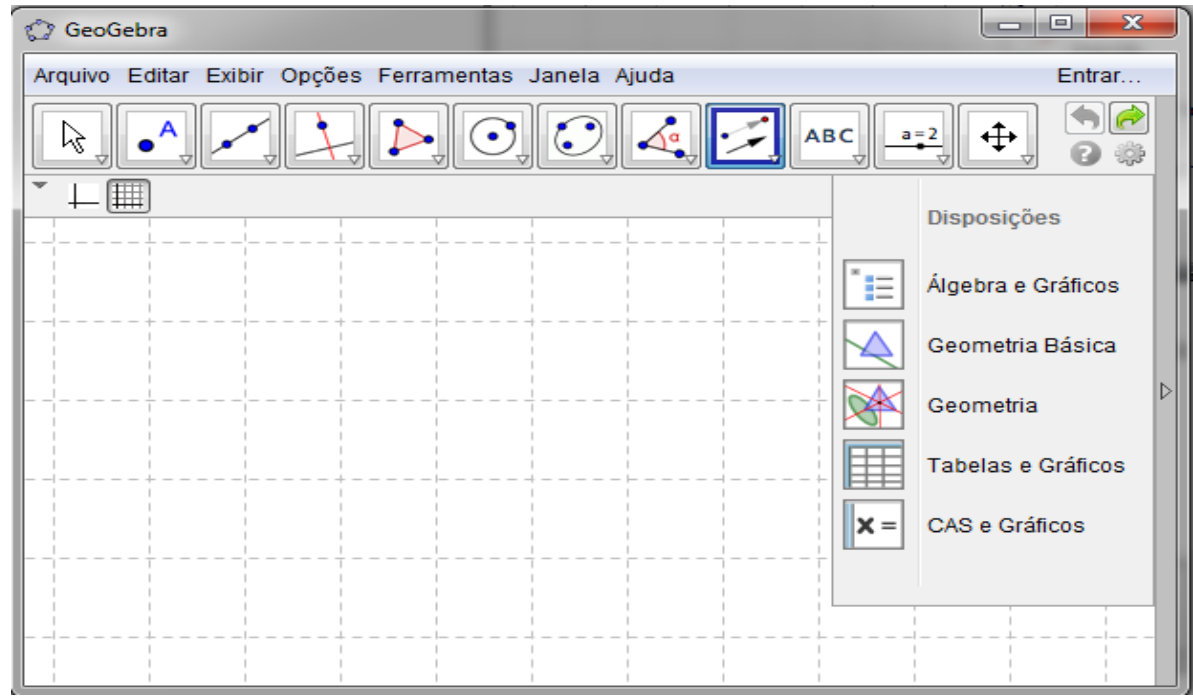

Figura 61: Geometria no GeoGebra

2. Vamos construir uma figura, por exemplo um polígono $A B C D E$, utilizar um vetor $\vec{u}$. O resultado final está representado no quadro abaixo, e enunciaremos um "passoa-passo" para a construção e manipulação da respectiva figura (vide Quadro 5.3.0.5 abaixo).

3. Vamos utilizar as "Ferramentas de Construção"; vide figura 59 e com todas as opções de ferramentas em B.2, como referência para a construção e manipulação dos objetos no GeoGebra. 


\subsubsection{Passo-a-passo para a Translação - Quadro 5.3.0.5}

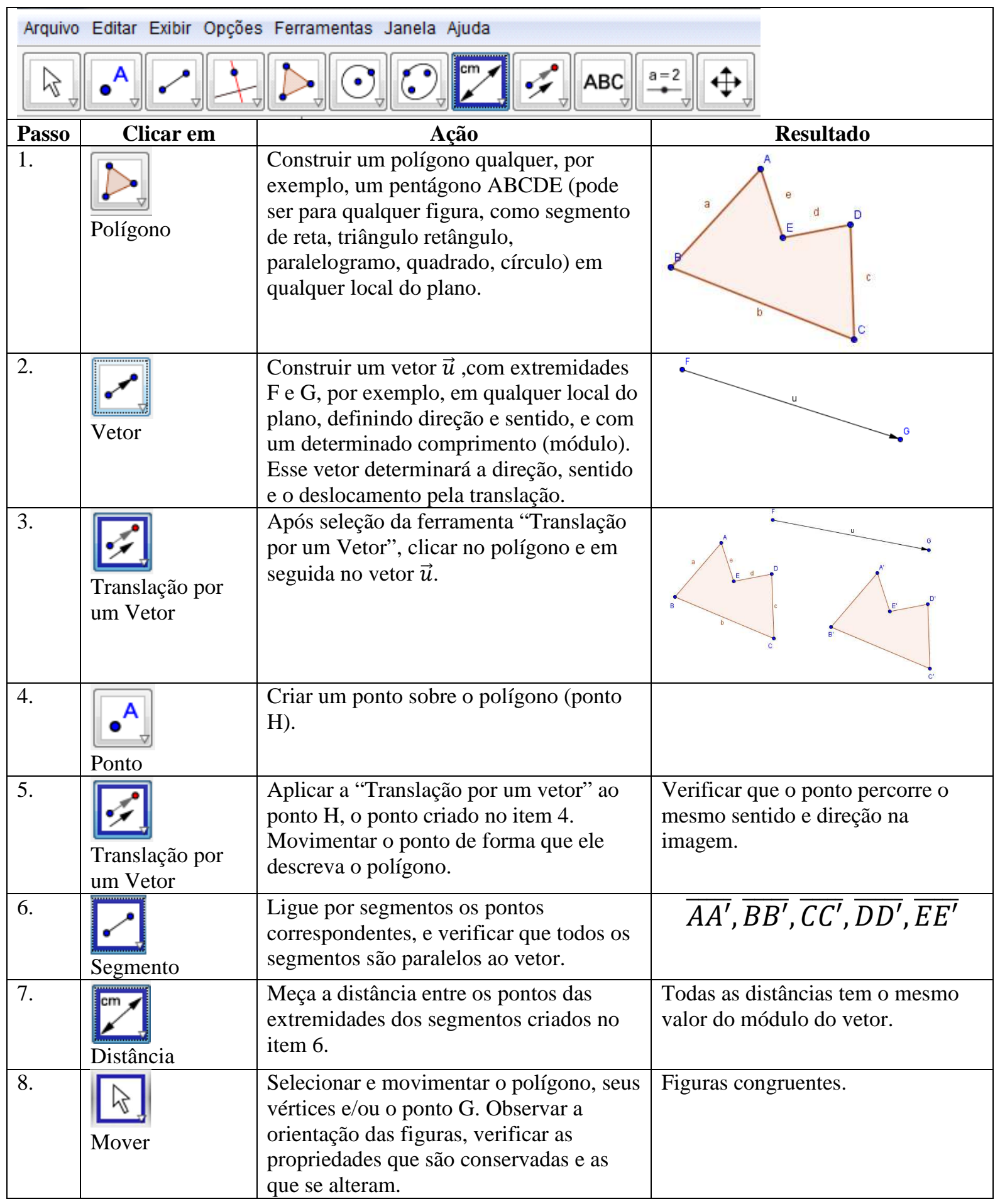


Um resultado possível, com todas as passagens do passo-a-passo pode ser exemplificada pela figura 62. Outras ferramentas do GeoGebra podem ser implementadas para aperfeiçoar a figura 62, como a aparência, nomes, cor, transparência, utilizando as propriedades de cada objeto, assim como colocar controle deslizante (slider) para variações de comprimentos de segmentos, vetores, ângulos, porém não é o objetivo desse estudo, e sim exemplificar o uso das ferramentas para as transformações geométricas.

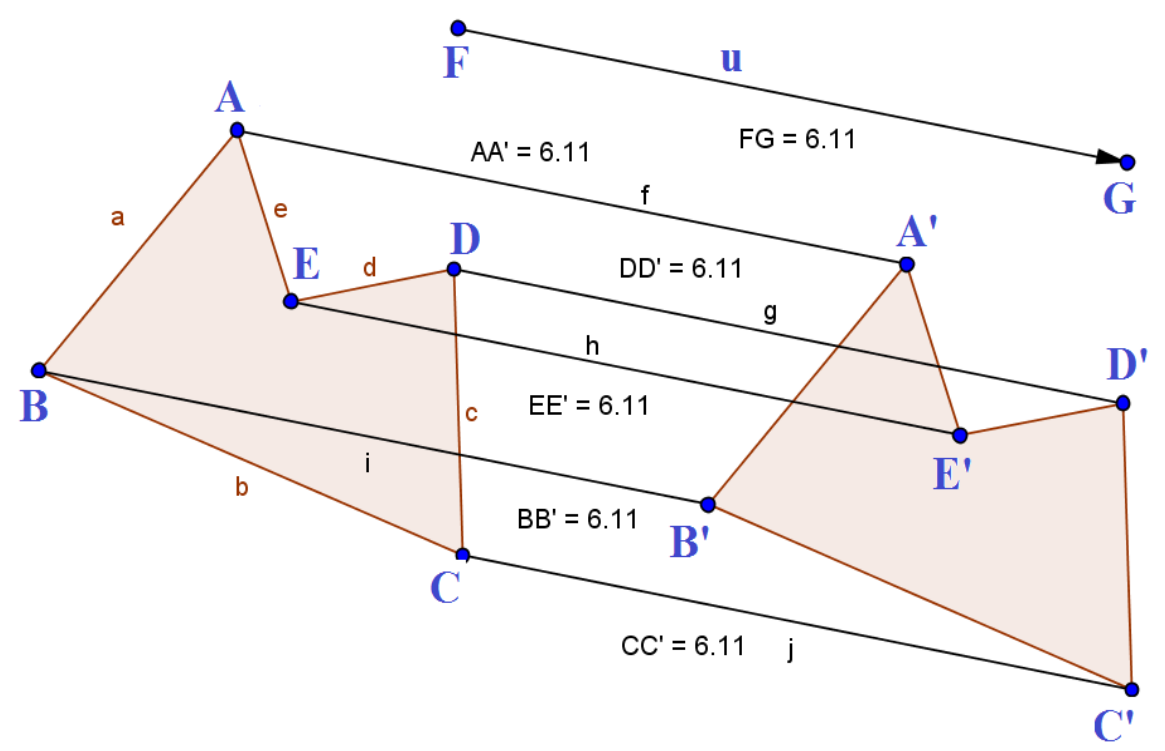

Figura 62: Translação

\subsubsection{2. Reflexão em torno de um ponto - (Half Turn)}

Como visto em 4.4.5, a implementação dessa transformação geométrica no GeoGebra, também chamada de Simetria Central, é muito simples, basta construir um objeto geométrico qualquer, construir um ponto e uma localização no plano como a referência (centro) da reflexão e utilizar a ferramenta Reflexão em Relação a um Ponto na barra de ferramentas do GeoGebra. Da mesma forma que fizemos para a translação, vamos colocar em uma tabela o "passo-a-passo para construção da "Reflexão em Torno de um Ponto" (vide Quadro 5.3.0.7). 


\subsubsection{Passo-a-passo para a Reflexão em Torno de um Ponto - Quadro 5.3.0.7}

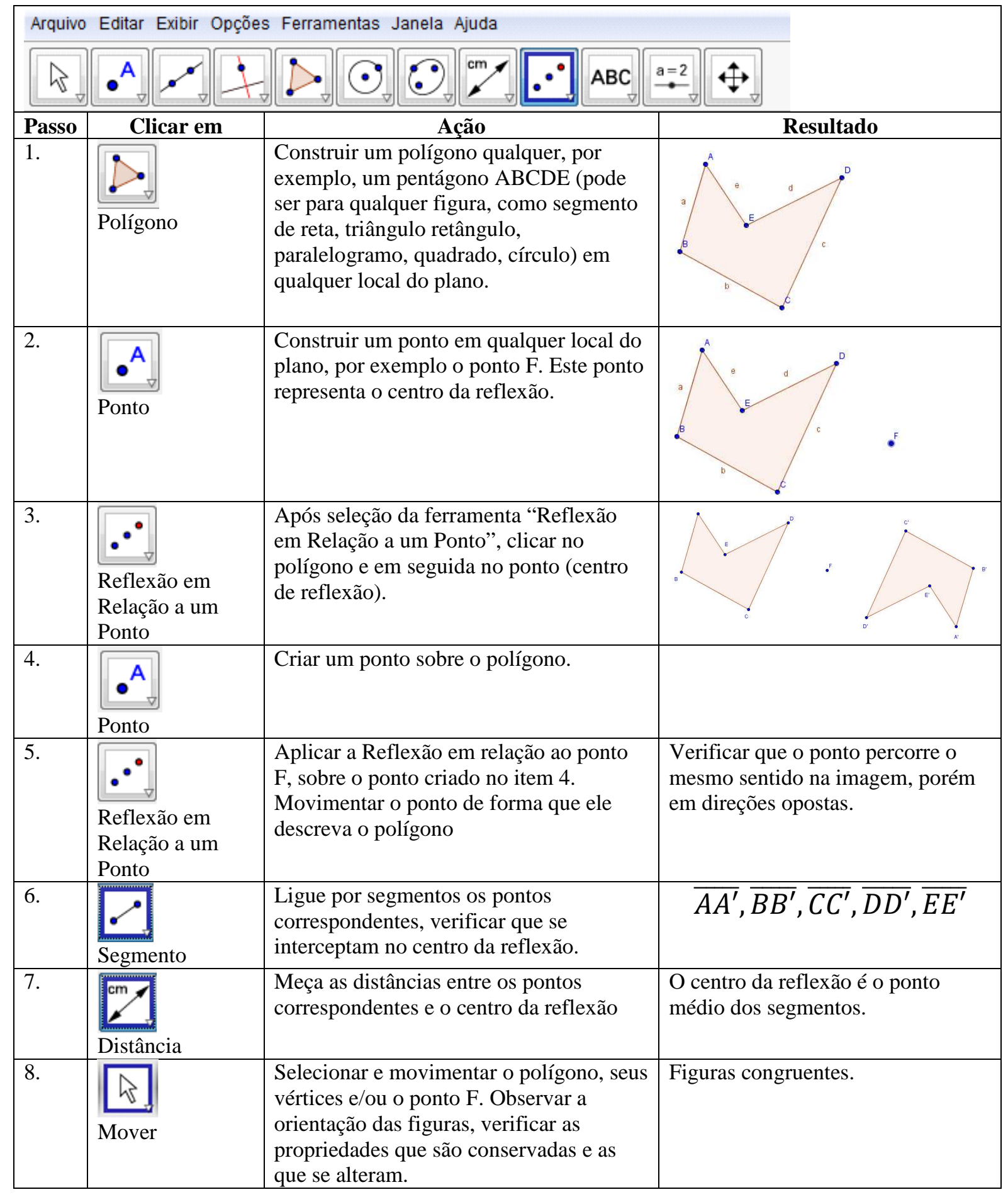


Da mesma forma, um resultado possível, com todas as passagens do passo-a-passo pode ser exemplificada pela figura 63 , alteramos nesse caso, o ponto centro da reflexão, de $F$ para $O$, geralmente o nome utilizado na literatura.

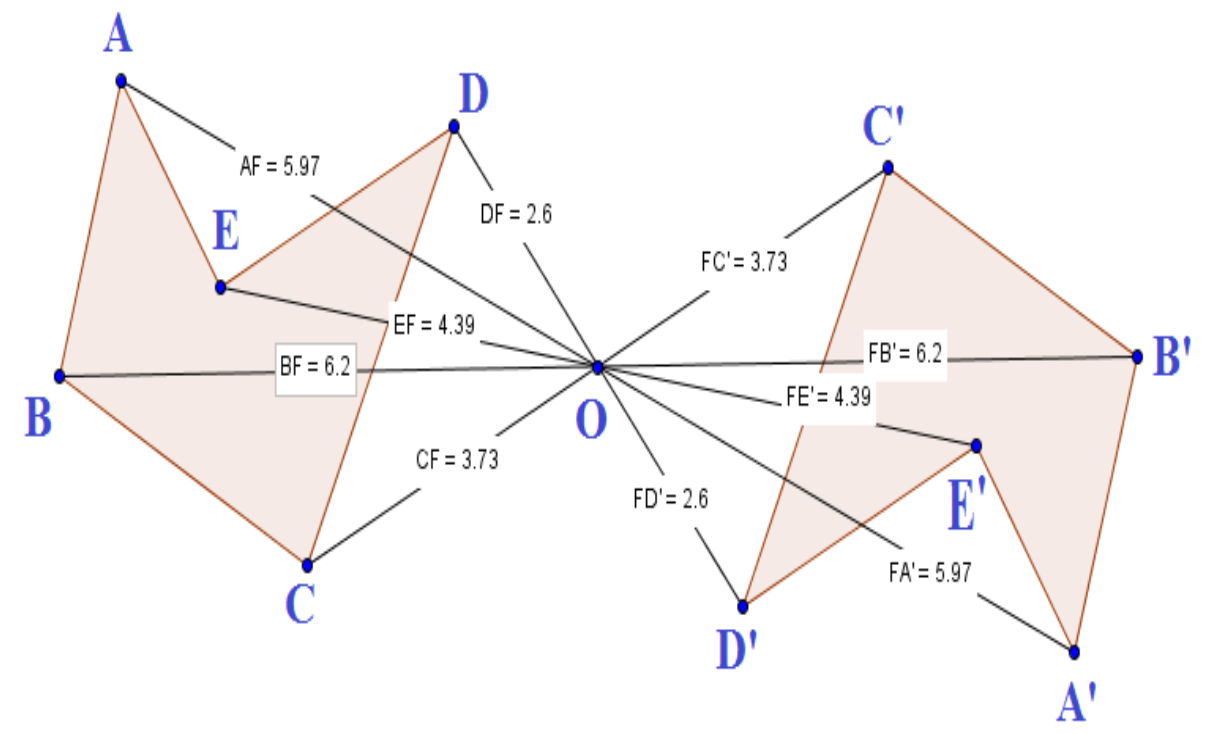

Figura 63: Reflexão em Torno de um Ponto

\subsubsection{3. Rotação em Torno de um Ponto}

Em 4.4.7 vimos que fazemos a rotação em torno de um ponto $O$ definindo um ângulo, e convencionamos o sentido anti-horário como o sentido de rotação positivo. Vamos construir os objetos seguindo o passo-a-passo do Quadro 5.3.0.9. 


\subsubsection{Passo-a-passo para a Rotação em Torno de um Ponto - Quadro 5.3.0.9}

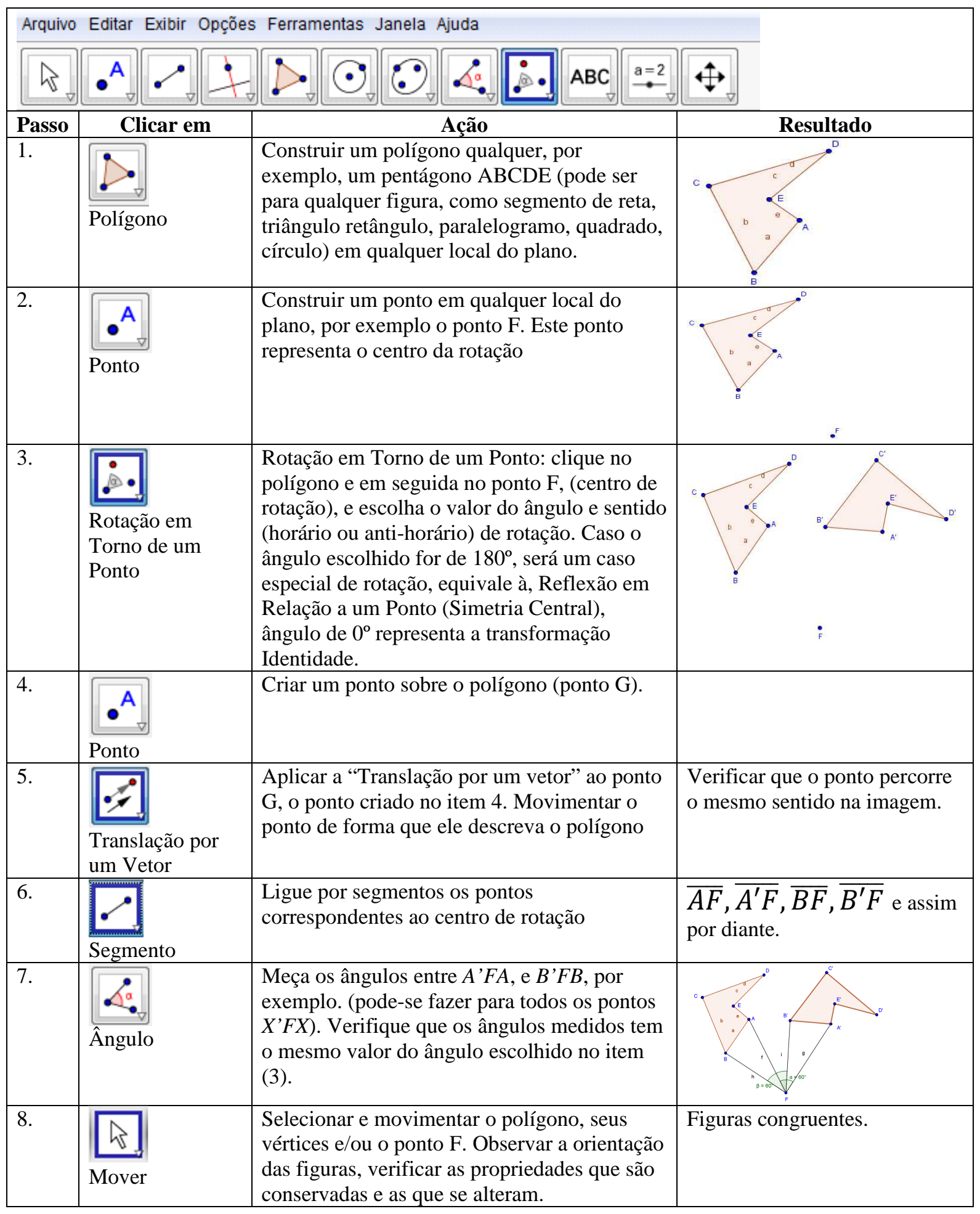


Pode-se implementar outros recursos para efeturarmos a variação do ângulo de rotação por meio de um controle deslizante (slider), um exemplo criado com essa ferramenta pode ser visualizada na figura 64 abaixo.

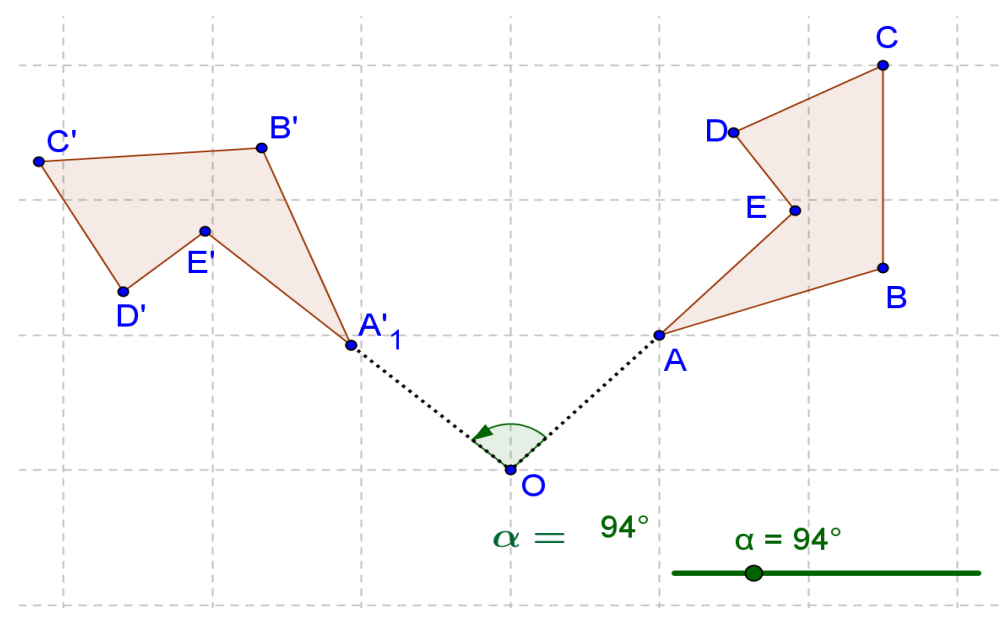

Figura 64: Rotação em Torno de um Ponto

\subsubsection{4. Reflexão em Relação a uma Reta-(Simetria)}

A maioria dos autores trata dessa isometria apenas por "Reflexão" ou simplesmente "Simetria", ou também Simetria Axial, e quando o fizermos neste trabalho daremos a mesma interpretação. Das isometrias, a "Reflexão em Relação a uma Reta" é considerada a mais importante, como vimos no Teorema 4.4.5, ou seja, "Cada isometria é um produto de pelo menos três reflexões", isto significa que podemos obter Translação, Reflexão em Torno de um Ponto, Rotação e, Reflexão com Deslizamento, como combinação de Reflexões. Outra denominação para Reflexão que encontramos é "Mirror", em inglês, cuja tradução literal; Espelho, por usarmos as características físicas da reflexão do espelho.

Muitas obras foram escritas, e muitas ainda serão, tratando da Simetria, que esta presente nas mais diversas áreas do conhecimento, como: Obras de Arte, Arquitetura, Arqueologia, Biologia, Botânica, Química, Física, Matemática, Letras, e muitas outras. $\mathrm{Na}$ natureza são inúmeros os exemplos onde a Simetria está presente e, um dos objetivos quando são analisados estes objetos é determinar eixos de simetria que o caracterizam.

O quadro 5.3.0.11 vai nos orientar a implementar a reflexão em relação a uma reta utilizando as ferramentas do GeoGebra, lembrando que no apêndice B, seção B.2. 


\subsubsection{Passo-a-passo para a Reflexão em Relação a uma Reta - Quadro 5.3.0.11}

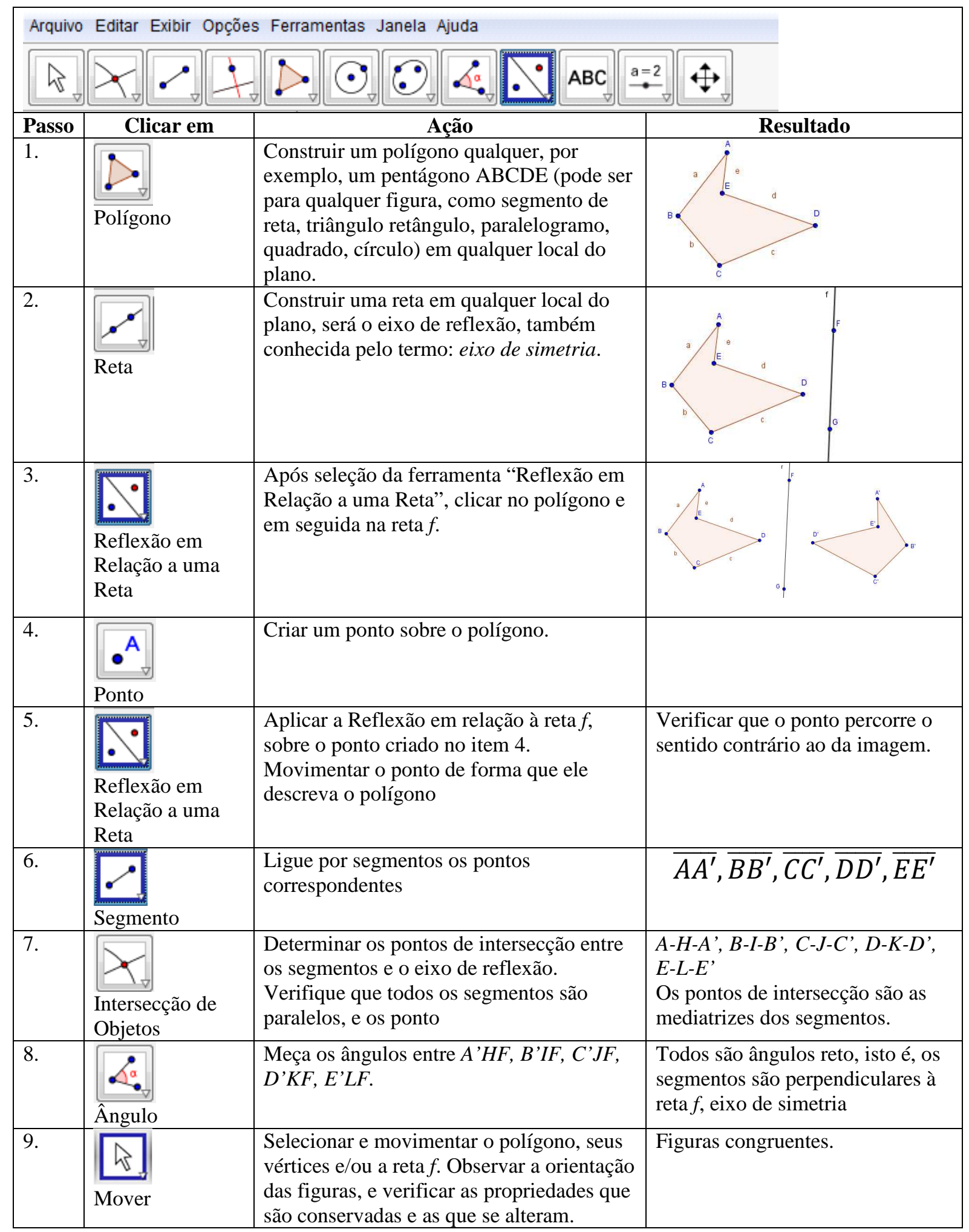


Assim como fizemos para os casos anteriores, abaixo colocamos a figura 65 resultado da sequência de passos efetuados do quadro 5.3.0.11, fizemos algumas alterações nos rótulos (nomes) de alguns objetos, e escondendo alguns. As propriedades que devem ser ressaltadas são: o perpendicularismo entre os segmentos (dos pontos correspondentes), e a reta $r$, eixo de simetria, e os pontos de intersecção dos segmentos com o eixo de simetria são os pontos médios dos segmentos, e com a ferramenta "distância" do GeoGebra medimos alguns segmentos.

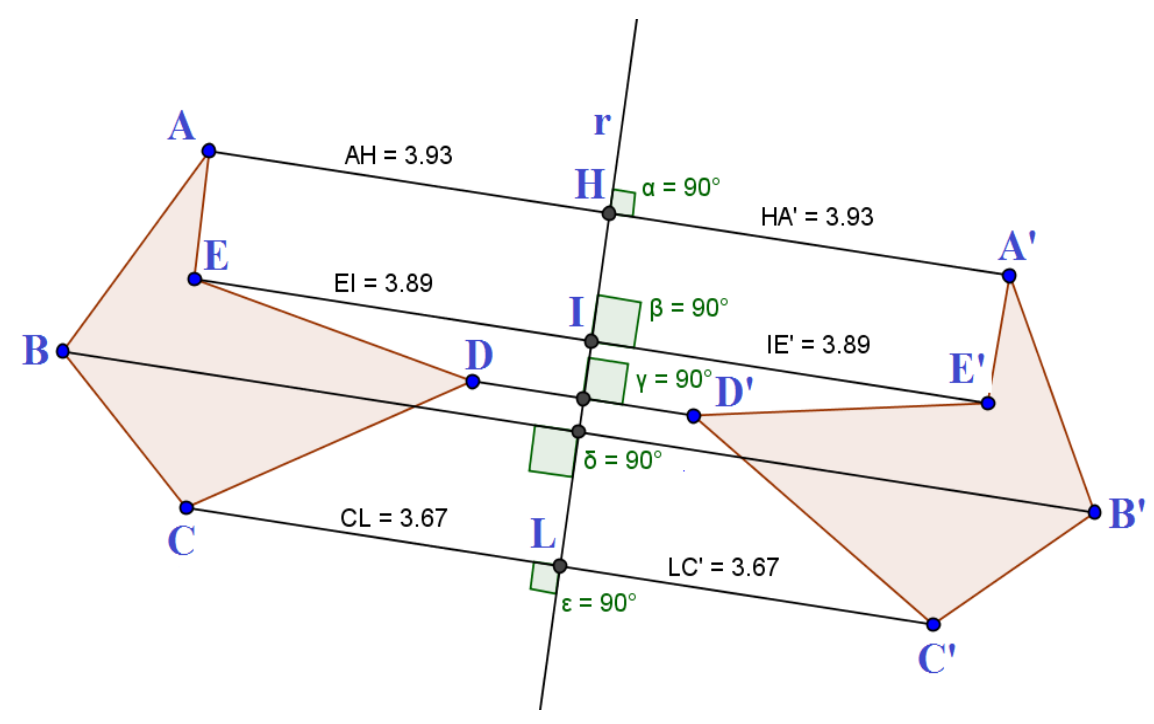

Figura 65: Reflexão em Relação a uma Reta

Apenas para ilustrar, vamos utilizar uma figura de um arquivo para exemplificarmos a utilização da ferramenta Reflexão em Relação a uma Reta no GeoGebra, aproveitaremos para aplicar as ferramentas de construção para Redimensionar, Distorcer e, Refletir a imagem importada, bem como trabalharmos nas propriedades dos objetos definindo cores, transparências, alterando rótulos, e opções de exibir ou não alguns objetos. Para esse caso, vamos seguir um outro passo-a-passo, do quadro 5.3.0.12 para implementarmos a figura, apresentada ao final desse quadro em referência. 
5.3.0.12 Passo-a-passo para a Reflexão em Relação a uma Reta com figura - Quadro 5.3.0.12

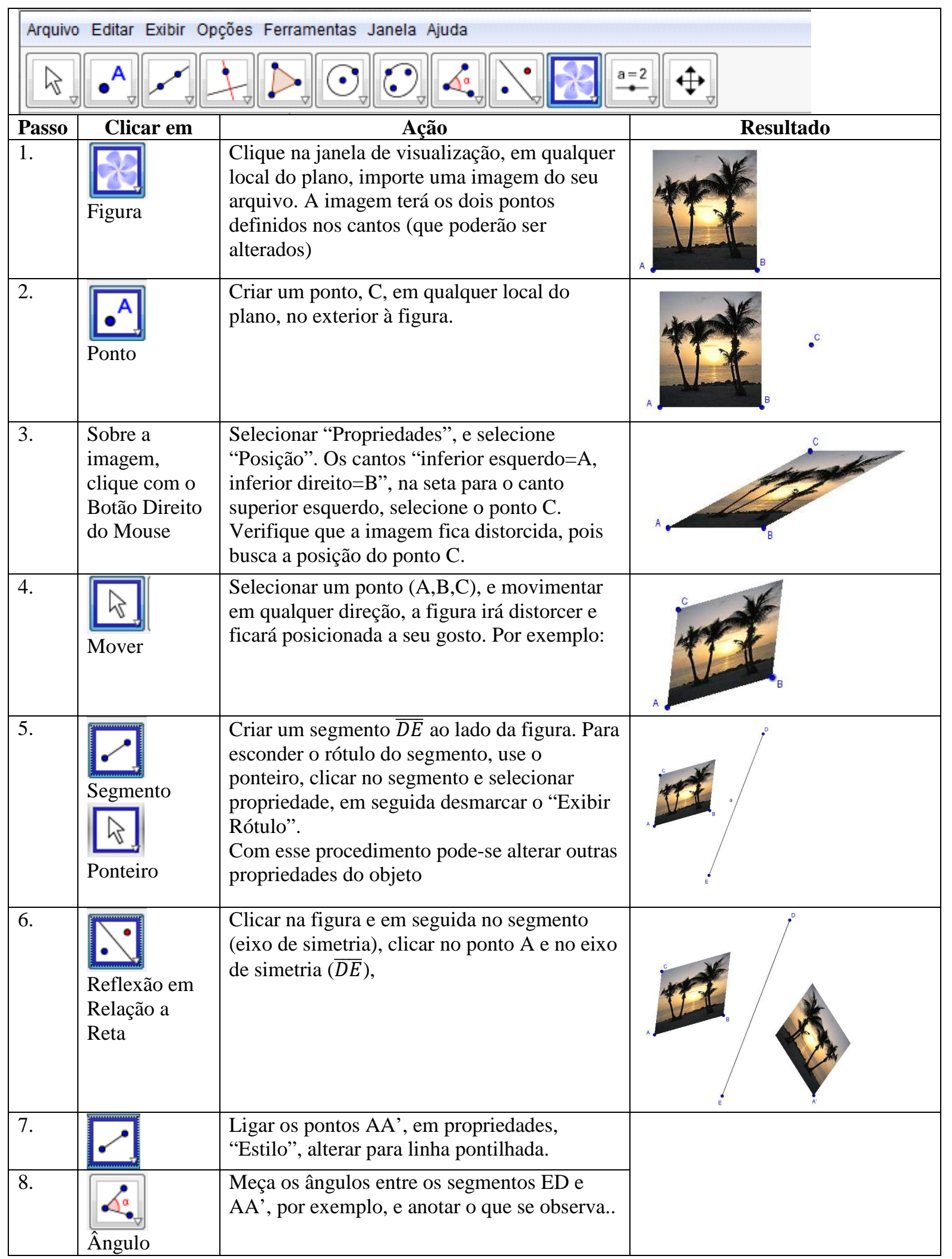




\begin{tabular}{|l|l|l|}
\hline 9. & $\begin{array}{l}\text { Selecionar e movimentar o polígono, seus } \\
\text { vértices e/ou a reta } f \text {. Observar a orientação } \\
\text { das figuras, verificar e anotar as propriedades } \\
\text { que são conservadas e as que se alteram. }\end{array}$ \\
\hline 10. & $\begin{array}{l}\text { Selecionar a figura imagem, com o botão } \\
\text { direito do mouse, clicar em "Propriedades", } \\
\text { Selecionar "Cor" e reduza a "Transparência", } \\
\text { por exemplo 70\%, apenas para diferenciar a } \\
\text { figura original e sua imagem. }\end{array}$ \\
\hline Mover
\end{tabular}

Abaixo a figura resultado do item (10) ampliada para melhor visualizar os detalhes.

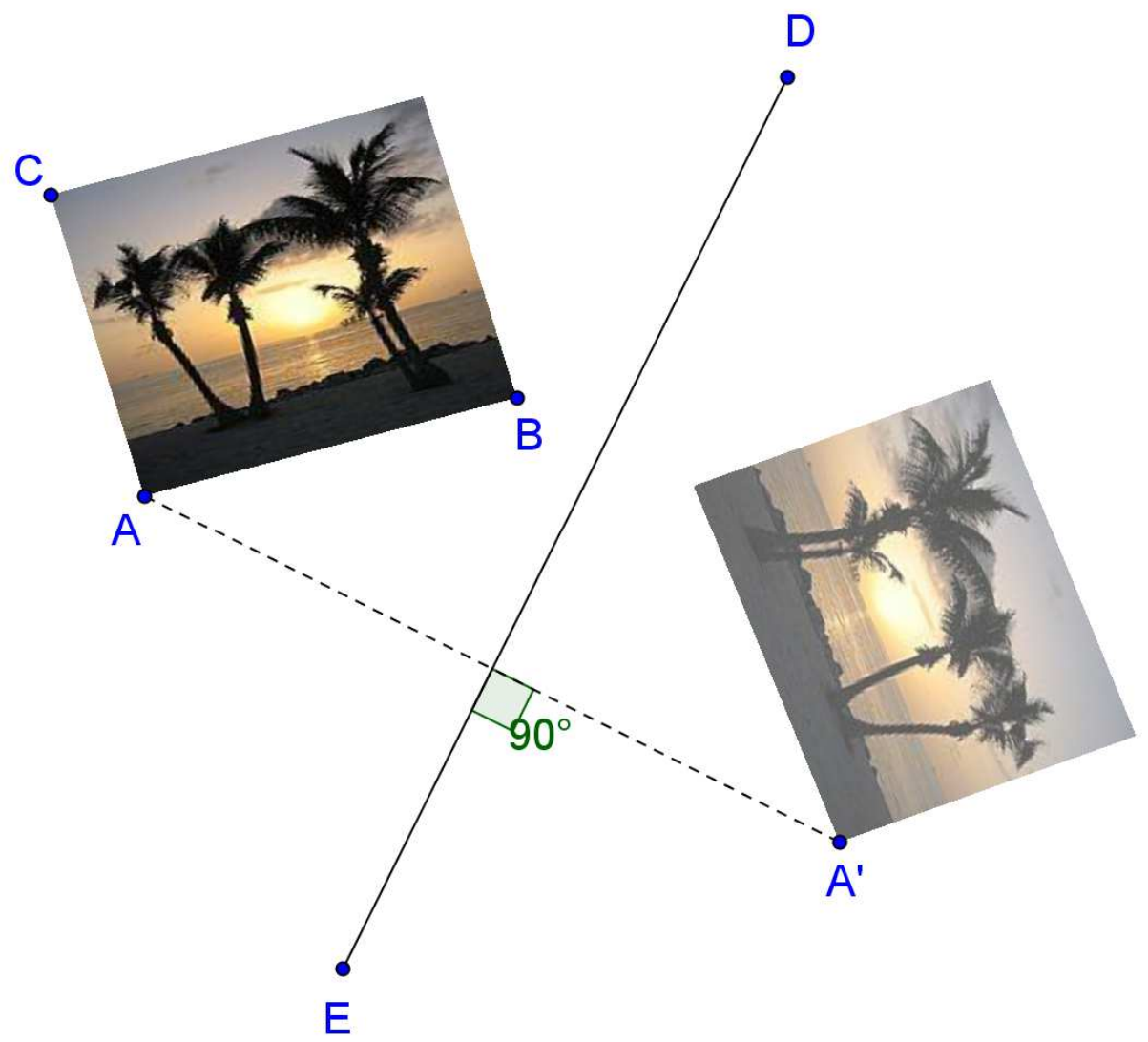




\subsubsection{5. Homotetia de razão $k$}

Como vimos na definição de homotetia em 4.5.1, a implementação no GeoGebra é muito simples, basta construirmos um objeto qualquer, como por exemplo um ponto, uma figura geométrica (polígono, círculo), uma foto, e marcarmos um ponto qualquer do plano, em seguida, basta clicarmos na barra do menu de ferramentas (opção 8 em B.1) do apêndice B e selecionarmos "Homotetia", com isso basta clicarmos no objeto construído, em seguida no ponto criado anteriormente, que será o centro da homotetia, e escolhermos um valor qualquer para $k$. (vide figura 66)

Vamos seguir o passo-a-passo do Quadro 5.3.0.14. 


\subsection{Transformações Geométricas}

como ferramenta de construção no GeoGebra

5.3.0.14 Passo-a-passo para a Homotetia- Quadro 5.3.0.14

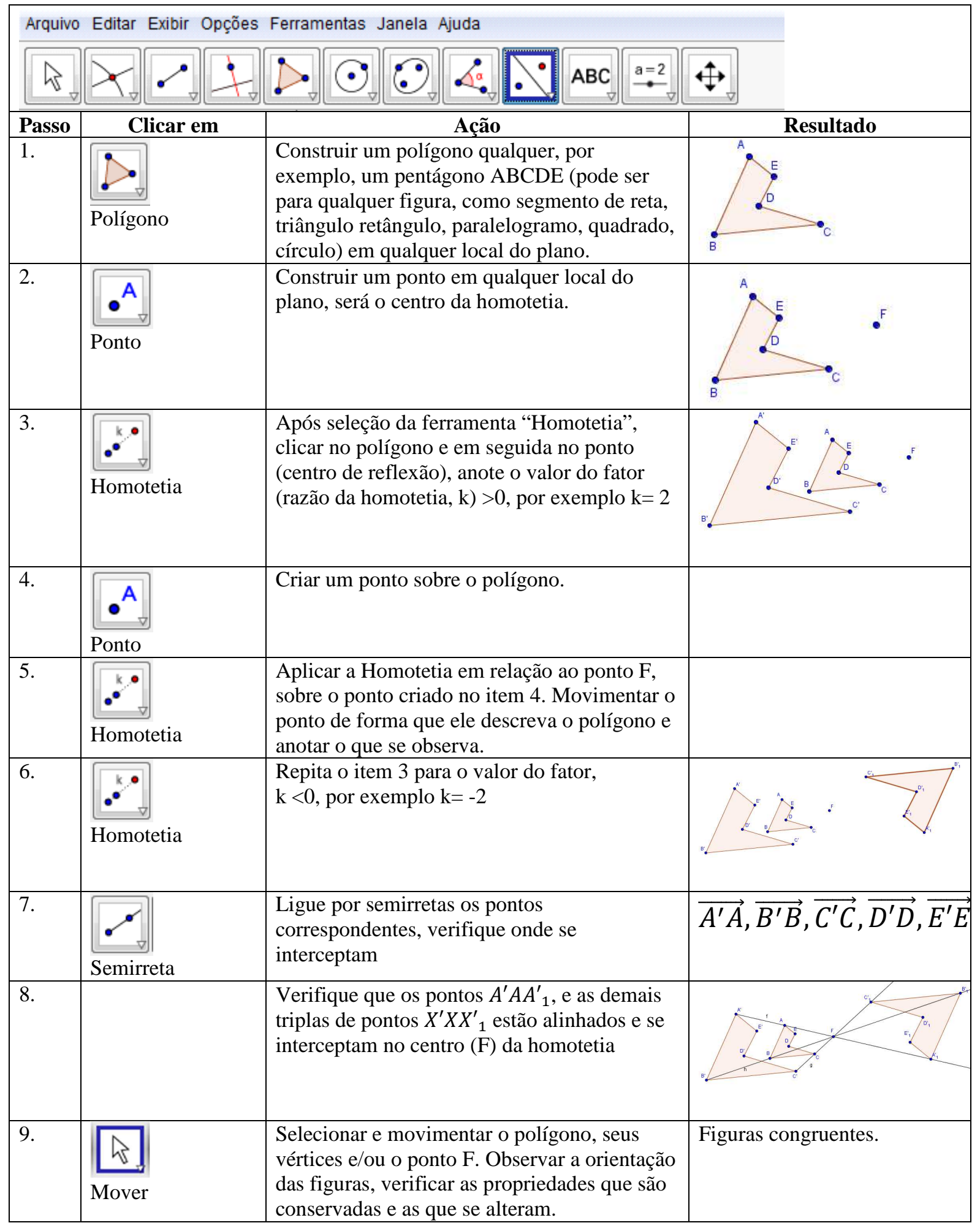


Apenas para ilustrar, a figua 66 é uma ampliação da figura do paso-a-passo do quadro 5.3.0.14.

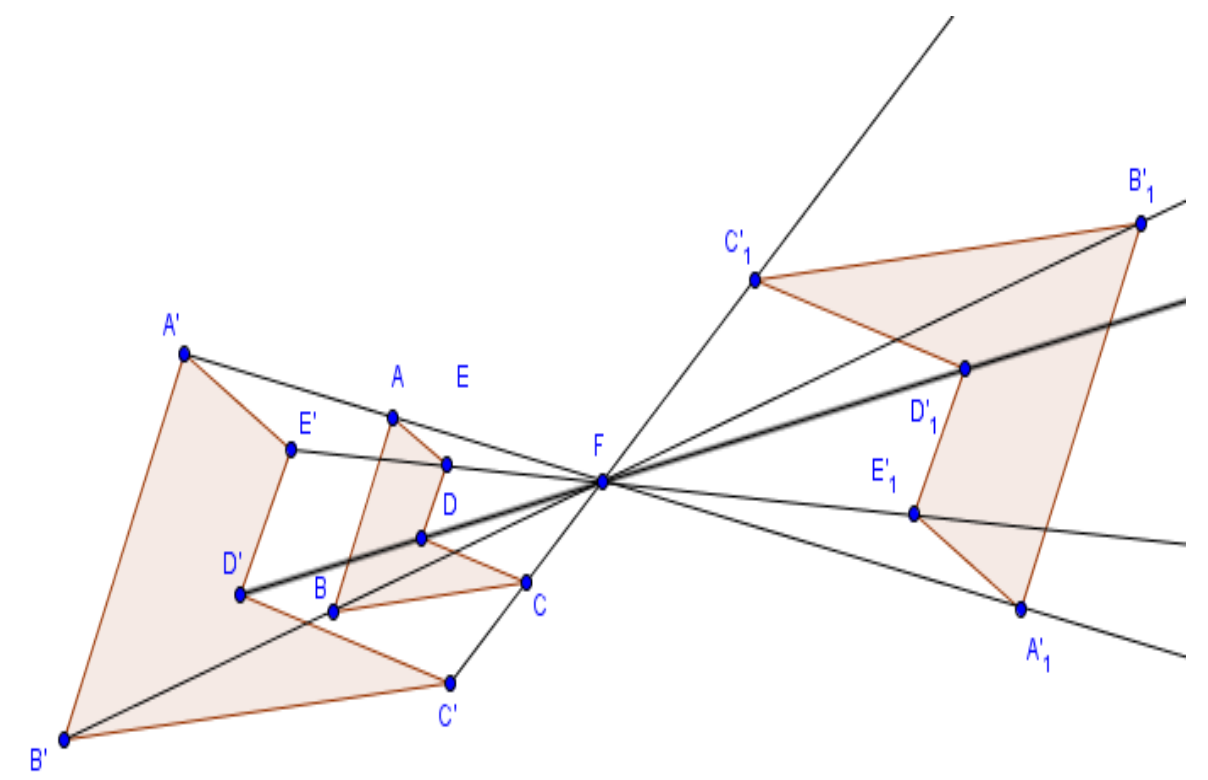

Figura 66: Homotetia 


\section{O uso de Máquinas Matemáticas para transformações geométricas}

Conforme mencionado anteriormente, em termos dos recursos a serem utilizados, as atividades da sequência didática incluirão:

- uso de uma coleção de instrumentos de Geometria, que estamos chamando de "Máquinas Matemáticas";

- uso do software GeoGebra para introduzir o conceito de transformação matemática e utilizar algumas máquinas matemáticas que simulam o seu funcionamento encontradas na web.

Neste trabalho, uma máquina matemática no contexto da Geometria Plana é um artefato concebido com uma finalidade específica: uma máquina faz um ponto, um segmento ou uma figura plana ser transformada de acordo com uma lei matemática definida pelo construtor. Uma máquina matemática pode ser um traçador de curva (Figura 67), um pantógrafo ou uma ferramenta para desenhar em perspectiva. Segundo Michela Maschietto,
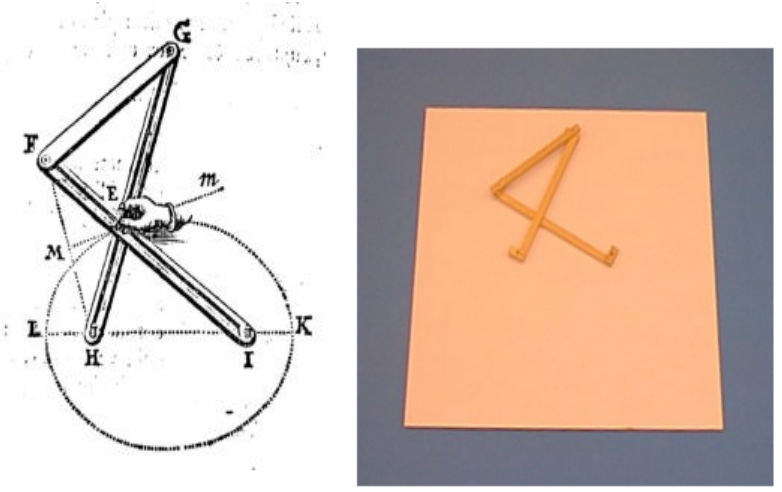

Figura 67: Traçador de Elipse

(MASCHIETTO, 2012), outro exemplo de máquina matemática bastante conhecida e utilizada por nós é o compasso (Figura 68(a)), tão presente no ambiente escolar. Ele pode ser considerado como o ancestral dos traçadores de curvas e dos pantógrafos. Um outro tipo de máquina matemática é representado pelos "perspectógrafos" que estão relacionados às origens da Geometria Projetiva (Figura 68(b)).

Essas máquinas matemáticas permitem explorar situações interessantes em sala de aula. Primeiro, questionando e buscando compreender o que a máquina faz. Num segundo 


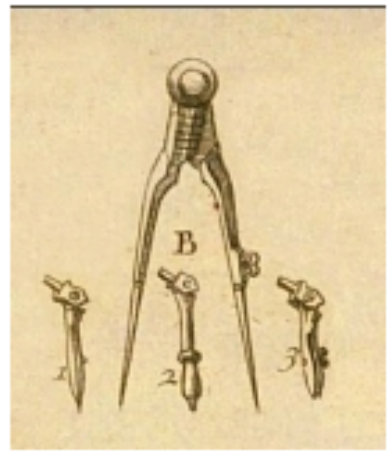

(a) Compasso

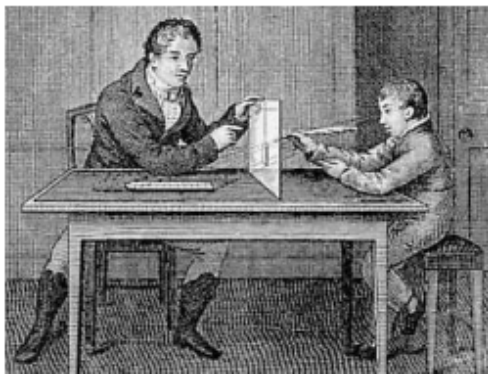

(b) Perspectógrafo

Figura 68: Algumas Máquinas Matemáticas

momento, porque ela faz isso. E enfim, como simular em um ambiente de Geometria Dinâmica o comportamento dessa máquina.

Apresentaremos na sequência as máquinas matemáticas que serão utilizadas, bem como o tipo de proposta de atividade para exploração das mesmas, visando caracterizar as transformações a partir de propriedades invariantes. Essas máquinas são traçadores de imagens de figuras por transformações geométricas do plano

\subsection{Máquina de translação: Paralelogramo}

O instrumento que realiza mecanicamente a translação é o chamado translator de Kempe, que é um duplo paralelogramo articulado.

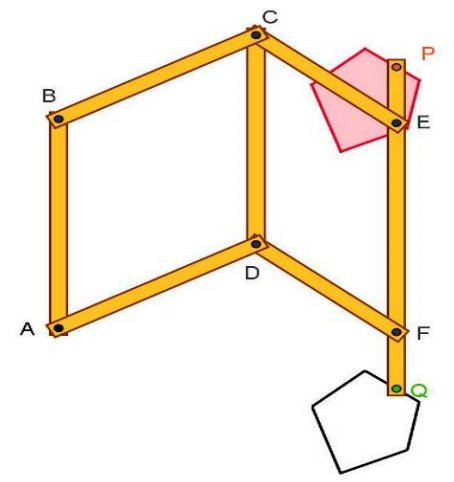

Figura 69: Translator de Kempe

Os dois paralelogramos articulados $A B C D$ e $D C E F$ têm o lado $C D$ comum e estão situados num mesmo plano. No primeiro paralelogramo, o lado $A B$ que é paralelo ao lado comum $C D$, é fixo no plano. Esse sistema permite realizar uma transformação geométrica: pilotando o segmento $P Q$ (com comprimento arbitrário), se o vértice $P$ (ou 
$Q$ ) é colocado sobre um ponto do plano, o ponto $Q$ (ou $P$ ) identifica automaticamente o ponto que lhe é correspondente por uma translação de vetor $\overrightarrow{P Q}$ (ou $\overrightarrow{Q P}$ ).

Como $A B\|D C\| F E \| Q P$, tem-se $\forall Q, \quad P=T_{\overrightarrow{Q P}}(Q)$, porque se tem constantemente $\overrightarrow{F E}=\overrightarrow{D C}=\overrightarrow{A B}$ e $\overrightarrow{Q P}=a \times \overrightarrow{F E}, \quad a \in \Re \geq 1$

\subsection{Simetrizadores}

Os mecanismos para efetuarmos as reflexões podem ser de dois tipos, as reflexões em relação a uma reta (simetria axial), e reflexão em relação a um ponto (simetria central), são os chamados simetrizadores.

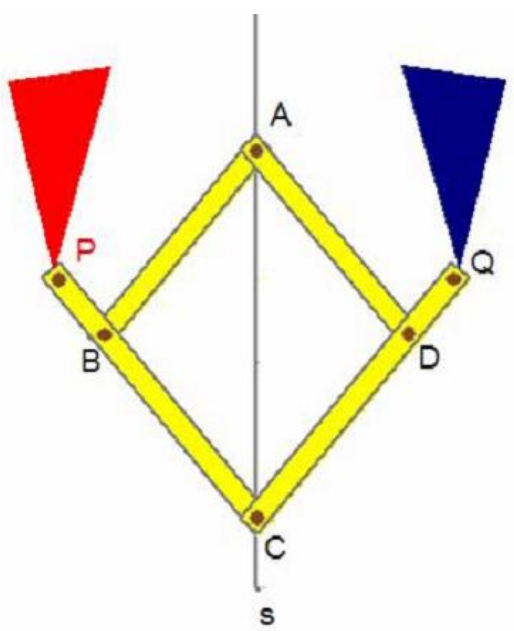

(a) Simetrizador Axial

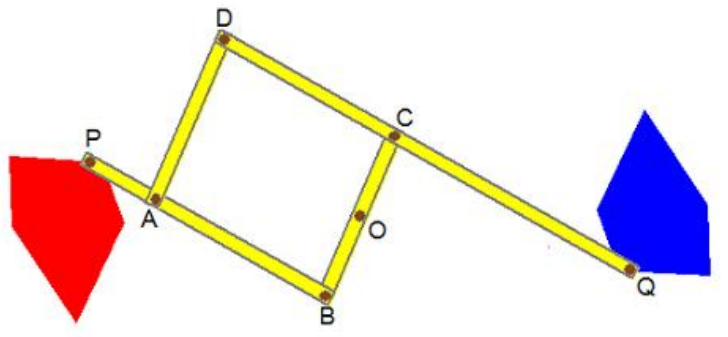

(b) Simetrizador Central

Figura 70: Simetrizadores

\subsection{Simetrizador Axial:}

O losango articulado $A B C D$ (Figura 70(a)) tem dois vértices opostos $A$ e $C$, que se movem em conjunto numa fenda retilínea $s$. Os pontos $P$ e $Q$ são escolhidos sobre os prolongamentos dos lados $C B$ e $C D$ tal que $B P=D Q$. Este sistema possui dois graus de liberdade: os pontos $P$ e $Q$ descrevem duas regiões planas (limitadas) situadas em dois semi-planos opostos em relação à fenda $s$. A posição de $P$ determina univocamente a posição de $Q$ (e vice-versa). A estrutura do dispositivo assegura que:

- o segmento $P Q$ é perpendicular a $s$;

- os pontos $P$ e $Q$ são equidistantes a $s$;

O pontos $P$ e $Q$ são então imagens um do outro por uma simetria axial ortogonal de eixo o suporte da fenda. 


\subsection{Simetrizador Central:}

Este mecanismo é constituído de um losango articulado $A B C D$ (Figura 70(b)), cujo lado $B C$ gira em torno de seu centro $O$ fixo no plano. O lado $B A$ é prolongado de um segmento $A P$, a partir de $A$, e o lado $D C$ é prolongado de um segmento $C Q=B P$ a partir de $C$. O aparelho realiza uma correspondência entre duas regiões limitadas do plano; os pontos $P$ e $Q$ estão sempre alinhados com $O$ e tem-se $P O=O Q$. Os pontos $P$ e $Q$, assim, se correspondem por uma simetria central de centro $O$.

\subsection{Outros simetrizadores:}

Os simetrizadores admitem outras construções, podemos citar como exemplo os dispositivos listados abaixo:

I) - O simetrizador central constituído por dois losangos congruentes $A B O C$ e $\bar{A}$ $\bar{B} O \bar{C}$, (Figura 71), , com um vértice $O$ comum, e formada a partir de seis barras rígidas e articuladas, duas das quais $(B \bar{B}$ e $C \bar{C}$ tem comprimento duplo do das outras quatro. Esses losangos são, eles mesmos, constantemente simétricos em relação a $O$, que será então o ponto fixo do instrumento.

Como, em particular,

$$
\forall A, \quad \bar{A}=R_{O}(A)
$$

a ponta cativa, $A$, deslocada ao longo da fronteira de $u$, leva a ponta livre, $\bar{A}$, a descrever a fronteira da figura $\bar{u}$,

$$
\bar{u}=R_{O}(u)
$$

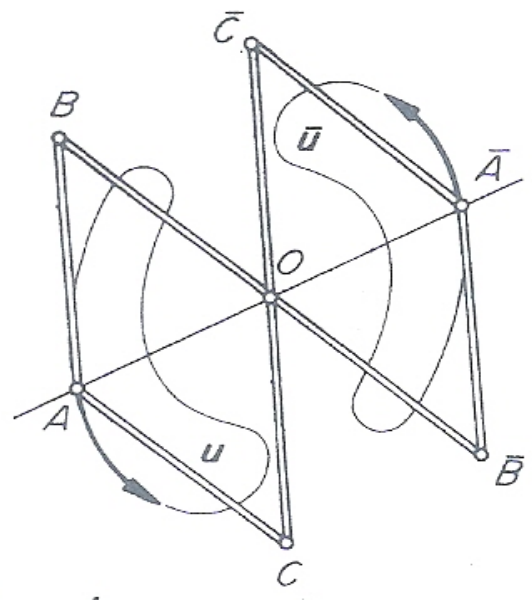

Figura 71: Pantógrafo Simetria Central-I

fonte: (PINHEIRO, 1986, p. 60) 
II) - O simetrizador central constituído por um paralelogramo $\bar{A} B C D$, (Figura $72)$, articulado e montado a partir de quatro barras rígidas, duas iguais $(A \bar{B}$ e $C D)$ e outras duas tais que uma $(A B)$ seja o dobro da outra $(\bar{A} D)$. O ponto médio, $O$, de um dos lados, $C D$, do paralelogramo será o ponto fixo do instrumento e teremos, constantemente,

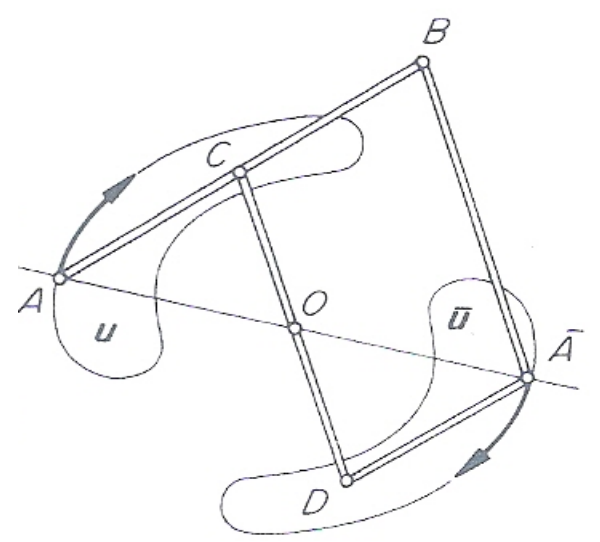

Figura 72: Pantógrafo Simetria Central-II

fonte: (PINHEIRO, 1986, p. 60)

$$
\forall A, \quad \bar{A}=R_{O}(A)
$$

Com efeito, no triângulo $A B \bar{A}$, a reta $C O$ passa pelo ponto médio de um lado, $A B$, e é paralela ao segundo lado, $\bar{A} B$; por isso, conterá o ponto médio $O$ do terceiro, $A \bar{A}$.

Se a ponta cativa, $A$, desloca-se na fronteira de $u$, a ponta livre $\bar{A}$ descreverá a de $\bar{u}$,

$$
\bar{u}=R_{O}(u)
$$

III) - O simetrizador formado por um losango $B C O D$, (Figura 73), articulado, e construído a partir de quatro barras rígidas, duas $(A B$ e $\bar{A} B)$ de comprimento duplo do das outras duas $(O C$ e $O D)$. O vértice $O$ é o ponto fixo do instrumento, e, no triângulo $A B \bar{A}$, tem-se constantemente $A C \simeq B C$ e $O C \| \bar{A} B$. Então $O A \simeq O \bar{A}$, ou, o que é o mesmo, $\forall A, \quad \bar{A}=R_{O}(A)$.

Se a ponta cativa, $A$, desloca-se na fronteira de $u$, a ponta livre $\bar{A}$ descreverá a de $\bar{u}$,

$$
\bar{u}=R_{O}(u)
$$




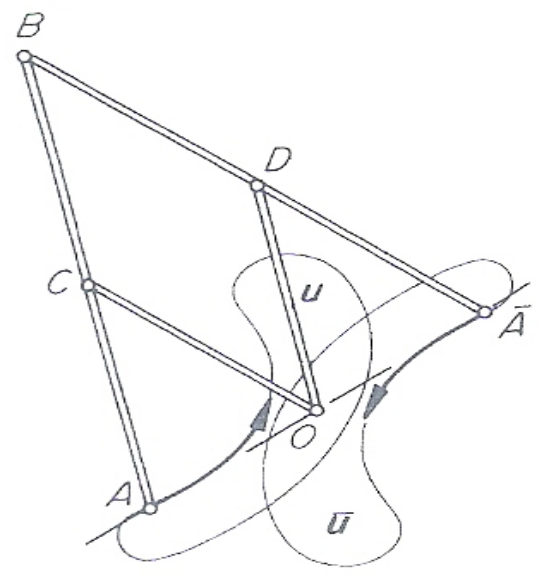

Figura 73: Pantógrafo Simetria Central-III fonte: (PINHEIRO, 1986, p. 60)

\subsection{Pantógrafos}

A nomenclatura utilizada neste capítulo ?? que versa sobre os sistemas articulados utiliza o termo pantógrafos para diferenciar alguns instrumentos, porém podemos dizer que todos os sistemas articulados são, em geral, denominados na literatura por pantógrafos, alguns são diferenciados pelo nome da pessoa que primeiramente o batizou.

\subsubsection{Pantógrafo de Sylvester para rotação}

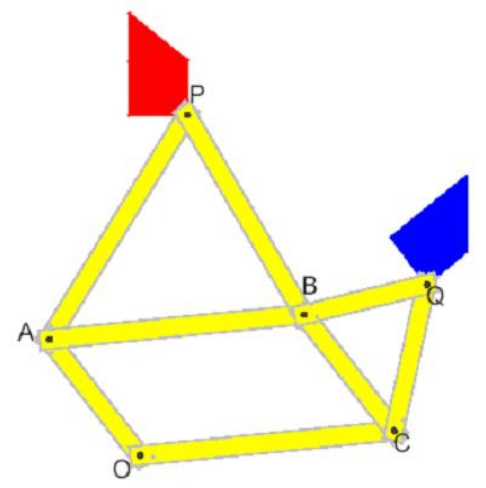

Figura 74: Pantógrafo de Sylvester-Rotação

Este mecanismo é constituído por um paralelogramo articulado $O A B C$ (Figura 74), onde o vértice $O$ é fixo no plano. Sobre os dois lados consecutivos $A B$ e $B C$ são construídos dois triângulos isósceles semelhantes $P A B$ e $B C Q$, com $A P=A B$ e $B C=C Q$. Ao mover o ponto $P$, o ponto $Q$ se desloca também enquanto que segmentos $P O$ e $Q O$ são mantidos iguais entre si, assim como os ângulos $P O Q, P A B$ e $B C Q$. Os pontos $P$ e 
$Q$ se correspondem então por uma rotação de centro $O$; o ângulo dessa rotação é o ângulo $P A B=B C Q$. 


\subsection{Rotor de Sylvester:}

Outra construção para o pantógrafo de Sylvester para a rotação é dada pelo sistema articulado da Figura 75, permite transformar por rotação uma figura, construindo a transformada, por movimento contínuo, (exatamente como o compasso ordinário gira um ponto isolado). O instrumento consta essencialmente, de um paralelogramo articulado $O M N P$ e duas hastes $M A$ e $P \bar{A}$, também articuladas em $M$ e $P$, respectivamente, e tais que:

$$
M A \simeq M N \quad \text { e } P \bar{A} \simeq P N
$$

Se a transformação a operar com a figura $u$ é a rotação $R_{O . \theta}$, devemos ajustar o instrumento de modo que

$$
x \widehat{M N} \simeq \widehat{N P} y=\theta
$$

tomando o vértice $O$ como o centro de rotação.
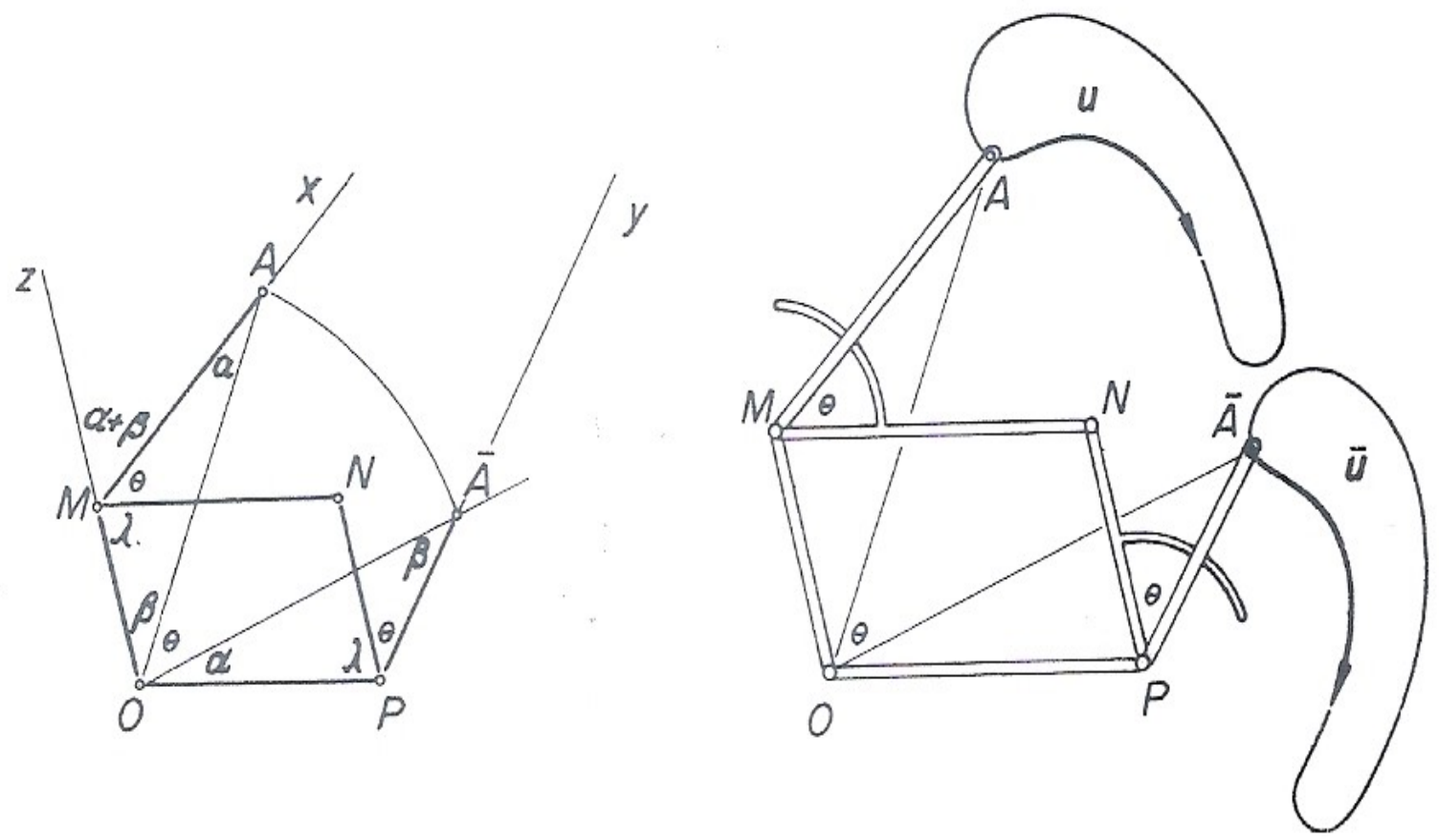

Figura 75: Rotor de Sylvester

fonte: (PINHEIRO, 1986, p. 131)

Nestas condições, os pontos $A$ e $\bar{A}$ são tais que

$$
\bar{A}=R_{O, \theta}(A) .
$$

Com efeito, pela congruência dos triângulos $O M A$ e $O P \bar{A}$ (onde $M A \simeq O P, O M \simeq P \bar{A}$ e $\widehat{O M} A \simeq \widehat{O P \bar{A}}=\lambda+\theta$ ), temos

$$
O A \simeq O \bar{A}
$$


e porque $\widehat{P O M} \simeq \widehat{N M} z$ (no paralelogramo $O M N P$ ) e $\widehat{A M} z=\alpha+\beta$ (no triângulo $O M A)$, temos também

$$
\widehat{A O \bar{A}}=\theta
$$

Então, se a ponta cativa $A$ do instrumento é levada a percorrer a fronteira de $u$, a ponta livre $\bar{A}$ descreverá a de $\bar{u}$ :

$$
\bar{u}=R_{O, \theta}(u)
$$




\subsubsection{Pantógrafo de Scheiner para homotetia}

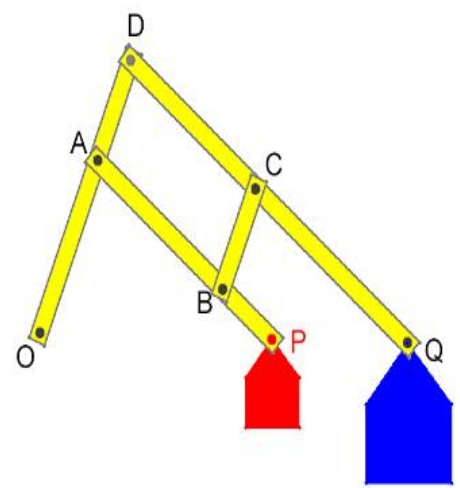

Figura 76: Pantógrafo de Scheiner-Homotetia

O sistema articulado é constituído por quatro barras $D O, D Q, A P$ e $A C$ (Figura 76 unidas pelos pontos $A, D$ e $C$ que giram em torno de $O$, mantendo o paralelogramo $A B C D$. O ponto $O$ é fixo no plano. Os pontos $P$ e $Q$ são escolhidos respectivamente sobre o prolongamento de $A B$ e $D C$ de forma que $D Q / A P=O D / O A=k$. Os pontos $O, P$ e $Q$ permanecem alinhados durante a utilização do instrumento. Os pontos $P$ e $Q$ estão em correspondência por uma homotetia de centro $O$ e razão $k(k>1)$, no caso do ponto $Q$ ser considerado o correspondente $P$. Se, ao contrário, o ponto $P$ é o correspondente de $Q$, a razão de homotetia é de $1 / k=O A / O D<1$.

\subsection{Roto-homotetia:}

pantografo di Sylvester para roto-homotetia

$O A B C$ é um paralelogramo articulado cujo vértice $O$ é implementado para o plano do modelo (Figura $77^{1}$ ). Nos lados $A B$ e $C B$ são construídos dois triângulos semelhantes tal que $P A / B C=P B / B Q=A B / C Q$. Os pontos $P$ e $Q$ tem dois graus de liberdade; Esta máquina gera uma correspondência entre duas regiões finitas do plano: os pontos $P$ e $Q$ se correspondem por uma roto-homotetia produto da rotação de centro $O$ e amplitude $\widehat{P A B}$ e da homotetia de centro $O$ e razão $O C / A P$.

Um sistema articulado a que já nos referimos antes (6.3.1.0.4 Figura 75) - o rotor de Sylvester - pode construir a transformada $\bar{u}$ de uma figura genérica $u$, por movimento contínuo. Trata-se de um paralelogramo articulado $S M N P$, (Figura 78), munido de duas

1 Figura extraída do site Associazione Macchine Matematiche, Rotoomotetia:pantografo di Sylvester, <http://www.macchinematematiche.org/index.php?option=com_content\&view=article\&id= $135 \&$ Itemid $=215 \&$ lang $=$ en $>,($ acessado em 22/julho/2015 - 16:25 h) 


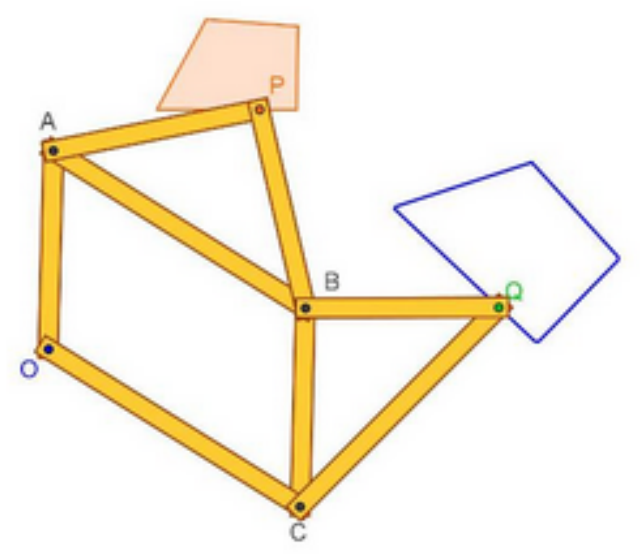

Figura 77: Roto-Homotetia-Sylvester

hastes $M A$ e $P \bar{A}$, também articuladas, em $M$ e $P$ respectivamente. Para a roto-homotetia $R_{S, \theta, k}$, ajustaremos o instrumento de modo que se tenha:

$$
\begin{aligned}
& \widehat{N M} x \simeq \widehat{N P} y=\theta \\
& \frac{M N}{M A}=\frac{P \bar{A}}{P N}=|k|
\end{aligned}
$$

Sendo $P N \simeq S M$ e $M N \simeq S P$ (SMNP é um paralelogramo), tem-se:

$$
\begin{gathered}
\frac{P \bar{A}}{S M}=\frac{S P}{M A}=|k| \quad \text { e, ademais } \\
\widehat{S P \bar{A}} \simeq \widehat{S M} A=\lambda+.
\end{gathered}
$$

Então, os triângulos $S P \bar{A}$ e $S M A$ são semelhantes, resultando daí:
1. $\frac{\overrightarrow{S A}}{\overrightarrow{S A}}=k$;
2. $\widehat{A S A}=\theta$

Desse modo, se a ponta cativa $A$ do instrumento é levada a percorrer a fronteira da figura $u$, a ponta livre $\bar{A}$ descreverá a fronteira de $\bar{u}$ :

$$
\bar{u}=R_{S, \theta, k}(u)
$$



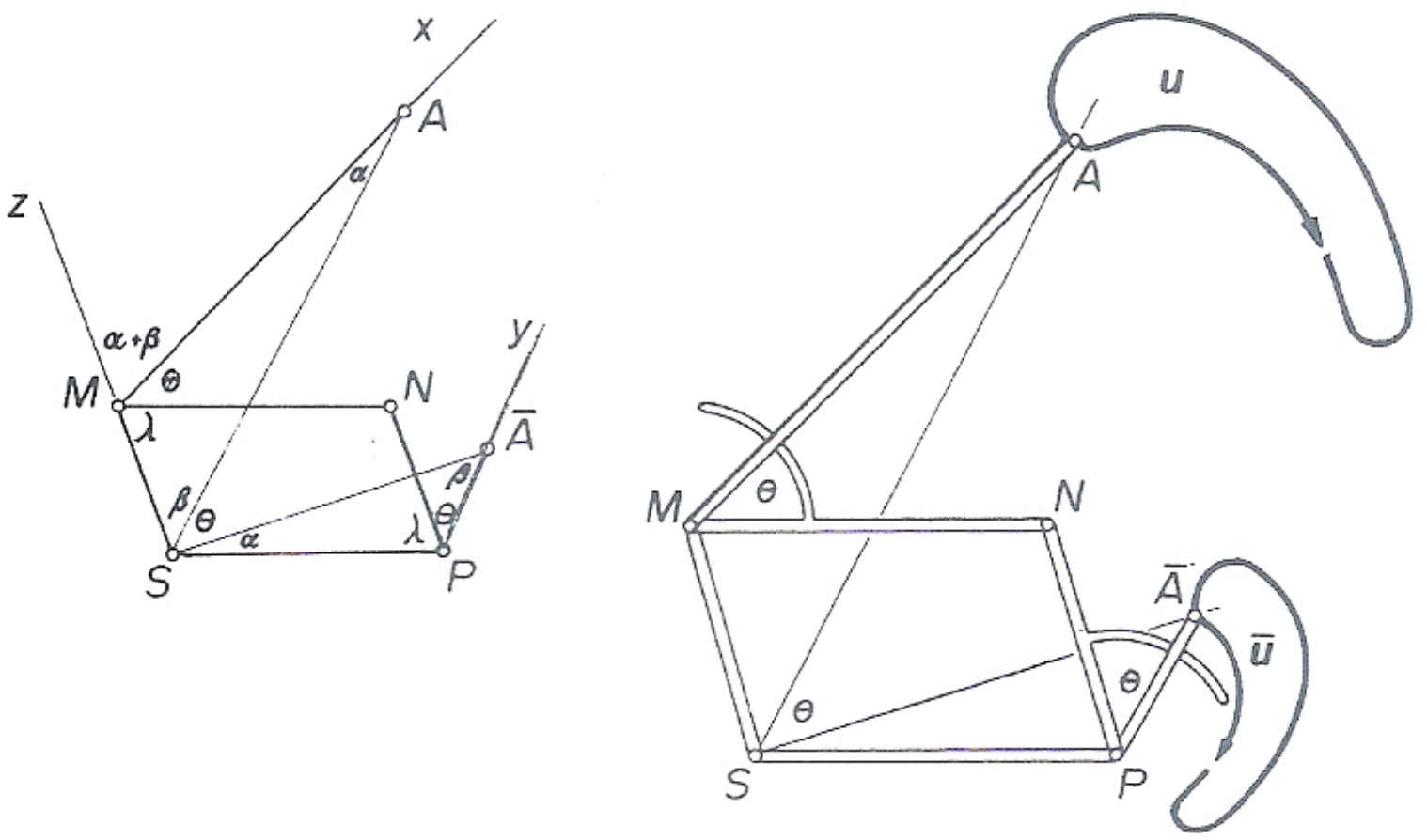

Figura 78: Roto-Homotetia

fonte: (PINHEIRO, 1986, p. 228)

\subsubsection{Combinação de pantógrafos}

O sistemas articulados podem ser agrupados para produzirem as transformações compostas.

\subsubsection{Translação Refletida-Reflexão Transladada-Glide Reflection}

O sistema consiste em combinar os dois pantógrafos vistos em 6.1 (translator de Kempe) para efetuar a translação, e em 6.2 (simetrizador axial) para a reflexão em relação a uma reta. Os dois dispositivos são interligados em $Q$ (Figura 79(b)), $A B$ irá deslizar sobre o eixo $s$, fixo, assim como estará fixo o segmento $M N$. O movimento do ponto $P$ ao longo de uma figura, irá produzir o movimento do ponto $P^{\prime}$ gerando a figura imagem. Reciprocamente, pode-se movimentar $P^{\prime}$, e as figuras serão produzidas pelo movimento em $Q$ e em $P$ (Figura 79(a)).

\subsubsection{Duas Reflexões com eixos paralelos - Translação}

O mecanismo permite verificar experimentalmente (em um caso particular) o seguinte teorema:

A composta de duas simetrias axiais com eixos paralelos, com s o primeiro eixo, e $r$ o segundo, é uma translação com direção perpendicular aos eixos de simetria, e módulo 


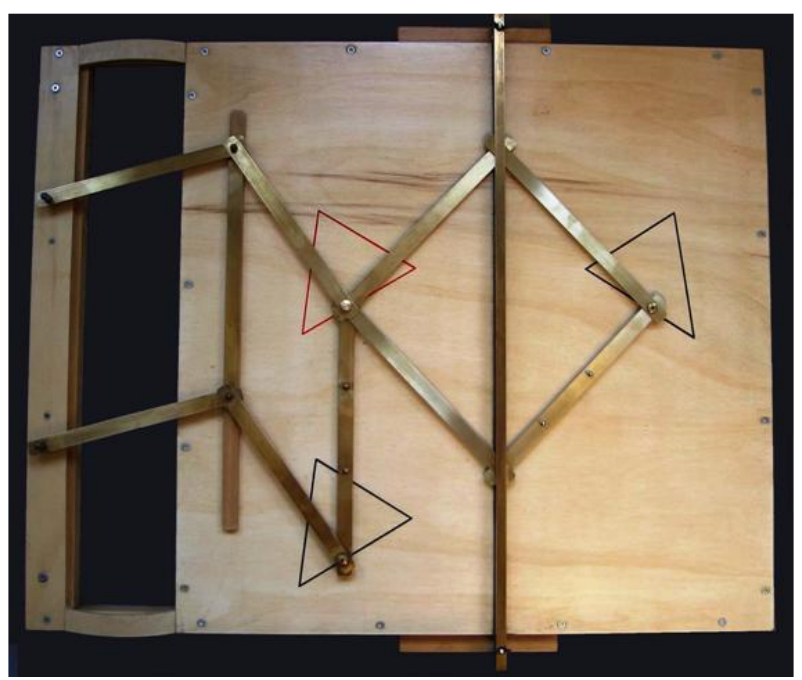

(a) Reflexão Transladada

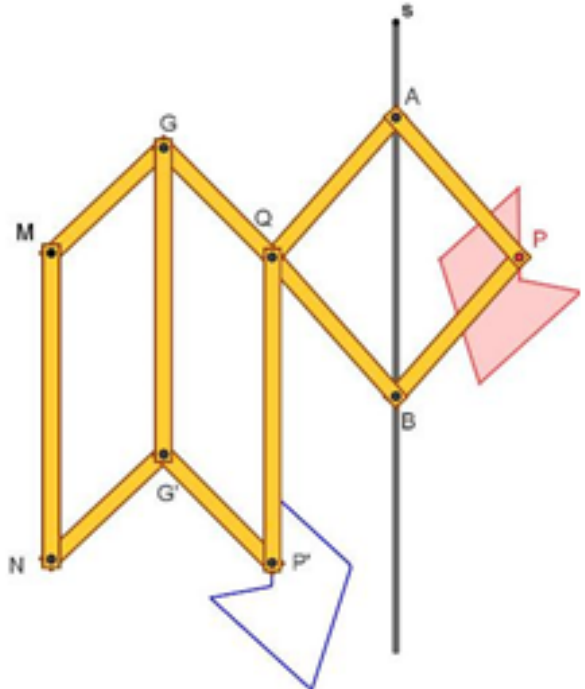

(b) Reflexão Transladada

Figura 79: Reflexão com Deslizamento

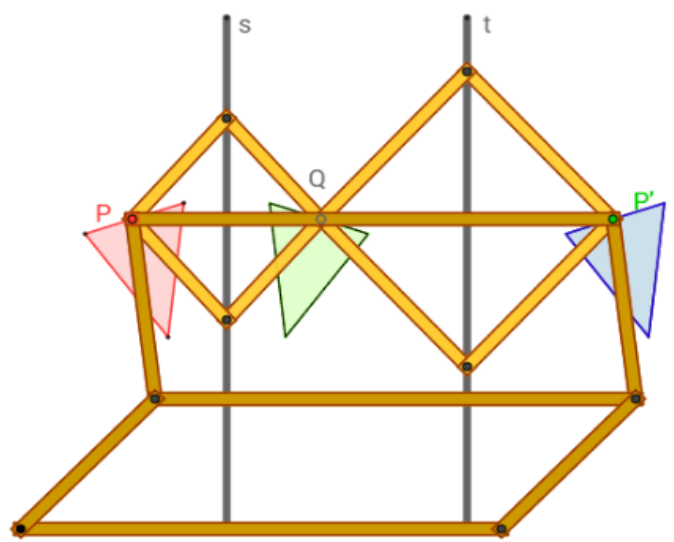

Figura 80: Duas Reflexões-Translação

igual ao dobro da distância entre os eixos.

Uma simetria pelo eixo $s$ (realizada mediante um losango articulado - Figura 80) leva o ponto $P$ em $Q$. Uma simetria de eixo $t$ (realizada com um instrumento do mesmo tipo) leva o ponto $Q$ a $P^{\prime}$.

Os mecanismos que produzem as duas simetrias axiais são acoplados em série (o ponto de chegada da primeira transformação é o ponto de partida da outra).

Um translator de Kempe é fixado no plano em direção ortogonal a $s$ e $t$, realiza a translação de módulo duas vezes a distância entre $s$ e $t$. Fixado o translator aos pontos $P$ e $P^{\prime}$ correspondentes à composta das duas simetrias, se observa que, movendo o ponto $P$, 
todo o sistema articulado se coloca em movimento sem bloquear-se, verificando em tal modo um caso particular do teorema.

Uma simulação deste dispositivo no GeoGebra está disponível em: <http://tube. geogebra.org $/ \mathrm{m} / 1433195>^{2}$.

\subsubsection{Duas reflexões axiais com eixos incidentes - Rotação}

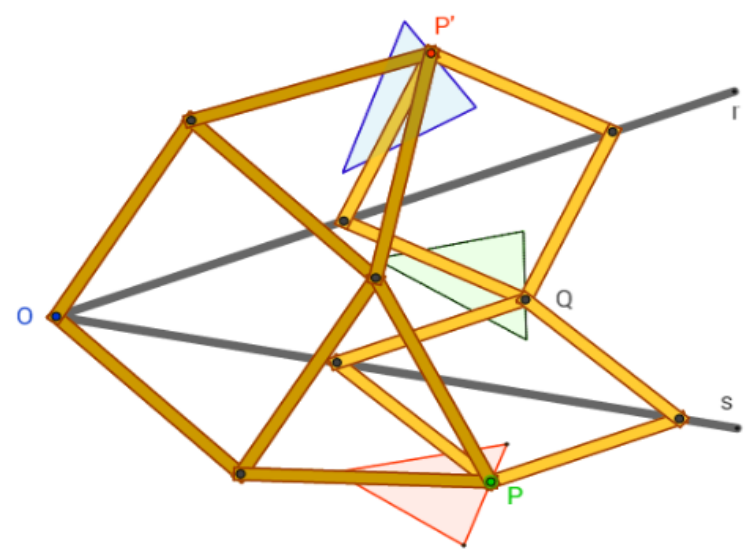

Figura 81: Duas Reflexões-Rotação

O mecanismo permite verificar experimentalmente ( em um caso particular) o seguinte teorema:

A composta de duas simetrias axiais com eixos incidentes, o primeiro dos eixos $s$, o segundo dos eixos $r$, é uma rotação com centro no ponto $O$, intersecção desses eixos, $e$ com amplitude igual ao dobro do ângulo formado por esses eixos de simetria.

Uma simetria de eixo $s$ (realizada mediante um losango articulado - Figura 81) leva o ponto $P$ em $Q$. Uma simetria de eixo $r$ (realizada com um instrumento do mesmo tipo) leva o ponto $Q$ em $P^{\prime}$.

Os mecanismos que produzem as duas simetrias axiais são acoplados em série (o ponto de chegada da primeira transformação é aquele de partida pela outra).

Um pantógrafo de Sylvester, fixado em $O$ no plano do modelo e vinculado ao ponto $P$ e $P^{\prime}$, realiza a rotação de centro $O$ e com o dobro da amplitude do ângulo formado por $s$ e $r$ e leva o ponto $P$ a $P^{\prime}$. Os três instrumentos formam um único sistema articulado com o qual se verifica uma perfeita mobilidade (impossível se o enunciado do teorema precedente não fosse verdadeiro).

2 Acessado no site: <http://www.macchinematematiche.org/index.php?option=com_content\&view= article\&id=89\&Itemid $=169 \&$ lang $=$ en $>$ em 24/jul/2015, 20:40 h. 
Uma simulação deste dispositivo no GeoGebra está disponível em: <http://tube. geogebra.org $/ \mathrm{m} / 1433215>^{3}$.

3 Acessado no site: <http://www.macchinematematiche.org/index.php?option=com_content\&view= article\&id=114\&Itemid=196\&lang $=$ en $>$ em 24/jul/2015, 22:16 h. 



\section{Metodologia - Uma Proposta de Ensino}

Neste capítulo, apresentaremos dentre várias opções metodológicas, algumas escolhas que julgamos apropriadas para o desenvolvimento desta pesquisa. Como mencionado anteriormente, nos preocuparemos com a elaboração de uma sequência de atividades que possa contribuir para o ensino das transformações geométricas no Ensino Fundamental II, envolvendo o uso de artefatos articulados, do tipo máquinas matemáticas, e o emprego de software de Geometria Dinâmica.

\subsection{Metodologia - Introdução}

Etimologicamente, pesquisa vem do Latim "perquierere" que significa "buscar com afinco", per = intensificado + quaerere = indagar, e tem como sinônimos: busca, procura, problema. Metaforicamente podemos associar a palavra pesquisa à palavra pesca, a qual é o esforço para retirar do esconderijo aquático o desejado peixe. De fato, o exercício de pesquisar é muito semelhante a uma pescaria. Assim como o peixe é desejado, mas estáa oculto de nós, assim o conhecimento desejado nos está oculto no início da pesquisa. Necessitamos de métodos e instrumentos, tanto na pesca como na pesquisa. Pesquisar é, pois, assim como a pesca, um trabalho de descobrimento e apreensão (aquisição) (OLIVEIRA, 2006).

Do ponto de vista das etapas de trabalho, Yin (YIN, 2009) apresenta em essência sugestões com

1. Definição do problema;

2. Design ou delineamento da pesquisa;

3. Obtenção dos dados;

4. Análise dos dados;

5. Redação.

Essencialmente, estaremos nesta etapa da pesquisa abordando os itens 1, 2, 3 e 4, e de maneira a efetuar um delineamento dinâmico, que vai ser ajustado à medida em que os dados vão sendo coletados e analisados, não sendo possível prever com absoluta exatidão tudo o que vai ocorrer. Essas etapas podem ser apresentadas em outras palavras, sem, contudo, diferirem na essência. 
Yin (op.cit.) ainda define um Delineamento (ou Projeto) de Pesquisa como a lógica que liga dados, informações e fatos coletados (e as conclusões construídas) às questões iniciais, ao problema da pesquisa. O delineamento de pesquisa também define o domínio de generalização, isto é, para quais situações, ou para qual população de eventos a teoria permanece válida.

Como metodologia, utilizaremos a abordagem qualitativa, entendendo que nessa perspectiva o

pesquisador colhe informações, examina cada caso separadamente e tenta construir um quadro geral [de uma dada] situação. É um exercício de ir juntando as peças, como num quebra-cabeça, até o entendimento global do problema (COSTA, 2001, p. 41).

A abordagem qualitativa em uma pesquisa também

consiste em descrições detalhadas de situações com o objetivo de compreender os indivíduos em seus próprios termos (GOLDENBERG, 2011, p. 53).

sendo assim, acredita-se ser esta a metodologia mais indicada para essa investigação.

O procedimento metodológico que escolhemos para o desenvolvimento dessa etapa do trabalho baseia-se na noção de Experimento de Ensino. Segundo Steffe e Thompson (2000), interpretar o que os alunos dizem e fazem, por meio de um diálogo desencadeado a partir das atividades e das questões elaboradas pelo pesquisador, é parte essencial em pesquisas desenvolvidas através de experimentos de ensino. Sendo assim, neste trabalho de pesquisa serão abordadas atividades que analisam como o coletivo, formado pelos alunos, pelos artefatos articulados e pelo software GeoGebra, serão explorados os conceitos e as propriedades acerca das transformações geométricas.

Ainda segundo Steffe eThompson (2000), os experimentos de ensino se constituem em uma sequência de episódios de ensino que objetiva a

exploração e explicação da atividade matemática dos estudantes (p. 273),

de modo a criar um espaço onde os alunos trabalhem em pequenos grupos enquanto o professor-pesquisador, através da análise das conjecturas, procura os auxiliar.

O experimento de ensino é uma ferramenta conceitual que os pesquisadores usam na organização de suas atividades. É primariamente uma ferramenta exploratória e tem por objetivo explorar a matemática dos estudantes (STEFFE; THOMPSON, 2000).

Nos experimentos de ensino, a interação entre pesquisador (agindo como professor) e alunos ocorre naturalmente nos encontros. O primeiro tenta se colocar na posição do aluno, buscando pensar como ele, visando explorar suas ações. 
Devido ao dinamismo, característica dos experimentos de ensino, esses não podem conter sequências fechadas de atividades e/ou conteúdos, uma vez que novos direcionamentos podem ser feitos pelo pesquisador à medida que novas questões vão surgindo.

\subsection{Considerações relativas às Atividades propostas}

Faremos algumas considerações relativas às atividades propostas, tanto em relação à atuação do professor mediador, como também em relação às eventuais dificuldades ou obstáculos que os alunos possam encontrar, analisando como os objetivos descritos neste estudo poderiam ser atingidos e como as atividades propostas podem ser desenvolvidas.

Analisaremos como alguns estudos embasam a elaboração de atividades didáticas, bem como a relação destas com os trabalhos de Piaget e Garcia (2011).

Brousseau (1996.) desenvolveu a Teoria das Situações Didáticas (TSD), que tem como objetivo analisar as interferências que ocorrem no ensino da Matemática e, posteriormente, modelar estratégias ótimas na resolução de problemas, considerando as relações entre o professor, aluno e o saber em jogo, no caso, a Matemática.

A tarefa principal do professor é a elaboração de uma situação em que o aluno, desconhecendo suas intenções e considerando seus conhecimentos anteriores, consiga elaborar uma resolução a partir de sua ação com um meio (milieu) propício à aprendizagem do saber em questão.

O aluno necessita assumir a responsabilidade de seu aprendizado, devendo se comprometer com a tentativa de criar alternativas de resolução à situação proposta.

\footnotetext{
"O professor tem, pois, de imaginar e propor aos alunos situações que eles possam viver e nas quais os conhecimentos apareçam como a solução ótima e passível de ser descoberta para os problemas colocados" (BRUN, 1996 apud MIRANDA; ROCHA, 2013, p. 81).
}

Procuramos utilizar a TSD na idealização das atividades, que possam proporcionar momentos de investigação de uma determinada situação. Um dos propósitos foi proporcionar ao aluno a vivência da dialética da ação-formulação-validação. Procuramos inserir construções geométricas que explorem um determinado conceito ou teorema ainda desconhecido ou implícito para os alunos. Desta forma, os alunos podem se apropriar desses conceitos que, posteriormente, serão institucionalizados com o auxílio do professor.

Propomos na sequência, momentos de discussões em que observamos as dialéticas da formulação e posterior validação das estratégias individuais.

Na concepção mais geral de ensino, a marca de um saber é a associação de boas perguntas com boas respostas. O professor propõe um problema; se o aluno resolver, demonstra que sabe; caso contrário, fica clara a necessidade de conhecimento, que requer 
uma informação, um ensino. A priori, todo método que permita a memorização das associações favorável, é aceitável (BROUSSEAU; BORGÉA, 2008, p. 33).

Uma modelização do processo de aprendizagem envolvendo professor, aluno e saber matemático, segundo Brousseau:

\begin{abstract}
À semelhança do que acontece na sociedade humana, o aluno aprende adaptando-se a um meio, que é fator de contradições, dificuldades, desequilíbrios. Esse saber, fruto de sua adaptação, manifesta-se por intermédio de novas respostas que são a marca da aprendizagem (BROUSSEAU; BORGÉA, 2008, p. 34).
\end{abstract}

Uma "situação" é um modelo de interações de um sujeito com um meio determinado. O recurso de que esse sujeito dispõe para alcançar ou conservar um estado favorável nesse meio é um leque de decisões que dependem do emprego de um conhecimento preciso. Consideremos o meio como subsistema autônomo, antagônico ao sujeito. Assim, Brousseau vai se interessar pelas situações ao tomar como objeto de estudo as circunstâncias que regem a difusão e a aquisição dos conhecimentos (BROUSSEAU; BORGÉA, 2008, p. 21).

Porém, um meio sem intenções didáticas é incapaz de induzir o aluno para a aquisição de conhecimentos matemáticos.

O objeto de estudo da didática da matemática é a situação didática, definida por Brousseau como:

[...] um conjunto de relações estabelecidas explicita e/ou implicitamente entre um aluno ou grupo de alunos, um certo meio (que abrange eventualmente instrumentos ou objetos) e um sistema educativo (representado pelo professor), com a finalidade de conseguir que esses alunos apropriemse de um saber constituído ou em vias de constituição (BROUSSEAU, 1996. apud PARRA; SAIZ, 1996, p. 28).

Essas relações estabelecem-se através de uma negociação entre professor e alunos cujo resultado tem sido denominado "contrato didático", que tem componentes explícitos e implícitos, define regras de funcionamento dentro da situação: distribuição de responsabilidades, determinação de prazos temporais a diferentes atividades, permissão ou proibição do uso de determinados recursos de ação, etc.

A primeira tentativa de "definição" do contrato didático é a seguinte:

Em uma situação de ensino, preparada e realizada por um professor, o aluno tem, em geral, como tarefa, de resolver um problema (matemático) que lhe é apresentado, mas o acesso a essa tarefa é feito através da interpretação das perguntas colocadas, das informações fornecidas, das obrigações estabelecidas, que são constantes da maneira de ensinar do professor. Esses hábitos (específicos) do professor esperados pelos alunos e os comportamentos do aluno esperados pelo professor constituem o contrato didático (BROUSSEAU, 1996. apud D'AMORE, 2005, p. 71) 
O objetivo fundamental da Didática da Matemática é averiguar como funcionam as situações didáticas, quer dizer, quais das características de cada situação são determinantes para a evolução do comportamento dos alunos e, consequentemente, de seus conhecimentos, por meio de uma série de situações reprodutíveis, que estabelecem os fatores determinantes para a evolução do comportamento dos alunos, a caracterização de um processo de aprendizagem. Assim, "o objeto central de estudo nessa teoria não é o sujeito cognitivo, mas a situação didática, na qual são identificadas as interações entre professor, aluno e saber".

De acordo com GÁLVEZ (1996), a teoria de Brousseau (1996.) esclarece a integração das dimensões epistemológicas, cognitivas e sociais no campo da Educação Matemática, permitindo compreender as interações sociais que ocorrem na sala de aula entre alunos e professores, as condições e a forma que o conhecimento matemático pode ser aprendido, sendo que o controle destas condições permitiria reproduzir e otimizar os processos de aquisição de conhecimento matemático escolar.

Para modelar a teoria das Situações Didáticas, Brousseau (1996.) propõe o sistema didático stricto sensu ou triângulo didático (figura 82), que comporta três elementos o aluno, o professor e o saber - que são partes constitutivas de uma relação dinâmica e complexa - a relação didática - que leva em consideração as interações entre professor e alunos (elementos humanos), mediadas pelo saber (elemento não-humano), que determina a forma como tais relações irão se estabelecer.

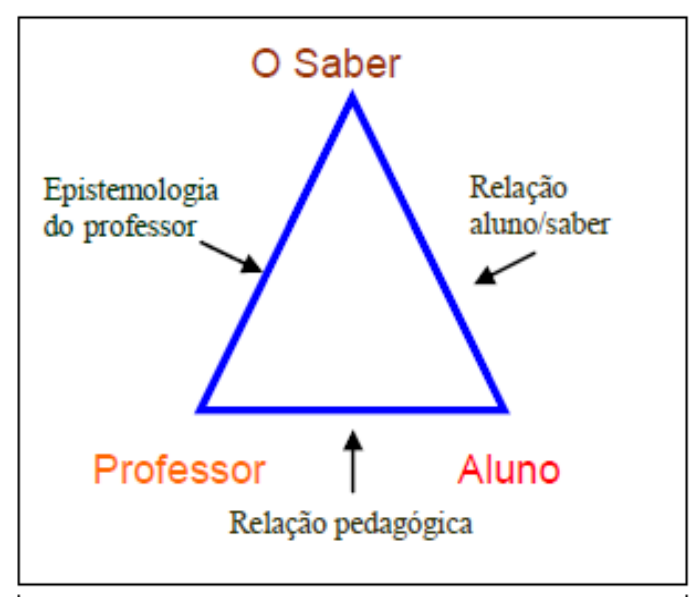

Figura 82: Triangulo Didático

fonte (POMMER, 2008)

Outro aspecto que facilita a análise das situações didáticas é sua classificação. Brousseau distingue, entre as situações que produz para seu estudo experimental, quatro tipos, cuja sequência, nos processos didáticos que organiza, é a seguinte:

1. As situações de ação, nas quais se gera uma interação entre os alunos e o meio 
físico. Os alunos devem tomar as decisões que faltam, para organizar sua atividade de resolução do problema formulado.

2. As situações de formulação, cujo objetivo é a comunicação de informações entre alunos. Para isso, devem modificar a linguagem que utilizam habitualmente, precisando-a e adequando-a às informações que devem comunicar.

3. As situações de validação, nas quais tenta-se convencer a um ou vários interlocutores da validade das afirmações que são feitas. Neste caso, os alunos devem elaborar provas para demonstrá-las. Não basta a comprovação empírica de que o que dizem é certo; é preciso explicar porque, necessariamente, deve ser assim.

4. As situações de institucionalização, destinadas a estabelecer convenções sociais. Nestas situações busca-se que o conjunto de alunos de uma aula assuma o significado socialmente estabelecido de um saber que foi elaborado por eles mesmos, em situações de ação, de formulação e de validação (BROUSSEAU, 1996. apud GÁLVEZ, 1996, p. 29-30). Mas é organizada pelo professor!

Para Brousseau (1996.), a análise a priori da situação se constitui num momento fundamental da investigação em didática, o pesquisador deve ser capaz de prever os efeitos da situação que elaborou, antes de colocá-la em prova na sala de aula; só posteriormente poderá comparar suas previsões com os comportamentos observados.

Uma parte importante da análise de uma situação didática consiste na identificação das variáveis didáticas e no estudo, tanto teórico quanto experimental, de seus efeitos. Entre as variáveis que intervêm em uma situação há as denominadas variáveis de comando, que podem ser manipuladas pelo professor para fazer evoluir os comportamentos dos alunos, que resultam determinantes para a aparição do conhecimento que a situação didática pretende ensinar.

Orientações didáticas atuais preconizam que o professor delegue ao aluno a maior responsabilidade possível na sua produção, no seu aprendizado. São orientações que devem transformar, dentro das possibilidades, as situações de ensino em situações de aprendizagem.

As concepções modernas de ensino exigirão do professor, que proponha problemas que provoque no aluno as adaptações necessárias para a aprendizagem. Tais problemas, escolhidos de modo que o estudante os possa aceitar, devem fazer, pela própria dinâmica, com que o aluno atue, fale, reflita e evolua por sua própria motivação (BROUSSEAU; BORGÉA, 2008, p. 34-35).

Brousseau (1996.) com isso introduz a noção de situação a-didática, na qual destaca o novo papel do professor, com uma atuação mais discreta, requer que o professor provoque 
a adaptação esperada em seus alunos por uma escolha judiciosa de "problemas"que ele coloca diante deles.

O estudante sabe muito bem que o problema foi escolhido para ajudá-lo a adquirir um novo conhecimento. Esta situação ou problema escolhido pelo professor é uma parte essencial de uma situação mais ampla em que o professor pretende devolver ao estudante uma situação a-didática, proporcione-lhe mais independência, e interação mais frutuosa possível. Estes problemas devem permitir aos alunos agirem, falarem e pensarem a evoluir por sua própria motivação.

As situações a-didáticas são as situações de aprendizagem nas quais o professor consegue fazer desaparecer sua vontade, suas intervenções, enquanto informações determinantes do que o aluno fará: são as que funcionam sem a intervenção do professor ao nível dos conhecimentos (BROUSSEAU, 1996. apud PARRA; SAIZ, 1996, p. 55-56).

Assim, por exemplo, num trabalho sobre reflexão em reta, indica-se que uma figura tem simetria em relação a uma reflexão em reta é a que se obtém quando uma dobra na folha da figura é feita sobre o traço da reta. A seguir, são propostas atividades nas quais os estudantes devem determinar os simétricos de várias figuras dadas, que não podem ser dobradas. O professor deixa para o aluno a tarefa de criar condições e conhecimentos para resolver as situações-problema (MABUCHI, 2000, p.127).

Em situação escolar, o professor organiza e constitui um meio, que pode ser por exemplo, um problema, que revela mais ou menos claramente sua intenção de ensinar ao aluno um saber determinado, mas que dissimula suficientemente esse saber e a resposta esperada para que o aluno os possa encontrar sozinho, por meio de uma adaptação pessoal ao problema formulado. O valor dos conhecimentos adquiridos dessa forma depende da qualidade do meio como motivador de um funcionamento "real", cultural do saber, e, portanto, do grau de recusa a-didática obtida (BROUSSEAU; BORGÉA, 2008, p. 90).

A maneira como o aluno é motivado a participar dessa nova situação é explicada pela noção de devolução, que Brousseau define como:

$\mathrm{O}$ ato pelo qual o professor faz com que o aluno aceite a responsabilidade de uma situação de aprendizagem (a-didática) ou de um problema e assume ele mesmo as consequências dessa transferência (BROUSSEAU; BORGÉA, 2008, p. 91).

De acordo com Brousseau,

Na didática moderna, o ensino é a devolução ao aluno de uma situação a-didática adequada e aprendizagem é a adaptação a esta situação (BROUSSEAU, 1996. apud PARRA; SAIZ, 1996, p. 51).

Portanto, o ensino tem como objetivo principal o funcionamento do conhecimento como produção livre do aluno nas suas relações com um meio a-didático. A distinção entre 
situações didáticas e a-didáticas e a noção de devolução recolocam novo papel do professor na teoria das situações didáticas.

Outro conceito importante no processo ensino-aprendizagem é, segundo Brousseau (1996.), o de obstáculo. Nas diversas pesquisas de didática, a análise do erro toma como base a noção de obstáculos.

A noção de obstáculo epistemológico foi descrita inicialmente pelo filósofo francês Gastão Bachelard, na obra A Formação do Espírito Científico, publicada em 1938. Bachelard observou que a evolução de um conhecimento pré-científico passa, quase sempre, pela rejeição de conhecimentos anteriores e se defronta com um certo número de obstáculos. Assim, esses obstáculos não se constituem na falta de conhecimento, mas, pelo contrário, são conhecimentos antigos, cristalizados pelo tempo, que resistem à instalação de novas concepções que ameaçam a estabilidade intelectual de quem detém esse conhecimento (PAIS, 2001, p. 39).

$\mathrm{Na}$ educação matemática os obstáculos interferem com maior intensidade na fase de gênese das primeiras ideias. Durante a aprendizagem, ao iniciar o contato com um conceito inovador, pode ocorrer uma revolução interna entre o equilíbrio aparente do velho conhecimento e o saber que se encontra em fase de elaboração.

Conforme Pais (2001), se por um lado, os obstáculos epistemológicos têm raízes históricas e culturais, por outro, estão relacionados também à dimensão social da aprendizagem. É nesse quadro que surgem dificuldades decorrentes de conhecimentos anteriores, bloqueando a evolução da aprendizagem.

De maneira geral, é difícil imaginar uma aula de matemática ou de física que não tenha como objeto a aprendizagem de um determinado conceito. Assim, é preciso entender como ocorre a reorganização intelectual de modo que o novo conhecimento entre em harmonia com os anteriores, sendo esse o momento que os obstáculos se manifestam.

Um obstáculo se manifesta pelos erros, os quais, em um sujeito, estão unidos por uma fonte comum: uma maneira de conhecer; uma concepção característica, coerente, embora incorreta; um "conhecimento" anterior bem-sucedido na totalidade de um domínio de ações, é no próprio ato de conhecer, intimamente, que aparecem, por uma espécie de necessidade funcional, as dificuldades e as confusões.

Segundo Guy Brousseau, o erro seria a expressão ou a manifestação explícita de um conjunto de concepções espontâneas ou reconstruídas integradas numa rede coerente de representações cognitivas, que se torna em obstáculo à aquisição de novos conceitos. A superação desses obstáculos seria então o projeto do ensino e o erro a passagem obrigatória.

Os erros são indícios de obstáculos para a aquisição de um conhecimento e, segundo essa visão, são necessários para o professor situar as concepções dos alunos, diagnosticar 
os obstáculos e adaptar as situações didáticas.

Dessa forma, o obstáculo não desaparece com a aprendizagem de um novo conhecimento. Pelo contrário, opõe resistência a sua aquisição, a sua compreensão, subsiste em estado latente e reaparece de súbito, em especial no contexto anterior, quando as circunstâncias o permitem (BROUSSEAU; BORGÉA, 2008, p. 50).

Para Brousseau:

Organizar a superação de um obstáculo consistiria em propor uma situação suscetível de evoluir e fazer evoluir o aluno segundo uma dialética conveniente. Tratar-se-á não de comunicar as informações que se queira ensinar, mas de encontrar uma situação na qual elas são as únicas a serem satisfatórias ou ótimas - entre aquelas às quais se opõem - para obter um resultado no qual o aluno se investiu (BROUSSEAU, 1996. apud ALMOULOUD, 2010, p. 40).

Quanto às dificuldades, lembremos o que Brousseau considerou:

A aquisição de uma noção é feita durante um longo período. Não se considera que ela deva ser completamente assimilada e, ainda mais, explicitada desde sua introdução. [...] Como na leitura, a uma primeira fase global sucede, num prazo mais ou menos longo, uma fase analítica. [...] Da manipulação ao desenho, do desenho ao "gráfico", depois ao símbolo, a ideia se precisa por um processo complexo de abstrações, de concretizações e representações (BROUSSEAU, 1996. apud PERRINGLORIAN, 1994, p. 99).

\subsection{Etapas do trabalho}

Neste tópico definiremos a forma de escolha do grupo de alunos no qual aplicaremos a sequência didática, os materiais e a forma de como serão distribuídos.

\subsubsection{Formação do grupo de alunos}

Vamos selecionar um grupo de alunos do $4^{\circ}$ ciclo do Ensino Fundamental II, conforme definido no PCN (BRASIL, 1998), com alunos das $7^{\mathrm{a}}$ e/ou $8^{\mathrm{a}}$ séries (atualmente $8^{\circ}$ e $9^{\circ}$ anos), e preferencialmente formaremos cinco grupos de quatro a cinco alunos por grupo. Essa formação tem o objetivo de poder distribuir a cada grupo um artefato (máquina matemática) diferente, para que cada grupo desenvolva as atividades propostas. Eventualmente, poderemos fazer ajustes necessários, como por exemplo, trocar os artefatos entre os grupos para que todos os alunos possam ter acesso ao conjunto de artefatos e atividades.

Outra questão a ser definida, e esta será feita com a coordenação do Ensino Fundamental da escola a ser selecionada, quais alunos poderão participar deste trabalho de pesquisa, o horário e o tempo de duração das atividades a serem aplicadas no grupo de 
alunos, se durante, ou fora o horário de aulas normais, quantos encontros são necessários para as tarefas, quantos no computador, qual o perfil dos alunos.

\subsubsection{Sugestões para a Construção de Máquinas Matemáticas}

A utilização das máquinas matemáticas em sala de aula requer que as mesmas sejam construídas, ou adquiridas no mercado. A aquisição no mercado é ainda limitada pela pouca oferta dos diferentes tipos de máquinas apresentadas neste estudo, além de ter custo mais elevado. A mais comum de ser encontrada é o "Pantógrafo de Madeira", que na verdade é um Pantógrafo para Homotetia, (cf. figura 83 abaixo).

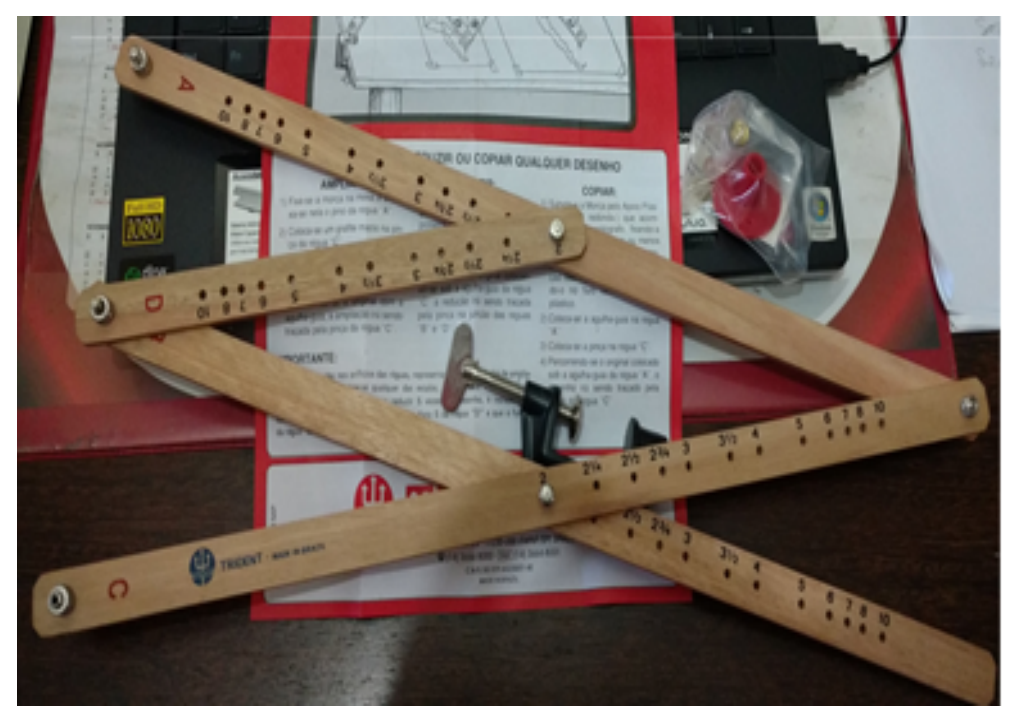

Figura 83: Pantógrafo de Madeira TRIDENT - mod. PME 40

fonte: Adquirido na loja O Projetista

\section{Descrição do Produto Pantógrafo de madeira TRIDENT $40 \mathrm{~cm}^{1}$}

Pantógrafo de madeira TRIDENT 40cm amplia, copia e reduz qualquer desenho. Fabricado em madeira dura de excelente qualidade, com furos de precisão. Ferragens de latão cromado. Acompanha morça para fixar na extremidade da mesa e suporte plástico para fixar em cima da mesa. Acompanha manual de instruções.Ref.: PME-40.

As Máquinas Matemáticas podem ser construídas utilizando materiais recicláveis encontrados no cotidiano, como embalagens de leite, caixa de café, ou outros produtos que são acondicionados em papel mais rígido, ou também com palitos de sorvete, de churrasco, ou outros tipos de materiais, como hastes de alumínio. A construção desses artefatos articulados pode ser desenvolvida nas aulas de Artes, agregando uma característica interdisciplinar ao estudo.

1 Detalhes técnicos disponível no site < http://www.oprojetista.com.br/produto/731_ Pantografo-de-madeira-TRIDENT-40cm.html\#desc_prod $>$ 
A figura 84 abaixo é apenas para ilustrar a construção de um Pantógrafo para a Translação utilizando embalagem de leite, onde nas articulações foram empregados colchetes (chamados de "bailarinas") e a própria tampa (parte superior da caixa de leite) foi utilizada para ser colocado um lápis. A fixação do pantógrafo em uma mesa, carteira de estudante, ou até na própria lousa, poderá ser feita utilizando algum material abrasivo, como fita adesiva, fita crep, ou mesmo tecidos do tipo velcro, ou de outra forma criativa.

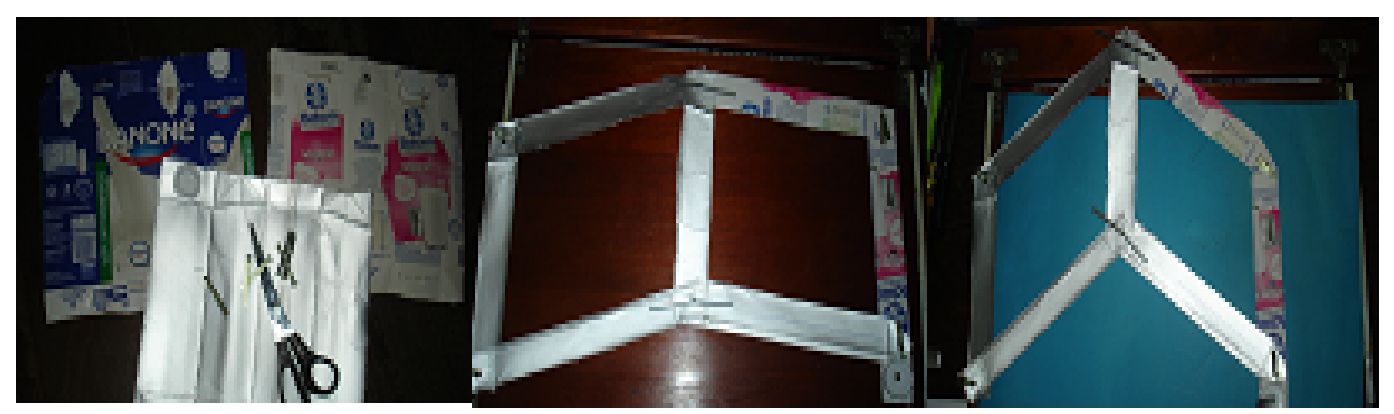

Figura 84: Pantógrafo para translação

fonte: Acervo do autor

Uma construção mais elaborada foi feita com hastes de alumínio, como na fig. 85 abaixo, e nas articulações foram utilizados um conjunto de parafusos, arruelas e porcas, e nos furos pode-se adaptar uma ponta de lápis para escrita, e uma ponta seca para contornar as bordas de uma figura qualquer, onde será aplicada a referida transformação geométrica. Para as barras ou articulações que devem ser fixas, sugerimos que se utilize parafuso ou algum tipo de presilha que fixe-a em algum ponto de uma mesa, como uma pequena morsa, ou ventosas que são utilizadas para se fixar em alguma superfície lisa. Pode-se, como já sugerimos, utilizar a criatividade para a fixação dos pantógrafos.

As furações feitas em cada barra podem ser úteis no estudo das variações que ocorrem na figura transformada, quando são alteradas as posições da ponta seca e da ponta de escrita, como as alterações nos campos de atuação dos pantógrafos, por exemplo.

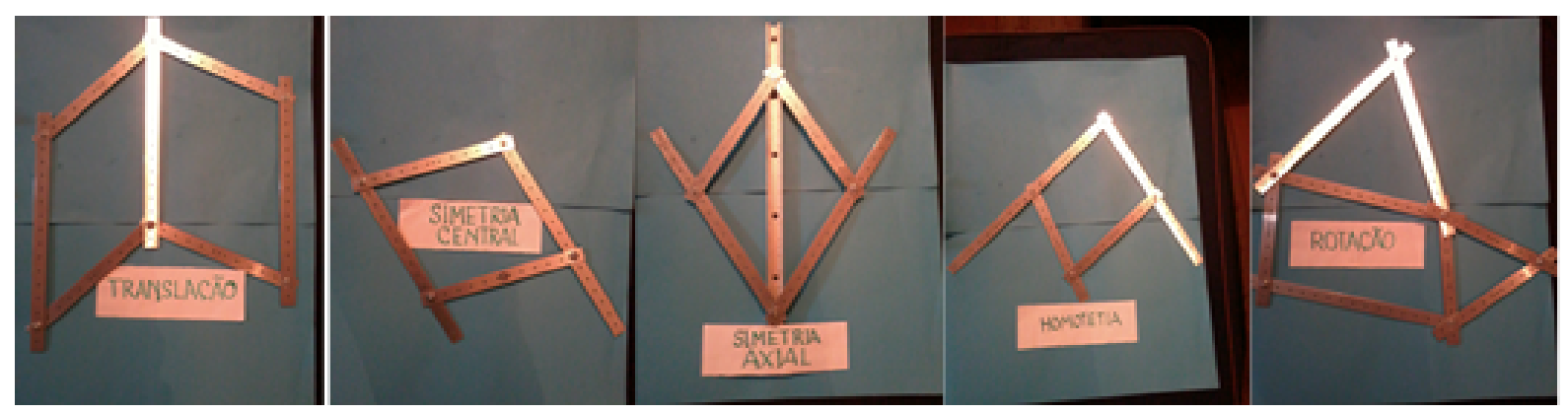

Figura 85: Pantógrafos de Alumínio fonte: Acervo do autor 
A construção desses dispositivos não se limita às sugestões apresentadas, a criatividade na escolha dos materiais e a maneira de construí-los são de certa forma extensas, e os próprios alunos podem, e devem, se evolver com tais construções, contribuindo para o enriquecimento de seus conhecimentos sobre transformações geométricas.

\subsubsection{Materiais a serem utilizados.}

Disponibilizaremos artefatos, do tipo sistemas articulados descritos abaixo, e poderão ser em número de cinco ou seis, isso vai depender de quantos grupos de alunos poderemos formar.

Utilizaremos o software GeoGebra, com os recursos de construção em Geometria Dinâmica, como interface para a implementação dos sistemas articulados, assim os alunos podem ter o contato com as máquinas matemáticas e simulá-las no computador, e explorálas livremente na apreensão dos conhecimentos das transformações geométricas. Para essa etapa será necessário articular com a instituição de ensino a disponibilização de pelo menos um computador para cada dois ou três alunos.

Um projetor, interligado ao computador do professor mediador, deverá ser uma ponte de ligação entre os experimentos e as descobertas dos alunos, com o repertório teórico necessário para a compreensão dos conceitos e propriedades das transformações geométricas, bem como aplicações que resultem, como um dos objetivos, na apreensão dos conceitos de congruência e semelhança entre figuras planas.

Artefatos articulados propostos (vide um quadro resumo no apêncide 7.4.4.1):

- Translador de Kempe para a translação;

- Pantógrafo para simetria axial;

- Pantógrafo para simetria central;

- Pantógrafo de Sylvester para rotação;

- Pantógrafo para homotetia.

\subsection{Atividades propostas}

Inicialmente, descreveremos as atividades que serão propostas aos alunos, e os ajustes que possam advir para aperfeiçoar o processo de coleta de dados.

A sequência das atividades seguirá inicialmente as etapas listadas abaixo: 
$1^{\circ}$ Utilização do GeoGebra para apreensão da utilização das ferramentas de construção de objetos matemáticos, efetuando as transformações geométricas vistas neste estudo, ou seja, translações, rotações, reflexão central, axial e homotetia;

$2^{\circ}$ Utilização das máquinas matemáticas estudadas para a implementação das transformações geométricas exercitadas na atividade descrita no item anterior; exploração das respectivas características dos artefatos;

$3^{\circ}$ Utilização do GeoGebra para a construção e utilização das máquinas matemáticas estudadas para o seu funcionamento virtual;

$4^{\circ}$ Utilização e estudo de diversos sites disponíveis (gratuitamente) na internet como fonte de recursos didáticos, com materiais úteis para o aprofundamento dos conhecimentos sobre transformações geométricas.

\subsubsection{Uso do GeoGebra nas transformações geométricas.}

O objetivo dessa atividade é que os alunos possam utilizar o software GeoGebra, conhecer as ferramentas de construção dos objetos matemáticos, efetuar as transformações geométricas. As etapas a serem observadas para que os alunos possam desenvolver essa atividade são:

a) Treinamento inicial com apresentação dos recursos e ferramentas do GeoGebra, que será feito pelo professor. Neste momento, serão introduzidas e utilizadas todas as ferramentas do Geogebra pertinentes à atividade;

b) Atividades envolvendo as ferramentas de transformações geométricas no Geogebra, conforme apresentadas na figura 60 (Tela do GeoGebra e opções para Transformações Geométricas) na seção 5.3 (Transformações Geométricas como ferramenta de construção no GeoGebra) da página 138.

c) Distribuição de uma sequência de construção de objetos matemáticos, uma para cada grupo, para que cada um deles seja capaz de efetuar as transformações geométricas estudadas.

Observação 7.4.1. Cada grupo será denominado por uma letra maiúscula, $\mathcal{A}, \mathcal{B}, \quad \mathcal{C}, \quad \mathcal{D}$ e $\mathcal{E}$, e vamos identificar cada uma das transformações geométricas (TG) por duas letras maiúsculas:

- TR : Translação;

- $\mathcal{R O}$ : Rotação em relação a um ponto;

- $\mathcal{R} \mathcal{C}$ : Reflexão central, (em relação a um ponto); 
- $\mathcal{R A}$ : Reflexão axial, (em relação a uma reta);

- $\mathcal{H O}$ : Homotetia.

Em síntese, com relação à etapa do item (c) acima, cada grupo receberá instruções para efetuar a manipulação dos objetos a serem construídos no GeoGebra, resumidas na tabela 6 abaixo, seguidas do passo-a-passo para cada tipo de transformação geométrica, conforme lista na observação 7.4.1.

Os passo-a-passo instruem o aluno a entender cada ferramenta envolvida, e tem o objetivo de padronizar uma sequência que seja uniforme, dentro do possível, para cada isometria, mas cada professor poderá fazer as devidas alterações quando julgar necessário, em função dos objetivos que queira atingir, dos itens que queira aprofundar, ou de outros recursos que queira utilizar, e também da maturidade que o grupo de alunos tenha sobre o uso do GeoGebra nas transformações geométricas. 
Tabela 6: Tipos de Transformações Geométricas e operações no GeoGebra

\begin{tabular}{|c|c|c|c|c|c|}
\hline TG & $\begin{array}{c}\text { Objetos } \\
\text { Matemáticos }\end{array}$ & Selecionar & $\begin{array}{l}\text { Efetuar as } \\
\text { operações }\end{array}$ & $\begin{array}{l}\text { Efetuar movimentos } \\
\text { dos objetos }\end{array}$ & $\begin{array}{c}\text { O que altera? } \\
\text { O que não altera }\end{array}$ \\
\hline$\overline{\bar{T} \mathcal{T R}}$ & $\begin{array}{l}\text { Polígono } \\
\text { Vetor } \\
\text { Segmento } \\
\text { Distância }\end{array}$ & $\begin{array}{l}\text { Translação } \\
\text { por um } \\
\text { Vetor }\end{array}$ & $\begin{array}{c}\text {-Segmentos pontos } \\
\text { correspondentes } \\
\text {-Distância } \\
\text { dos segmentos }\end{array}$ & $\begin{array}{c}\text { polígono inicial, } \\
\text { vetor, pontos } \\
\text { da fig. inicial }\end{array}$ & \\
\hline $\mathcal{R O}$ & $\begin{array}{l}\text { Polígono } \\
\text { Ponto } \\
\text { Ângulo } \\
\text { Distância }\end{array}$ & $\begin{array}{c}\text { Rotação } \\
\text { em Torno de } \\
\text { um Ponto } \\
\text { - Valor de } \\
\alpha \text { e } \\
\text { sentido }\end{array}$ & $\begin{array}{c}\text {-Ligar centro } \\
\text { de rotação com } \\
\text { ponto inicial } \\
\text { e com seu ponto } \\
\text { correspondente, } \\
\text { dist }(\mathrm{OA}) ; \operatorname{dist}\left(\mathrm{OA}^{\prime}\right) \\
\text {-Ângulo A'OA }\end{array}$ & $\begin{array}{l}\text { polígono inicial, } \\
\text { um ponto da fig. } \\
\text { inicial, centro } \\
\text { de rotação }\end{array}$ & \\
\hline $\mathcal{R}$ & $\begin{array}{l}\text { Polígono } \\
\text { Ponto } \\
\text { Segmento } \\
\text { Distância }\end{array}$ & $\begin{array}{c}\text { Reflexão } \\
\text { em Relação } \\
\text { a um Ponto }\end{array}$ & $\begin{array}{l}\text {-Segmentos pontos } \\
\text { correspondentes } \\
\text {-Distância dos } \\
\text { segmentos }\end{array}$ & $\begin{array}{l}\text { polígono inicial, } \\
\text { pontos da fig. } \\
\text { inicial, } \\
\text { centro da } \\
\text { reflexão }\end{array}$ & \\
\hline $\mathcal{R A}$ & $\begin{array}{c}\text { Polígono } \\
\text { Reta } \\
\text { Segmento } \\
\text { Distância } \\
\text { Ângulo } \\
\text { Intersecção } \\
\text { Dois Objetos }\end{array}$ & $\begin{array}{l}\text { Reflexão } \\
\text { em Relação } \\
\text { a uma Reta }\end{array}$ & $\begin{array}{l}\text {-Segmentos pontos } \\
\text { correspondentes, } \\
\text {-Ponto intersecção } \\
\text { segmentos e Reta } \\
\text {-Distância entre } \\
\text { ponto/intersecção } \\
\text {-ângulo segmentos } \\
\text { e Reta }\end{array}$ & $\begin{array}{l}\text { polígono inicial, } \\
\text { pontos da fig. } \\
\text { inicial, } \\
\text { posição da Reta }\end{array}$ & \\
\hline $\mathcal{H} \mathcal{O}$ & $\begin{array}{l}\text { Polígono } \\
\text { Ponto } \\
\text { Segmentos } \\
\text { Distância }\end{array}$ & Homotetia & $\begin{array}{c}\text {-Segmentos pontos } \\
\text { correspondentes } \\
\text {-Razão entre } \\
\text { segmentos }\end{array}$ & $\begin{array}{l}\text { polígono inicial, } \\
\text { pontos da fig. } \\
\text { inicial, centro } \\
\text { da homotetia }\end{array}$ & \\
\hline
\end{tabular}

Para as atividades descritas na tabela 6 , elaboramos a sequência abaixo a serem aplicadas aos alunos. 


\subsubsection{Passo-a-passo para a Translação - Quadro 7.4.1.1}

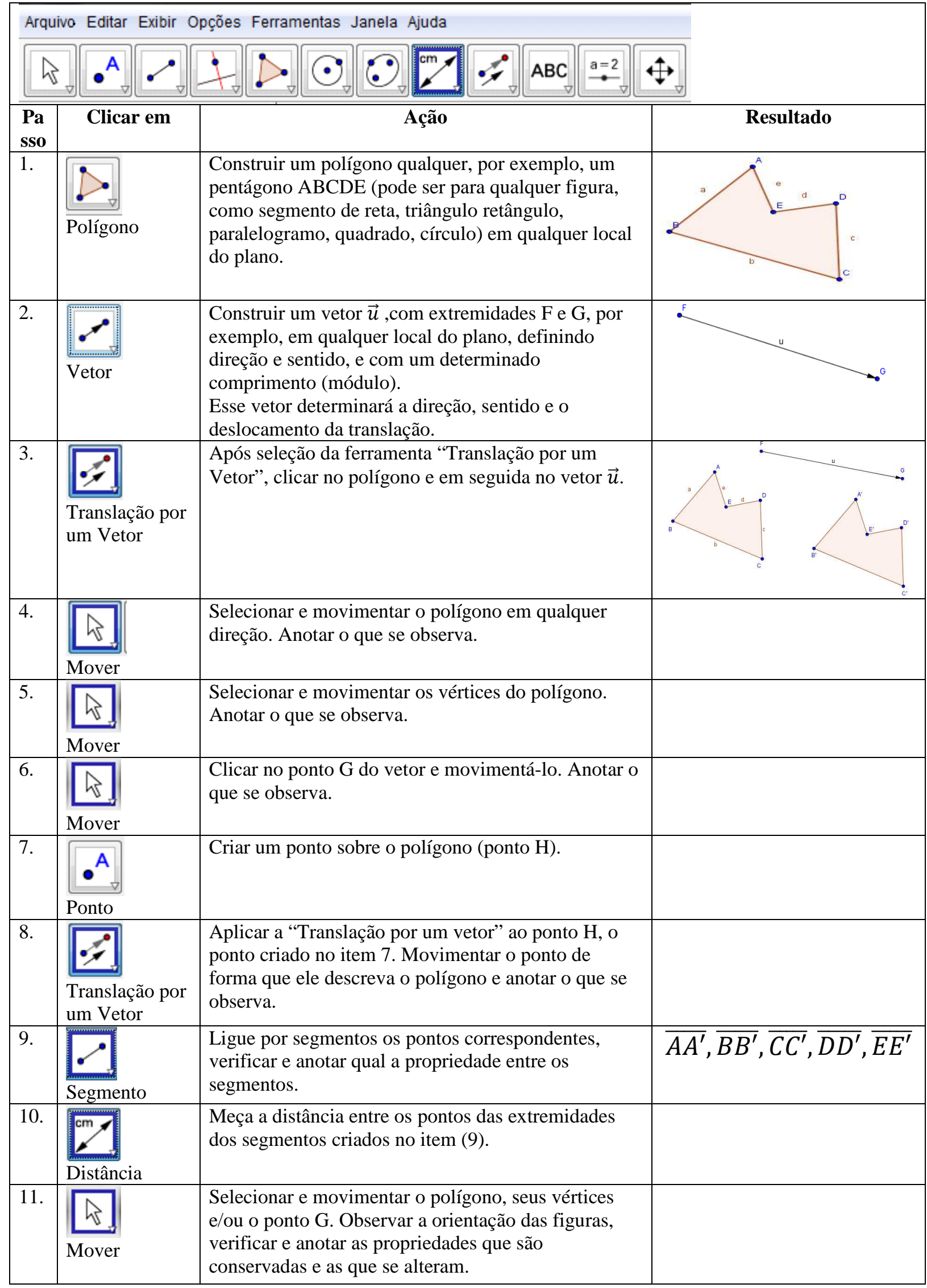




\subsubsection{Passo-a-passo para a Reflexão em Torno de um Ponto - Quadro 7.4.1.2}

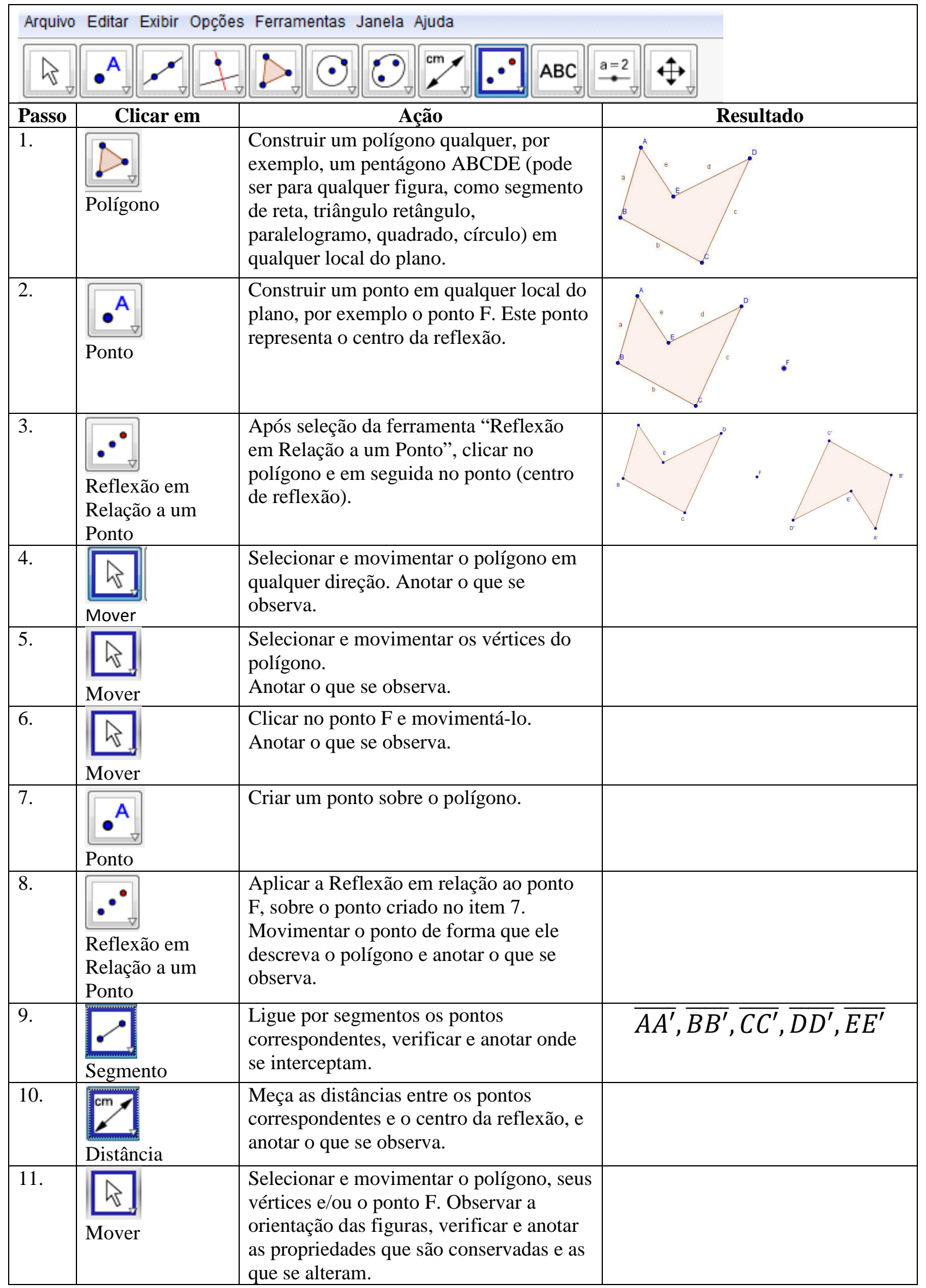




\subsubsection{Passo-a-passo para a Rotação em Torno de um Ponto - Quadro 7.4.1.3}

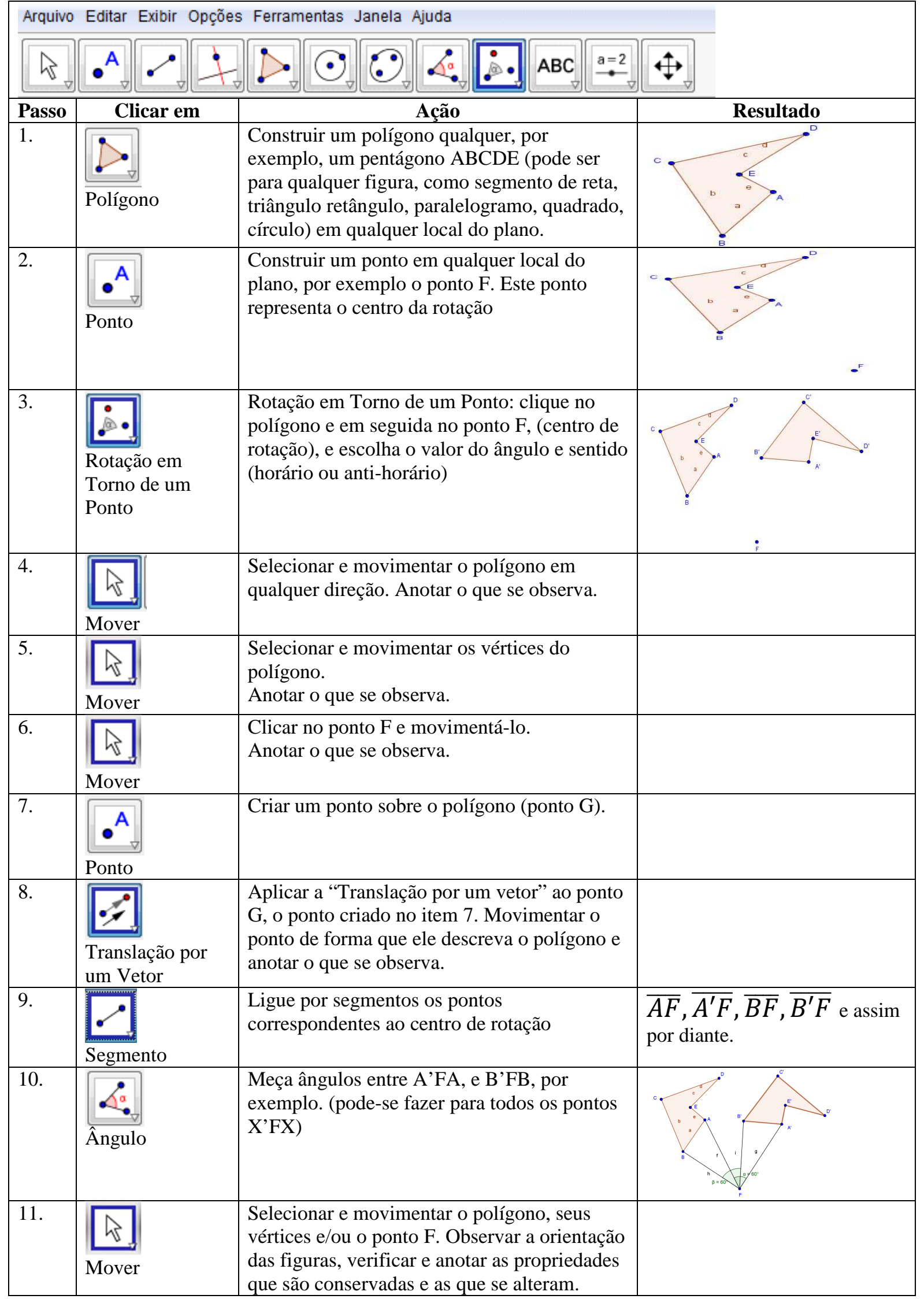




\subsubsection{Passo-a-passo para a Reflexão em Relação a uma Reta - Quadro 7.4.1.4}

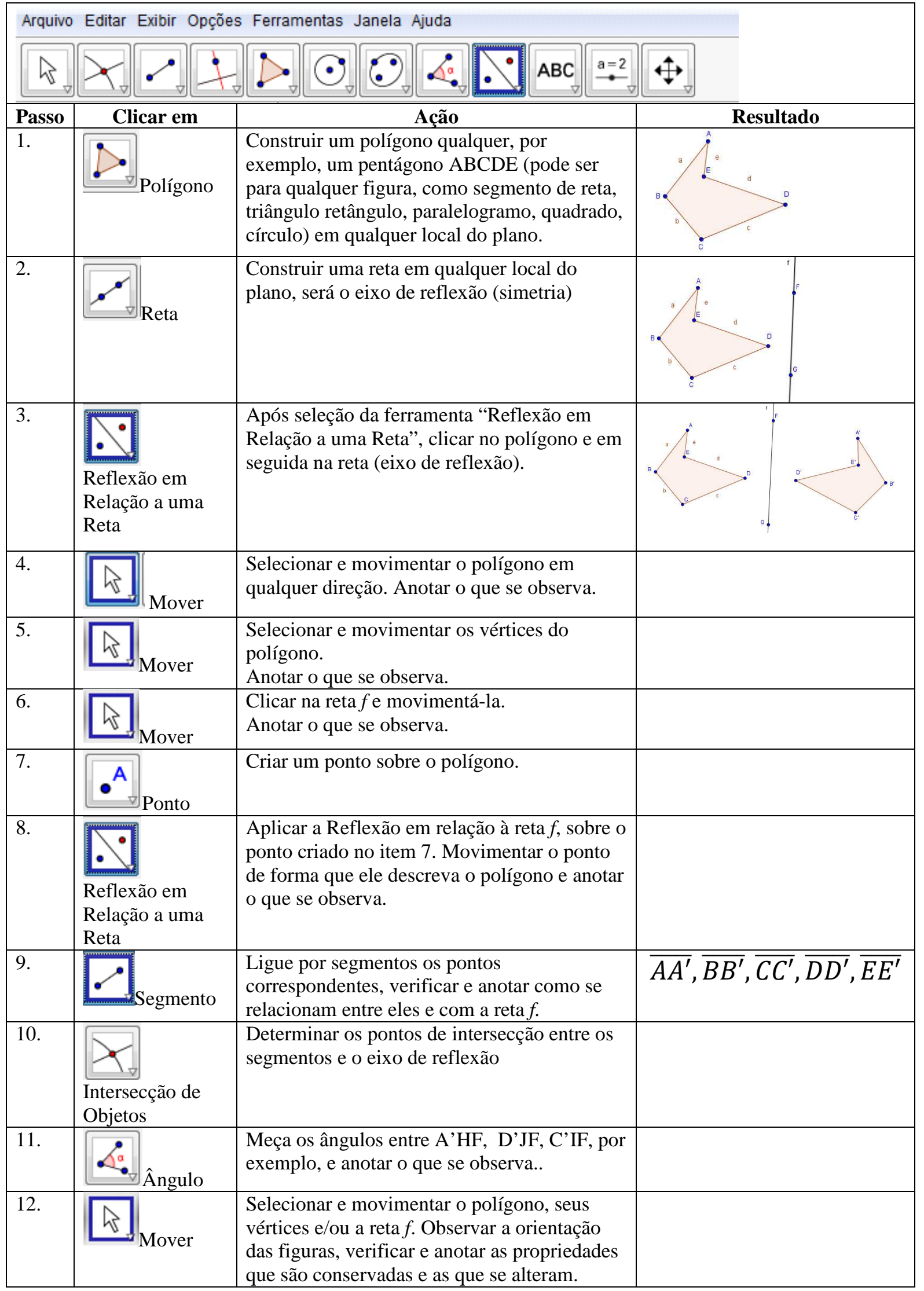




\subsubsection{Passo-a-passo para a Homotetia- Quadro 7.4.1.5}

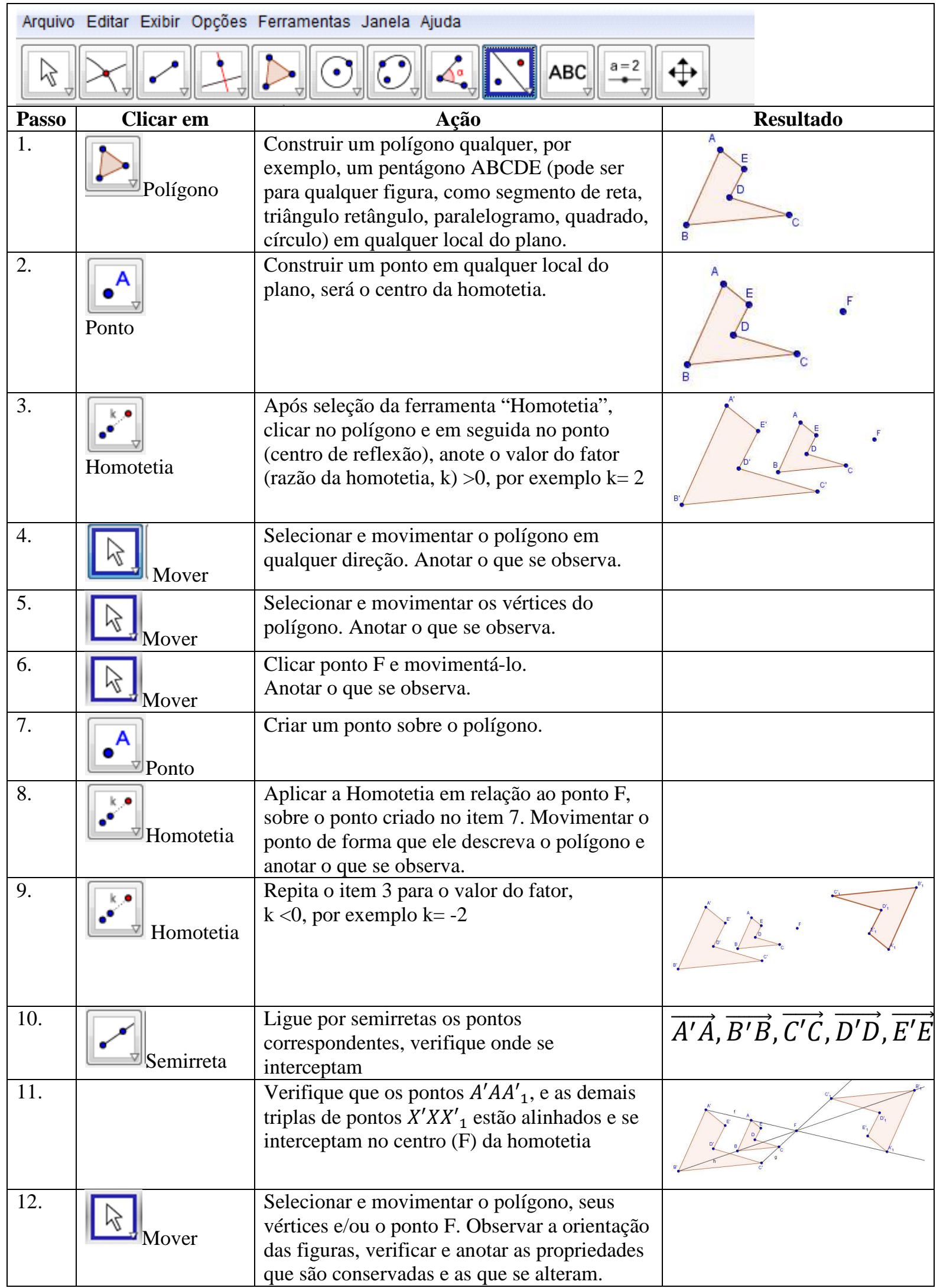




\subsubsection{Análise e utilização dos artefatos articulados}

Os artefatos listados acima serão distribuídos um para cada grupo de alunos, sem nenhuma instrução da sua finalidade e do funcionamento de cada um deles. O objetivo é que os alunos os explorem, e possam responder a algumas perguntas que serão formuladas após o período exploratório dos artefatos. Para esse período, não haverá um tempo mínimo para conclusão da análise inicial, irá depender da evolução dos trabalhos e das dificuldades observadas. Os alunos serão estimulados a trocarem ideias em seus grupos (intra) e com os demais (inter), onde as descobertas de um grupo poderão ser incorporadas pelos demais.

Neste primeiro momento, a função do professor mediador será apenas de observador, não interferindo nas discussões dos alunos. Ele, irá apenas esclarecer dúvidas e fornecer informações sobre a proposta, estimulando continuamente a participação dos alunos.

Questionário a ser formulado após o período de análise dos artefatos:

1. Alguém do grupo já conhecia algum destes dispositivos?

2. Se sim, em que contexto conheceu o(s) dispositivo(s)? (revista, internet, livros, na escola, etc.)?

3. Para que servem? O que é possível fazer com eles?

4. O que o grupo percebeu ou identificou com relação aos dispositivos fornecidos?

5. Faça comentários ou indique dúvidas que não foram abordados e/ou esclarecidos.

Após o contatato inicial com os artefatos, cada grupo receberá uma ficha (Ficha do Aluno), para o estudo da respectiva máquina matemática, operando-a e respondendo as questões propostas.

\subsubsection{Fichas do Aluno - Máquinas Matemáticas}

A seguir apresentamos as fichas ${ }^{2}$ que serão entregues aos alunos para uso com as máquinas matemáticas, esse exercício será aplicado após terem estudado as transformações geométricas usando o software GeoGebra, com isso muitas das dúvidas teóricas foram esclarecidas. A entrega dos kits será feita um para cada grupo, cada grupo irá trabalhar com um dos artefatos. Poderemos avaliar se haverá trocas de kits entre os grupos, para que todos eles possam ter contato com cada um dos artefatos, ou se cada grupo exporá para os demais, compartilhando o aprendizado que adquiriu com a máquina correspondente.

2 Fichas adaptadas das fichas elaboradas por Bonetti Anna Lina do MPI - Dipartimento di Matematica dell'Università di Modena e Reggio Emilia, disponíveis no site $<$ http://archiviomacmat.unimore.it/Sito_Macchine/Materiale/materiale_didattico/Progetto_ collaborativo_MPI/macchine/macchine.htm>, acessado em 22/08/2015, às 11: 45 h 


\subsubsection{1-Máquina de Kempe para Translação}

Data

GRUPO

Página 1

Nome dos alunos

\section{Estudo da Máquina Matemática -1 -}

\begin{tabular}{|l|l|}
\hline $\begin{array}{l}\text { Faça um esboço da máquina articulada, e coloque } \\
\text { as medidas das hastes que a compõe. }\end{array}$ & $\begin{array}{l}\text { Esboce a haste com a respectiva medida que irá } \\
\text { representar as distâncias entre os pontos } \\
\text { correspondentes da figura inicial e sua imagem. }\end{array}$ \\
&
\end{tabular}

1) Desenhe em uma folha anexa um segmento $R S$ e com a máquina, obtenha a sua transformada, que chamaremos de $R^{\prime} S^{\prime}$

2) Explore a transformação entre as duas figuras traçadas, faça a medida dos segmentos e complete as tabelas com Sim ou Não para as seguintes questões:

\begin{tabular}{|l|l|}
\hline & resposta \\
\hline RS // R'S'? & \\
\hline med(RS)=med( R'S') ? & \\
\hline
\end{tabular}

\begin{tabular}{|l|l|}
\hline & resposta \\
\hline RR' // SS' ? & \\
\hline $\operatorname{med}\left(\mathrm{RR}^{\prime}\right)=\operatorname{med}\left(\mathrm{SS}^{\prime}\right)$ ) ? & \\
\hline
\end{tabular}

Agora desenhe outra figura: um triângulo, um quadrilátero, uma circunferência, será a figura $F$, com a máquina matemática faça sua transformada, será a figura $F^{\prime}$, agora complete as sentenças:

Meça a distância entre quaisquer dois pontos da figura $F$ e a distância entre dois pontos correspondentes da figura $F^{\prime}: \overline{A B}=$ $\overline{A^{\prime} B^{\prime}}=$ ; a distância entre os pontos correspondentes é mantida?

Ligue com um segmento, dois a dois, os pontos correspondentes, como vão ficar os segmentos entre eles? Paralelos? São do mesmo tamanho?

Se com a ponta seca diretora da máquina articulada, movo contornando um polígono no sentido horário, o ponto de escrita se move na figura transformada também no sentido horário?

A transformação geométrica que posso fazer com esta máquina é a.

já estudada no laboratório com o software GeoGebra.

Escreva uma definição desta transformação: 


\section{Estudo da Máquina Matemática -1 -}

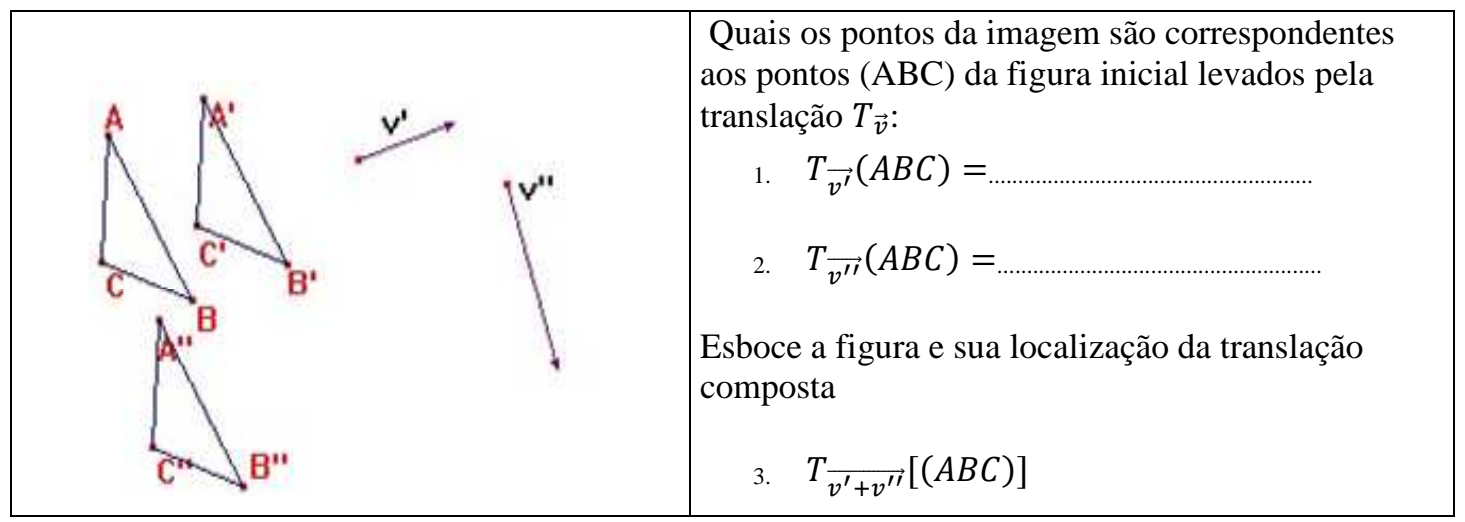

Recordando que: definimos invariantes de uma transformação geométrica as características de uma figura que se mantiveram inalteradas na transformação. Complete a tabela a seguir, sempre com a transformação geométrica em questão:

\begin{tabular}{|l|l|l|l|}
\hline & \multicolumn{1}{|c|}{} & verdadeiro & falso \\
\hline A & A distância entre os pontos é invariante & & \\
\hline B & A posição da figura transformada no plano é invariante & & \\
\hline C & A amplitude dos ângulos é invariante & & \\
\hline D & $\begin{array}{l}\text { Se duas retas são concorrentes pode ocorrer que suas transformadas não sejam } \\
\text { concorrentes }\end{array}$ & & \\
\hline E & Pontos unidos por segmento permanecem unidos nas suas transformadas & & \\
\hline F & $\begin{array}{l}\text { Em uma isometria a distância entre pontos correspondentes tem sempre o } \\
\text { mesmo valor }\end{array}$ & & \\
\hline G & Duas figuras simétricas em relação a um ponto nem sempre são congruentes & & \\
\hline
\end{tabular}




\section{Estudo da Máquina Matemática -1 - \\ Translador de Kempe.}

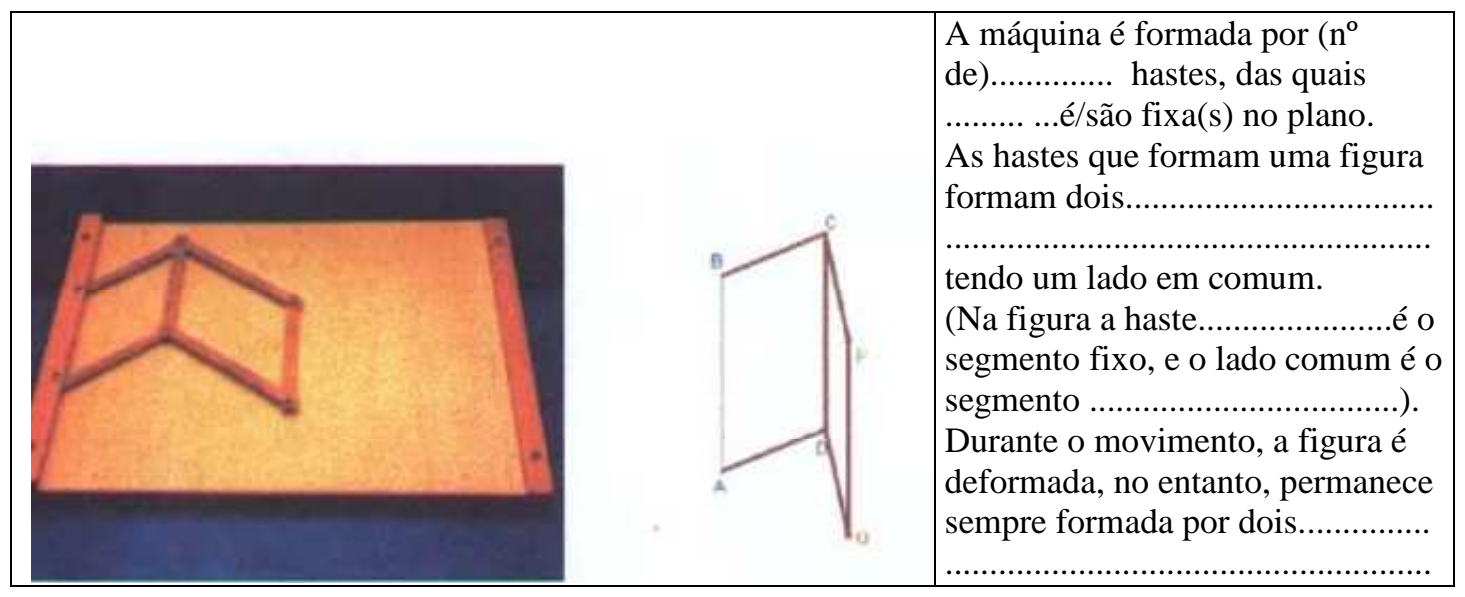

Indique na tabela abaixo com um $\mathbf{X}$ a característica da máquina que permanece variante ou invariante durante o movimento:

\begin{tabular}{|l|l|l|}
\hline propriedade & variante & invariante \\
\hline Paralelismo entre $A B, C D, O P$ & & \\
\hline Amplitudes dos ângulos entre segmentos & & \\
\hline Comprimento das hastes & & \\
\hline Comprimento das diagonais dos paralelogramos & & \\
\hline & & \\
\hline
\end{tabular}

Além disso, qual é o alcance da máquina que você tem na sua bancada?....

Qualquer plano ou apenas um semi-plano? qual é exatamente?

Se a haste é fixada à sua esquerda, a que distância você pode operar o mecanismo à sua direita? (Você pode responder com uma medida ou explicar em palavras qual a correspondência em relação à distância).............

Para cima e para baixo até que ponto a máquina pode operar? (Você pode responder com uma medida ou explicar em palavras qual a correspondência em relação à distância).

Qual é a haste da máquina que representa o vector da translação?

Assim, com esta máquina, quantas translações podemos implementar?

A introdução de modificações neste equipamento permite conseguir ter uma outra translação?.

Quais são as áreas de plano cobertas pelo equipamento? (Máximo até onde se pode chegar o ponto $P$ ? Descrevendo o quê?

E o ponto traçado por $Q$ ? 


\subsubsection{2-Máquina para Simetria Central}

Data

GRUPO.

Página 1

Nome dos alunos

\section{Estudo da Máquina Matemática - 2 -}

Faça um esboço da máquina articulada, e coloque as medidas das hastes que a compõe.
Esboce a haste com a respectiva medida que irá representar as distâncias entre os pontos correspondentes da figura inicial e sua imagem.

1) Desenhe em uma folha anexa um ponto $P$ e a sua transformada $P^{\prime}$; ligue os pontos $P$ e $P^{\prime}$ com uma régua: o que você observa?.

2) Trace agora um segmento $R S$, e sua transformada $R$ ' $S^{\prime}$ (atenção para indicar corretamente as transformadas de $R$ e de $S$ !). Ligue com uma régua $R \operatorname{com} R^{\prime}$ e $S \operatorname{com} S^{\prime}$ : o que você observa?

3) Explore a transformação entre as duas figuras traçadas, faça a medida dos segmentos e complete as tabelas com Sim ou Não para as seguintes questões ( $O$ é o ponto em cuja máquina é fixada ao plano):

\begin{tabular}{|l|r|}
\hline & resposta \\
\hline RS // R'S'? & \\
\hline $\operatorname{med}(\mathrm{RS})=\operatorname{med}\left(\mathrm{R}^{\prime} \mathrm{S}^{\prime}\right)$ ) ? & \\
\hline
\end{tabular}

\begin{tabular}{|l|l|}
\hline & resposta \\
\hline $\mathrm{SO} \cong \mathrm{S}^{\prime} \mathrm{O} ?$ & \\
\hline $\operatorname{med}(\mathrm{RO})=\operatorname{med}\left(\mathrm{R}^{\prime} \mathrm{O}\right) ?$ & \\
\hline
\end{tabular}

Agora desenhe outra figura: um triângulo, um quadrilátero, uma circunferência, será a figura $F$, com a máquina matemática faça sua transformada, será a figura $F^{\prime}$, agora complete as sentenças:

Meça a distância entre quaisquer dois pontos da figura $F$ e a distância entre dois pontos correspondentes da figura $F^{\prime}: \overline{A B}=$ $\overline{A^{\prime} B^{\prime}}=$ ; a distância entre os pontos correspondentes é mantida?

Se ligarmos com um segmento, dois a dois, os pontos correspondentes, todos os segmentos que obtemos possuem o mesmo ponto médio?. Qual é esse ponto?

Se com a ponta seca diretora da máquina articulada, movo contornando um polígono no sentido horário, o ponto de escrita se move na figura transformada também no sentido horário?.

A transformação geométrica que posso fazer com esta máquina é a. já estudada no laboratório com o software GeoGebra.

Escreva uma definição para esta transformação. 


\section{Estudo da Máquina Matemática - 2 -}

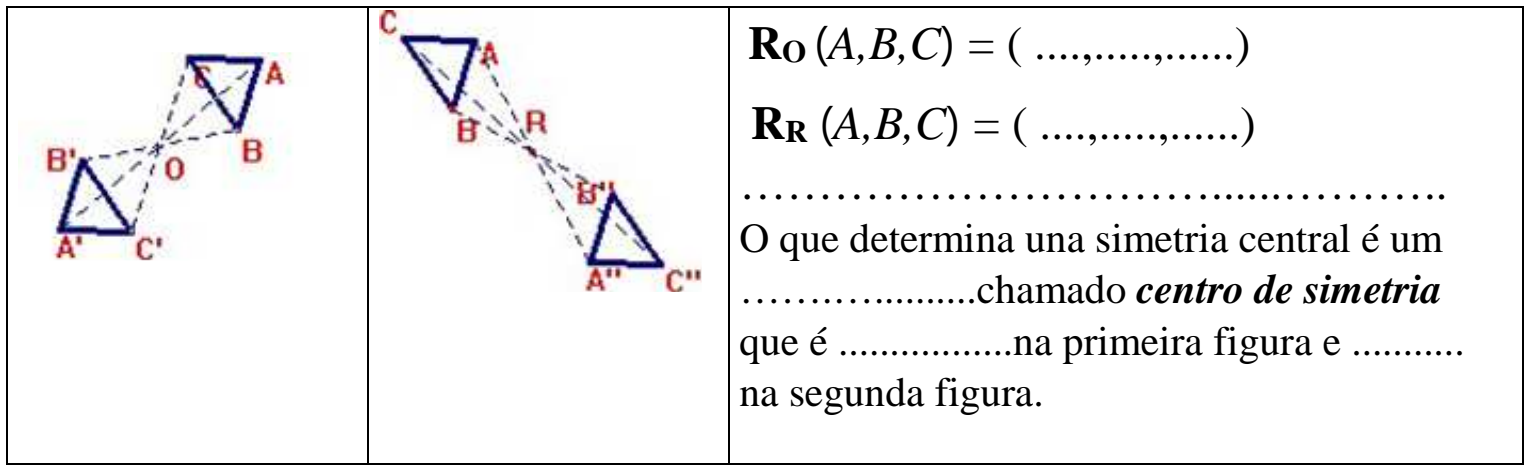

Definimos agora uma simetria central de centro $O$ como uma relação

$R_{O}(A, B, C)=\left(A^{\prime}, B^{\prime}, C^{\prime}\right)$

Recordando que: definimos invariantes de uma transformação geométrica as características de uma figura que se mantiveram inalteradas na transformação. Complete a tabela a seguir, sempre com a transformação geométrica em questão:

\begin{tabular}{|l|l|l|l|}
\hline & & verdadeiro falso \\
\hline A & A distância entre os pontos é invariante & & \\
\hline B & A posição no plano é invariante & & \\
\hline C & A amplitude dos ângulos é invariante & & \\
\hline D & $\begin{array}{l}\text { Se duas retas são concorrentes pode ocorrer que suas transformadas não sejam } \\
\text { concorrentes }\end{array}$ & & \\
\hline E & A orientação é mantida ao ser percorrida a figura em um sentido & & \\
\hline F & Numa simetria central existem pontos simétricos, exceto o centro de simetria & & \\
\hline G & Duas figuras simétricas em relação a um ponto nem sempre são congruentes & & \\
\hline H & $\begin{array}{l}\text { Em uma isometria a distância entre pontos correspondentes tem sempre o mesmo } \\
\text { valor }\end{array}$ & & \\
\hline
\end{tabular}




\section{Estudo da Máquina Matemática - 2 -}

Pantógrafo para a simetria central.

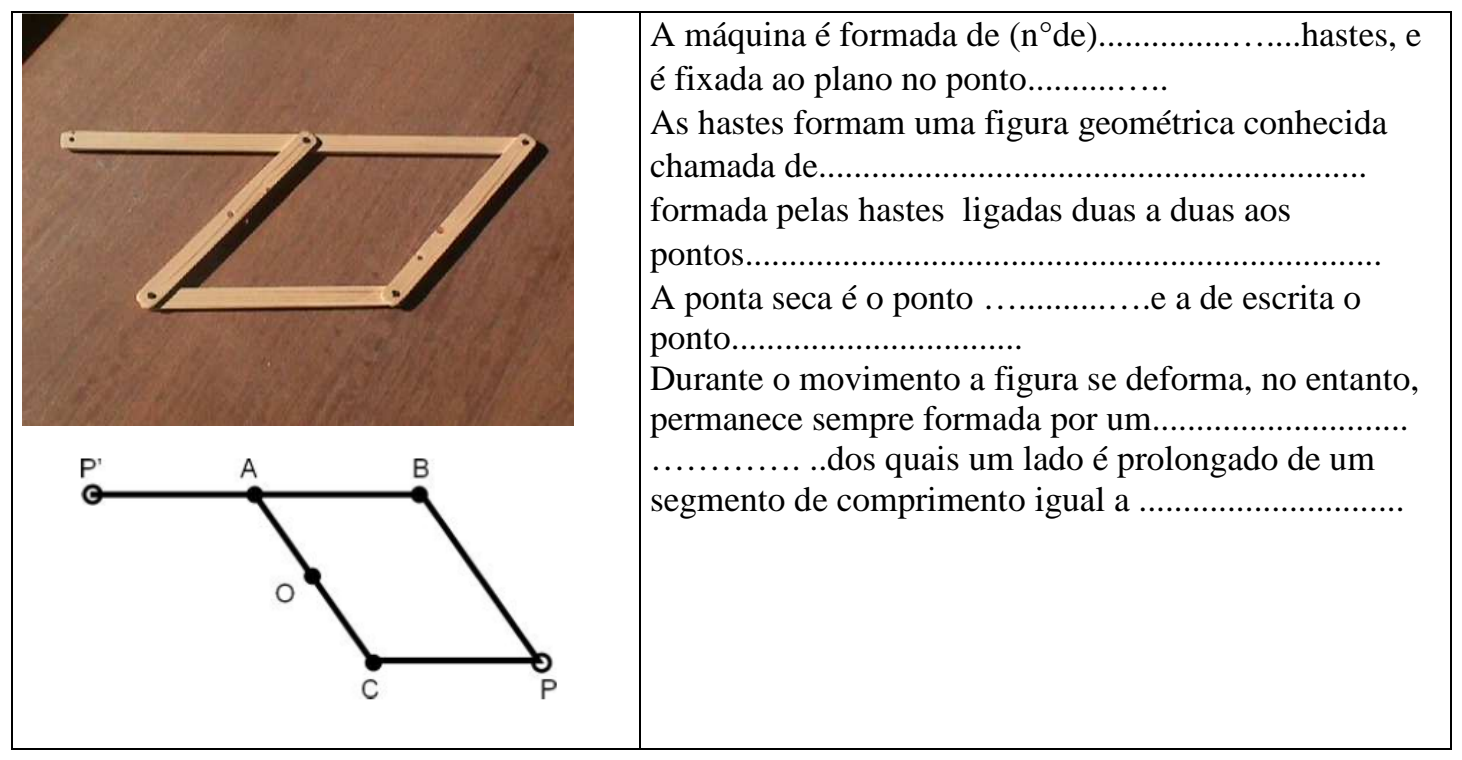

Indique na tabela abaixo com um $\mathbf{X}$ a característica da máquina que permanece variante ou invariante durante o movimento:

\begin{tabular}{|l|l|l|}
\hline propriedade & variante & invariante \\
\hline Paralelismo entre AB e CD; e entre BC e DA. & & \\
\hline Amplitude dos ângulos. & & \\
\hline Comprimentos das hastes. & & \\
\hline Comprimento da diagonal do paralelogramo. & & \\
\hline Distância entre os pontos OP e OP' & & \\
\hline
\end{tabular}

Além disso: qual é o campo de ação da máquina que você tem em sua bancada?

Todo o plano ou só uma parte?. ..qual exatamente?....

Tente alinhar os três pontos $\mathrm{P}, \mathrm{O}, \mathrm{C}$, de modo que $\mathrm{P}$ e $\mathrm{C}$ tenha uma distância máxima.

Tente alinhar os três pontos $\mathrm{P}, \mathrm{O}, \mathrm{C}$, de modo que $\mathrm{P}$ e $\mathrm{C}$ tenha uma distância mínima, neste caso OC mede.................(1).Com esta máquina se pode construir o simétrico de um ponto que dista a $\mathrm{O}$ distância da medida (1)?

Com esta máquina o centro de rotação é fixo ou varia?.

Portanto esta máquina determina uma e uma única simetria central?.

Se modificar a máquina, alterando o comprimento dos dois lados congruentes $\mathrm{AB}$ e $\mathrm{CD}$, altera a simetria ou altera somente a área de operação da máquina?

E se o lado CD fosse a metade do lado $\mathrm{AD}$ (e, portanto, também de $\mathrm{CA}$ ), come mudaria o campo de ação da máquina? 


\subsubsection{3-Máquina para Simetria Axial}

Data

GRUPO.

Página 1

Nome dos alunos....

\section{Estudo da Máquina Matemática - 3 -}

Faça um esboço da máquina articulada, e coloque as medidas das hastes que a compõe
Esboce a haste com a respectiva medida que irá representar as distâncias entre os pontos correspondentes da figura inicial e sua imagem.

1) Desenhe em uma folha em anexo um ponto $P$ e a sua transformada $P$ '; ligue os pontos $P$ e $P$, com uma régua: o que você observa?.

2) Trace agora um segmento $R S$, e sua transformada $R$ ' $S$ ' (atenção para indicar corretamente as transformadas de $R$ e de $S$ !). Ligue com uma régua $R$ com $R$ ' e $S$ com $S^{\prime}$ : o que você observa?

3) Explore a transformação entre as duas figuras traçadas, faça a medida dos segmentos e complete as tabelas com Sim ou Não para as seguintes questões:

\begin{tabular}{|l|l|}
\hline & resposta \\
\hline RS//R'S'? & \\
\hline med(RS)=med( R'S') ? & \\
\hline
\end{tabular}

\begin{tabular}{|l|l|}
\hline & resposta \\
\hline $\mathrm{SH} \cong \mathrm{S}^{\prime} \mathrm{H} ?$ & \\
\hline med(RK)=med (R'K) ? & \\
\hline
\end{tabular}

(onde $H$ e $K$ são os pontos de intersecção entre o eixo de simetria e os segmentos $S S^{\prime}$ e $R R^{\prime}$ )

Agora desenhe outra figura: um triângulo, um quadrilátero, uma circunferência, será a figura $F$, com a máquina matemática faça sua transformada, será a figura $F^{\prime}$, agora complete as sentenças:

Meça a distância entre quaisquer dois pontos da figura $F$ e a distância entre dois pontos correspondentes da figura $F^{\prime}: \overline{A B}=\ldots \ldots \ldots \ldots \ldots \ldots \ldots . . ; \overline{A^{\prime} B^{\prime}}=\ldots \ldots \ldots \ldots \ldots \ldots \ldots . .$. ; a distância entre os pontos correspondentes é mantida?

Se ligarmos com um segmento, dois a dois, os pontos correspondentes, obtenho um segmento no qual os pontos médios dos segmentos construídos se encontram.

Se com a ponta seca diretora da máquina articulada, movo contornando um polígono no sentido horário, o ponto de escrita se move na figura transformada também no sentido horário?

A transformação geométrica que posso fazer com esta máquina é a já estudada no laboratório com o software GeoGebra.

Tente escrever uma definição para esta transformação: 


\section{Estudo da Máquina Matemática - 3 -}

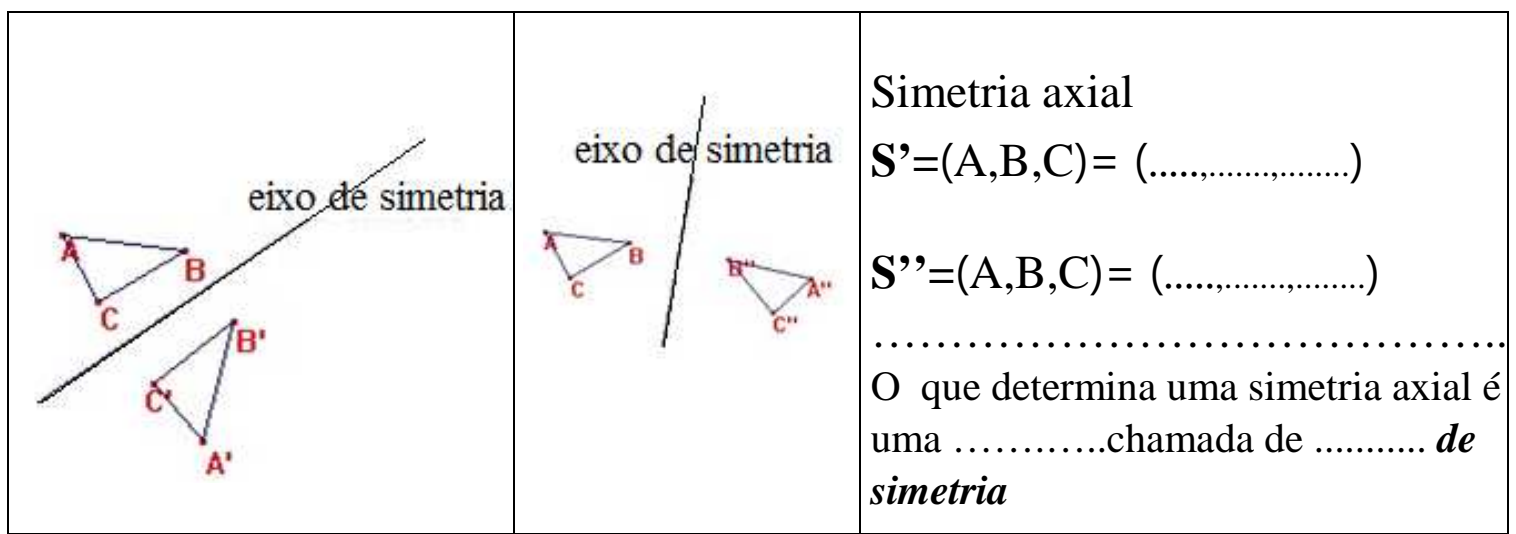

\section{Definimos agora uma simetria axial de eixo "r" como uma relação}

$R_{r}(A, B, C)=\left(A^{\prime}, B^{\prime}, C^{\prime}\right)$

Recordando que: definimos invariantes de uma transformação geométrica as características de uma figura que se mantiveram inalteradas na transformação. Complete a tabela a seguir, sempre com a transformação geométrica em questão:

\begin{tabular}{|l|l|l|l|}
\hline & \multicolumn{1}{|c|}{} & verdadeiro & falso \\
\hline A & A distância entre os pontos é invariante & & \\
\hline B & A posição no plano é invariante & & \\
\hline C & A amplitude dos ângulos é invariante & & \\
\hline D & $\begin{array}{l}\text { Se duas retas são concorrentes pode ocorrer que suas transformadas não sejam } \\
\text { concorrentes }\end{array}$ & & \\
\hline E & A orientação é mantida ao ser percorrida a figura em um sentido & & \\
\hline F & $\begin{array}{l}\text { Em uma simetria axial existem pontos simétricos, exceto os pontos do eixo de } \\
\text { simetria }\end{array}$ & & \\
\hline G & Duas figuras simétricas em relação a um eixo nem sempre são congruentes & & \\
\hline
\end{tabular}




\section{Estudo da Máquina Matemática - 3 -}

Pantógrafo para a simetria axial.
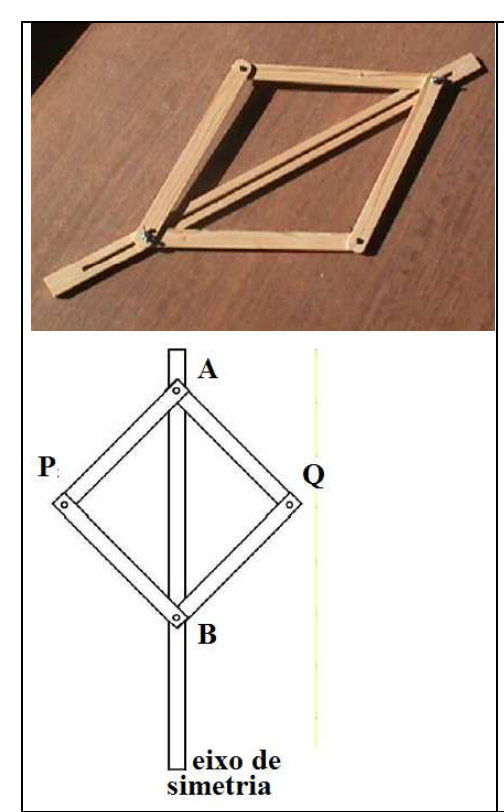

A máquina é formada de $\left(\mathrm{n}^{\circ} \mathrm{de}\right) \ldots \ldots \ldots \ldots \ldots . . .$. hastes; pode deslizar sobre o plano formado pelo eixo de simetria, onde correm os pontos.

As hastes formam uma figura geométrica conhecida chamada de. de $\left(n^{\circ}\right) \ldots . .$. lados, cujos

vértices são os pontos

A máquina é limitada a deslizar ao longo do eixo de simetria, os vértices ; isto é, a $\mathrm{AB}$ diagonal pode variar a sua mas não sua direção.

Durante o movimento, a figura é deformada, no entanto, continua a ser um .porque os quatro lados são

Indique na tabela abaixo com um $\mathbf{X}$ a característica da máquina que permanece variante ou invariante durante o movimento:

\begin{tabular}{|l|l|l|}
\hline propriedade & variante & invariante \\
\hline Paralelismo entre AQ e BP; entre BQ e PA & & \\
\hline Amplitude dos ângulos & & \\
\hline Comprimento das hastes & & \\
\hline Comprimento da diagonal do losango & & \\
\hline $\begin{array}{l}\text { Todos os pontos correspondentes são simétricos em relação ao eixo } \\
\text { de simetria }\end{array}$ & & \\
\hline
\end{tabular}

Além disso: qual é o campo de ação da máquina que você tem em sua bancada?

Todo o plano ou só uma parte?. .qual exatamente?....

Tente coincidir os pontos A e B, com isso, P e Q estarão a uma distância máxima do eixo de simetria de medida.

Tente alinhar os pontos A, P, B, Q, em relação ao eixo de simetria:

1. qual é o simétrico de $\mathrm{A}$ ?

2. qual é o simétrico de B?

3. qual é o simétrico de P?

4. qual é o simétrico de Q?

Se modificar a máquina, alterando o comprimento das quatro hastes, altera a transformação ou apenas o campo de ação da máquina?. 


\subsubsection{4-Máquina de Sylvester para Rotação}

Data

GRUPO

Página 1

Nome dos alunos.

\section{Estudo da Máquina Matemática - 4 -}

Faça um esboço da máquina articulada, e coloque as medidas das hastes que a compõe
Esboce as hastes com as respectivas medidas que irão representar os pontos correspondentes da figura inicial e sua imagem

1) Desenhe em uma folha em anexo um ponto $P$ e a sua transformada $P^{\prime}$; com uma régua ligue o ponto $P$ com o ponto fixo (chamado $\mathrm{O}$ ) da máquina e faça a mesma coisa com $P^{\prime}$ : quanto mede $O P$ ? ............e $O P^{\prime} ? \ldots \ldots \ldots \ldots \ldots \ldots . . . .$. Meça com um transferidor o ângulo $P O P '$; quanto vale a medida?...

2) Trace agora um segmento $R S$, sua transformada $R$ ' $S^{\prime}$ (atenção para indicar corretamente a transformada de $R$ e de $S$ !). Una com uma régua $R$ com $O$ e $R^{\prime}$ com $O$; quanto vale o ângulo

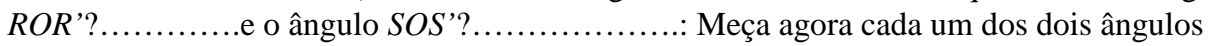
dos vértices dos triângulos isósceles que são componentes da máquina matemática para efetuar rotações; quanto medem?:

3) Explore a transformação entre as duas figuras traçadas e complete a tabela

\begin{tabular}{|l|l|}
\hline$\wedge \wedge$ & resposta \\
\hline$\wedge \mathrm{ROR}^{\prime}=\mathrm{SOS}{ }^{\prime}$ & \\
\hline $\operatorname{med}(\mathrm{RS})=\operatorname{med}\left(\mathrm{R}^{\prime} \mathrm{S}^{\prime}\right)$ & \\
\hline
\end{tabular}

\begin{tabular}{|l|l|}
\hline $\operatorname{med}(\mathrm{RO})=\operatorname{med}\left(\mathrm{R}^{\prime} \mathrm{O} ?\right)$ & \\
\hline $\operatorname{med}(\mathrm{SO})=\operatorname{med}\left(\mathrm{S}^{\prime} \mathrm{O} ?\right)$ & \\
\hline
\end{tabular}

Agora desenhe outra figura: um triângulo, um quadrilátero, uma circunferência, será a figura $F$, com a máquina matemática faça sua transformada, será a figura $F^{\prime}$, agora complete as sentenças:

Meça a distância entre dois pontos quaisquer da figura $F$ e a distância entre os dois pontos correspondentes da figura $F^{\prime}: \overline{A B}=$ $\overline{A^{\prime} B^{\prime}}=$ ; a distância entre os pontos correspondentes é mantida?.

Se com a ponta seca diretora da máquina articulada, movo contornando um polígono no sentido horário, o ponto de escrita se move na figura transformada também no sentido horário?....

A transformação geométrica que posso fazer com esta máquina é a. já estudados em laboratório com o software GeoGebra.

Tente escrever uma definição para esta transformação: 


\section{Estudo da Máquina Matemática - 4 -}

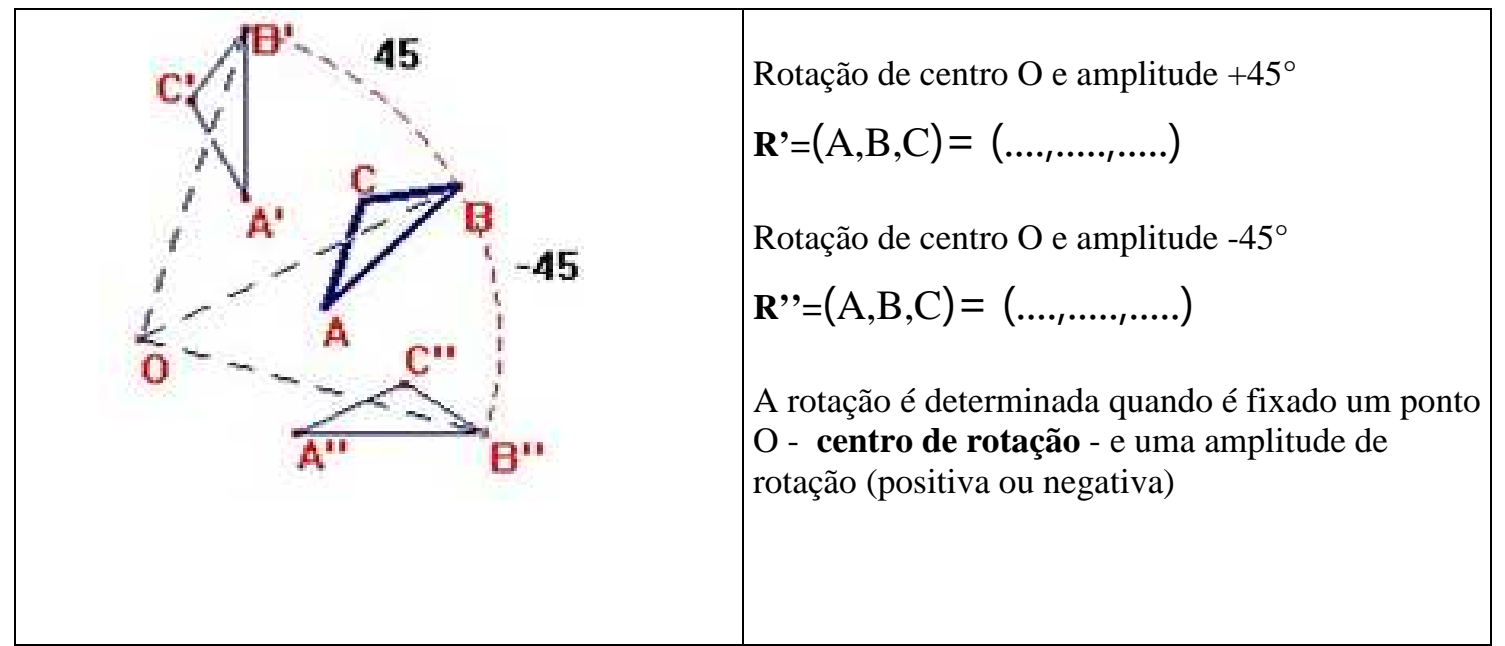

Definimos agora rotação como uma correspondência biunívoca entre os pontos do plano

$$
\boldsymbol{R}_{\boldsymbol{O}, \boldsymbol{\alpha}}(\boldsymbol{A}, \boldsymbol{B}, \boldsymbol{C})=\left(\boldsymbol{A}^{\prime}, \boldsymbol{B}^{\prime}, \boldsymbol{C}^{\prime}\right)
$$

Recordando que: definimos invariantes de uma transformação geométrica as características de uma figura que se mantiveram inalteradas na transformação. Complete a tabela a seguir, sempre com a transformação geométrica em questão:

\begin{tabular}{|l|l|l|l|}
\hline & & verdadeiro falso \\
\hline A & A distância entre os pontos é invariante & & \\
\hline B & A posição no plano é invariante & & \\
\hline C & A amplitude dos ângulos é invariante & & \\
\hline D & $\begin{array}{l}\text { Se duas retas são concorrentes pode ocorrer que suas transformadas não } \\
\text { sejam concorrentes }\end{array}$ & & \\
\hline E & A orientação é mantida ao ser percorrida a figura em um sentido & & \\
\hline F & Numa rotação existem pontos imagem, exceto o centro de rotação & & \\
\hline
\end{tabular}




\section{Estudo da Máquina Matemática - 4 -}

Pantógrafo de Sylvester para a rotação.

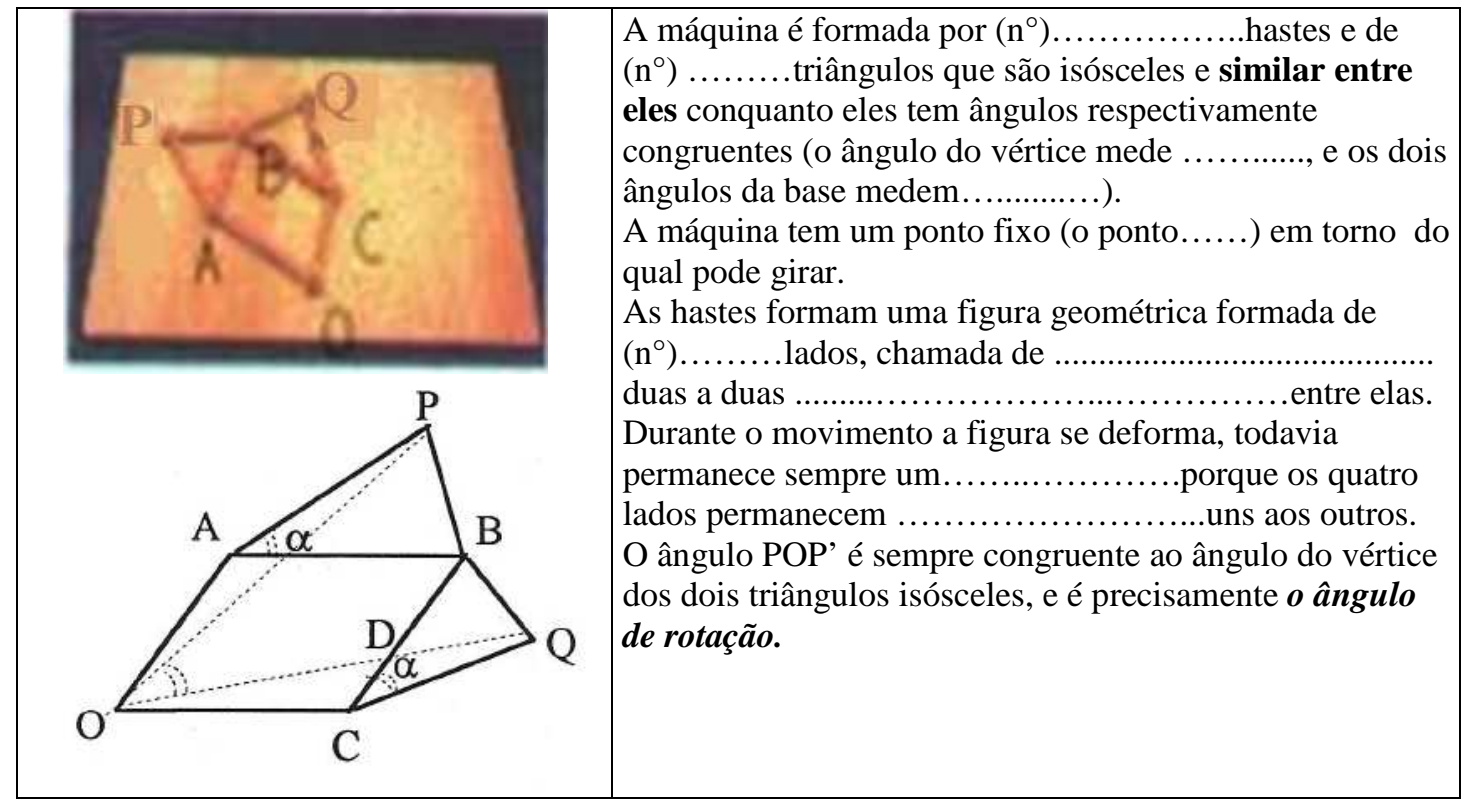

$\mathrm{O}$ angulo $P O P$ ' é sempre congruente ao ângulo nos vértices opostos às bases $P B$ e $Q B$, dos dois triângulos isósceles, e é precisamente o ângulo de rotação

Indique na tabela abaixo com um $\mathbf{X}$ a característica da máquina que permanece variante ou invariante durante o movimento:

\begin{tabular}{|l|l|l|}
\hline propriedade & variante & invariante \\
\hline Paralelismo ente OA e BC e entre AB e OC & & \\
\hline Amplitude dos ângulos dos dois triângulos & & \\
\hline Comprimento das hastes & & \\
\hline Comprimento das diagonais do paralelogramo & & \\
\hline Amplitude dos ângulos do paralelogramo & & \\
\hline
\end{tabular}

Além disso: qual é o campo de ação da máquina que você tem em sua bancada?

Todo o plano ou só uma parte?.

qual exatamente?.

Tente alinhar $O A P$ e $O C Q \ldots$ O que você pode dizer sobre o alcance do campo de ação da máquina?.

Se modificar a máquina, alterando o comprimento dos quatro lados do losango, mas deixando inalterada a ângulo do vértice do triângulo isósceles, a mudança altera a transformação ou somente o campo de ação da máquina? 


\subsubsection{5-Máquina de Schiner para Homotetia}

Data

GRUPO.

Página 1

Nome dos alunos

\section{Estudo da Máquina Matemática - 5 -}

Faça um esboço da máquina articulada, e coloque as medidas das hastes que a compõe
Esboce as hastes com as respectivas medidas que irão representar os pontos correspondentes da figura inicial e sua imagem

1) Desenhe em uma folha em anexo um ponto $P$, um ponto $O$ (centro da homotetia), e a transformada $P^{\prime}$; ligue os pontos $P$ e $P^{\prime}$ com uma régua: o que você observa?

2) Trace agora um segmento $R S$, e sua transformada $R^{\prime} S^{\prime}$, para $k>0$ (atenção para indicar corretamente as transformadas de $R$ e de $S$ !,). Ligue com uma régua $R \operatorname{com} R$ ' e $S \operatorname{com} S^{\prime}$ : o que você observa?.

3) Explore a transformação entre as duas figuras traçadas, faça a medida dos segmentos e complete as tabelas com Sim ou Não para as seguintes questões:.

\begin{tabular}{|l|l|l|}
\hline & \multicolumn{2}{|c|}{ respostas } \\
\hline & $\mathrm{k}<0$ & $\mathrm{k}>0$ \\
\hline $\mathrm{RS} / \mathrm{R}^{\prime} \mathrm{S}^{\prime} ?$ & & \\
\hline $\operatorname{med}(\mathrm{RS})=\operatorname{med}\left(\mathrm{R}^{\prime} \mathrm{S}^{\prime}\right)$ & & \\
\hline
\end{tabular}

\begin{tabular}{|l|l|l|}
\hline & \multicolumn{2}{|c|}{ respostas } \\
\hline & $\mathrm{k}<0$ & $\mathrm{k}>0$ \\
\hline RR'//SS'? & & \\
\hline med(RR')=med( SS') ? & & \\
\hline
\end{tabular}

4) Repita os itens (2) e (3) para $\mathrm{k}<0$.

Agora desenhe outra figura: um triângulo, um quadrilátero, uma circunferência, será a figura $F$, com a máquina matemática faça sua transformada, será a figura $F^{\prime}$, agora complete as sentenças:

Meça a distância entre dois pontos quaisquer da figura $F$ (use $\mathrm{k}>0$ ) e a distância entre os dois pontos correspondentes da figura F': $\overline{A B}=$ $\overline{A^{\prime} B^{\prime}}=$ ; a distância entre os pontos correspondentes é mantida?

Se ligarmos com um segmento, dois a dois, os pontos correspondentes, esses segmentos construídos se encontram? Onde?

Se com a ponta seca diretora da máquina articulada, movo contornando um polígono no sentido horário, o ponto de escrita se move na figura transformada também no sentido horário?....

$\mathrm{O}$ que muda quando fazemos $\mathrm{k}<0$ ?.

A transformação geométrica que posso fazer com esta máquina é a já estudada no laboratório com o software GeoGebra.

Tente escrever uma definição para esta transformação: 


\section{Estudo da Máquina Matemática - 5 -}

Homotetia
$H_{0},(\mathrm{~A}, \mathrm{~B}, \mathrm{C})=(\ldots \ldots, \ldots \ldots, \ldots \ldots)$

Definimos agora uma homotetia de centro "O" de razão "k" como uma relação

$$
\boldsymbol{R}_{\boldsymbol{O}, \boldsymbol{k}}(\boldsymbol{A}, \boldsymbol{B}, \boldsymbol{C})=\left(\boldsymbol{A}^{\prime}, B^{\prime}, \boldsymbol{C}^{\prime}\right)
$$

Recordando que: definimos invariantes de uma transformação geométrica as características de uma figura que se mantiveram inalteradas na transformação. Complete a tabela a seguir, sempre com a transformação geométrica em questão:

\begin{tabular}{|l|l|l|l|}
\hline & & verdadeiro & falso \\
\hline A & A distância entre os pontos é invariante & & \\
\hline B & A posição no plano é invariante & & \\
\hline C & A amplitude dos ângulos é invariante & & \\
\hline D & $\begin{array}{l}\text { Se duas retas são concorrentes pode ocorrer que suas transformadas não sejam } \\
\text { concorrentes }\end{array}$ & & \\
\hline E & A orientação é mantida ao ser percorrida a figura em um sentido para $\mathrm{k}>0$ & & \\
\hline F & A orientação é mantida ao ser percorrida a figura em um sentido para $\mathrm{k}<0$ & & \\
\hline G & $\begin{array}{l}\text { Em uma homotetia existem pontos homotéticos exceto o ponto centro de } \\
\text { homotetia }\end{array}$ & & \\
\hline H & Duas figuras homotéticas nem sempre são congruentes & & \\
\hline I & Duas figuras homotéticas são sempre semelhantes & & \\
\hline
\end{tabular}




\section{Estudo da Máquina Matemática - 5 -}

Pantógrafo de Schiner para homotetia.

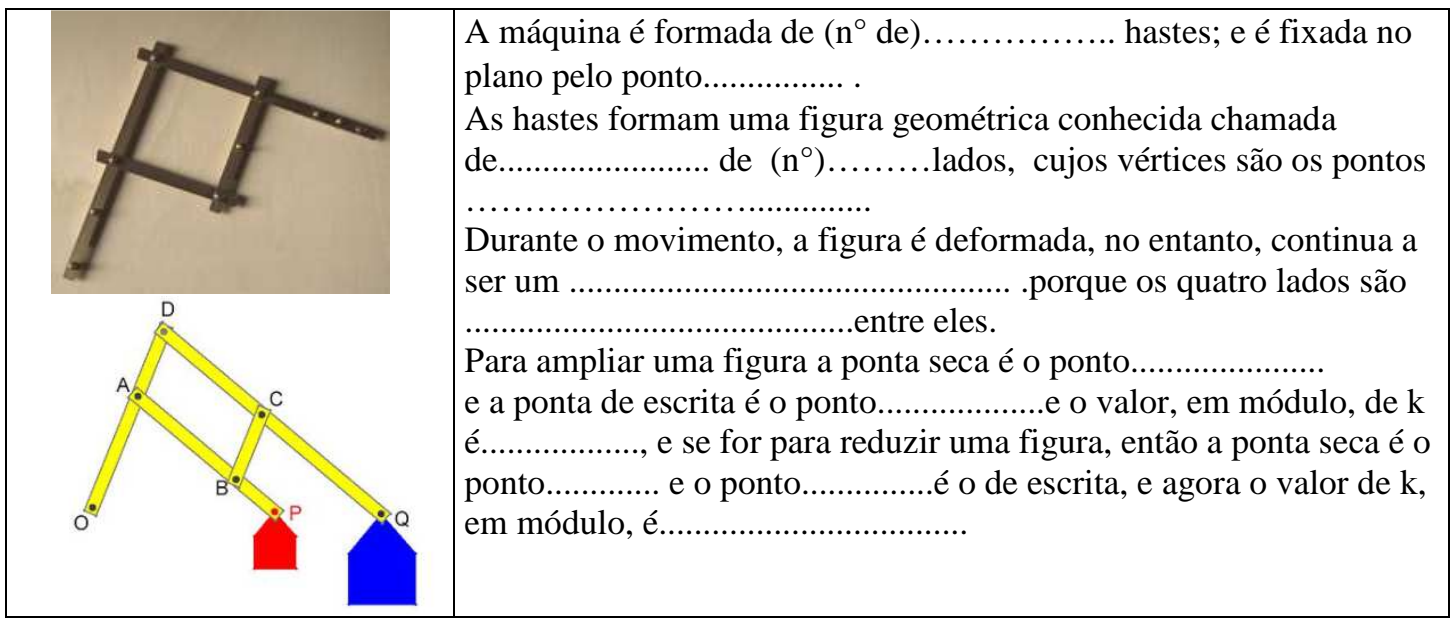

Indique na tabela abaixo com um $\mathbf{X}$ a característica da máquina que permanece variante ou invariante durante o movimento:

\begin{tabular}{|l|l|l|}
\hline propriedade & variante & invariante \\
\hline Paralelismo entre AB e DC; entre AD e BC & & \\
\hline Amplitude dos ângulos & & \\
\hline Comprimento das hastes & & \\
\hline Comprimentos das diagonais do paralelogramo & & \\
\hline & & \\
\hline
\end{tabular}

Além disso: qual é o campo de ação da máquina que você tem em sua bancada?

Todo o plano ou só uma parte?. .qual exatamente?.

Movimente a máquina de modo que $O$ e $Q$ tenha uma distância máxima.

Movimente a máquina, de modo que $O$ e $Q$ tenha uma distância mínima, nesse caso, meça a distância de $O$ a $Q$ (medida 1).................Com esta máquina pode-se construir o simétrico de um ponto que dista de $O$ a distância da medida (1)?

Com esta máquina o centro de homotetia é fixo ou varia?

Portanto esta máquina determina uma e uma única homotetia?.

Se modificar a máquina, alterando o comprimento dos dois lados $A P$ e $D Q$, do mesmo valor, altera a homotetia ou altera somente a área de operação da máquina?

E se o lado $B C$ fosse transferido, paralelamente na direção ao lado $D O$, se aproximando (se afastando) do lado $D O$, mudaria o campo de ação da máquina?.

Se modificar a máquina, alterando o comprimento das quatro hastes, altera a transformação ou apenas o campo de ação da máquina? 


\subsubsection{Utilização do GeoGebra na implementação dos artefatos articulados}

A implementação dos instrumentos articulados, máquinas matemáticas, no GeoGebra, requer o conhecimento na utilização dos recursos das ferramentas de construção (B.2) em um estágio um pouco mais avançado.

Como referência podemos citar o trabalho de mestrado no PROFMAT-IMPA, da mestranda Patrícia Mello Bittencourt (BITTENCOURT, 2014), onde constam todos os passos (66) para a construção do pantógrafo para ampliação e redução (Homotetia). Por outro lado, encontramos na internet, diversos artefatos implementados no GeoGebra prontos para serem utilizados pelos professores em sala de aula, para que possibilite aos alunos, alguns recursos que possam incentivá-los a terem o interesse para a compreensão das propriedades das transformações geométricas.

Abaixo um quadro onde constam algumas simulações encontradas na web, outras estão disponíveis, basta acessar os sites de busca e procurá-los. 


\subsubsection{Quadro Simulações das Máquinas Matemáticas}

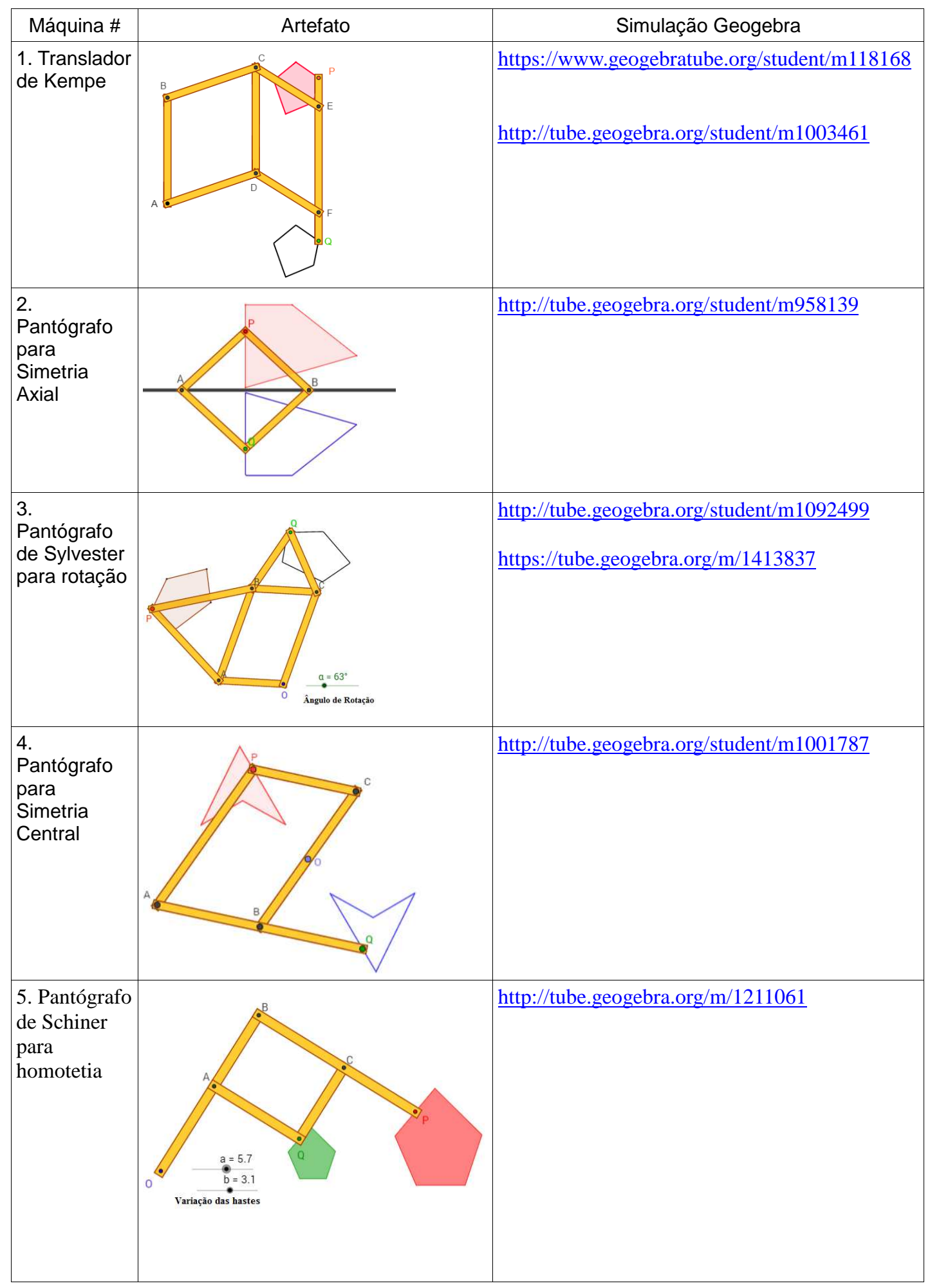




\section{Conclusões}

Pretendemos abordar de uma maneira geral, ao finalizarmos este estudo, uma reflexão do resultado que obtivemos, $[\ldots]$

\section{Considerações Finais}

Dentre as motivações elencadas no início deste estudo, cabe ressaltar que tornar o estudo das Transformações Geométricas na Escola Básica mais dinâmico, enfatizando alguns aspectos conceituais importantes, com a possibilidade do uso de software de geometria dinâmica - Geogebra - e de artefatos - máquinas matemáticas, nos permitiu avaliar, como um dos objetivos propostos, o potencial desses recursos.

Elaboramos uma devida organização deste trabalho e iniciamos pelo estudo da abordagem do desenvolvimento histórico e cognitivo das Transformações Geométricas, e nos utilizamos da obra de Piaget e Garcia (2011) do livro intitulado Psicogênese e História das Ciências, que para esses autores, a gênese do conhecimento na criança é clarificada e aprofundada pelo estudo histórico do pensamento científico, e caracterizam-se por três etapas do desenvolvimento, trata-se da tríade dialética, intra-, inter- e transfigural.

Procuramos identificar na análise dos documentos oficiais, em particular os PCN (1998) para o ensino de sexta ao nono anos da Educação Básica, especificamente em relação à Matemática, quais as recomendações para inserção das transformações geométricas nos currículos oficiais, bem como analisamos as propostas do Currículo do Estado de São Paulo (SÃO PAULO, 2012), e os Cadernos de Matemática da Secretaria de Educação do Estado de São Paulo (SÃO PAULO, 2014-2017). Selecionamos alguns livros didáticos aprovados pelo Programa Nacional do Livro Didático (PNLD) 2014 do Ministério da Educação (BRASIL, 2013) para verificarmos como esse objeto de ensino é transposto para os livros.

Vale ressaltar que na leitura dos PCN fica evidente as sugestões para o uso de diferentes fontes de informação e de recursos tecnológicos, como o uso de software, para a aquisição e construção do conhecimento, identificando simetrias, congruências e semelhanças em figuras tridimensionais, na natureza, nas artes e edificações, e ainda produzir e analisar transformações e ampliações/reduções de figuras geométricas planas, identificando seus elementos variantes e invariantes, desenvolvendo o conceito de congruência e semelhança.

Ao analisarmos a Proposta Curricular do Estado de São Paulo, Matemática e suas Tecnologias, (SÃO PAULO, 2012), ficou evidente também a sugestão para o uso de diferentes tecnologias, considerando que esta imprime um ritmo sem precedentes à 
aquisição de conhecimentos. Verificamos, de maneira geral, que é possível reconhecer, em situações de ensino, uma polarização entre as atividades preparatórias - como a observação e a manipulação de objetos concretos, a caracterização das formas mais frequentes através das atividades empíricas - e a sistematização do conhecimento geométrico que se seguirá, onde predominarão as definições precisas, o enunciado cuidadoso, o encadeamento de proposições nas justificativas formais ou informais de certos resultados (MACHADO, 1990). Nessa perspectiva, nos utilizamos do Tetraedro Epistemológico, assim definido por Machado (1990) no Capítulo XX.

Assim, é possível caracterizarmos o conhecimento geométrico através do que Machado (1990) considera as quatro faces de um tetraedro, que se articulam mutuamente, e se relacionam permanentemente: a Percepção, a Construção, a Representação e a Concepção.

Com efeito, percebemos na análise dos conteúdos dos Cadernos de Matemática da Secretaria de Educação Do Governo do Estado de São Paulo, (SÃO PAULO, 2014-2017), em relação ao tema deste estudo - Transformações Geométricas - que essa interação contínua se faz presente desde a iniciação nessa disciplina no $6^{\circ}$ ano, que realiza -se por meio da percepção das formas geométricas e de suas propriedades, caracterizando conforme Piaget e Garcia (2011), a etapa intrafigural, e procura-se desenvolver as habilidades de compreender, reconhecer, identificar simetrias, eixos de simetria e construir figuras geométricas elementares, prosseguindo no $7^{\circ}$ ano, onde procura-se ampliar conceitos importantes nas formas geométricas encontradas no cotidiano, identificando simetria axial e de rotação, e a nosso ver configurando o início da etapa interfigural, finalizando nos cadernos do $9^{\circ}$ ano, onde são explorados os conceitos de semelhança entre figuras planas, sugerindo como estratégia a resolução de situações-problema.

Prosseguimos em nosso trabalho, a análise dos livros didáticos de coleções do PNLD 2014 (Brasil, 2013) e selecionamos inicialmente, dentre as dez coleções, com base no sumário e de comentários da resenha do PNLD mencionado, três livros didáticos, Matemática - Ideias e Desafios (ONAGA e MORI, 2009), Projeto Teláris - Matemática (DANTE, 2013) e Vontade de Saber Matemática (PATARO e SOUZA, 2012).

Nos propusemos a verificar em cada coleção: o comentário da resenha do PNLD em relação ao tópico Transformação Geométrica (TG), a proposta no Manual do Professor em sua coleção, os conteúdos abordados, como os conceitos são introduzidos, as atividades propostas para desenvolver os conteúdos, as atividades propostas para os alunos em relação ao tópico visto, os materiais didáticos utilizados e as considerações relevantes.

Em função destas verificações, pudemos sintetizar, a nosso ver, na forma de destaques, o que cada coleção apresenta em relação à TG, cada qual com seu valor na exploração de determinado tópico, e de um modo geral, conforme a proposta dos autores. Se tivéssemos que escolher dentre as coleções a que estivesse mais próxima do estudo que nos propusemos desenvolver neste trabalho, indicaríamos a coleção 3, por sugerir a utilização de software 
para o desenvolvimento de determinados tópicos, e também para algumas atividades propostas, bem como menciona o uso de pantógrafo para o caso do estudo da homotetia.

Destaques da Coleção 1: Matemática - Ideias e Desafios: uso de dobraduras e de papel quadriculado, propõe atividades experimentais e lúdicas, enfatiza a relação de congruência entre figuras, faz uma abordagem mais intrafigural, destacando as propriedades nas figuras planas, dando pouca ênfase nos aspectos interfigurais. Notamos que não foi bem explorada a relação entre semelhança e homotetia.

Destaques da Coleção 2: Projeto Teláris: utiliza uma abordagem inicial intuitiva, mas com sistematização posterior com o uso de linguagem simbólica, mais formal, faz uma revisão de todas as transformações geométricas propostas, caracterizando-as como correspondências biunívocas, tratando as transformações geométricas como aplicações entre figuras inicial e final. Enfatiza que a translação, reflexão e rotação são isometrias: figuras inicial e final congruentes, e que na homotetia, as figuras inicial e final são semelhantes. Trata os aspectos intra e interfigurais, porém estaticamente.

Destaques da Coleção 3 - Vontade de Saber Matemática: utiliza praticamente em toda a coleção, após cada tópico analisado, seções com o título, Acessando Tecnologia, e no caso das transformações geométricas, propõe o uso do GeoGebra para a reflexão em relação a uma reta e para a rotação em torno de um ponto, com explicações claras e de fácil entendimento para o uso das ferramentas deste software de geometria dinâmica. Para a homotetia, menciona o uso de pantógrafo como maneira de executar as operações de ampliação e redução de figuras planas.

De certa maneira, dentre as dez coleções vistas no PNLD 2014 (Brasil, 2013), a coleção 3 propõem o uso de tecnologias, para o desenvolvimento de vários tópicos, além dos relativos às transformações geométricas, e vem ao encontro do estudo que faz parte do nosso trabalho, o que nos deixa esperançosos para que esses e outros recursos possam ser incorporados no cotidiano das salas de aula, e que se possa avaliar seu potencial no ensino-aprendizagem.

Reservamos um capítulo para tratarmos das propriedades das transformações geométricas e para dar um embasamento teórico às isometrias e homotetias, a nosso ver necessárias para compreendermos os conceitos envolvidos. Analisamos todas as transformações e acreditamos que possa facilitar a compreensão ao utilizarmos as ferramentas que nos propusemos explorar neste estudo, ou seja, o uso do software GeoGebra e o uso dos artefatos articulados nas transformações geométricas. Acrescentamos alguns tópicos sobre a composição de transformações, que pode servir como sugestão para serem exploradas em trabalhos posteriores.

A maioria das demonstrações de teoremas, proposições, corolários, foram colocadas em um apêndice, para que possam ser consultadas quando necessário, apenas algumas 
dessas demonstrações acompanham o enunciado por julgarmos que possam contribuir para o seu entendimento.

Quanto ao uso do software GeoGebra (Software System for Dynamic Geometry and Algebra, disponível em < http://geogebra.org>, como já mencionado no texto, o escolhemos por ser software gratuito, multiplataforma, código aberto, combina recursos de geometria dinâmica, álgebra, tabelas, gráficos, probabilidade, estatística, cálculos simbólicos, em um único ambiente e com potencial para estudo das transformações, destacando aspectos interfigurais e propriedades das transformações, e a inserção dos exemplos com passoa-passo, poderá facilitar o contato com as funcionalidades e ferramentas disponíveis do software. A sugestão que fizemos de páginas da Internet para a obtenção de inúmeros materiais, como o GeoGebraTube (<https://tube.geogebra.org>), poderá enriquecer e dinamizar o estudo das transformações geométricas em sala de aula, e em laboratório de matemática.

Complementando o estudo, inserimos o uso de Máquinas Matemáticas para transformações geométricas, que são artefatos concebidos com finalidade específica: transforma um ponto, um segmento ou uma figura plana de acordo com uma "lei matemática", e permitem explorar situações interessantes em sala de aula: questionar e buscar compreender o que cada máquina faz, e porque ela faz isso, associa-las às propriedades mais importantes e os seus respectivos conceitos, buscar significados.

Conceituamos cada um dos artefatos que selecionamos para esse estudo, que genericamente são chamados de pantógrafos. Incluímos quatro artefatos para o estudo das isometrias: translação, rotação, simetrias axial e central, e um pantógrafo para homotetia. Inserimos algumas combinações de pantógrafos para propiciar ao leitor a oportunidade de poder efetuar outras montagens e combinações de pantógrafos para o estudo dos resultados a serem obtidos, e de certo modo estimular tanto os alunos quanto os professores à usarem a criatividade.

Sugerimos a construção das máquinas matemáticas com o uso de diversos materiais recicláveis, e que pode ser realizada em outras disciplinas, como por exemplo, em Artes, agregando uma característica interdisciplinar ao estudo, e com isso propusemos algumas atividades, que não se esgotam nesse trabalho, e são apenas sugestões para que o professor/facilitador possa aplica-los em sala de aula, laboratório de matemática, ou outros espaços que possam ser associados no desenvolvimento do estudo das transformações geométricas.

A nosso ver, as atividades com o uso do GeoGebra associado o uso de Máquinas Matemáticas, não deve necessariamente ser aplicada nessa ordem, mas pode-se inicialmente apresentar os artefatos articulados para que sejam manipulados, constituindo a fase da percepção, conforme o Tetraedro Epistemológico (fig. XX), podendo tanto passar para uma das outras fases, o da concepção e em seguida o da representação. Pode-se também, 
como foi sugerida a construção dos artefatos, nas aulas de Arte, por exemplo, iniciar pela fase da construção e manipulação dos artefatos, e em seguida à concepção e representação das transformações, embasando os alunos à percepção dessas transformações e com isso podendo representa-las com o conteúdo teórico aprendido, o que significa compreender o significado das transformações geométricas, focando nas propriedades essenciais, de variância e invariância, paralelismo, congruência e semelhança, entre outras.

Em nosso estudo pudemos também associar e compreender essas fases com os estudos de Piaget e Garcia (2011) quanto às etapas intrafigurais e interfigurais presentes na construção, percepção, concepção e representação das transformações.

Uma das propostas desse estudo, aplicadas às atividades, consiste na utilização do GeoGebra para implementarmos os artefatos articulados. Como essa atividade demanda um conhecimento mais profundo das ferramentas do software, sugerimos a leitura do trabalho de mestrado, feito no PROFMAT-IMPA (BITTENCOURT, 2014) como referência, implementado para a homotetia, e também como sugestão para outros estudos, ou seja, a implementação para as isometrias.

Incluímos também um quadro com sugestões das implementações das máquinas matemáticas que se encontram em sites da internet, e que podem ser utilizadas em sala de aula, e como já havíamos mencionado, o material encontrado na internet é muito farto, e os professores podem enriquecer suas aulas, estimulando seus alunos a desenvolverem a compreensão dos significados, uma forma de aprendizagem.

Para finalizar essas considerações, enfatizamos que não só podemos falar sobre transformações geométricas, com o uso de certas ferramentas tecnológicas disponíveis voltadas para a educação, ou adaptadas a ela, não só as disponíveis, mas também que possam ser construídas utilizando diversos tipos de materiais, mas falarmos das transformações que possam contribuir para o ensino-aprendizagem.

Entendemos que nosso papel como educador é permitir que nossos alunos possam compreender o significado dos diversos conteúdos que lhe são apresentados, significado esse que se constrói por meio de relações de movimentos transformadores, e que estão em permanente estado de atualização, daí a importância de se conhecer a história dessas transformações. Esse estudo é uma parte deste movimento, e contribuiu sobremaneira com o aprendizado do autor desse estudo, houve compreensão e consciência dos temas abordados, de suas aplicações, suas possibilidades de poder mudar, de poder criar, abrindo novas perspectivas de estudo.

Podemos afirmar com plena convicção, que desde o início desse trabalho de dissertação, quando ainda fazíamos planos quanto ao tema a ser escolhido, tínhamos certeza apenas de aplicar recursos tecnológicos que pudessem ser facilitadores no ensino e na aprendizagem da matemática. Assim, houve uma enorme transformação com o próprio 
autor desde o início dos trabalhos à finalização, que permanece em constante movimento, houve enormes ganhos, e esperamos que haja ganhos também para quem fizer uso desse estudo.

Esses movimentos, que trabalham figuras estáticas, com suas propriedades analisadas na etapa intrafigural, e que ganham movimento com as transformações, passando à análise das propriedades na etapa interfigural, permite que no estudo das isometrias e homotetias das figuras geométricas planas, reconheçamos estes movimentos, transportando as figuras para outras regiões do plano, e o que nos interessa é saber da variância ou invariância de certas características das figuras, o que altera, o que preserva.

Essa maneira de pensar o movimento, movimento que mantem sem modificar, ou modificando propriedades, nos remete a dois pensadores filosóficos da antiguidade, Heráclito e Parmênides ${ }^{3}$.

Heráclito de Éfeso (535 - 475 a.C.) foi o filósofo pré-socrático considerado o "Pai da dialética". Heráclito parte do princípio de que tudo é movimento, e que nada pode permanecer parado, tudo se move, exceto o próprio movimento. Mas este é apenas um pressuposto de uma doutrina que vai mais além. O devir, a mudança que acontece em todas as coisas é sempre uma alternância entre contrários: coisas quentes se esfriam, coisas frias se esquentam; coisas úmidas secam, coisas secas umedecem, etc. A realidade acontece, então, não em uma das alternativas, posto que ambas são apenas parte de uma mesma realidade, mas sim na mudança, ou, como ele chama, na guerra dos opostos.

Não se pode percorrer duas vezes o mesmo rio, e não se pode tocar duas vezes a mesma substância mortal no mesmo estado; por causa da impetuosidade e da velocidade da mutação, esta se dispersa e se recolhe, vem e vai. Não se pode banhar no mesmo local de um rio, serão banhos distintos, a agua não é a mesma, houve mudança, movimento.

"Tudo flui como um rio" é o célebre aforisma no qual a tradição filosófica subsequente identificou sinteticamente o pensamento de Heráclito com o tema do devir, em contraposição à filosofia do Ser própria de Parmênides, o filósofo da unidade e da identidade do Ser.

Parmênides de Eléia (530 ?- 460 a.C) inaugura algo radicalmente novo na filosofia ao considerar não os elementos, mas o abstrato. No seu pensamento, há uma recusa como meio de chegar à verdade. De modo simplificado, a doutrina de Parmênides sustenta o seguinte: unidade e a imobilidade do Ser; o mundo sensível é uma ilusão; o Ser é uno, eterno, não-gerado e imutável; não se confia no que vê. O pensamento de Parmênides é tradicionalmente visto como o oposto ao de Heráclito de Éfeso.

Por fim, nosso mundo dividia-se em duas esferas: aquela das qualidades positivas (luz, quente, ativo, masculino, fogo, vida) e aquela das qualidades negativas (escuridão, frio, passivo, feminino, terra, morte). A esfera negativa era apenas uma negação da esfera

$\overline{3}$ Textos extraídos e adaptados do site: https://pt.wikipedia.org, acessado em 06/02/2016, às 15:00 h. 
positiva, isto é, a esfera negativa não continha as propriedades que existiam na esfera positiva.

Ao invés das expressões "positiva" e "negativa", Parménides usa os termos metafísicos de "Ser" e "Não-Ser". O Não-Ser era apenas uma negação do Ser. Mas Ser e Não-Ser são imutáveis e imóveis.

Toda nossa realidade é imutável, estática, e sua essência está incorporada na individualidade divina do Ser-Absoluto, o qual permeia todo o Universo. Esse Ser é onipresente, já que qualquer descontinuidade em sua presença seria equivalente à existência de seu oposto - o Não-Ser.

Nessa perspectiva, esses dois pensadores estão presentes quando estamos nos referindo às transformações geométricas, mudamos, movimentamos para que não haja mudanças, para que haja uma relação de imutabilidade, quando tratamos das isometrias, da mesma maneira quanto às homoetias, tanto nas ampliações quanto nas reduções de figuras, procuramos características que permaneceram imutáveis, bem como as que foram alteradas pelos movimentos de transformação, e de certa forma, mudanças ocorrem tanto quanto manipulamos os objetos nas telas dos computadores, ou utilizamos as máquinas matemáticas para realizar esses movimentos. Mudamos, transformamos para que haja imutabilidade, e ao mesmo tempo, compreendendo esses significados pode-se atingir a aprendizagem.

\section{Sugestões para Pesquisas Futuras}

Esse trabalho é uma parte desse movimento, outras transformações geométricas podem ser propostas para a continuidade desse estudo, que como dissemos, está em constante e contínua atualização, como as transformações afins, transformações conforme, transformações espaciais, além de outras, e também com a utilização de outros recursos tecnológicos que possam ser avaliados quanto à sua eficácia para o ensino-aprendizagem.

Finalmente, leia o trabalho de (ALON, 2009) no qual apresenta-se uma reflexão sobre a utilização da Lei de Pareto para tentar definir/escolher problemas para as diferentes fases da vida acadêmica. A direção dos novos passos para a continuidade da vida acadêmica deveriam ser discutidos com seu orientador. 



\section{Referências}

ALMOULOUD, S. A. Fundamentos da didática da matemática. [S.1.]: Editora UFPR, 2010. Citado na página 177.

ALON, U. How to choose a good scientific problem. Molecular cell, Elsevier, v. 35, n. 6, p. 726-728, 2009. Citado na página 213.

ALVES, S.; GALVÃO, M. Um estudo geométrico das transformações elementares. Instituto de Matemática e Estatística, Universidade de São Paulo, 1996. Citado 4 vezes nas páginas 111, 112, 116 e 121.

BITTEnCOURT, P. M. Utilização do GeoGebra na Construção de Instrumentos:

Pantógrafo. Disserta (Mestrado) - Profmat-IMPA, Mestrado Profissional em Matemática, Rio de Janeiro, 2014. Citado na página 205.

BOYER, C. B. História da Matemática. [S.1.]: Copyright (c) 1991, by John Wiley \& Sons. Inc., 1996. Citado na página 33.

BRASIL. Parâmetros Curriculares Nacionais - Matemática - Ensino de primeira a quinta séries. [S.l.]: Secretaria de Educação Fundamental, 1997. Citado na página 48.

BRASIL. Parâmetros Curriculares Nacionais - Matemática - Ensino de quinta a oitava séries. [S.l.]: Secretaria de Educação Fundamental, 1998. Citado 9 vezes nas páginas 29, 47, 48, 49, 50, 51, 53, 54 e 177.

BRASIL. Guia de Livros Didáticos : PNLD 2014: Matemática - Ensino Fundamental: Anos Finais. [S.l.]: Secretaria de Educação Básica, 2013. Citado 5 vezes nas páginas 29, $47,59,60$ e 73.

BROUSSEAU, G. Fundamentos e métodos da didática da matemática.(2006). Didática das Matemáticas. Trad. Maria José Figueiredo. Lisboa, Instituto Piaget. Col. Horizontes Pedagógicos, p. Cap.1 p.35-113, 1996. Citado 7 vezes nas páginas 171, 172, 173, 174, 175, 176 e 177.

BROUSSEAU, G.; BORGÉA, C. Introdução ao estudo das situações didáticas: conteúdos e métodos de ensino. [S.1.]: Ática, 2008. Citado 4 vezes nas páginas 172, 174, 175 e 177.

BRUN, J. Didáctica das matemáticas. Tradução de FIGUEIREDO, MJ Lisboa/Portugal: Instituto Piaget - (Coleção Horizontes Pedagógicos), n. Cap. 1, p. 35-113, 1996. Citado na página 171.

BURTON, D. M. The history of mathematics: An introduction. Six. [S.l.]: Nineteem Century Contributions> Lobachevsky to Hilbert, 2007. 12 p. Citado na página 34.

COSTA, S. F. Método Científico: Os Caminhos da Investigação. [S.l.]: Copyright (C) 2011, Editora Harbra, 2001. Citado na página 170.

COXETER, H. S. M.; GREITZER, S. L. Geometry revisited. [S.1.]: Copyright (c) 1967, by Yale University, Handom House and The L. W. Singer Company, 1967. Citado 2 vezes nas páginas 124 e 132. 
DAHAN-DALMEDICO, A.; PEIFFER, J. History of Mathematics Highways and Byways. [S.1.]: MMA, 2010. Citado 4 vezes nas páginas 31, 32, 33 e 34.

D'AMBROSIO, U. A influência da tecnologia no fazer matemático ao longo da história. VII Seminário Nacional da História da Ciência e da Tecnologia, São Paulo, 1999. Citado na página 27.

D'AMORE, B. Epistemologia e didática da Matemática. [S.1.]: Escrituras Editora e Distribuirdora de Livros Ltda. - Tradução: Maria Cristina Banoni Barufi, 2005. Citado na página 172 .

DANTE, L. R. Projeto Teláris: Matemática. [S.1.]: Abril Educação, 2013. Citado na página 60.

DODGE, C. W. Euclidean Geometry and Transformations. [S.l.]: Copyright (C) 1972, Dover Publications Inc., 1972. Citado na página 130.

EVES, H. História da Matemática - para uso em sala de aula - v3 - Geometria. [S.l.: s.n.], 1992. Citado na página 35.

GÁlveZ, G. A didática da matemática. Parra, C. e Saiz, I,. Didática da Matemática, p. 26-35, 1996. Citado 2 vezes nas páginas 173 e 174.

GOLDENBERG, M. A arte de pesquisar: como fazer pesquisa qualitativa em ciências sociais. [S.1.]: Rio de Janeiro Record 2011, 2011. Citado na página 170.

JAHN, A. P. Des transformations des figures aux transformations ponctuelles: étude d'une séquence d'enseignement avec Cabri-géomètre II Relation entre aspects géométriques et fonctionnels en classe de Seconde. Tese (Doutorado), 1998. Citado na página 44.

JEGER, M. Transformation geometry. [S.1.]: English Version by A. W. Deicke and A. G, Howson Copyright (c) 1966 George London Allen and Unwin Ltda., 1969. Citado na página 108.

JENNINGS, G. A. Modern Geometry with Applications. [S.l.]: Springer-Verlag New York, Inc, 1966. Citado 7 vezes nas páginas 84, 88, 89, 90, 109, 110 e 111.

LEDERGERBER-RUOFF, E. B. Isometrias e ornamentos do plano euclidiano. [S.1.]: Atual Editora Ltda., São Paulo, 1982. Citado 2 vezes nas páginas 111 e 120.

LIMA, E. L. Isometrias. [S.l.]: SBM - Coleção Professor de Matemática - Copyright (C) 2007, 1996, 1996. Citado 3 vezes nas páginas 111, 116 e 122.

MABUCHI, S. T. Transformações geométricas: a trajetória de um conteúdo ainda não incorporado às práticas escolares nem à formação de professores. Tese (Doutorado) Dissertação de mestrado, Universidade Católica de São Paulo, Brasil, 2000. Citado 4 vezes nas páginas $31,32,33$ e 175 .

MACHADO, N. J. Matemática e língua materna: análise de uma impregnação mútua. [S.l.]: Cortez Editora, 1990. Citado 3 vezes nas páginas 44, 45 e 46.

MAN, Y.-K.; LEUNG, H.-K. Teaching transformational geometry via dynamic geometry software. In: Redesigning Pedagogy International Conference: Research, Policy, Practice, Singapore. [S.l.: s.n.], 2005. Citado na página 136. 
MASCHIETTO, M. Les machines mathématiques comme ressources: de la formation à la classe. Enseignement des mathématiques et contrat social: Enjeux et défis pour le, v. 21, p. 939-942, 2012. Citado na página 153.

MIRANDA, G. M.; ROCHA, M. V. A tecnologia na elaboração de materiais didáticos. RIT-REVISTA INOVAÇÃO TECNOLÓGICA, v. 3, n. 1, 2013. Citado na página 171.

MORI, I.; ONAGA, D. S. Matemática: idéias e desafios, 8®. [S.l.]: Saraiva S.A., 2009. Citado na página 60.

NASCIMENTO, M. R. L. do. A Inserção das Tecnologias nas Escolas e a Cultura Escolar. Disserta (Mestrado) - Faculdade de Formação de Professores, Universidade do Estado do Rio de Janeiro, São Gonçalo, 2012. Citado na página 27.

OLIVEIRA, J. L. de. A escola na sociedade contemporânea: Reflexões acerca da influência das novas tecnologias nas práticas pedagógicas. In: Congresso Nacional De Educação, Campina Grande. Anais Eletrônicos. [S.l.: s.n.], 2015. Citado na página 28.

OLIVEIRA, M. S. de. Orientações Metodológicas para Monografias de Lato Sensu. [S.1.]: UFLA/FAEPE,2006 - Lavras, 2006. Citado na página 169.

PAIS, L. C. Didática da Matemática: uma análise da influência francesa. [S.l.]: Autêntica Editora, 2001. Citado na página 176.

PARRA, C.; SAIZ, I. Didática da matemática: reflexões psicopedagógicas. 2001. ed. [S.l.]: Artmed, 1996. Citado 2 vezes nas páginas 172 e 175.

PERRIN-GLORIAN, M.-J. Théorie des situations didactiques: naissance, développement et perspectives. Vingt ans de didactique des mathématiques en France, p. 97-147, 1994. Citado na página 177.

PIAGET, J.; GARCIA, R. Psicogênese e História das Ciências (G. Unti, Trad.). [S.l.]: Petrópolis: Editora Vozes.(Trabalho original publicado em 1983), 2011. Citado 16 vezes nas páginas 29, 31, 32, 33, 35, 36, 37, 38, 39, 40, 41, 42, 43, 44, 79 e 171.

PINHEIRO, V. A. Geometrografia 2. [S.l.]: Aula Editora - Rio de Janeiro, 1986. Citado 6 vezes nas páginas 111, 156, 157, 158, 160 e 164.

POMMER, W. M. Brousseau e a ideia de situação didática. São Paulo: SEMA-Seminários de Ensino de Matemática/FEUSP - Coordenação: Profo Dro Nilson José Machado, 2008. Citado na página 173.

SÃO PAULO. Currículo do Estado de São Paulo: Matemática e suas Tecnologias - Ensino Fundamental e Ensino Médio. [S.l.]: Secretaria de Educação do Estado de São Paulo, 2012. Citado 5 vezes nas páginas 47, 54, 55, 56 e 57.

SÃO PAULO. Cadernos de Matemática. [S.1.]: Secretaria de Educação do Estado de São Paulo, 2014-2017. Citado 4 vezes nas páginas 29, 47, 57 e 58.

SANTAROSA, L. M. A.; GRAVINA, M. Aprendizagem da matemática em ambientes informatizados. In: IV Congresso RIBIE. Brasília. [S.l.: s.n.], 1998. Citado na página 28.

SANTOS, M. A. dos. Novas tecnologias no ensino de matemática: possibilidades e desafios. Mirante, v.1, 2011. Citado na página 27. 
SCHNEIDER, C. L. Matemática: O processo de ensino-aprendizagem. website: Só Matemática, 2015. Citado na página 28.

SHINE, C. Y. Homotetias, composição de homotetias e o problema 6 da imo 2008. Eureka - Rio de Janeiro, v. 29, p. 32 a 43, 2009. Citado na página 125.

SOUZA, J.; PATARO, P. M. Vontade de Saber Matemática. [S.1.]: FTD, 2012. Citado na página 60.

STEFFE, L. P.; THOMPSON, P. W. Teaching experiment methodology: Underlying principles and essential elements. Handbook of research design in mathematics and science education, p. 267-306, 2000. Citado na página 170.

STRÄSSER, R. Research on dynamic geometry software (dgs)â"an introduction. Zentralblatt für Didaktik der Mathematik, Springer, v. 34, n. 3, p. 65-65, 2002. Citado na página 135.

VILLIERS, M. D. Some pitfalls of dynamic geometry software. Learning and Teaching Mathematics, a journal of the Association of Mathematics Education of America (MMA), (<http://academic.sun.za/mathed/AMESA>), v. 4, n. 46, p. 52, February 2006. Citado na página 135.

WHITEHEAD, A. N. Science and the modern world. [S.l.]: Cambridge University Press, 2011. Citado na página 9.

YAGLOM, I. M. Geometric Transformations I. [S.l.]: The Mathematical Association of America (MMA), Copyright (C), 1962, by Yale University, 1962. 12 p. Citado 6 vezes nas páginas 111, 112, 113, 115, 120 e 123.

YAGLOM, I. M. Geometric Transformations II. [S.l.]: The Mathematical Association of America (MMA), Copyright (C), 1962, by Yale University, 1962. 12 p. Citado 8 vezes nas páginas 79, 125, 126, 127, 128, 129, 131 e 133.

YIN, R. K. Case study research: Design and methods. [S.l.]: Copyright (c) 2009 by Sage Publications, Inc., 2009. Citado na página 169. 
Apêndices 



\section{APÊNDICE A - Definições e demonstrações complementares}

\section{Definição A.0.1. Conjunto e Função}

Ha dois conceitos em matemática em termos dos quais as definições e teoremas devem ser formulados na mais exata forma possível, conjuntos e funções. São por eles mesmos considerados fundamentais, isto é, eles não são definidos em termos de nenhuma outra coisa.

Grosso modo dizemos que um conjunto é uma coleção de elementos, ou membros, que são objetos distintos que constituem um conjunto. A relação básica entre um objeto e o conjunto é a relação de pertinência: quando um objeto $a$, que pode até mesmo ser outro conjunto, é um dos elementos que compõem o conjunto $A$, dizemos que $a$ pertence a $A$, e representamos por: $a \in A$, caso contrário diremos que $a \notin A$.

Em geometria comumente as figuras são definidas como um conjunto de pontos do plano, ou do espaço 3-dimensional, ou mais genericamente de um espaço n-dimensional. Como exemplo, consideremos um círculo que é o conjunto de todos os pontos do plano que se encontram a dada distância (o raio) de um dado ponto (o centro). Linhas e planos, podem ser definidos como conjuntos de pontos no espaço que satisfazem uma condição definida. Em geometria, os conceitos de ponto, linha, plano, espaço, são considerados fundamentais.

Função é uma lei de correspondência pela qual cada elemento de um conjunto (Domínio) corresponde um e apenas um elemento de um outro conjunto (Contra Domínio)

1. Qual o conjunto de valores para os quais a função é definida (o domínio de definição da função)?

2. Qual o conjunto de valores assumidos pela função (imagem da função)?

A generalização do conceito usual de função na geometria é dado pelos conceitos de "aplicação" e "transformação". Aqui o domínio de definição e a variação de valores não serão mais tomados como conjunto de números mas conjuntos de pontos numa linha, em um plano ou espaço.

Demonstração do teorema 4.3.1 da página 84. Indicando por $I$ o conjunto de 
todas as isometrias do plano e, lembrando a definição 4.2 .5 de subgrupo, temos que $I d \in I$ e, portanto, $I$ é não vazio.

Dados $f, g \in I$ e sendo $P, Q$ pontos distintos do plano e fazendo $P^{\prime}=f(P)$, $Q^{\prime}=f(Q), P^{\prime \prime}=g\left(P^{\prime}\right)$ e $Q^{\prime \prime}=g\left(Q^{\prime}\right)$, concluímos que $P^{\prime} Q^{\prime}=P Q$ e $P^{\prime \prime} Q^{\prime \prime}=P^{\prime} Q^{\prime}$ e por consequência $P^{\prime \prime} Q^{\prime \prime}=P Q$, isto é, $P^{\prime \prime}=g(f(P))=(g \circ f)(P)$ e $Q^{\prime \prime}=g(f(Q))=(g \circ f)(Q)$ de modo que $g \circ f \in I$.

Finalmente é imediato verificar que se $f \in I$ então $f^{-1} \in I$.

Demonstração do teorema 4.3.2 da página 84. Sejam $f_{1}$ e $f_{2}$ duas isometrias. Esta claro da definição 4.2.3 que $f_{2} \circ f_{1}$ é uma transformação. Sejam $P$ e $Q$ pontos. Pela definição 4.3 .2 o fato de $f_{1}$ ser uma isometria implica que $f_{1}(P) f_{1}(Q)=P Q$, e o fato de $f_{2}$ ser uma isometria implica que $f_{2}\left(f_{1}(P)\right) f_{2}\left(f_{1}(Q)\right)=f_{1}(P) f_{1}(Q)=P Q$. Portanto $\left[\left(f_{2} \circ f_{1}\right)(P)\right]\left[\left(f_{2} \circ f_{1}\right)(Q)\right]=P Q$.

Seja $f$ uma isometria e sejam $P$ e $Q$ dois pontos. Desde que $f$ é uma isometria,

$$
f\left(f^{-1}(P) f\left(f^{-1}(Q)\right)=f^{-1}(P) f^{-1}(Q)=P Q\right.
$$

e portanto $f^{-1}$ é uma isometria.

Demonstração de itens do Teorema 4.3.3 da página 85:

Demonstração do item 1; f preserva colinearidade.

Propriedade A.0.1. Sejam $P, Q$ e $R$ três pontos distintos e colineares e sejam $P^{\prime}, Q^{\prime}$ e $R^{\prime}$ suas imagens por $f$. Então um dos pontos deve estar entre os outros dois, digamos que $P-Q-R$. (Os outros dois casos são tratados analogamente). Desde que $P R=P Q+P R$ segue que $P^{\prime} R^{\prime}=P^{\prime} Q^{\prime}+Q^{\prime} R^{\prime}$. Supondo que $P^{\prime}, Q^{\prime}$ e $R^{\prime}$ sejam não colineares (hipótese RAA, Redução Ao Absurdo). Então pela desigualdade triangular (assumindo como já demonstrado na geometria elementar) implica que $P^{\prime} Q^{\prime}<P^{\prime} Q^{\prime}+Q^{\prime} R^{\prime}$, mas isso contraria a afirmação inicial, portanto devemos rejeitar a hipótese RAA e concluir que $P^{\prime}, Q^{\prime}$ e $R^{\prime}$ são colineares, ou seja, a isometria $f$ preserva a colinearidade de pontos.

Demonstração do item 2; f preserva estar-entre.

Propriedade A.0.2. Sejam $f$ uma isometria e $P, Q, R$ três pontos distintos do plano, e $P^{\prime}=f(P), Q^{\prime}=f(Q)$ e $R^{\prime}=f(R)$. Desde que $P^{\prime} Q^{\prime}=P Q, Q^{\prime} R^{\prime}=Q R$ e $P^{\prime} R^{\prime}=P R$ segue que, se $P Q+Q R=P R$ então $P^{\prime} Q^{\prime}+Q^{\prime} R^{\prime}=P^{\prime} R^{\prime}$, isto é, $P-Q-R$ implica $P^{\prime}-Q^{\prime}-R^{\prime}$. Em outras palavras, se o ponto $Q$ está entre $P$ e $R$ então $Q^{\prime}$ está entre $P^{\prime}$ e $R^{\prime}$, ou seja, $f$ preserva a relação "estar entre". 
Propriedade A.0.3. O segmento de reta $\overline{P Q}$ é o menor caminho que liga $P$ a $Q$. Se $f$ é uma isometria então segue que $f(\overline{P Q})$ deve ser o menor caminho que liga $f(P)$ a $f(Q)$, desde que isometria preserva distância. Portanto $f(\overline{P Q})$ também é um segmento de reta.

$$
f(\overline{P Q})=\overline{f(P) f(Q)}
$$

Ou seja, $f$ preserva segmentos.

Demonstração do item 4; f preserva ponto médio.

Propriedade A.0.4. Da colinearidade, $A-M-B$, fazendo $A M=M B \Rightarrow A^{\prime} M^{\prime}=M^{\prime} B^{\prime}$, pois $A^{\prime}-M^{\prime}-B^{\prime}$, ou seja, se $M$ é o ponto médio do segmento $\overline{A B}$ então $M^{\prime}$ é o ponto médio do segmento $\overline{A^{\prime} B^{\prime}}$, e desse modo $\boldsymbol{f}$ preserva o ponto médio.

Demonstração do item 5; f preserva retas.

Propriedade A.0.5. Toda isometria $f: \Pi \rightarrow \Pi^{\prime}$ transforma retas em retas.

Com efeito, seja $r \subset \Pi$ uma reta. Tomemos dois pontos distintos $A$ e $B$ em $r$, façamos $A^{\prime}=f(A), B^{\prime}=f(B)$ e chamemos de $r^{\prime}$ a reta do plano $\Pi^{\prime}$ que passa por $A^{\prime}$ e $B^{\prime}$. Dado qualquer $X \in r$, um dos três pontos $A, B$ e $X$ esta entre os outros dois. Digamos que $B$ esta entre $A$ e $X$, ou seja $A-B-X$. (Os outros dois casos são tratados analogamente). Então $A X=A B+B X \operatorname{logo}$, pondo $X^{\prime}=f(X)$, vem $A^{\prime} X^{\prime}=A^{\prime} B^{\prime}+B^{\prime} X^{\prime}$, portanto $B^{\prime}$ pertence ao segmento $A^{\prime} X^{\prime}$. Assim os pontos $A^{\prime}, B^{\prime}$ e $X^{\prime}$ são colineares. Como vimos, $f$ preserva a colinearidade. Isso mostra que $\forall X \in r \Rightarrow X^{\prime} \in r^{\prime}$ e podemos escrever, $f(\overleftrightarrow{A B}) \subset \overleftrightarrow{A^{\prime} B^{\prime}}$. Analogamente sendo $f^{-1}$ uma isometria temos que $f^{-1}\left(\overleftrightarrow{A^{\prime} B^{\prime}}\right) \subset \overleftrightarrow{A B}$. Logo $\overleftrightarrow{A^{\prime} B^{\prime}}=f\left(f^{-1}\left(\overleftrightarrow{A^{\prime} B^{\prime}}\right)\right) \subset f(\overleftrightarrow{A B})$ e portanto , $f(\overleftrightarrow{A B})=\overleftrightarrow{A^{\prime} B^{\prime}}$, ou seja $r^{\prime}=f(r)$ e podemos afirmar que $f$ preserva retas.

Demonstração do item 6; f preserva semi-retas.

Propriedade A.0.6. Desde que a semi-reta $\overrightarrow{A B}$ é a união de $\overline{A B}$ e todos os pontos $P$ tais que $A-B-P$ então $\overrightarrow{A^{\prime} B^{\prime}}$ é a união de $\overline{A^{\prime} B^{\prime}}$ e todos os pontos $P^{\prime}$ tais que $A^{\prime}-B^{\prime}-P^{\prime}$, logo $f(\overrightarrow{A B})=\overrightarrow{A^{\prime} B^{\prime}}$, ou seja $\boldsymbol{f}$ preserva semi-retas.

Demonstração do item 8; f preserva triângulos.

Propriedade A.0.7. Se $A, B, C$ são pontos não colineares então $A^{\prime}, B^{\prime}, C^{\prime}$ também são não colineares, caso contrário teríamos a isometria $f^{-1}$ levando pontos colineares $\left(A^{\prime}, B^{\prime}, C^{\prime}\right)$ em não colineares $(A, B, C)$. Desde que o triângulo $\triangle A B C$ é a união de três segmentos $\overline{A B}, \overline{B C}, \overline{C A}$ concluimos que $f(\triangle A B C)=\triangle A^{\prime} B^{\prime} C^{\prime}$ e, portanto, $\boldsymbol{f}$ preserva triângulos. 
Demonstração do item 9, 10 e 11; f preserva ângulos, perpendicularismo e paralelismo.

Propriedade A.0.8. Mais geralmente, dado qualquer ângulo $A \widehat{B} C$ temos que $A^{\prime} \widehat{B}^{\prime} C^{\prime}=$ $f(A \widehat{B} C)$, e como vimos $f(\triangle A B C)=\triangle A^{\prime} B^{\prime} C^{\prime}$, isto é, $f$ preserva segmentos, e portanto os triângulos $\triangle A B C$ e $\triangle A^{\prime} B^{\prime} C^{\prime}$ tem ângulos correspondentes com medidas iguais. Podemos concluir que $\boldsymbol{f}$ preserva ângulos e preserva as medidas dos ângulos, ou seja, $m\left(A^{\prime} \widehat{B}^{\prime} C^{\prime}\right)=m(A \widehat{B} C)$.

Em particular, se $\overrightarrow{A B}$ é perpendicular a $\overrightarrow{B C}$ então $\overrightarrow{A^{\prime} B^{\prime}}$ é perpendicular a $\overrightarrow{B^{\prime} C^{\prime}}$ pois $m(A \widehat{B} C)=90^{\circ}$ implica $m\left(A^{\prime} \widehat{B}^{\prime} C^{\prime}\right)=90^{\circ}$, logo $\boldsymbol{f}$ preserva perpendicularismo.

Segue que $\boldsymbol{f}$ preserva paralelismo desde que retas paralelas possuem uma perpendicular comum.

Demonstração da proposição 4.3.1 da página 86: Seja $f$ uma isometria do plano e $A, B$ pontos distintos do plano tais que $f(A)=A$ e $f(B)=B$; portanto nosso objetivo é demonstrar que $f(P)=P \quad \forall P \in \overleftrightarrow{A B}$.

Se $P=A$ ou $P=B$ não há nada a provar. Vamos considerar $P \in \overleftrightarrow{A B}, P \neq A$, $P \neq B$

Sendo $P^{\prime}=f(P)$ sabemos que $P^{\prime} \in \overleftrightarrow{A B}$, pois $f$ é uma colineação do plano, e que $A P^{\prime}=A P, B P^{\prime}=B P$, pois $f$ é uma isometria do plano. A conclusão $P^{\prime}=P$ é consequência imediata da seguinte observação:

Na reta $\overleftrightarrow{A B}$ existem dois, e apenas dois, pontos cuja distância a $A$ é $A P$, o próprio ponto $P$ e um outro na semi-reta oposta de $\overrightarrow{A P}$; contudo se conhecemos a distância $B P$ ao ponto $B$ então o ponto $P$ fica unicamente determinado.

Demonstração do teorema 4.3.4: Com efeito, sejam $A, B$ e $C$ pontos não colineares do plano $\Pi$, tais que $f(A)=A, f(B)=B$ e $f(C)=C$. Considere $\overleftrightarrow{A B}$ a reta $r$ e $\overleftrightarrow{A C}$ a reta s. Pela proposição 4.3.1 acima, $\forall X \in r, f(X)=X$ e $\forall Y \in s, f(Y)=Y$. Seja $Z$ um ponto qualquer do plano $\Pi$. Façamos passar por $Z$ uma reta $t$ que corta $r$ e $s$ respectivamente nos pontos $X$ e $Y$. Como $f(X)=X$ e $f(Y)=Y$, concluímos que $f$ fixa todos os pontos da reta $t$, em particular $f(Z)=Z$. Sendo $Z$ um ponto arbitrário de $\Pi$, resulta que $f=I d$.

Demonstração do teorema 4.3.5 da página 86: Com efeito, nas condições acima a isometria $f^{-1} \circ g: \Pi \rightarrow \Pi$ deixa fixos os pontos $A, B$ e $C$, ou seja,

$$
\left(f^{-1} \circ g\right)(A)=f^{-1}(g(A))=f^{-1}(f(A))=\left(f^{-1} \circ f\right)(A)=I d(A)=A ;
$$

analogamente $\left(f^{-1} \circ g\right)(B)=B$ e $\left(f^{-1} \circ g\right)(C)=C$, logo $\left(f^{-1} \circ g\right)=I d$, donde $f=g$. 


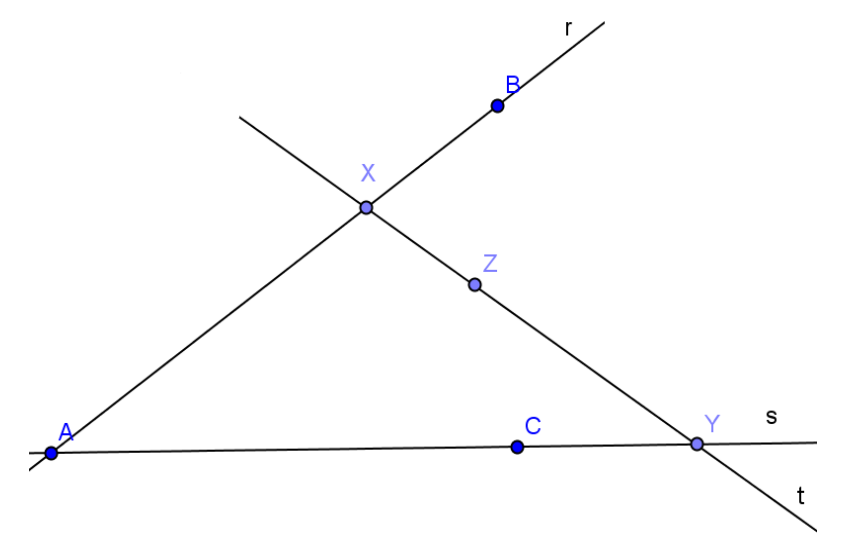

Figura 86: Fixa três pontos não colineares=Identidade

Demonstração da proposição 4.4.1 da página 96: Suponha que exista $P$ tal que $T_{\vec{v}}(P)=P$. Temos então $T_{\vec{v}}(P)=P+\vec{v}$ de modo que $\vec{v}=\overrightarrow{0}$, contrariando a hipótese que $\vec{v} \neq 0$.

Demonstração do teorema 4.4.1 da página 96: Verificamos imediatamente a existência de uma translação $T_{\vec{v}}$ observando que se $\vec{v}=\overrightarrow{P Q}$, temos que $T_{\overrightarrow{P Q}}(P)=Q$.

A unicidade da translação segue da definição 4.4 .1 de soma de ponto com vetor: se $Q=P+\vec{v}$, então o segmento orientado $\overrightarrow{P Q}$ é o representante do vetor $\vec{v}$ com origem em $P$, isto é $\vec{v}=\overrightarrow{P Q}$.

Pelo teorema 4.4.1 na página 96, se $T_{\overrightarrow{P Q}}(R)=S$ então $T_{\overrightarrow{P Q}}=T_{\overrightarrow{R S}}$ para os pontos $P, Q, R$ e $S$ distintos do plano, ou seja , $\overrightarrow{P Q}$ e $\overrightarrow{R S}$ são equipolentes e representantes do mesmo vetor $\vec{v}$.

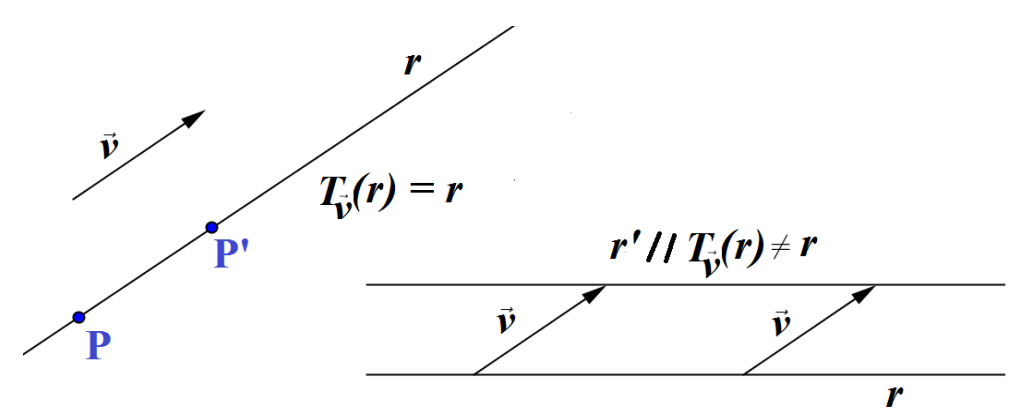

Figura 87: Proposição 4.4.2 Invariância de reta

Demonstração da proposição 4.4 .2 da página 97: Seja $r$ uma reta paralela à direção do vetor $\vec{v}$ (representamos por $r \| \vec{v}$ ).

Dado $P \in r$, o ponto $P^{\prime}=T_{\vec{v}}(P)$ é tal que $P^{\prime}=P+\vec{v} \in r$, pois $\vec{v}$ é paralelo a $r$. Daí $T_{\vec{v}}(r) \subset r$. Analogamente, dado $P \in r$ temos $P^{\prime}=P+(-\vec{v})$ também em $r$, e como 
$T_{\vec{v}}\left(P^{\prime}\right)=P$ segue que $r \subset T_{\vec{v}(r)}$.

Portanto, $r$ é invariante pela translação $T_{\vec{v}}$.

Se $s$ é uma reta invariante por $T_{\vec{v}}$, temos que,

$$
\forall P \in s \quad T_{\vec{v}}(P)=P+\vec{v}=P^{\prime} \in s
$$

Escolhendo um vetor $\vec{w}$ na direção de $s$ temos então,

$$
\forall P \in s, \quad \vec{v}=P^{\prime}-P=\lambda(P) \vec{w}, \quad \operatorname{com} \quad \lambda(P) \in R ;
$$

$\operatorname{logo}, \vec{v}$ e $\vec{w}$ são paralelos e $s$ é uma reta paralela à direção do vetor $\vec{v}$.

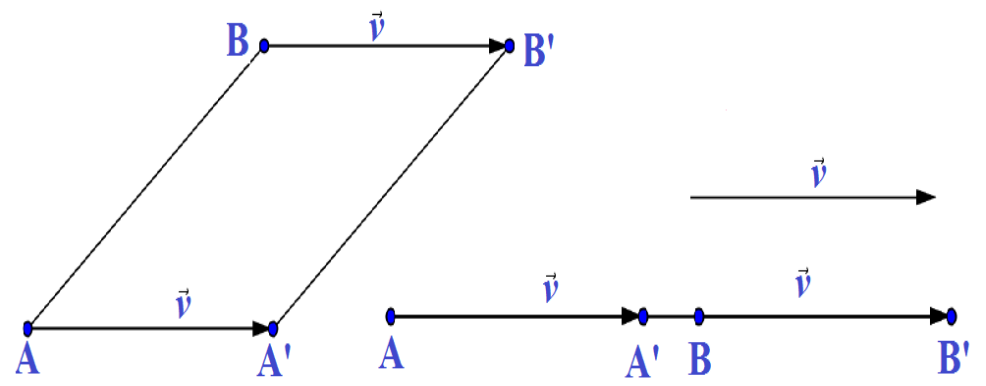

Figura 88: Proposição 4.4.3 paralelogramo

Demonstração da proposição 4.4.3 da página 97: Das hipóteses, $\vec{v}=A^{\prime}-A=$ $B^{\prime}-B$, e daí os segmentos $A A^{\prime} \| B B^{\prime}$ e $A A^{\prime}=B B^{\prime}$, portanto, lados de um paralelogramo. O paralelogramo será degenerado se $\vec{v} \| A B$.

Demonstração da proposição 4.4.4 da página 97: Sendo o quadrilátero $A B B^{\prime} A^{\prime}$, por hipótese, um paralelogramo (vide fig.88), temos $A A^{\prime}=B B^{\prime}=\vec{v}, T_{\vec{v}}(A)=A^{\prime}$ e $T_{\vec{v}}(B)=B^{\prime}$.

Para mostrarmos a unicidade, observamos que se existir uma $T_{\vec{w}}$ tal que $T_{\vec{w}}(A)=A^{\prime}$, e $T_{\vec{w}}(B)=B^{\prime}$, então $A+\vec{w}=A^{\prime}$ e $B+\vec{w}=B^{\prime}$; consequentemente, $\vec{w}=A A^{\prime}=B B^{\prime}=\vec{v}$, então $T_{\vec{w}}=T_{\vec{v}}$ e a translação é única.

Demonstração do teorema 4.4.2 da página 97: Sejam $\vec{v}=\overrightarrow{A B}$ e $\vec{w}=\overrightarrow{C D}$, então;

$$
P+\vec{v}=T_{\vec{v}}(P)=T_{\vec{w}}(P)=P+\vec{w}, \quad \forall P .
$$

Daí, $\vec{v}=\vec{w}$, ou seja, $\overrightarrow{A B}=\overrightarrow{C D}$. Como os vetores coincidem, temos $A B \| C D$ e $A B=C D$ tem o mesmo sentido, portanto o $A B D C$ é um paralelogramo.

Se $A B D C$ é um paralelogramo então temos que os vetores $\overrightarrow{A B}=\overrightarrow{C D}$ então $T_{\overrightarrow{A B}}=T_{\overrightarrow{C D}}$ também ocorre.

Demonstração da proposição 4.4.5 da página 98: Fixemos um ponto $A$ e seja $A^{\prime}=f(A)$. O $A P P^{\prime} A^{\prime}$ é por hipotese um paralelogramo, onde $P^{\prime}=f(P)$. Pela Proposição 


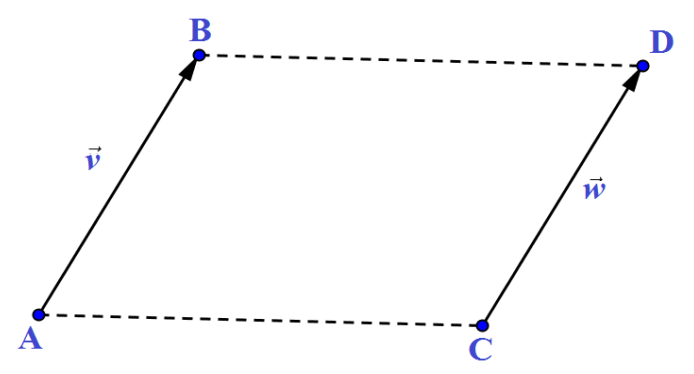

Figura 89: Teorema 4.4.2 ABDC Paralelogramo

4.4.4, existe uma única translação $T_{\vec{v}}$, com $\vec{v}=\overrightarrow{A A^{\prime}}$, tal que $T_{\vec{v}}(A)=A^{\prime}$ e $T_{\vec{v}}(P)=P^{\prime}$. Temos então que $f$ e $T_{\vec{v}}$ coincidem em todos os pontos do plano.

Demonstração para provar que a reflexão em relação a uma reta é uma isometria, referente ao enunciado da observação 4.4.6 na página 108.

Para provar que $R_{r}$ é uma isometria, consideramos dois casos:

$1^{\circ}$ Caso: $X$ e $Y$ estão do mesmo lado da reta $r$ no plano $\Pi$. Então traçamos os segmentos $X A$ e $X^{\prime} A^{\prime}$, paralelas a $r$, com $A$ e $A^{\prime}$ sobre $Y Y^{\prime}$. Os triângulos retângulos $X A Y$ e $X^{\prime} A^{\prime} Y^{\prime}$ tem os catetos com o mesmo comprimento, logo o mesmo ocorre com suas hipotenusas, isto é, $\overline{X Y}=\overline{X^{\prime} Y^{\prime}}$.

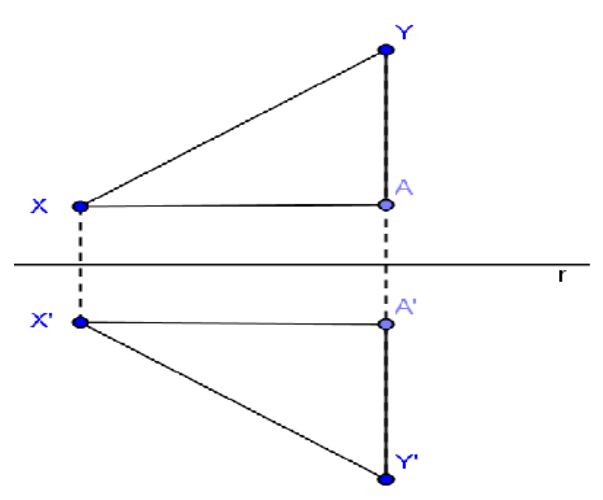

Figura 90: Reflexão em torno de uma reta- $1^{\circ}$ Caso

$2^{\circ}$ Caso: $X$ e $Y$ estão em lados opostos à reta $r$. Sejam $A$ e $B$ os pontos de interseção de $X Y$ e $X X^{\prime}$ com a reta $r$. Os triângulos retângulos $A B X$ e $A B X^{\prime}$ tem o cateto $A B$ comum e $\overline{B X}=\overline{B X^{\prime}}$, logo suas hipotenusas tem o mesmo comprimento: $\overline{A X}=\overline{A X^{\prime}}$. Analogamente, $\overline{A Y}=\overline{A Y^{\prime}}$. Assim os triângulos $A X X$ e $A Y Y^{\prime}$ são isósceles, portanto suas medianas são bissetrizes: $\alpha=\alpha^{\prime}$ e $\beta=\beta^{\prime}$. Por outro lado, $\alpha=\beta$ como ângulos opostos pelo vértice.

Então $\alpha+\alpha^{\prime}=\beta+\beta^{\prime}$. Como $\beta+\beta^{\prime}$ é o suplemento do ângulo $X \widehat{A} Y^{\prime}$, segue que 
$\alpha+\alpha^{\prime}$ também é, $\operatorname{logo} X^{\prime}, A$ e $Y^{\prime}$ são colineares. Portanto

$$
\overline{X^{\prime} Y^{\prime}}=\overline{X^{\prime} A}+\overline{A Y^{\prime}}=\overline{X A A Y}=\overline{X Y} .
$$

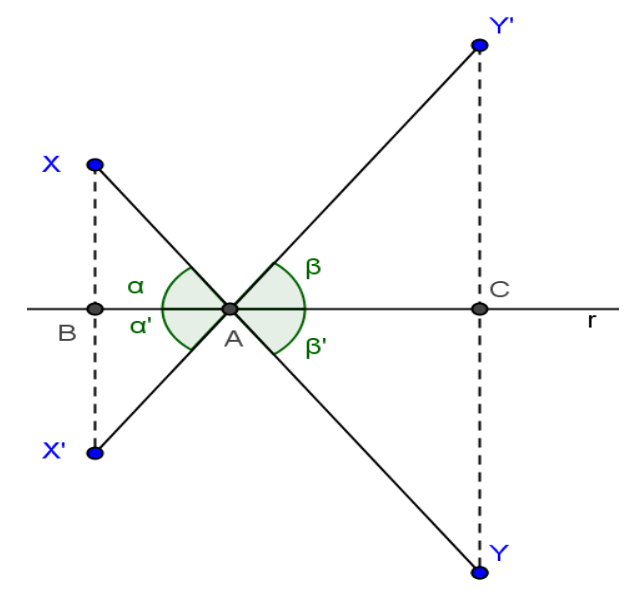

Figura 91: Reflexão em torno de uma reta-2 ${ }^{\circ}$ Caso 


\section{APÊNDICE B - Quadros, Tabelas e Figuras Complementares}

\section{B.1 Menu das ferramentas do GeoGebra}

As figuras de ferramentas elencadas neste apêndice visam propiciar o entendimento para seguir o passo a passo das tabelas:

1. Tabela 5.3.0.5.1 para a construção da Translação;

2. Tabela 5.3.0.7.2 para a construção de Reflexão em Torno de um Ponto;

3. Tabela 5.3.0.9.3 para a construção de Rotação em Torno de um Ponto;

4. Tabela 5.3.0.11.4 para a construção de Reflexão em Relação a uma Reta;

5. Tabela 5.3.0.14.5 para a construção da Homotetia de centro $O$ e razão $k$.

Todas as construções são relativas à seção 5.3 na página 137.

Na seção B.2 a seguir, um quadro completo de todas as opções das ferramentas de construção dos objetos no GeoGebra.

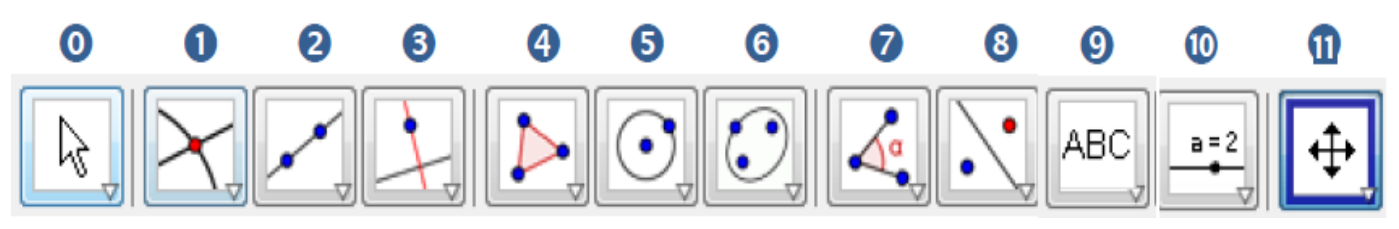

Figura 92: Ferramentas de Construção 


\section{B.2 Menu das ferramentas completas do GeoGebra}

Ferramentas de apoio para a construção dos objetos e sua manipulação na seção 5.3, referente ao estudo das transformações geométricas no GeoGebra.

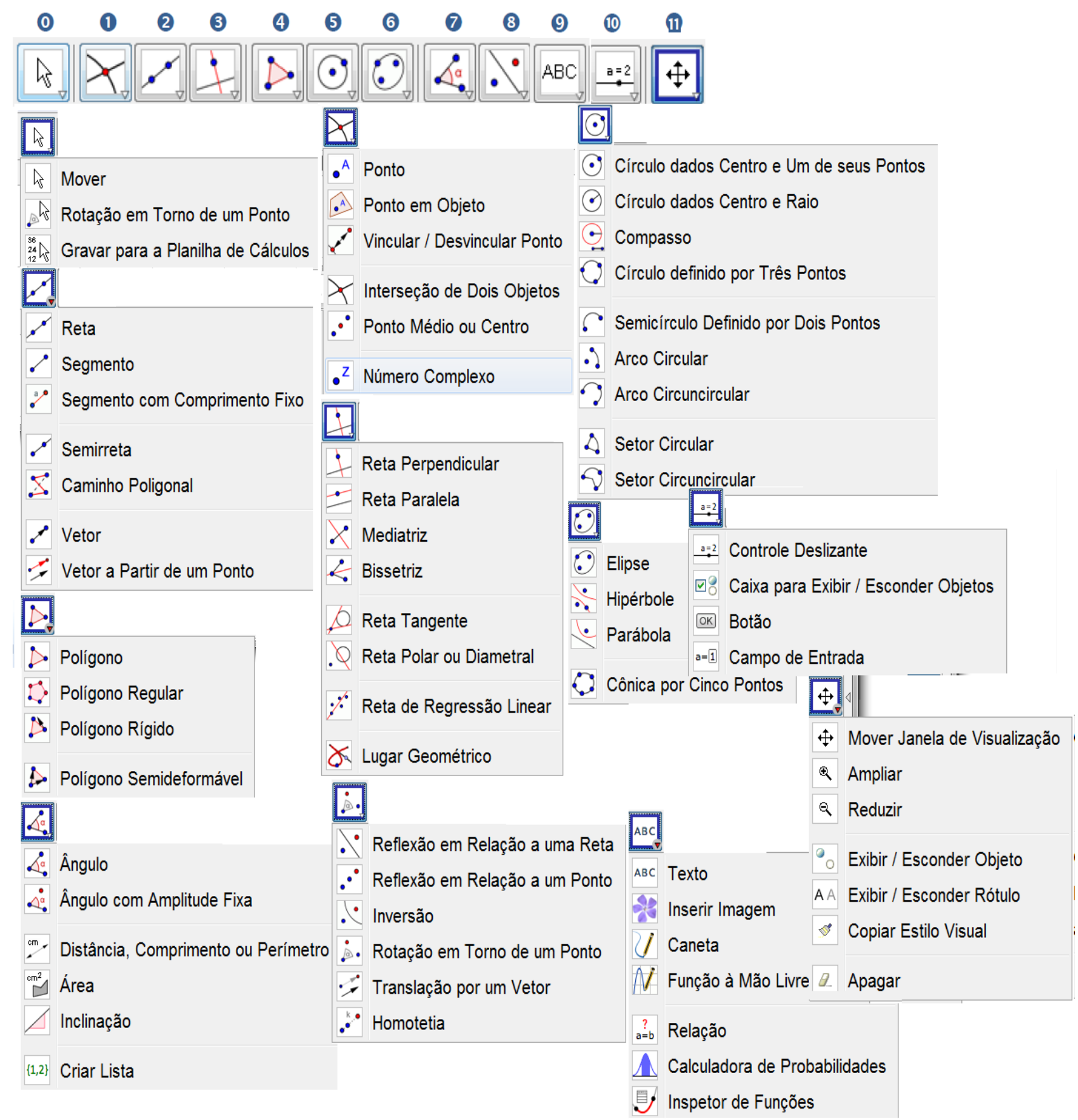

Figura 93: Ferramentas de Construção Completa 


\section{Índice}

Cognitivo, 35

História, 31 



\section{Glossário}

Esta é a descrição do glossário.

homotetia é a ampliação ou a redução de distâncias e áreas a partir de um ponto fixo. 29

isometria é uma transformação geométrica que, aplicada a uma figura geométrica, mantém as distâncias entre pontos. Ou seja, os segmentos da figura transformada são geometricamente iguais aos da figura original, podendo variar a direção e o sentido. Os ângulos mantêm também a sua amplitude. Existe isometrias simples e isometrias compostas. As isometrias simples podem ser rotações, translações e reflexões.. 29

Máquina Matemática mecanismos, artefatos. 30

artefato objeto fabricado pelo homem que dá informações sobre a cultura do seu criador e usuários. 233

mecanismo é um conjunto de elementos rígidos, móveis uns relativamente a outros, unidos entre si mediante diferentes tipos de junções chamadas pares cinemáticos (pernas, uniões de contato, passadores, etc.), cujo propósito é a transmissão e/ou transformação de movimentos e forças. São, portanto, as abstrações teóricas do funcionamento das máquinas, e de seu estudo se ocupa a Teoria de Mecanismos.. 30, 233

simetria é uma relação de paridade em respeito a altura, largura e comprimento das partes necessárias para compor um todo. 34

tecnologia do grego - "técnica, arte, ofício" e - "estudo") é um termo que envolve o conhecimento técnico e científico e a aplicação deste conhecimento através de sua transformação no uso de ferramentas, processos e materiais criados e/ou utilizados a partir de tal conhecimento. 30, 233

tecnológico que faz uso de tecnologia. 30 